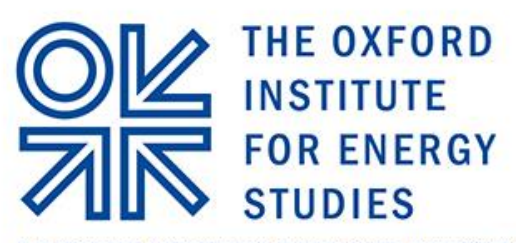

A RECOGNIZED INDEPENDENT CENTRE OF THE UNIVERSITY OF OXFORD

May 2019

\title{
Challenges of Industrial Gas Demand in the Czech Republic, Poland and Slovakia
}

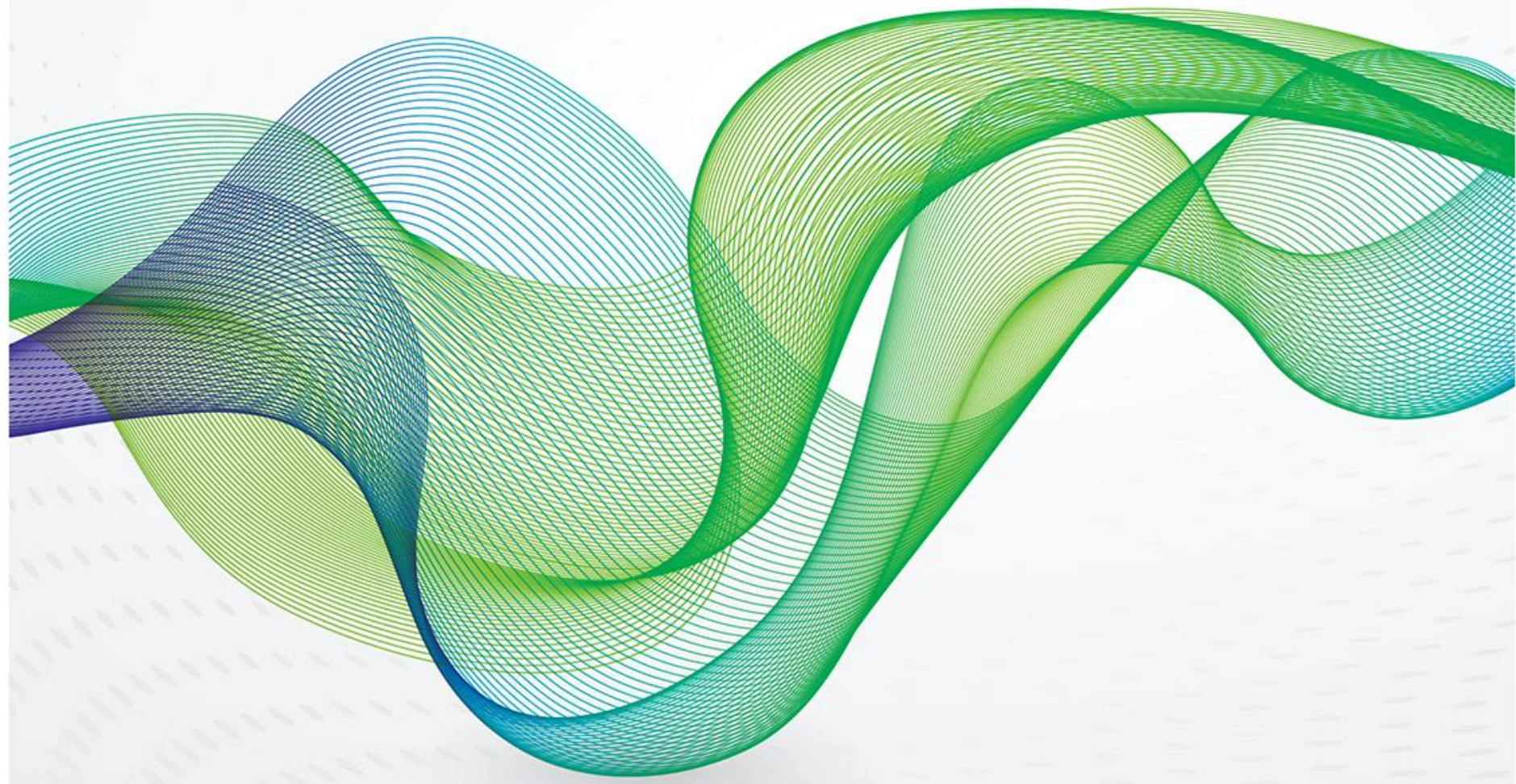



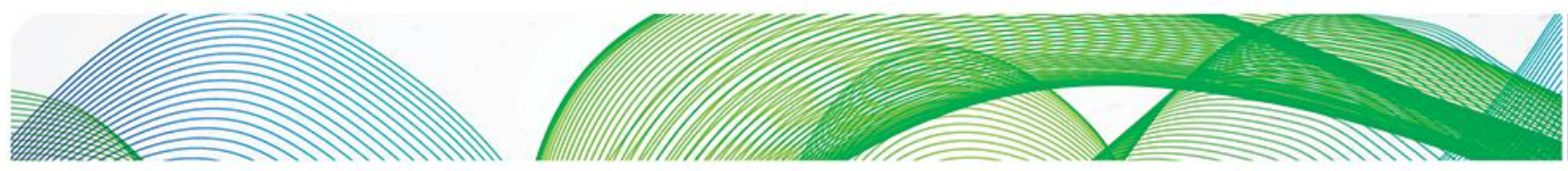

\section{잊조}

The contents of this paper are the author's sole responsibility. They do not necessarily represent the views of the Oxford Institute for Energy Studies or any of its members.

Copyright $\odot 2019$

\section{Oxford Institute for Energy Studies}

(Registered Charity, No. 286084)

This publication may be reproduced in part for educational or non-profit purposes without special permission from the copyright holder, provided acknowledgment of the source is made. No use of this publication may be made for resale or for any other commercial purpose whatsoever without prior permission in writing from the Oxford Institute for Energy Studies.

ISBN 978-1-78467-138-9

DOI: https://doi.org/10.26889/9781784671389 

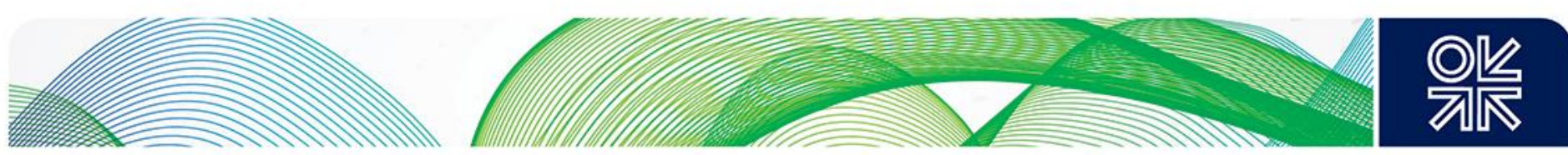

\section{Acknowledgements}

The research on this paper required a number of trips to the region and support from local key industrial companies, gas companies, regulators, industrial associations, and ministries. The list of the industrial companies which I visited, talked to or researched is exhaustive but all are the major gas consumers within their key sector and country. Having access to these companies was crucial for me to understand the technological processes of the key industrial sectors and importance of natural gas to them. I thank all those representatives who met me and had the patience to explain their particular concerns.

In the Czech Republic, my grateful thanks go especially to RWE CEO Martin Herrmann, Roman Budisky and their colleagues who arranged access to many of their largest clients and accompanied me to many of those meetings. My many thanks also go to representatives from the Department of Gas and Liquid Fuels of the Ministry of Industry and Trade, Energy Regulatory Office ERU, and Net4Gas.

In Poland, my thanks go particularly to Daniel Borkowski, Attorney at Law at Legal Partner, who managed to open some doors in Poland, despite the current reluctance by officials to pass on any information regarding natural gas. Also my thanks go to Dr Inż. Andrzej Sikora of Instytut of Studiow Energetycznych, Krzysztof Jaworski of Izba Energetyki Przemysłowej i Odbiorców Energii, and representatives of the Ministry of Energy, PGNiG, Energy Regulatory Office URE, and Gas-System.

In Slovakia, a special thanks to Dr Milan Sedlácek from eustream, who helped me to understand the intricacies of the Slovak gas market. I would also like to thank representatives from the Ministry of Economy of the Slovak Republic, the Regulatory Office for Network Industries and SPP for their support.

Many thanks to colleagues at OIES for their comments and help, especially James Henderson and Anouk Honore.

The contents of this paper do not necessarily represent the views of the OIES, our sponsors or the people I have thanked for acknowledgements.

All the opinions expressed and any remaining errors are my sole responsibility. 

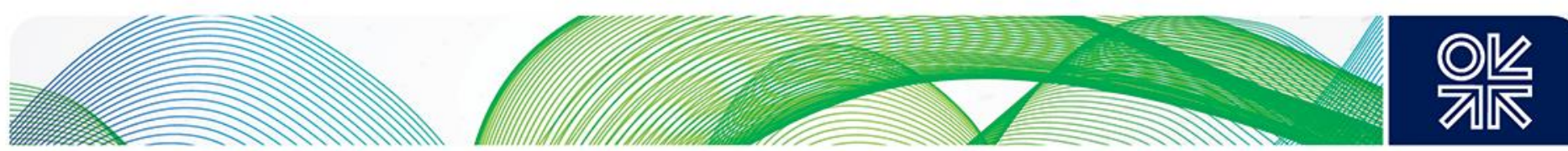

\section{Preface}

The Natural Gas Programme at OIES has embarked on a series of papers investigating gas demand in the industrial sector. Much of the recent focus on gas demand has been in the electricity sector, due to the impact caused by the rise of renewables for environmental reasons. However, while this is clearly a vital issue for the future of natural gas, the use of gas in the industrial and commercial sectors remains a fundamental demand base and deserves further analysis.

This paper focuses on Central and Eastern Europe, and in particular uses three countries, Poland, the Czech Republic and Slovakia, as case studies. The region has some unique characteristics which reflect its history as part of the old Soviet bloc, namely the continued prevalence of heavy industry, high levels of energy inefficiency compared to the rest of Europe and understandable concerns over security of supply, especially of gas from Russia. In addition, the region is not blessed with significant energy reserves, other than of coal with its environmental implications. As a result, the future of gas demand in the industrial sector is a particularly relevant topic as it contrasts the goal of improving carbon emissions and efficiency with the perceived security of supply risks.

Zuzana Princova addresses the topic with a detailed bottom up analysis of individual sectors within each country, and her research will be of significant use to those looking for an in-depth breakdown of the key demand drivers. Her findings are laid out in summary form at the start of the document, though, for those wishing to get an overview of the region and an understanding of the most important issues. Overall, though, this paper provides a significant contribution to research on the gas industry in Central and Eastern Europe and offers an important insight into some of the unique drivers of gas demand in the region.

James Henderson
Director, Natural Gas Programme
Oxford Institute for Energy Studies 

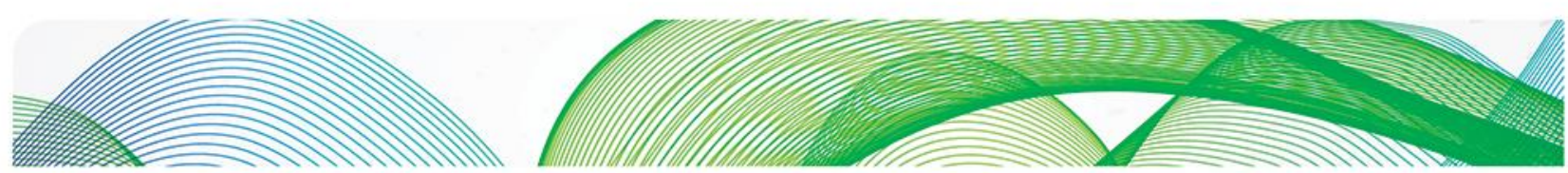
이제

\section{Contents}

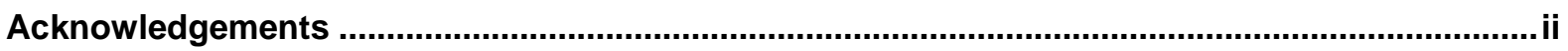

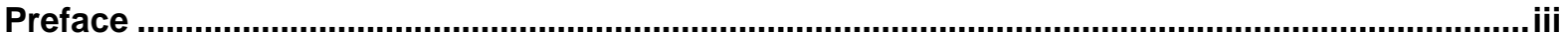

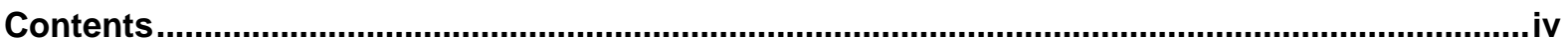

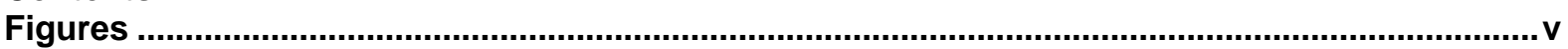

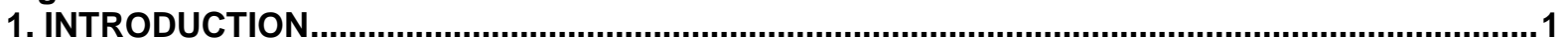

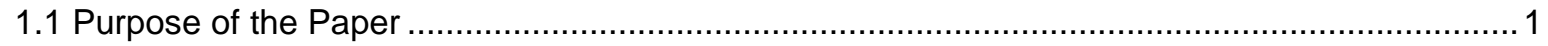

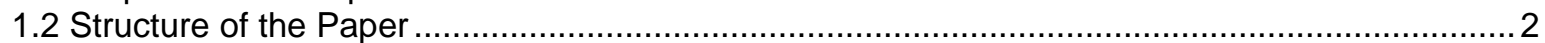

2. CHALLENGES AND OUTLOOK FOR INDUSTRIAL GAS DEMAND

2.1 Major Challenges to be Expected in the Czech Industrial Sector .............................................

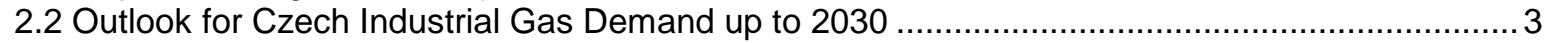

2.3 Major Challenges to be Expected in the Polish Industrial Sector ........................................... 6

2.4 Outlook for Polish Industrial Gas Demand up to 2030 ......................................................... 7

2.5 Major Challenges to be Expected in the Slovak Industrial Sector ............................................ 9

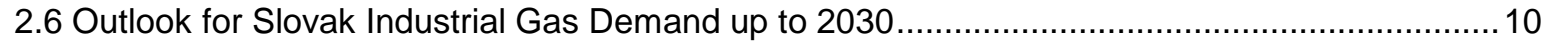

3. FUTURE EU INDUSTRIAL CHALLENGES AND POLICY ....................................................12

4. INDUSTRIAL NATURAL GAS DEMAND IN THE CZECH REPUBLIC ….................................13

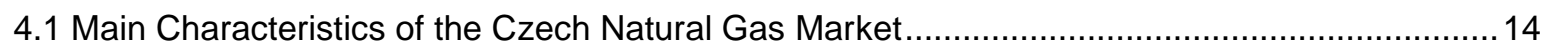

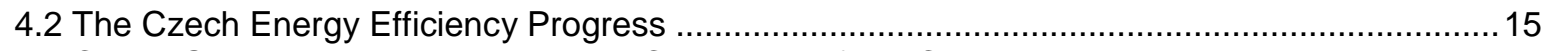

4.3 Czech Gas Price Developments and Competition from Coal .............................................. 16

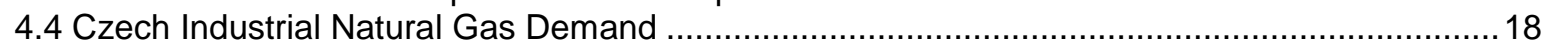

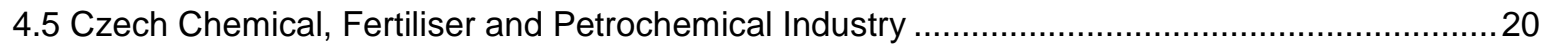

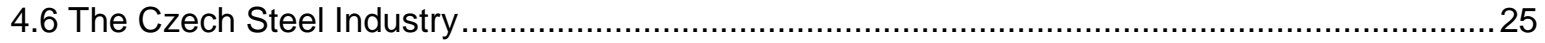

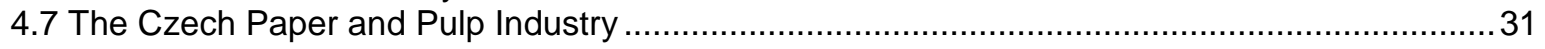

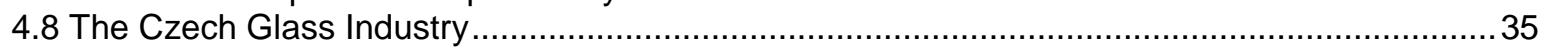

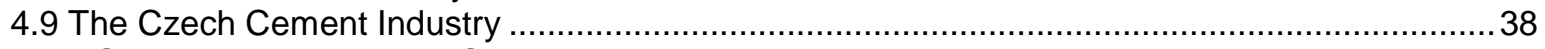

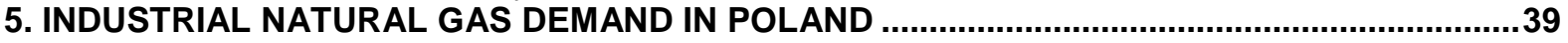

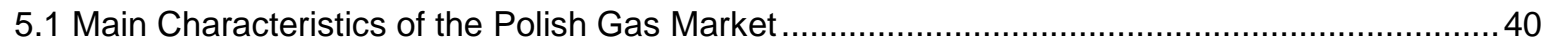

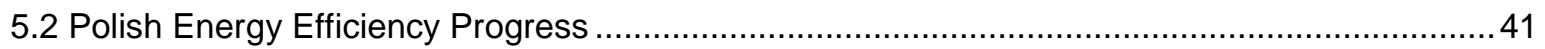

5.3 Polish Gas Price Developments and Competition from Coal ................................................. 42

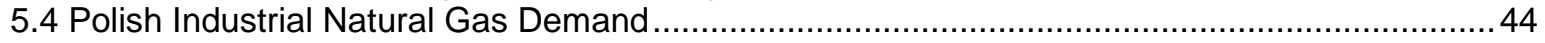

5.5 The Polish Chemical, Fertiliser and Petrochemical Industry ............................................. 45

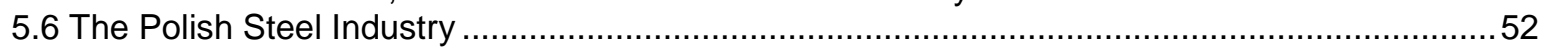

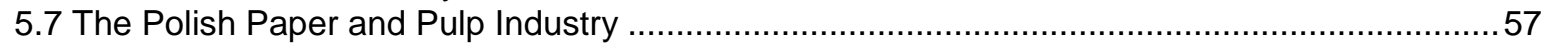

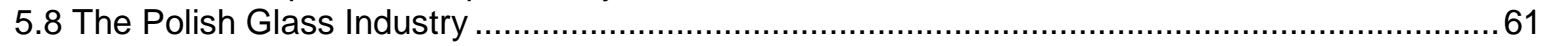

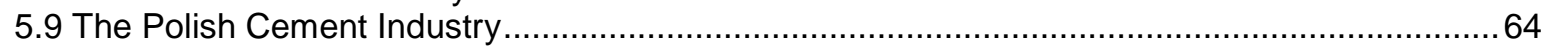

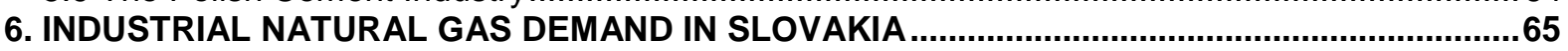

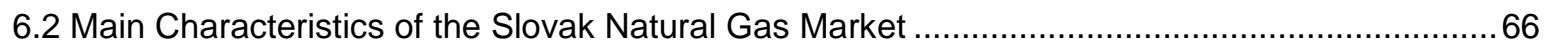

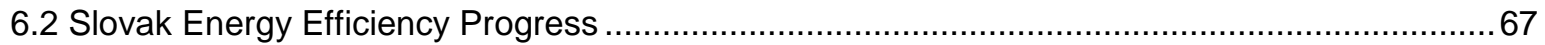

6.3 Slovak Gas Price Developments and Competition from Coal ..............................................68

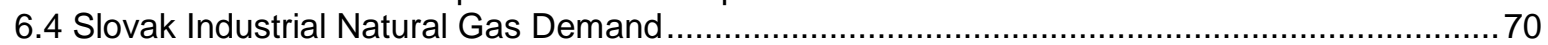

6.5 The Slovak Chemical, Fertiliser and Petrochemical Industry ............................................... 72

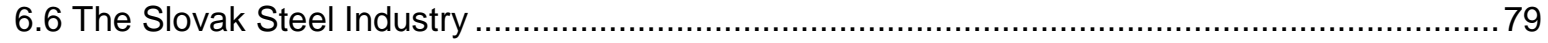

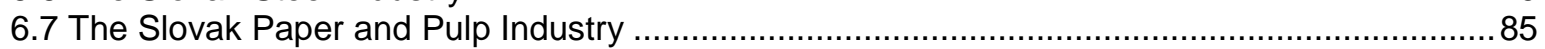

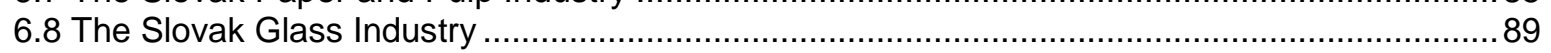

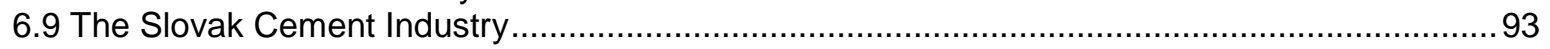

APPENDIX 1- EU Industrial Future Challenges and Policy..........................................................94

APPENDIX 2 - The Czech Governmental Energy Strategy ..........................................................99

APPENDIX 3 - The Czech Energy Efficiency Progress ..........................................................101

APPENDIX 4 - The Polish Governmental Energy Strategy ........................................................102

APPENDIX 5 - The Polish Energy Efficiency Progress ............................................................104

APPENDIX 6 - The Slovak Governmental Energy Strategy …....................................................105

APPENDIX 7 - The Slovak Energy Efficiency Progress ..........................................................108 

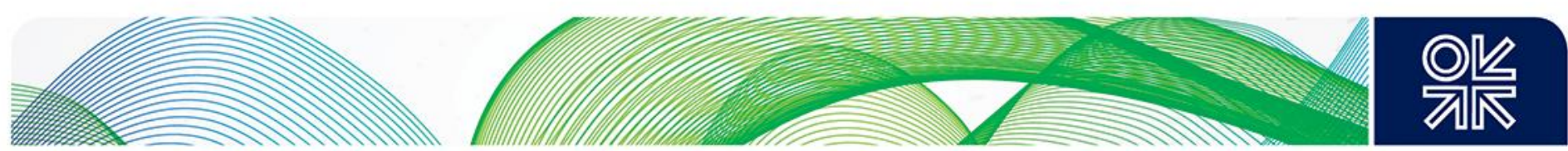

\section{Figures}

Figure 1: Czech Commercial and Industry Natural Gas Demand Forecast 2016-2030 (Reference

Scenario) ........

Figure 2: Czech Commercial and Industry Natural Gas Demand Forecast 2016-2030 (Optimistic

Scenario)

Figure 3: Polish Industrial Natural Gas Demand Forecast 2016-2030 (Reference Scenario) ...............8

Figure 4: Polish Industrial Natural Gas Demand Forecast 2016-2030 (Optimistic Scenario) ...............8

Figure 5: Slovak Industrial Natural Gas Demand Forecast 2015-2030 (Reference Scenario).............11

Figure 6: Slovak Industrial Natural Gas Demand Forecast 2015-2030 (Optimistic Scenario) .............11

Figure 7: Czech Natural Gas Consumption, by Customer Category 2007-2017 ................................. 15

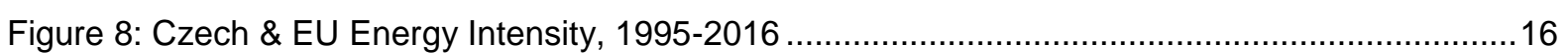

Figure 9: Czech Natural Gas Price for Medium Size Industrial Consumers, Excluding Taxes and

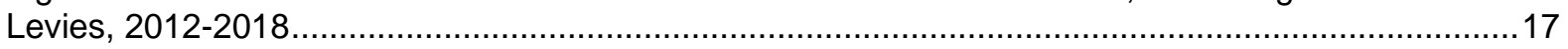

Figure 10: Czech Natural Gas Prices for Medium Size Household, Including Taxes, 2008-2018 .......17

Figure 11: Czech Natural Gas for Medium Industry \& Hard \& Brown Coal Producer Price Indices,

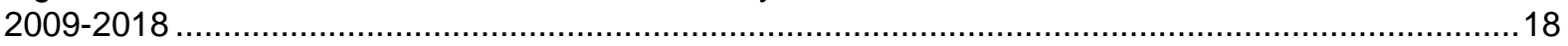

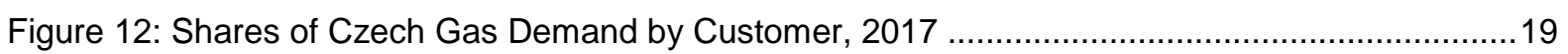

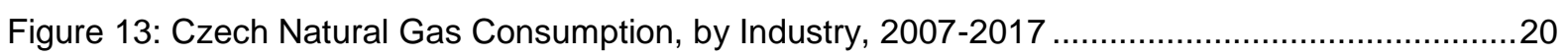

Figure 14: Czech Chemical Industry Energy Demand, Share by Fuel, 2016 ...................................21

Figure 15: Czech Natural Gas Demand by NACE 19 \& 20 \& 21 \& 22, 2007-2017 ...........................21

Figure 16: Czech Production \& Gas Demand by NACE20 Indices, 2007-2017 .................................22

Figure 17: Chemical/Petrochemical Non-Energy Natural Gas Use, 2008-2016 ...............................22

Figure 18: Czech Nitrogen Fertiliser Production \& Feedstock Demand Indices, 2008-2016 .............23

Figure 19: Czech Reference Chemical Industry Natural Gas Demand Forecast 2016-2030..............24

Figure 20: Czech Optimistic Chemical Industry Natural Gas Demand Forecast 2016-2030 ..............25

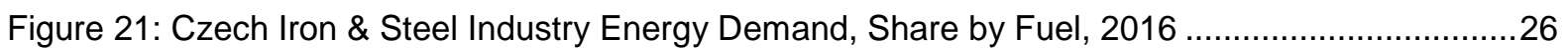

Figure 22: Czech Iron \& Steel Product Energy Intensity, 2005-2017 ..............................................27

Figure 23: Czech Natural Gas Consumption by Iron \& Steel Industry, 2007-2017 ............................28

Figure 24: Czech Steel Production and Gas Demand by Metal Industry Indices, 2007-2017 ............28

Figure 25: Czech Reference Iron \& Steel Industry Natural Gas Demand Forecast 2016-2030 ...........30

Figure 26: Czech Optimistic Iron\& Steel Natural Gas Demand Forecast 2016-2030.........................30

Figure 27: Czech Paper Industry Energy Demand, Share by Fuel, 2016 ............................................ 31

Figure 28: Czech Energy Intensity of Paper Production, 2007-2017 ...............................................32

Figure 29: Czech Natural Gas Consumption by Pulp and Paper Industry, 2007-2017 ......................32

Figure 30: Czech Paper Production \& Natural Gas Consumption Indices, 2007-2017 .......................33

Figure 31: Czech Reference Paper Industry Gas Demand Forecast 2016-2030 ...............................34

Figure 32: Czech Optimistic Paper Industry Gas Demand Forecast 2016-2030................................34

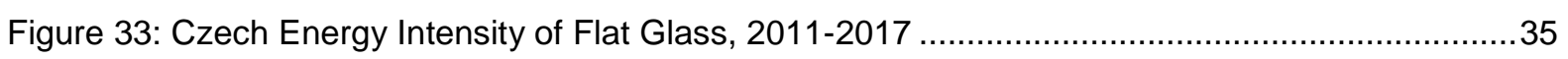

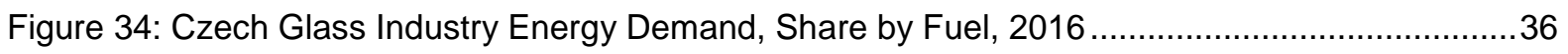

Figure 35: Czech Glass Industry Natural Gas Consumption, 2007-2017 ....................................... 36

Figure 36: Czech Reference Glass Industry Natural Gas Demand Forecast 2016-2030 ...................37 

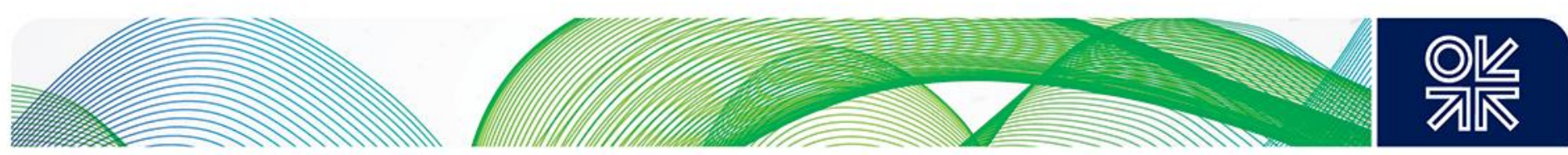

Figure 37: Czech Optimistic Glass Industry Natural Gas Demand Forecast 2016-2030 ...................38

Figure 38: Fuels Used in Czech Cement Production, 1990-2017 .................................................39

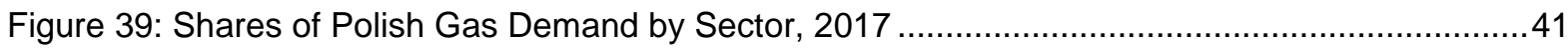

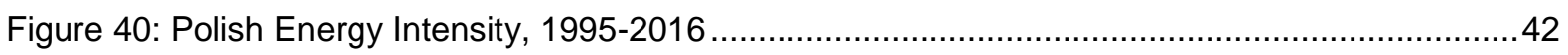

Figure 41: Polish Gas Prices for Medium Size Industries, Excluding Taxes and Levies, 2008-2018 ..43

Figure 42: Polish Gas Prices for Medium Size Household, Including Taxes, 2008-2018 …...............43

Figure 43: Polish Natural Gas for Medium Industry \& Steam Coal for Electricity Plants Price Indices,

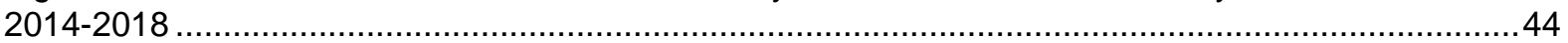

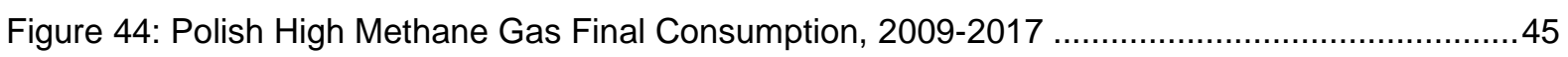

Figure 45: Polish NACE19 \& 20 Energy Demand, by Fuel, 2017 .....................................................46

Figure 46: Natural Gas Demand by Polish Chemical and Petrochemical Industry, 2009-2017 ..........47

Figure 47: Natural Gas Demand by Polish Petrochemical Industry, 2009-2017 ..............................47

Figure 48: Polish Crude Oil Processed \& NACE19 Gas Demand Indices, 2009-2017 ......................48

Figure 49: Polish NACE20 Fertiliser Feedstock Use, 2009-2017 ................................................... 48

Figure 50: Polish NACE20 Natural Gas Energy Demand, 2009-2017 ..............................................49

Figure 51: Polish Nitrogen Fertiliser Production \& Non-Energy Gas Demand Indices, 2009-2017 .....49

Figure 52: Polish Reference Petrochemical and Chemical Industries Natural Gas Demand Forecast

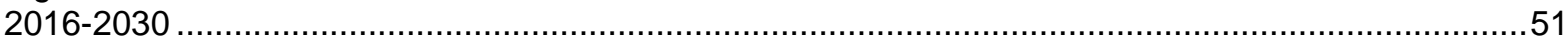

Figure 53: Polish Optimistic Petrochemical and Chemical Industries Natural Gas Demand Forecast,

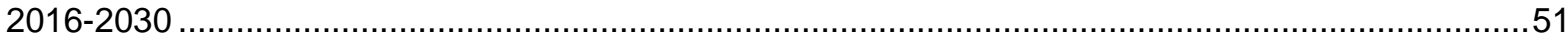

Figure 54: Polish Iron and Steel Industry Energy Demand, \% Share by Fuel, 2017 .........................52

Figure 55: Polish Crude Steel Energy Intensity, 2006-2016 ........................................................53

Figure 56: Revenues and Profits by Iron and Steel Industry, 2005-2016 ........................................53

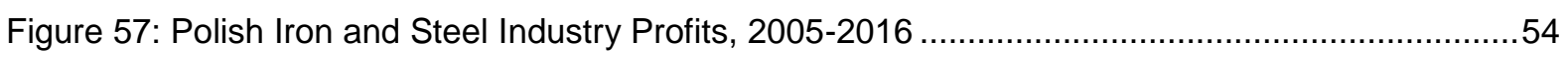

Figure 58: Polish High Methane Gas Consumption by Steel \& Metal Industry, 2009-2017 ................55

Figure 59: Polish Steel Production \& NACE24 Gas Demand Indices, 2009-2017 .............................55

Figure 60: Polish Reference Iron \& Steel Industry Natural Gas Demand Forecast 2016-2030 ...........57

Figure 61: Polish Optimistic Iron \& Steel Industry Natural Gas Demand Forecast 2016-2030 ...........57

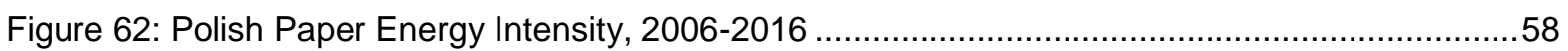

Figure 63: Polish Paper Industry Energy Demand, \% Share by Fuel, 2017 ......................................58

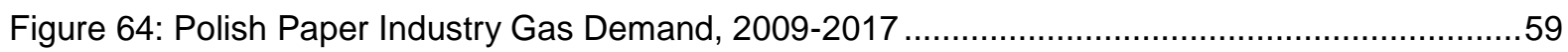

Figure 65: Polish Paper Production Sales and Gas Consumption by NACE17 Indices, 2009-2016 ...59

Figure 66: Polish Reference Paper Industry Natural Gas Demand Forecast 2016-2030 ..................61

Figure 67: Polish Optimistic Paper Industry Natural Gas Demand Forecast 2016-2030 ....................61

Figure 68: Polish Paper Industry Energy Demand, \% Share by Fuel, 2017 ....................................62

Figure 69: Polish Energy Intensity of Glass Production Industry, 2010-2016 ..................................62

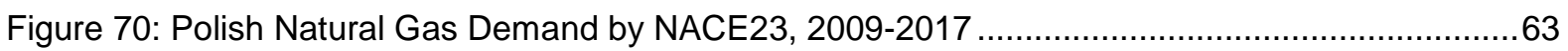

Figure 71: Polish Reference NACE23 Natural Gas Demand Forecast 2016-2030 ............................64

Figure 72: Polish Optimistic NACE23 Natural Gas Demand Forecast 2016-2030 .............................64

Figure 73: Share of Fuels in Polish Cement Production, 2009, 2015 .........................................65

Figure 74: Shares of Slovak Final Gas Demand by Sector, 2017 ..................................................66 

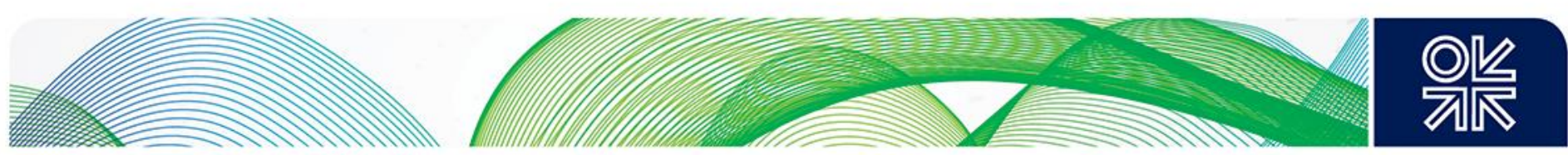

Figure 75: Slovak Energy Intensity, 1995-2016. .68

Figure 76: Slovak Gas Prices for Medium Size Industries, Excluding Taxes, 2008-2018.................69

Figure 77: Slovak Gas Prices for Medium Size Household, Including Taxes, 2008-2018 .................69

Figure 78: Slovak Natural Gas and Steam Coal Price Indices, 2008-2017 ...................................70

Figure 79: Slovak Industrial Natural Gas Consumption by Sector, 2008-2017 …...............................72

Figure 80: Natural Gas Demand by Slovak Chemical \& Petrochemical Industry, 2008-2017.............73

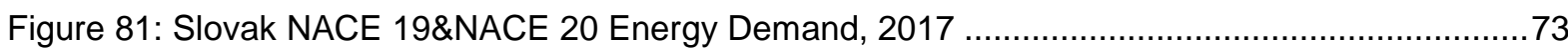

Figure 82: Slovak Non Energy Fertiliser/Petrochemical Feedstock Demand, 2001-2017 …..............74

Figure 83: Slovak Petrochemical Industry Energy Natural Gas Demand, 2008-2017.......................75

Figure 84: Slovak NACE20 Natural Gas Demand, 2008-2017 .................................................75

Figure 85: Slovak Indices of Gross Value Added and Natural Gas Demand by NACE20, 2008-2017 76

Figure 86: Slovak Reference Natural Gas Demand Forecast by Chemical Industry 2015-2030 .........78

Figure 87: Slovak Optimistic Natural Gas Demand Forecast by Chemical Industry 2015-2030 ..........78

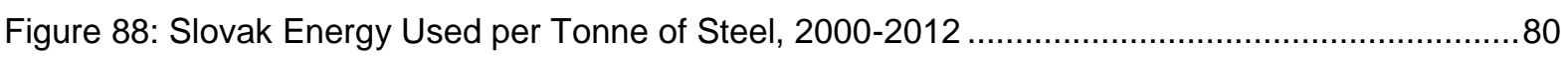

Figure 89: US Steel Košice Revenues and Operating Profits, 2007-2017 ......................................80

Figure 90: Slovak Iron \& Steel Industry Energy Demand, Share by fuel, 2017 ................................... 81

Figure 91: Slovak Natural Gas Demand by Iron and Steel Industry, 2008-2017 ..............................81

Figure 92: Slovak Steel Production and Gas Demand by Steel Industry Indices, 2008-2017 ............82

Figure 93: Slovak Reference Steel and Metal Industry Natural Gas Demand Forecast 2015-2030 _...84

Figure 94: Slovak Optimistic Iron \& Steel Industry Natural Gas Demand Forecast 2015-2030 ..........85

Figure 95: Slovak Paper Industry Energy Demand, \% Share by Fuel, 2017 ...................................86

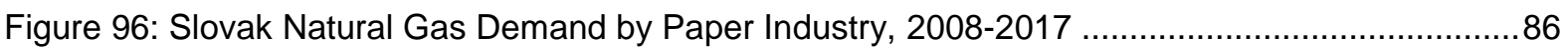

Figure 97: Slovak Gas Demand and Gross Value Added by NACE17 Indices, 2008-2017 ...............87

Figure 98: Slovak Reference Paper Industry Natural Gas Demand Forecast 2015-2030 ..................88

Figure 99: Slovak Optimistic Paper Industry Natural Gas Demand Forecast 2015-2030 ...................89

Figure 100: Slovak NACE23 Energy Demand, \% Share by Fuel, 2017 ...........................................90

Figure 101: Slovak Natural Gas Demand by NACE23, 2008-2017 ...............................................91

Figure 102: Slovak Indices of Natural Gas Use and Value Added by NACE 23, 2008-2017 ..............91

Figure 104: Slovak Optimistic Natural Gas Demand by NACE 23, 2015-2030 ...............................93 

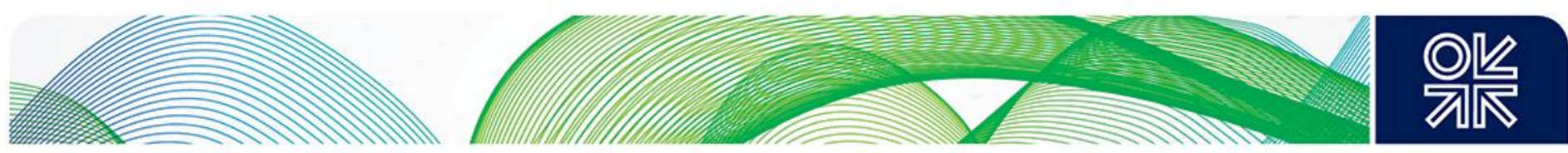

\section{INTRODUCTION}

\subsection{Purpose of the Paper}

The unique history of Central and Eastern Europe has made a profound mark on the culture, political stance and economies of these countries. Thirty years on from the collapse of the communist regime their economies continue to rely on heavy industry. Not only had they inherited these heavily polluting sectors from the previous administration, but Western Europe also used the opportunity to evacuate many of its heavy industries to Central and Eastern Europe. The focus of this paper is on the three Central European countries, as they have the most advanced economies in the region due to substantial reorganisation and modernisation and by and large they conform to EU regulations.

Despite efforts to cut down energy consumption, all three countries continue to have energy intensity almost twice as high as the EU-28 average. This is first of all due to the high contribution to their GDP (between $40 \%$ and $44 \%$ ) of industry, especially heavy industry. However, the heavy dependence on local coal is another reason why these economies have resisted switching to more environmentally friendly fuels like natural gas and continue to use some outdated energy-gobbling technologies.

Central Europe is poorly endowed with natural energy resources apart from coal. The weighty reliance on energy imports has made these countries very sensitive to security of supply issues. The interruption in Russian natural gas supplies in 2009 with its major negative impact, especially on the Slovak economy, has increased focus on the diversification of primary energy sources and lowering dependence on Russian gas imports. The official energy policies of Poland and Slovakia therefore focus primarily on the security of energy supplies which provide justification for their governments to continue to support and subsidise their local coal industry. All three governments plan to retain their coal-fired electricity plants, only retrofitting them; there is no plan to switch to natural gas. In fact all the countries have built at least one natural gas-fuelled power plant but they have all been mothballed and only lately used occasionally for peak purposes. All three countries plan to build nuclear plant in order to solve the emissions problem in future. However, none of the governments has secured financing for the plants.

Natural gas is considered too expensive and in Poland it has become almost a toxic topic since it is seen as continuation of enslavement to Russia. The current Polish government is determined to wean itself off any Russian gas imports by 2022, and is willing to pay higher prices for LNG and to build a Baltic Pipeline connecting Poland to Norway, through which PGNiG plans to supply the Polish market with gas from the Norwegian Continental Shelf from the end of 2022. It is not a coincidence that Poland and Slovakia (to a lesser degree) continue to treat natural gas as a hot political potato since both countries have mixed economic systems of private businesses combined with centralized economic planning and government regulation. The Czech Republic has the most deregulated natural gas market within the EU since it fully privatised the incumbent gas company Transgas in 2002. As a result, political influence has declined since 2002. The Czech Republic has also achieved such flexibility that it buys directly from Gazprom only when the contract price is below the German hub price and thus the question of dependency is no longer a real concern.

In contrast the Polish government has control over strategic decisions regarding the gas market. Current Polish energy policy envisages reduction of electricity produced from coal to $60 \%$ by 2030 , but this is mainly due to the projected increase of energy demand, while the overall amount of coal used would decrease only marginally before 2030 , with new coal plants still planned to be built. Poland is unlikely to meet any of the EU environmental 2020 targets and will struggle to get anywhere near them in 2030 . The official energy policy does not incorporate these binding targets. Nevertheless, industry will have to meet the new regulations on emissions which will come into effect in 2020, and will impose much stricter limits for companies which have previously been exempted. This will impose a heavy financial burden on certain industries within the next decade. The Czech and Slovak Republics have made much more progress and are likely to meet their 2020 environmental targets. The 2030 targets will be more of a challenge however, since the major initial cuts in emissions were partly achieved by closing down some industrial sectors rather than by major investment in environmental technology or a major switch to renewables across the economy. Future industrial development in Central Europe will thus be largely determined by EU policies in the next decade. 

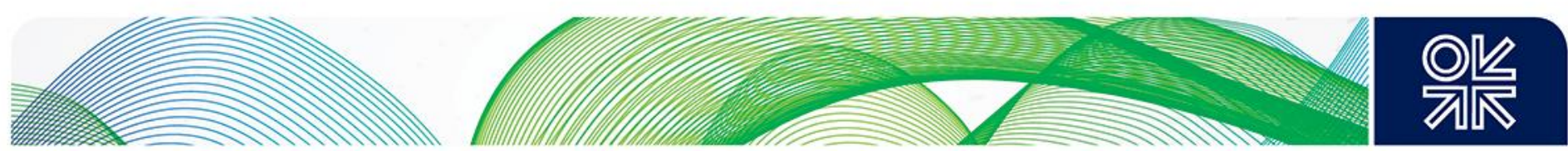

Central Europe is not a large market for natural gas. Currently these three countries consume together some $33 \mathrm{bcm} / \mathrm{y}$ of natural gas, and it plays only a moderate role in total primary energy supply in the Czech Republic and Poland. Slovakia has inherited an extensive gas infrastructure which gives natural gas a more prominent role. Given the high industrial presence in these economies, industry is the most important natural gas consumer and is responsible for $67 \%$ of final natural gas consumption in Poland, $49 \%$ in the Czech Republic and $42 \%$ in Slovakia - a combined total of over $19 \mathrm{bcm} / \mathrm{y}$.

The most striking point is that none of these countries has provided any credible analysis nor forecast of industrial gas consumption. One of the main weaknesses of their energy strategy is that no attention is given to industrial customers, although they currently account for the largest proportion of their gas demand. Nobody talks about the elephant in the room. No analysis of industrial gas demand has been undertaken by any of these governments and all the focus has been turned to gas-fired electricity and CHP plants, which are unlikely to be built within the next decade.

This was the starting point of this research, which was carried out with the objective of analysing current and potential industrial gas demand over the next decade. Unlike the electricity sector whose demand for natural gas is highly-price sensitive, the industrial sector is slower in reacting to natural gas price swings. Modern industrial plants are very capital-intensive and take several years to build or adjust. Consequently, they have limited flexibility when it comes to choosing energy and feedstock sources. The focus has been on the five most energy intensive industries (chemical and petrochemical, steel, paper and pulp, glass and cement industries) as they are responsible for the bulk of industrial gas demand in all three countries. According to our findings, the Central European industry will see incremental growth of up to $4.2 \mathrm{bcm} / \mathrm{y}$ by 2030 . The methodology used was a bottom-up approach by looking at each sector in each of the markets and building up a forecast from there.

Two scenarios have been generated by the Author, a Reference Scenario which attempts to synthesise sometimes contradictory drivers and to be the most realistic, and an Optimistic Scenario.

\subsection{Structure of the Paper}

Chapters 2, 3 and 4 summarise the major challenges facing each of the three selected countries in turn and the outlook for gas demand in their industrial sectors. Chapter 5 summarises the areas in which policies which will define industrial development in key industries of Central Europe. The following three chapters examine in detail the main characteristics of the natural gas market and energy efficiency development in the Czech Republic, Poland and Slovakia. The appendices offer additional information which is not covered in the main text, including an overview of the EU challenges and policies regarding the five key industrial sectors, Czech, Polish and Slovak governmental energy strategy and energy efficiency progress.

\section{CHALLENGES AND OUTLOOK FOR INDUSTRIAL GAS DEMAND}

\subsection{Major Challenges to be Expected in the Czech Industrial Sector}

Industrial development in the next decade will be largely determined by EU policies. Czech industry will have to meet the new regulations on emissions which will come to effect in 2020 and impose much stricter limits for companies which have so far been exempt. The 2020 package is a set of binding legislation to ensure the EU meets its climate and energy targets for the year 2020. ${ }^{1}$ Czech industry will be facing three main challenges.

\footnotetext{
The package sets three key targets: $20 \%$ cut in greenhouse gas emissions (from 1990 levels); $20 \%$ of EU energy from renewables; and $20 \%$ improvement in energy efficiency. The targets were set by EU leaders in 2007 and enacted in legislation in 2009. The EU countries have also agreed on a new 2030 Framework for climate and energy for the period between 2020 and 2030. On 14 June 2018, the Commission, the Parliament and the Council reached a political agreement which includes a binding renewable energy target for the EU for 2030: a 40\% cut in greenhouse gas emissions compared to 1990 levels; at least a $32 \%$ share of renewable energy consumption; and at least 32.5\% energy savings compared with the business-as-usual scenario.
} 

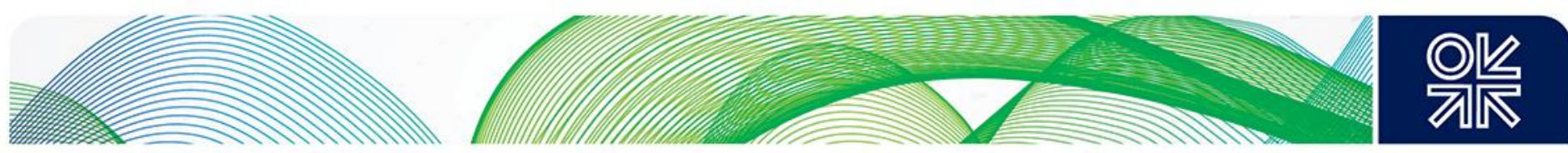

It has fulfilled the first task of cutting its greenhouse emissions by $20 \%$ from 1990 levels by 2020 . According to Eurostat statistics ${ }^{2}$ it had cut emissions by $34 \%$ in 2016 compared to 1990 levels. This was achieved at a time when the economy was growing significantly. At present, achieving a $40 \%$ cut in emissions by 2030 seems achievable without too much of an additional burden on industry as it seems that the investment in environmental technology has largely been carried out. The challenge for industry will be to keep investing and continue cutting emissions. It will be largely smaller and medium sized companies which will need to invest and install environmental technology.

The second target is for all EU states to increase the use of renewables to $20 \%$ of the gross energy balance by 2020, although some countries, including the Czech Republic were given exemptions. The Czech exemption set a target of $13 \%$ by $2020^{3}$ but it achieved $14.9 \%$ by 2016 , a small decline from $15 \%$ in 2015 . The $32 \%$ target for 2030 will thus be challenging since the country is still committed to nuclear power and relies heavily on local coal. The current Czech energy strategy envisages a gradual development of renewable energy sources, primarily photovoltaic and wind power plants and it is anticipated that communal waste will be more widely used in electricity production than at present. There will also be an increase in electricity production from biogas-fired power stations. However, it will not be a sharp increase, because economic support will be available only in connection with heat supplies, the options for which are very limited in rural areas. Nevertheless, it is certainly possible for the Czech Republic to achieve the $32 \%$ target with moderate investments over the next decade.

The third challenge for Czech industry is to reduce energy intensity. The target for 2020 is a $20 \%$ reduction in primary energy consumption since 2010 and $32.5 \%$ by 2030. In 2016 primary energy consumption was of 39.9 Mtoe and its national target for 2020 is 39.6 Mtoe. ${ }^{4}$ This means that it will be able to meet the 2020 target, but the 2030 target will be more of a challenge. The European Commission has calculated that the additional cost of achieving increased energy efficiency by $30 \%$ will be around EU9 billion/y for the whole Union. The Czech Republic will need to contribute CZK5 billion/y, a big challenge for Czech industry.

Apart from the challenges outlined above, continuous investment in R\&D will be important in order to keep the industry competitive. The Czech Republic has kept trend with the rest of the EU but investment in research has slowed down slightly since 2014. The EU target for the Czech Republic is to spend $1 \%$ of GDP on R\&D. ${ }^{5}$ Over the last five years it has been well above target with R\&D expenditure of between $1.7 \%$ and $2 \% / y$. As many of the largest companies are owned by international corporations there is a danger that they will try to extract maximum dividends rather than invest in new technology. On the other hand, the international companies, especially the German companies, have invested in modern technologies which give local industry access to the most up to date innovations.

\subsection{Outlook for Czech Industrial Gas Demand up to 2030}

The Czech economy has fared much better than the average EU economy. Strong economic growth continued in 2018 and 2019, driven by robust private demand and a dynamic external sector. The industrial sector will show similar healthy growth in all key industries with a couple of exceptions. It is likely to show an average annual growth of $1.5 \%$ to $2 \%$ over the next decade, stronger than the average EU economy growth. ${ }^{6}$

However, labour shortages will weigh on growth. Historically low unemployment will drive wages up. It can be expected that within the next decade the country will be losing the advantage of cheaper labour cost, reducing its competitive advantage.

\footnotetext{
2https://ec.europa.eu/eurostat/tgm/refreshTableAction.do?tab=table\&plugin=1\&pcode=sdg 13 10\&language=en 

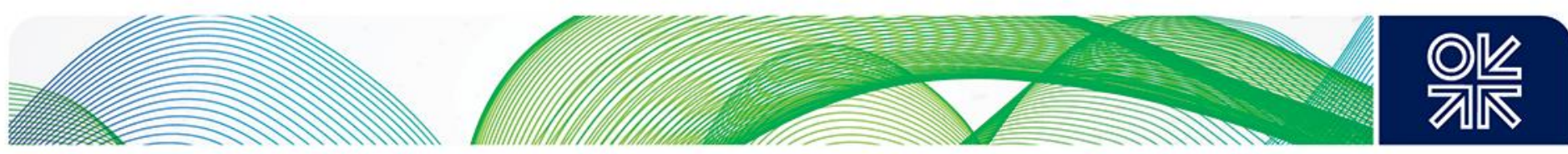

The government has released a number of forecasts on gas demand till 2050, largely focusing on the electricity industry. The scenarios vary between a low carbon scenario where coal is largely replaced by renewable, nuclear and gas fuels and a fossil scenario where coal continues to be the main fuel for the electricity industry. ${ }^{7}$ These scenarios have been updated and revised a number of times but the government has provided no guidance on which of these scenarios is more likely because it has not made a final decision on financing. On closer analysis, the current set of scenarios is very optimistic when it comes to replacement of coal by other fuels. All scenarios assume a high increase in demand for gas, due to substitution of brown coal, decommissioning of existing nuclear power plant and commissioning of new ones during the interim period from 2035 to 2040.

The official forecasts envisage an expansion of nuclear power, although the government has not been able to secure any financing for the planned nuclear plants. The official natural gas strategy is solely focused on the electricity sector while no analysis has been provided for other sectors. The official forecast assumes that gas demand by other sectors will gradually decline as energy savings more than offset the future growth of these sectors.

A new gas-fired power station is unlikely to be built by 2030 unless natural gas prices decline to such an extent that they compete with coal prices in the longer term. However, there will be a steady increase in the use of natural gas for electricity and steam production as small-scale and micro-CHP are gradually installed by mid and small companies. The key Czech industries have a great potential for growth and although the growth in natural gas demand will be slower, there will be a sturdy growth in industrial gas demand throughout the next decade.

Our Reference scenario assumes that gas demand by the key industries, inclusive of the automotive and food sectors, will increase from $2.6 \mathrm{Bcm} / \mathrm{y}$ in 2017 to $3.3 \mathrm{bcm} / \mathrm{y}$ in 2030 . The automotive industry will continue to show a robust growth of $5 \% / y$ by 2020 and then slow down to $3 \% / y$. The food industry is likely to grow at a steady rate of $1.5 \% / y$ throughout the forecasting period. The development of the other key industries is explained in Chapter 6.

Gas demand by other commercial and industrial customers will show less buoyant growth because further energy efficiency savings are largely expected. Gas demand is expected to grow at a moderate rate by $1 \% / y e a r$, and to increase from $1.3 \mathrm{bcm} / \mathrm{y}$ in 2017 to $1.5 \mathrm{bcm} / \mathrm{y}$ by 2030 .

There will only be a small increase in gas demand by the electricity and steam sector by 2030 , increasing from $1.2 \mathrm{bcm} / \mathrm{y}$ in 2017 to $1.5 \mathrm{bcm} / \mathrm{y}$ in 2030. The more structural changes are only expected after 2030.

Total energy, industrial and commercial gas demand is expected to grow from $5.2 \mathrm{bcm}$ in 2017 to $6.3 \mathrm{bcm}$ in 2030 in the reference scenario. Czech gas demand will thus reach the pre-financial crisis levels of the early 2000 s. 

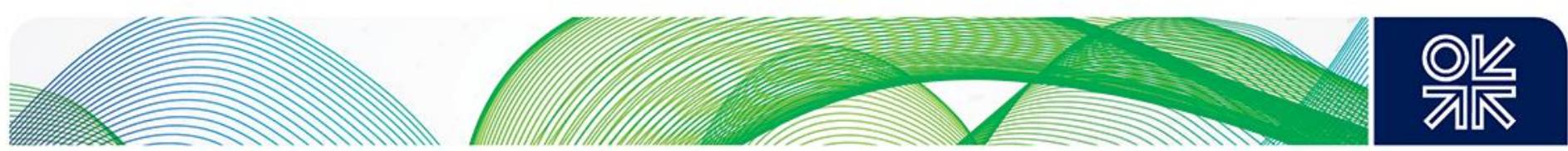

Figure 1: Czech Commercial and Industry Natural Gas Demand Forecast 2016-2030 (Reference Scenario)

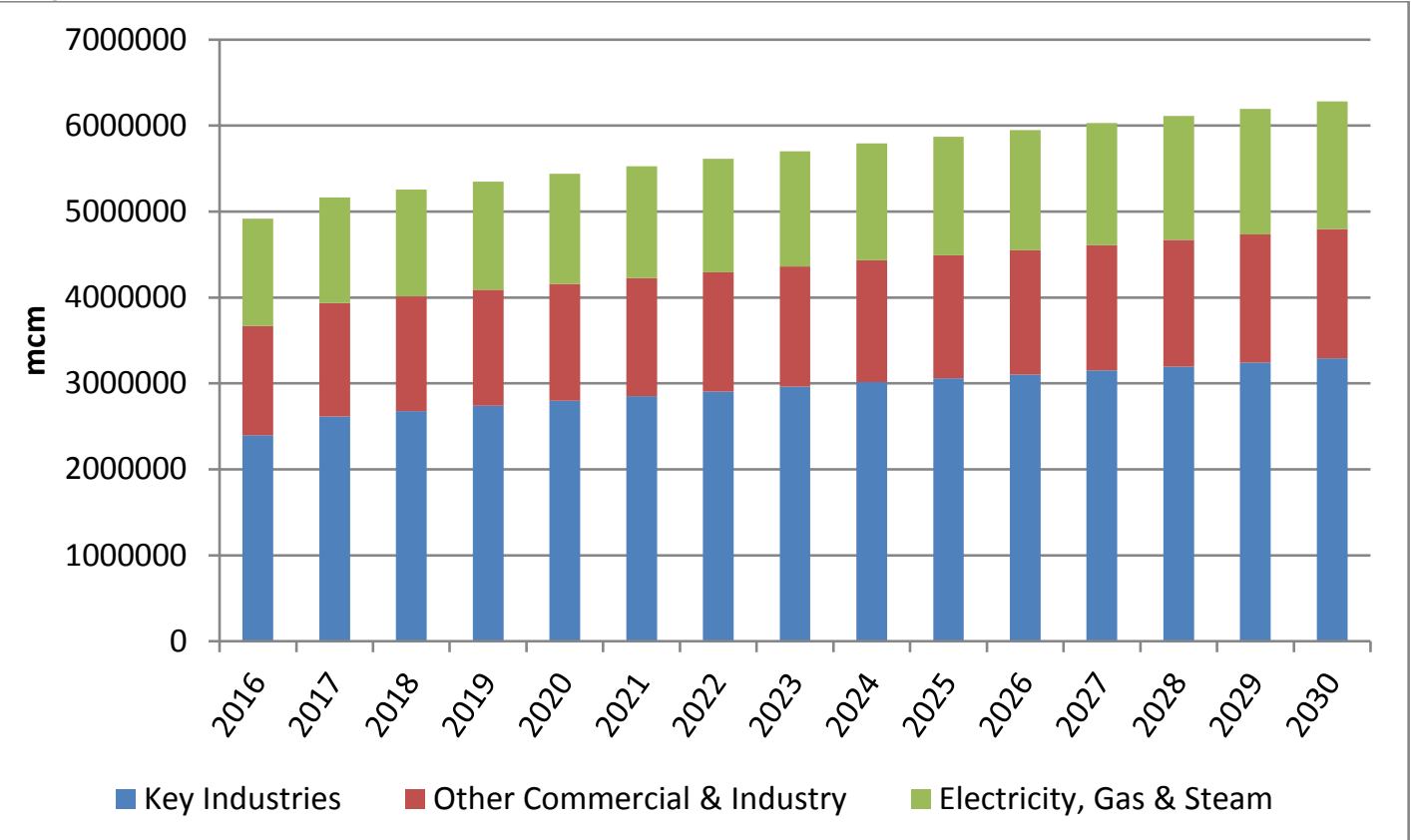

Source: Author's forecast

The Optimistic scenario envisages the key industries showing a strong growth in natural gas demand, especially in 2018-2022, due to higher exports and increased domestic demand. The scenario foresees gas demand by the key industries increasing from $2.6 \mathrm{bcm} / \mathrm{y}$ in 2017 to $3.6 \mathrm{bcm} / \mathrm{y}$ in 2030. It is assumed that food, other industry and electricity sectors are likely to show similar growth as in the Reference forecast. In the Optimistic scenario total industrial and commercial natural gas demand is expected to grow from $5.2 \mathrm{bcm}$ in 2017 to $6.6 \mathrm{bcm}$ in 2030 .

Figure 2: Czech Commercial and Industry Natural Gas Demand Forecast 2016-2030 (Optimistic Scenario)

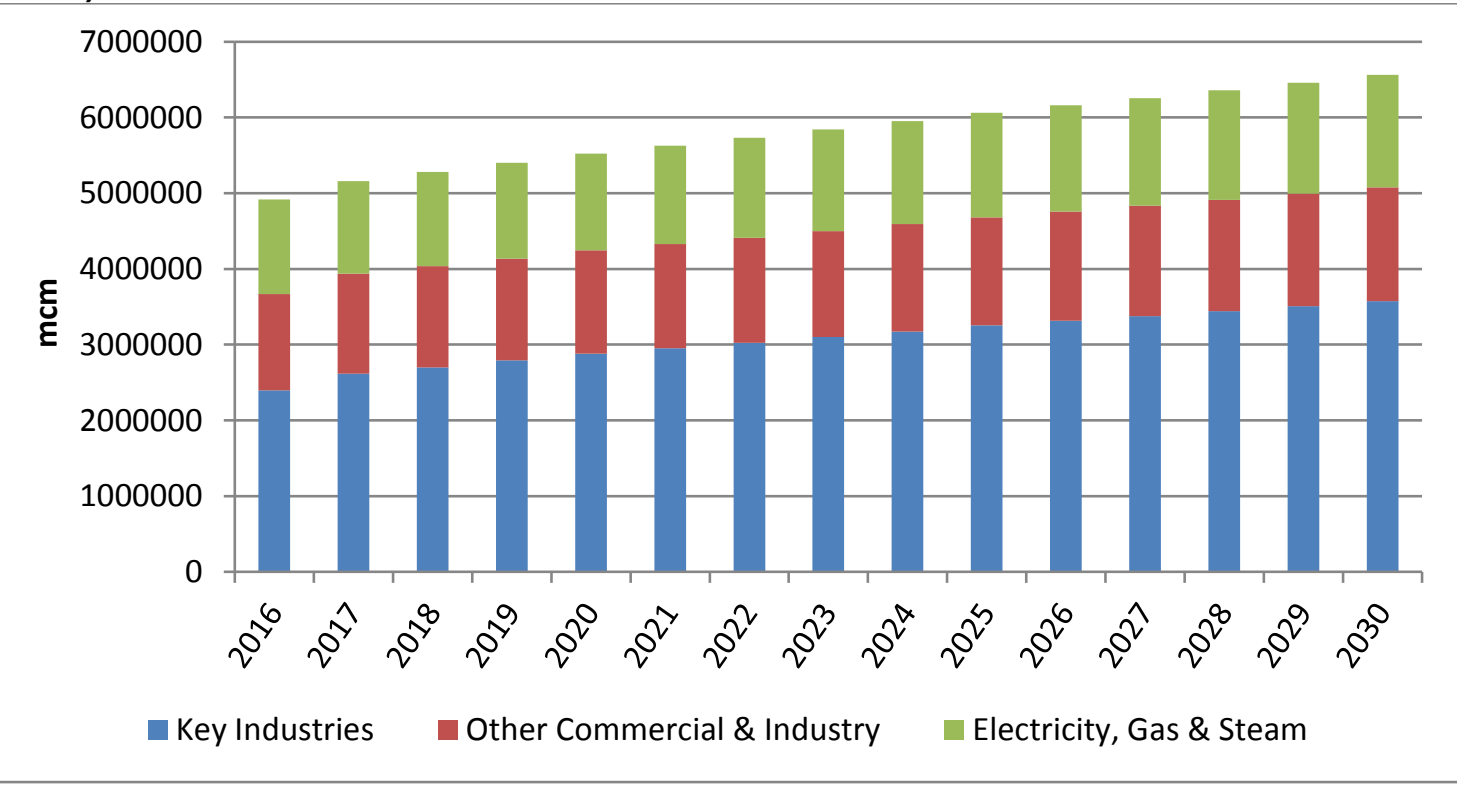

Source: Author's forecast 

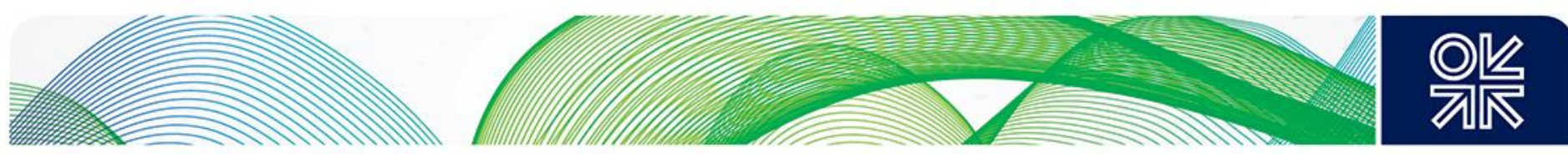

\subsection{Major Challenges to be Expected in the Polish Industrial Sector}

Like the rest of Central Europe, industrial development in Poland will be largely determined by EU policies in the next decade and Polish industry especially will have to face stringent regulation on emissions which will come into effect in $2020 .^{8}$ There will be three main challenges within the next decade. The first challenge will be to cut emissions. Since the industry in general continues to be heavily dependent on local coal and has been unable to meet environmental quotas till now, it will be particularly costly for heavy energy using industries post 2020. The new regulations impose much stricter limits for companies which have been so far exempt.

Poland so far has failed to reach the first target of cutting its greenhouse emissions by $20 \%$ from 1990 levels by 2020. According to Eurostat statistics ${ }^{9}$ Poland cut emissions by only $15 \%$ in 2016 compared to 1990 levels, although its economy grew significantly during the same time. At present, achieving a $40 \%$ cut in emissions by 2030 seems to be a major challenge and it will undoubtedly put an additional burden on industry since large parts have not been modernised. Large, medium and small companies will need to invest heavily in environmental technology in order to meet the challenge.

The second challenge is to increase the use of renewables to $20 \%$ by 2020 . Some countries were given exemptions, and the Polish target was set at $15 \%$ by $2020 .{ }^{10}$ In 2016 , Poland used $11.3 \%{ }^{11}$ of renewables in its gross final energy consumption. Again, it seems highly unlikely that Poland will manage to meet the 2020 target. The target of a $32 \%$ share of renewables in the gross energy balance by 2030 will also be very challenging since Poland is still committed to nuclear power and relies heavily on local coal. The current government energy strategy (PEP2040) published in late 2018 envisages that the share of renewables will grow to only $21 \%$ by 2030 . Given the reluctance of the current government to reduce its reliance on domestic coal, it can be assumed that Poland will not be able to meet either 2020 nor 2030 targets, which is likely to result in financial penalties imposed by the EU which are likely to put a significant financial burden on industry.

The third challenge for Polish industry is to reduce energy intensity; the target for 2020 is a $20 \%$ reduction compared to 2005 and $32.5 \%$ by $2030 .{ }^{12}$ The target is defined as the achievement of a 13.6 Mtoe reduction in primary energy consumption between 2010 and 2020 which, with economic growth, means improving the energy efficiency of the country's economy. By 2016, Poland managed to reduce primary energy consumption by 11.9 Mtoe to 66.7 Mtoe and its national target for 2020 is 71.6 Mtoe. However, energy consumption has started to grow faster since 2016 which puts meeting the target in jeopardy.

Apart from the EU environmental targets outlined above continuous investment in R\&D will be important in determining whether industry remains competitive. Poland's record on R\&D has been poor. The EU recommendation for investment is around 3\% of GDP, but Poland's target has been reduced to $1.7 \%$. Nevertheless it has consistently failed to meet even this target, with investment well below $1 \% .{ }^{13} \mathrm{~A}$ slight improvement has been recorded since 2014 when Poland started to increase its investment in R\&D and by 2017 it went up to $1.07 \%$, which is still well below the required level. Since a large proportion of principal companies are owned by international groups or by the State Treasury there is a continuing

\footnotetext{
${ }^{8}$ The package sets three key targets: $20 \%$ cut in greenhouse gas emissions (from 1990 levels); $20 \%$ of EU energy from renewables; and 20\% improvement in energy efficiency. The targets were set by EU leaders in 2007 and enacted in legislation in 2009. The EU countries have also agreed on a new 2030 Framework for climate and energy for the period between 2020 and 2030. On 14 June 2018, the Commission, the Parliament and the Council reached a political agreement which includes a binding renewable energy target for the EU for 2030: a 40\% cut in greenhouse gas emissions compared to 1990 levels; at least a $32 \%$ share of renewable energy consumption; and at least $32.5 \%$ energy savings compared with the business-as-usual scenario.

${ }^{9}$ https://ec.europa.eu/eurostat/tgm/refreshTableAction.do?tab=table\&plugin=1\&pcode=sdg 13 10\&language=en

${ }^{10} \mathrm{https}: / /$ ec.europa.eu/eurostat/web/europe-2020-indicators/europe-2020-strategy/headline-indicators-scoreboard ${ }^{11} \mathrm{https}$ ://ec.europa.eu/eurostat/web/europe-2020-indicators/europe-2020-strategy/headline-indicators-scoreboard

12 https://ec.europa.eu/eurostat/web/europe-2020-indicators/europe-2020-strategy/headline-indicators-scoreboard

${ }^{13} \mathrm{https}$ //ec.europa.eu/eurostat/web/europe-2020-indicators/europe-2020-strategy/headline-indicators-scoreboard
} 

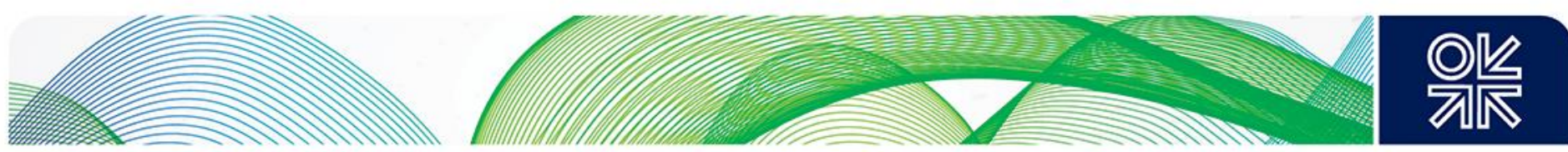

danger that the government will divert money elsewhere and some international companies may try to extract maximum dividends rather than invest in research. On the other hand, the international companies have a better record in investment that the local companies. Those industrial sectors which are dominated by international groups are likely to benefit from up to date innovations and modern technology.

\subsection{Outlook for Polish Industrial Gas Demand up to 2030}

The Polish industrial sector will be closely linked with future Polish economic growth. The Polish economy has shown a much healthier growth than most EU countries over the last decade. Economic growth is estimated at $5.1 \%$ in 2018 , on par with growth of $4.8 \%$ in 2017 , driven by private consumption due to increasing employment and strong consumer confidence. Growth is also fuelled by higher investment, as Poland draws on EU funds to accelerate public investment. However, GDP growth is likely to slow down to $3.7 \%$ in 2019 and 3.3\% in 2020 as European growth slows due to reduction in international trade, and private consumption will cool down, according to the EU forecast. ${ }^{14}$ It is expected that the industrial sector will continue to show healthy growth over the next decade. The Polish economy is likely to show average growth between $2 \%$ and $4 \% / y e a r$ over the next decade, a stronger growth than the average EU economy. ${ }^{15}$

According to the latest government forecast ${ }^{16}$ released last year, Poland will aim to reduce the coal share in electricity production to $60 \%$ from the current $77 \%$ while increasing the renewables share to $21 \%$ of final energy consumption by 2030 . The current strategy is still based on the premise of constructing a nuclear power plant by 2033 and envisages that the natural gas share of primary energy consumption will remain stable or grow only slowly. Currently, the share of gas in TPES is $14.7 \%$ while its share in electricity generation is only 4.7\%. PEP2040 anticipates that the natural gas share of electricity produced will grow from $5.8 \%$ in 2020 to $9.5 \%$ in 2030 and $16.4 \%$ by 2040 . Gas consumption by the electricity sector is planned to increase to $2.4 \mathrm{bcm}$ in 2020 , to $4.2 \mathrm{bcm}$ in 2030 and $7.8 \mathrm{bcm}$ in 2040. However, in order to achieve this, the gas market would have to be fully liberalised while large investment would have to be committed to the gasification of the country. The current rate of gasification is around $58 \%$ which is envisaged to grow to $61 \%$ by 2022 according to PEP2040. The strategy does not foresee any significant increase in cogeneration as gas-fired generation is seen only as a back-up policy.

On closer analysis, the current strategy is very optimistic when it comes to replacement of coal by other fuels, given the historical reluctance to switch away from coal and the continuing future price competitiveness of coal in the next decade. Moreover, the official forecast envisages a nuclear power plant construction although the government has not been able to secure any financing for it. The official natural gas strategy focuses on the electricity sector and no analysis has been provided for other sectors, especially industry. The official forecast assumes that gas demand by other sectors will gradually decline as energy savings will more than offset the future growth of these sectors.

This paper assumes that some of the key energy-intensive industries have a great potential for growth while others will see a decline. Overall industrial gas demand will show a gradual growth till 2025 and then it will start to tail off again.

The Reference Scenario assumes that gas demand by the key industries will decline from $7.4 \mathrm{bcm} / \mathrm{y}$ in 2017 to $7.1 \mathrm{bcm} / \mathrm{y}$ in 2030 . The food industry is likely to grow strongly till 2022 by $2.5 \%$ and then slow down to $1.5 \% / y$ throughout the rest of the forecasting period. Gas demand by other commercial and industrial customers will show a less buoyant growth as energy efficiency savings are largely expected within this group and are expected to increase from $0.9 \mathrm{bcm} / \mathrm{y}$ in 2017 to $1.1 \mathrm{bcm} / \mathrm{y}$ by 2030 .

\footnotetext{
${ }^{14}$ https://ec.europa.eu/info/business-economy-euro/economic-performance-and-forecasts/economic-performancecountry/poland/economic-forecast-poland_en

15 https://data.oecd.org/gdp/gdp-long-term-forecast.htm

${ }^{16}$ https://www.gov.pl/web/energia/polityka-energetyczna-polski-do-2040-r-zapraszamy-do-konsultacji
} 

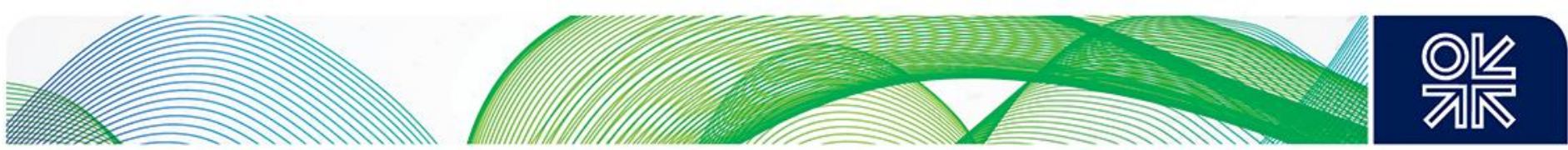

Only a small increase in demand by the electricity and steam industry is expected by 2030 . The more structural changes are only expected after 2030. The reference scenario expects gas demand in the electricity and steam industry to increase from $1.3 \mathrm{bcm} / \mathrm{y}$ in 2017 to $1.7 \mathrm{bcm} / \mathrm{y}$ in 2030 . Total energy, industrial and commercial gas demand is thus expected to grow from $10.3 \mathrm{bcm}$ in 2017 to 11.1 in 2025 and then drop to $10.7 \mathrm{bcm}$ in 2030, according to the reference natural gas demand forecast.

\section{Figure 3: Polish Industrial Natural Gas Demand Forecast 2016-2030 (Reference Scenario)}

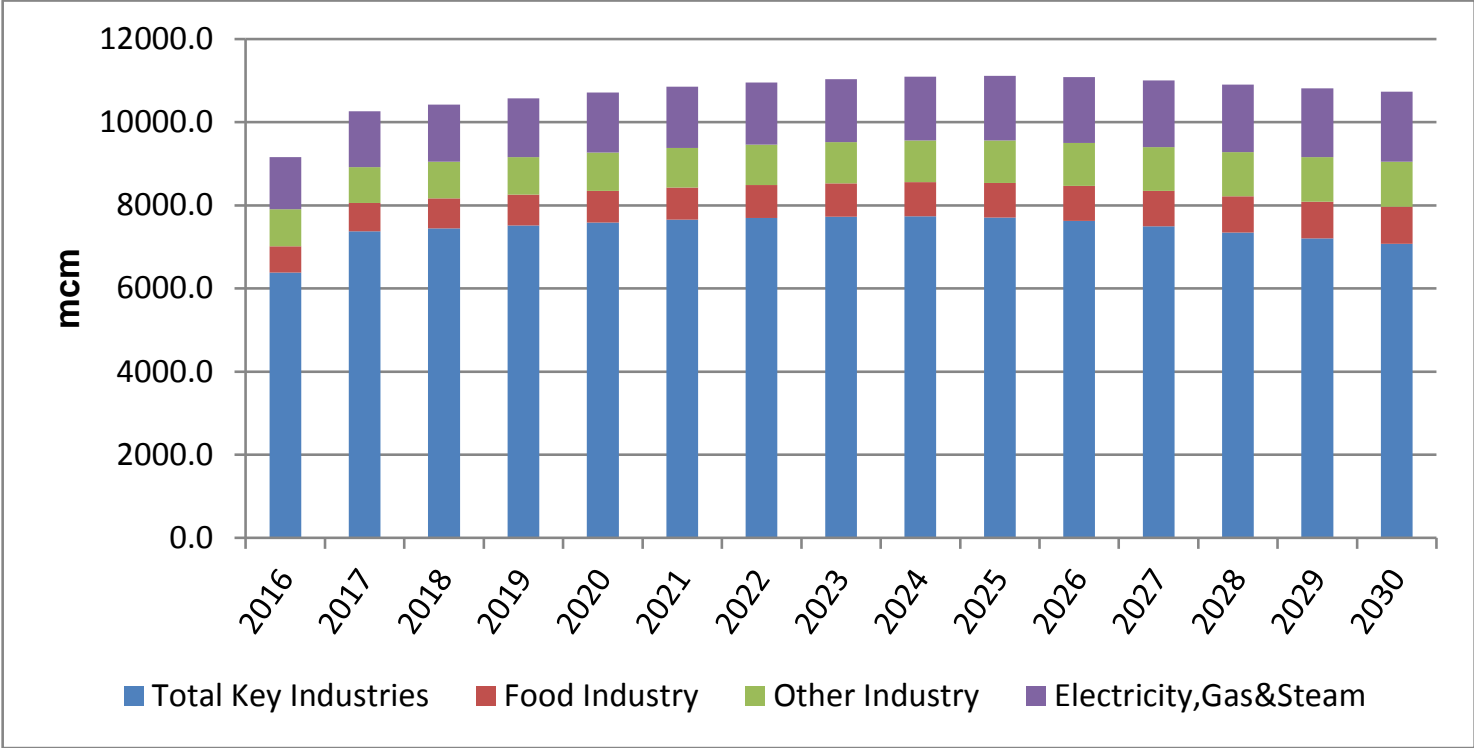

Source: Author forecast

The Optimistic Scenario envisages the key industries showing a stronger growth in natural gas demand, especially in 2018-2022 due to higher exports and increased domestic demand. It foresees gas demand by the key industries increasing from $7.4 \mathrm{bcm} / \mathrm{y}$ in 2017 to $8.4 \mathrm{bcm} / \mathrm{y}$ in 2030 . It is assumed that food, other industry and electricity sectors are likely to show similar growth as in the Reference forecast. In the Optimistic scenario total industrial and commercial natural gas demand is expected to grow from $10.3 \mathrm{bcm}$ in 2017 to $12.0 \mathrm{bcm}$ in 2030.

Figure 4: Polish Industrial Natural Gas Demand Forecast 2016-2030 (Optimistic Scenario)

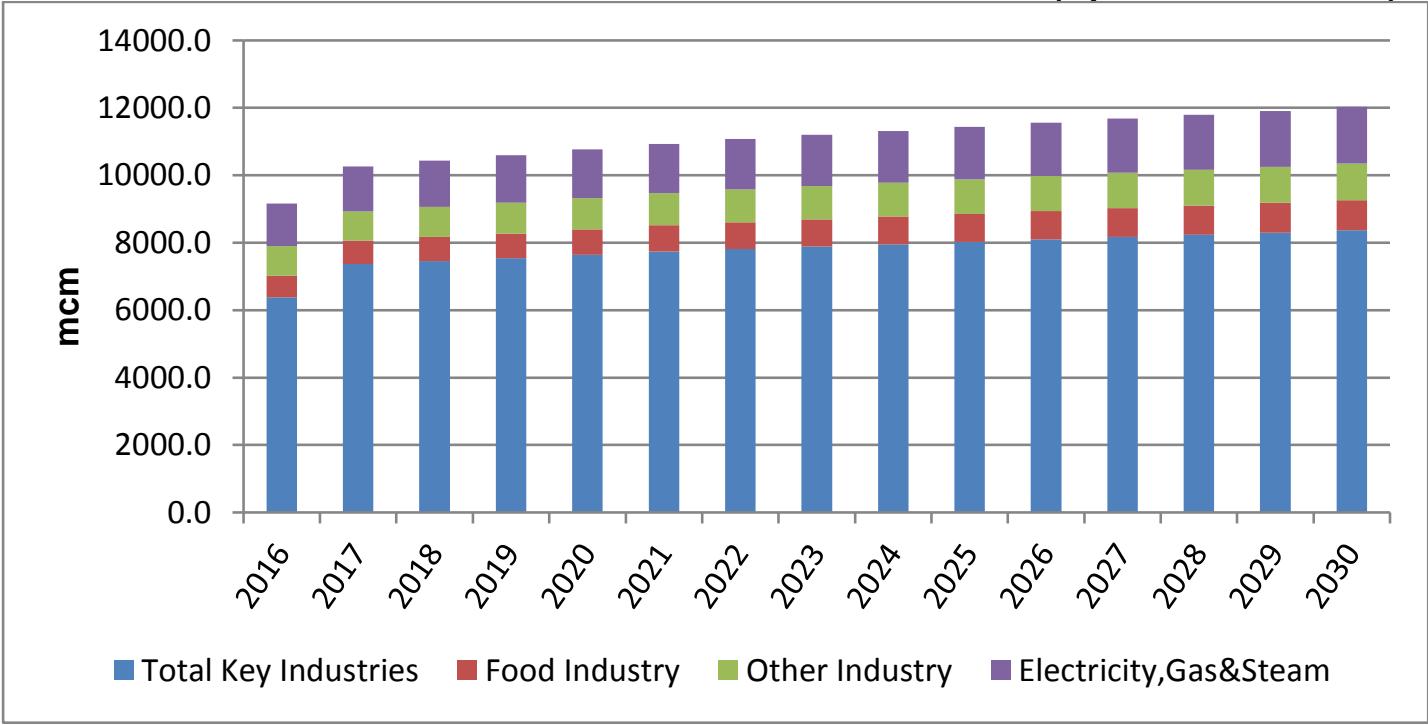

Source: Author forecast 

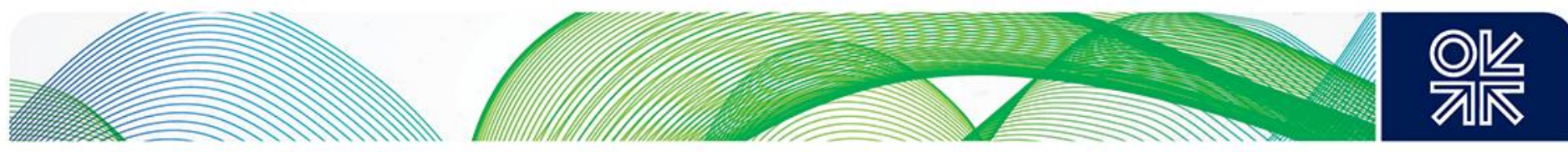

\subsection{Major Challenges to be Expected in the Slovak Industrial Sector}

Future Slovak industrial development will be dictated to a large extent by EU policies. Slovak industry will face three main challenges within the next decade. The new 2030 Framework for climate and energy for the period between 2020 and 2030 set the targets for $2030 .{ }^{17}$ The new regulation on emissions which will come into effect in 2020 will impose much stricter limits for companies which have been so far excluded from quotas; this will especially affect U. S. Steel Košice.

As a country, Slovakia has more than fulfilled its first target of cutting greenhouse emissions by $20 \%$ from 1990 levels by 2020. According to Eurostat statistics ${ }^{18}$ Slovakia cut emissions by $44 \%$ in 2016 compared to 1990 levels. This was achieved while the economy grew significantly, but the major initial cuts in emissions were largely achieved by closing down some industrial sectors rather than major investment in environmental technology or a major switch to renewables. On the surface, maintaining the emissions below $40 \%$ by 2030 seems achievable without too much of an additional burden on industry. However, some individual companies which were exempted from quotas so far will be hit by the new targets and may find it difficult to raise the investment needed. Moreover, smaller and medium sized companies would need to invest in and install environmental technology, which may prove to be a challenge. In the next decade it will certainly be a test for the industry to keep investing and to continue cutting emissions.

The second target is for the EU states to increase the use of renewables to $20 \%$ by 2020 . Slovakia was given an exemption and its target was set at $14 \%$ by $2020 .{ }^{19}$ In 2016 , Slovakia used $12 \%$ of renewables in its gross final energy consumption but the share declined from $12.9 \%$ in $2015 .{ }^{20}$ The promising trend in the use of renewables seems to have been halted, partly due to the withdrawal of certain subsidies, which slowed down the process in the past couple of years. The target of a $32 \%$ share of renewables in the gross energy balance by 2030 will thus be challenging because Slovakia is still committed to nuclear power and relies on local coal. The current Slovak energy strategy focuses on security and stability of energy supplies, and nuclear power is given priority. According to the government reference scenario, nuclear power should have a market share of almost $31 \%$ by 2030 , followed by natural gas $(23 \%)$, oil $(17.8 \%)$, coal $(12.5 \%)$, and renewables $(15.8 \%$ and well below the EU target). It looks that the country has no aspiration to meet the target and only envisages a gradual increase in the use of renewables. Slovakia is unlikely to meet the target unless the EU sets and imposes strict penalties which would persuade the government to change its course of action and increase investment in the environment throughout the next decade.

The third challenge for Slovak industry is to reduce energy intensity. The target for 2020 is $20 \%$. In 2016. Slovakia achieved primary energy consumption of 15.5 Mtoe and its national target for 2020 is 16.4 Mtoe..$^{21}$ Although it has met the 2020 target the 2030 target of $32.5 \%$ will be more of a challenge, and finding the investment needed to achieve it will put an additional burden on local companies.

One of the most important challenges will be for Slovakia to improve the record of its investment in $R \& D$, which will determine industrial competitiveness. IT has not kept step with the rest of the EU because gross domestic expenditure on R\&D represented only $0.88 \%$ of GDP in 2017 . The target for Slovakia is to achieve $1.2 \%$ while the EU average is $2.04 \%$. However, investment in research has

\footnotetext{
7 The package sets three key targets: $20 \%$ cut in greenhouse gas emissions (from 1990 levels); $20 \%$ of EU energy from renewables; and $20 \%$ improvement in energy efficiency. The targets were set by EU leaders in 2007 and enacted in legislation in 2009. The EU countries have also agreed on a new 2030 Framework for climate and energy for the period between 2020 and 2030. On 14 June 2018, the Commission, the Parliament and the Council reached a political agreement which includes a binding renewable energy target for the EU for 2030: a 40\% cut in greenhouse gas emissions compared to 1990 levels; at least a $32 \%$ share of renewable energy consumption; and at least $32.5 \%$ energy savings compared with the business-as-usual scenario.

${ }^{18} \mathrm{https}: / /$ ec.europa.eu/eurostat/tgm/refreshTableAction.do?tab=table\&plugin=1\&pcode=sdg 13 10\&language=en $19 \mathrm{https}$ ://ec.europa.eu/eurostat/web/europe-2020-indicators/europe-2020-strategy/headline-indicators-scoreboard ${ }^{20} \mathrm{https}$ :/ec.europa.eu/eurostat/tgm/table.do?tab=table\&init=1\&language=en\&pcode=t2020_31\&plugin=1

${ }^{21}$ https://ec.europa.eu/eurostat/web/europe-2020-indicators/europe-2020-strategy/headline-indicators-scoreboard
} 

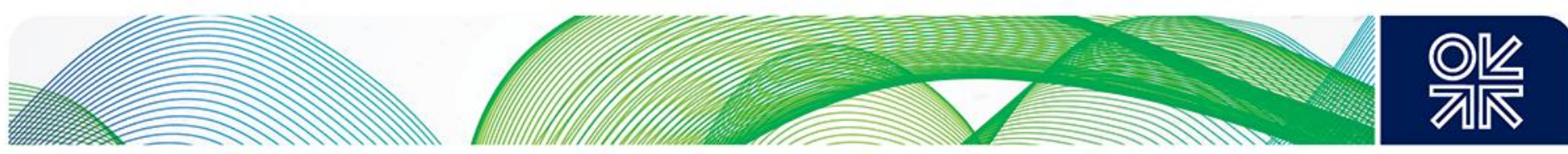

started to grow since 2012, with the exception of $2016 .{ }^{22}$ The Slovak government lacks any programme on industrial innovation, which is left solely to private companies. Since the largest companies are principally owned by international companies there is a danger that they will try to extract maximum dividends rather than investing in new technology. On the other hand the international companies, especially the German ones, have invested into modern technology over the last decade, providing an access to up to date innovations and modern technology for local industry.

\subsection{Outlook for Slovak Industrial Gas Demand up to 2030}

Over the past two decades, the Slovak Republic has been one of the fastest-growing transitional economies mainly thanks to export-oriented manufacturing, underpinned by the automotive sector. Until 2009, annual GDP growth reached double digit values. The global financial crisis slowed growth, but the economy has recovered relatively rapidly. GDP per capita is converging towards the OECD average but is still $25 \%$ lower than the OECD and EU averages, and regional disparities are important. Most economic activity is concentrated in western Slovakia (OECD, 201723). Robust economic growth will continue in $2019(4.1 \%)$ and $2020\left(3.5 \%{ }^{24}\right)$, driven by robust private demand and dynamic exports. The industrial sector will show a similar healthy growth in most of the key industries with a couple of exceptions. The Slovak economy is likely to show a growth of between $2.0 \%$ and $2.5 \% / y$ on average over the next decade, continuing to outperform the average EU economy. However, some labour skill shortages will weigh on growth. It can be expected that within the next decade Slovakia will gradually lose the advantage of cheaper labour costs, which will reduce its competitive advantage.

The Ministry of Economy has developed three energy forecast scenarios: high; reference; and energysaving. The reference scenario sees gas demand showing a slight recovery followed by stagnation after 2025 depending on the extent to which natural gas is used as a replacement for coal (combined cycle power plants). The official natural gas strategy has solely focused on the electricity sector while little analysis has been provided for other sectors. The official forecast assumes that gas demand by other sectors will gradually decline as energy savings more than offset the future growth of these sectors.

In this paper's Reference Scenario, the key industries will show only a small growth in natural gas demand throughout the next decade. Gas demand by the key industries, inclusive of the automotive and food sectors, will grow from $2.2 \mathrm{bcm}$ in 2017 until 2025 and then slowly decline to $2.2 \mathrm{bcm}$ by 2030 . The development of gas demand by the key industries is explained for each of the industries in Chapter 8. Gas demand by the automotive industry will continue to show a steady growth of $2 \% / y$ throughout the period, driven by the strong growth in car production. Similarly, gas demand by the food industry is likely to grow at a steady rate of $2 \% / y$ throughout the forecasting period. Gas demand by other commercial and industry customers will show similar growth of $2 \% / y$ as this area of the economy will see strong growth, although major energy savings are expected within this group of customers. Gas demand by other commercial and industry customers is expected to increase from $0.5 \mathrm{bcm} / \mathrm{y}$ in 2017 to $0.7 \mathrm{bcm} / \mathrm{y}$ by 2030 . In the reference scenario total industrial and commercial natural gas demand is expected to grow from $3.3 \mathrm{bcm}$ in 2017 to $3.5 \mathrm{bcm}$ in 2030.

\footnotetext{
22 https://ec.europa.eu/eurostat/web/europe-2020-indicators/europe-2020-strategy/headline-indicators-scoreboard ${ }^{23} \mathrm{https}$ ://www.oecd.org/environment/waste/Policy-Paper-Making-the-Slovak-Republic-a-more-resource-efficient-economy.pdf ${ }^{24} \mathrm{https}$ ://ec.europa.eu/info/business-economy-euro/economic-performance-and-forecasts/economic-performancecountry/slovakia/economic-forecast-slovakia en
} 

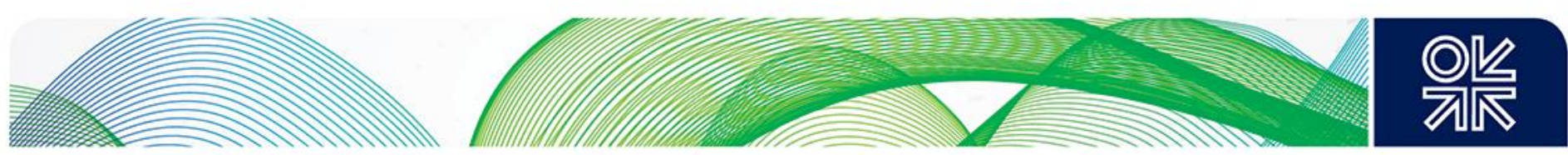

Figure 5: Slovak Industrial Natural Gas Demand Forecast 2015-2030 (Reference Scenario)

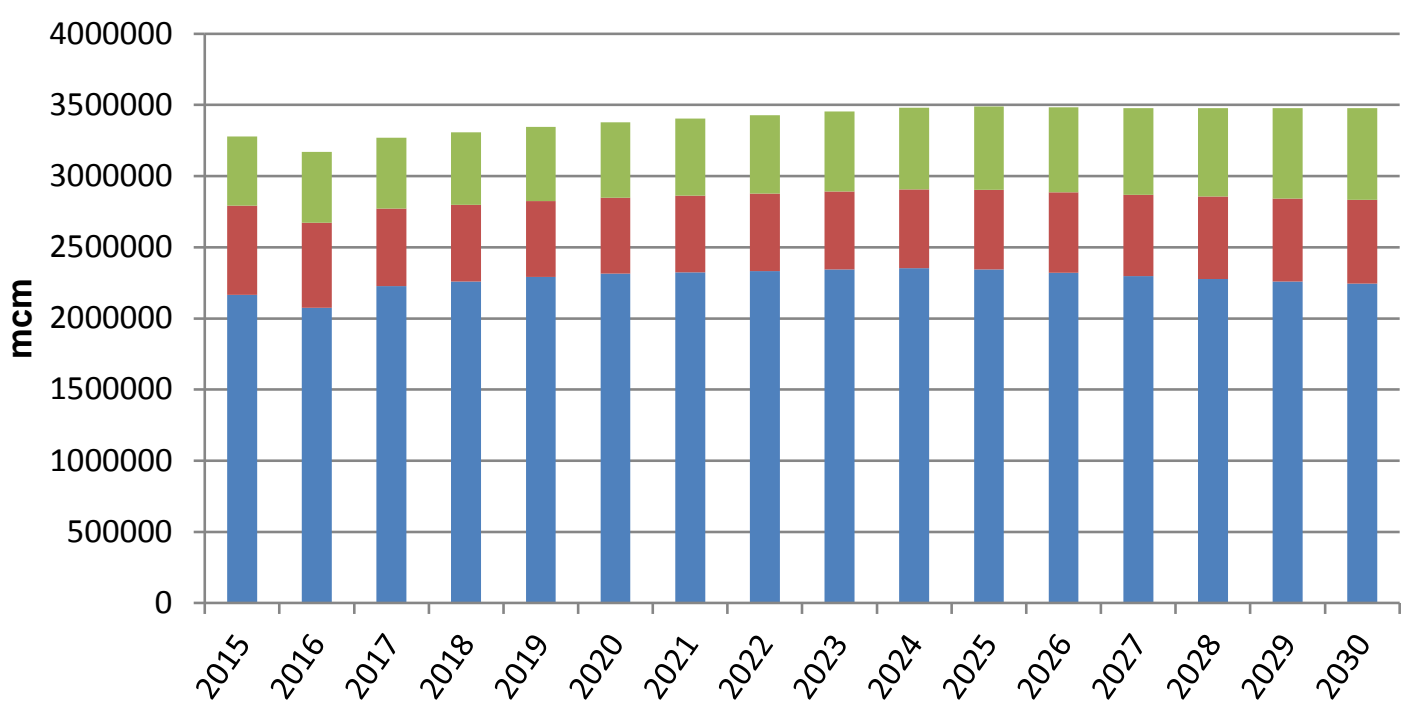

Total Key Industries Electricity, Gas \& Steam Industry Other Industry \& Commerce

Source: Author's forecast

In the Optimistic Scenario the key industries will show a stronger growth in natural gas demand, especially in 2018-2025. Gas demand by the key industries, inclusive of the automotive and food sectors, increases from $2.2 \mathrm{bcm} / \mathrm{y}$ in 2017 to $2.8 \mathrm{bcm} / \mathrm{y}$ in 2030 . Gas demand by the automotive industry will show a stronger growth of 3\%/y between 2018 and 2025, driven by faster growth in car production. Similarly, gas demand by the food industry is likely to grow more rapidly between 2018 and 2025 . The forecast for each of the key industry is explained above in the dedicated sections. Similarly, gas demand by other commercial and industry customers will show stronger growth of $3 \% / y$ fuelled by robust growth of the sector. The electricity and heat plant sector will also show healthy progress. Total industrial and commercial natural gas demand is expected to grow from $3.27 \mathrm{bcm}$ in 2017 to $4.07 \mathrm{bcm} / \mathrm{y}$ in 2030 .

Figure 6: Slovak Industrial Natural Gas Demand Forecast 2015-2030 (Optimistic Scenario)

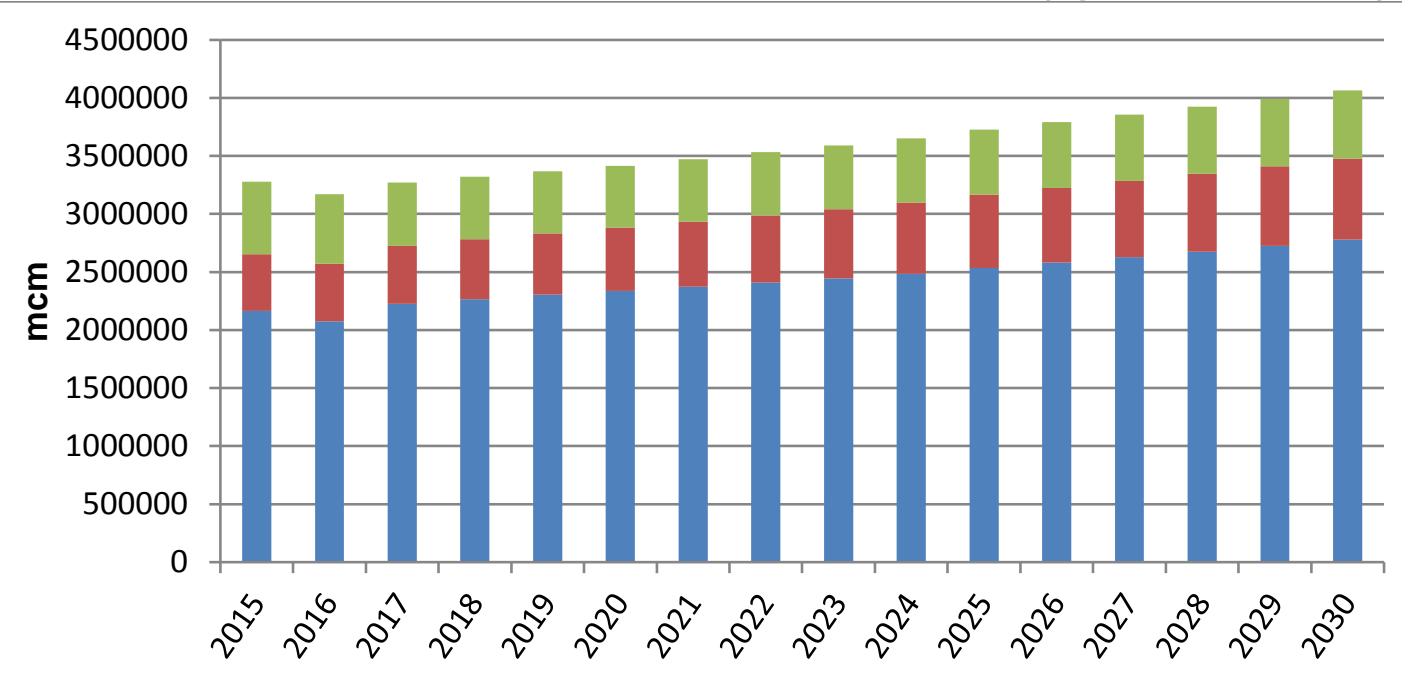

Total Key Industries Other Industry \& Commerce Electricity, Gas \& Steam Industry 

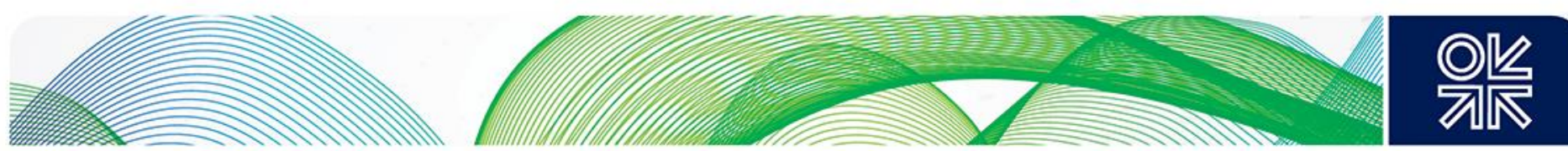

\section{FUTURE EU INDUSTRIAL CHALLENGES AND POLICY}

EU industrial policy will significantly determine the future of the energy intensive industries in Central Europe. The description of the major challenges and policies relevant to the steel, fertilisers, petrochemical, pulp and paper, glass and cement industries is in APPENDIX 1

In short, the following EU policies and developments will define the future of the key industries.

The future of the EU steel industry will depend on the following:

1. The EU regulatory framework;

2. Imports from non-EU - restrictive measures include tariff barriers, non-tariff measures such as technical regulations or conformity assessment procedures, export incentives, and restrictions on steel making raw materials;

3. Exports - the Commission supports the liberalisation of international trade under the World Trade Organisation (WTO)Energy prices - energy costs are crucial to competitiveness for the EU steel sector since energy costs represent up to $40 \%$ of the total operational costs of steelmaking;

4. Growth in demand for steel and initiatives for linked industries; and

5. Accesses to raw materials - as resources are scarce in Europe.

EU fertilisers industry:

1. The combined costs of feedstock and energy for a steam-reforming plant;

2. Capital cost of fertilisers plants;

3. The supply and demand of ammonia equilibrium will determine ammonia prices; and

4. Relocation of ammonia cyclical projects to locations where feedstock prices are low. The future trend in ammonia plants is clearly toward larger plants (capacities ranging from 3,000 to 4,000 tonnes/day) and locations with low-cost gas supplies.

EU petrochemical industry:

1. Future Common Industrial Policy and Common Energy Policy

2. Energy and feedstock costs versus Middle East and the USA;

3. High Regulatory Compliance Costs (e.g. REACH, Seveso Directive, Industrial Emissions Directive, 7th Environment Action Programme...). The sector is heavily regulated as regards health, safety and environmental protection, as well as climate change and energy issues. A stable and predictable regulatory environment for the chemicals sector is a key requirement for future competitiveness;

4. Population growth in the EU is low, affecting negatively demand growth for chemicals in general -elderly population, shrinking working age classes, high saturation levels; and

5. Non-energy raw material availability and cost issues (e.g. Bio based feedstock, rare earths, minerals). 

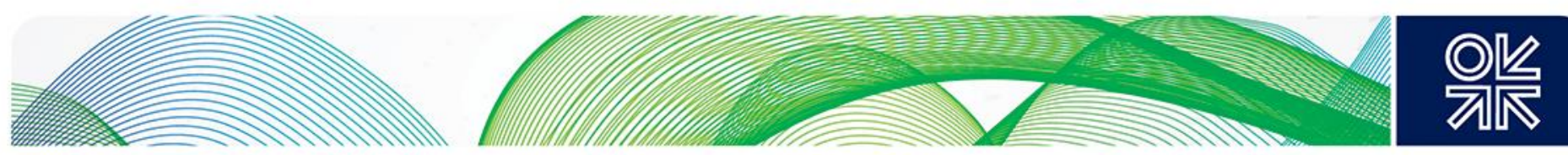

EU pulp and paper industry:

1. The EU environmental, energy, and transport policies;

2. Trade barriers and protectionist subsidies imposed by non-EU countries;

3. Raw material supply;

4. Recycling - Improvements in separate collection systems and innovation in sorting and recycling technology can further increase the quality and availability of secondary raw materials;

5. Rate of decline in paper consumption due to digitalisation; and

6. Energy prices - especially natural gas prices compared to North America.

EU glass industry:

1. Energy prices;

2. Energy efficiency improvements;

3. EU regulatory framework;

4. Non-EU country trade barriers such as compulsory testing and certification schemes;

5. Substitution by other products;

6. The counterfeiting of European designs; and

7. Recycling - one of the principal issues for the container glass industry is recycling which can positively affect its popularity.

EU cement industry:

1. The EU environmental, energy, and transport policies;

2. Energy efficiency improvements;

3. Energy prices; and

4. Raw material supply.

\section{INDUSTRIAL NATURAL GAS DEMAND IN THE CZECH REPUBLIC}

Natural gas plays only a moderate role in Czech total primary energy supply while large industrial consumers are responsible for $45 \%$ of total gas consumption. The Czech industry has made significant progress in increasing energy efficiency and a recent survey suggests that the further potential for natural gas savings is up to $10 \%$ only. The period of high natural gas prices has stimulated energy savings and investment in energy efficient technology. Natural gas prices in the Czech Republic are the lowest among the European OECD states for both household and industry customers. Despite the competitive advantages the Czech industry enjoys, natural gas demand was dented by the international recession and gas demand has only started to recover since 2015 once gas prices weakened. The key Czech industries have a great potential for growth and although the growth in natural gas demand will be slower, there will be a sturdy growth in industrial gas demand throughout the next decade. Apart from the fertiliser and petrochemical industry reliant on natural gas as feedstock and the cement industry, all other key industrial sectors will see gas demand grow over the next decade, driven by foreign investments, a strongly growing economy, increasing production capacity, and expanding exports of key industry products. In the scenarios prepared for this paper total industrial and commercial natural gas demand is expected to grow from the current $5.2 \mathrm{bcm}$ to $6.3 \mathrm{bcm}-6.6 \mathrm{bcm}$ in 2030 . 

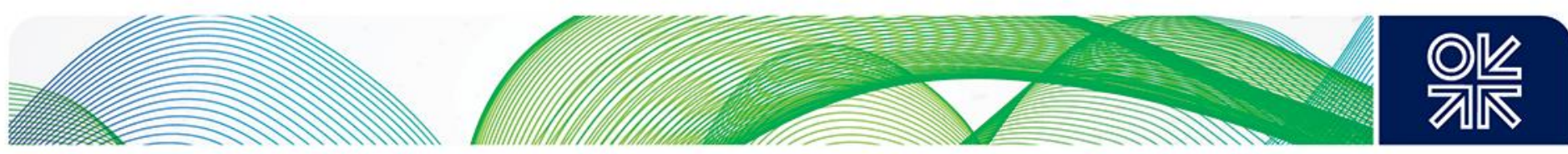

The Czech Republic with a population of 10.5 million and an area of $78,866 \mathrm{~km}^{2}$ has one of the most developed and industrialised economies in Central and Eastern Europe: Bohemia and Moravia were the industrial heartland of the Austro-Hungarian Empire where $70 \%$ of industrial production was concentrated. Czech industry is focused on metallurgy, engineering, automobiles, electronics, chemistry, food and beverage processing, and production of glass, medicines, textile and paper. In 2017 , the industry and energy sector made up $44.2 \%$ of gross domestic product (GDP) while the service sector contributed $46.8 \%$ and agriculture $2.2 \%{ }^{25}$

\subsection{Main Characteristics of the Czech Natural Gas Market}

The Czech gas industry was largely reorganised when the incumbent gas company Transgas was privatised in 2002 when RWE Gas AG acquired a 97\% shareholding in Transgas and between 40\% and $49 \%$ shareholdings in eight gas distribution companies. The virtually total Transgas dependence on one source of gas from Russia had become a hot potato for successive governments and this was one of the main reasons for the privatisation. As a result, political influence has declined since 2002 and the Czech gas industry has now been transformed and liberalised, complying with the EC Third Package. The industry has unbundled its energy suppliers from the network operators; it has a fully independent energy regulator; it has increased transparency in retail markets; and the transmission company Net4Gas is involved in cross-border cooperation with transmission system operators and the creation of European Networks for Transmission System Operators.

Natural gas plays only a moderate role in total primary energy supply (TPES). In 2016, gas share in TPES was $16.9 \%$ while its share in electricity generation was only $4.5 \%$. Over the last ten years, final gas consumption fell by $12.4 \%$, more steeply than the $10.2 \%$ decline in TPES. ${ }^{26}$ The Czech Republic share of natural gas in TPES ranks eighth-lowest of the member countries of the International Energy Agency (IEA), and the fifth-lowest in terms of its share in electricity generation. ${ }^{27}$

Despite minor variations in some years, Czech natural gas demand steadily declined between 2006 and 2014, then started to slowly recover. The largest drop in consumption, by $12 \%$, was registered in 2014 when consumption totalled 7.3bcm, the lowest ever gas consumption since 1995. Gas demand in the heating season accounted for approximately $71 \%$ of total annual consumption in $2017^{28}$ which shows that natural gas is largely used for heating purposes, including in industry, rather than industrial processes.

Czech natural gas demand was $8.5 \mathrm{bcm}$ in 2017 , driven by the growing economy, higher demand from households and most importantly by demand from industry and its one gas power station. The combined cycle unit at the Počerady power station started to operate from 2016 for peak purposes. In 2017, the gas share in electricity production increased to $6.3 \%$ as a result. ${ }^{29}$

In 2017 , large industrial consumers represented $45.1 \%$ of total gas consumption, followed by households with $28.5 \%$, and medium and small consumers accounted for $25.1 \% .{ }^{30}$ Gas demand was affected by the last recession, especially during the second phase after 2010, although different groups of consumers registered decline differently. Household demand declined more rapidly between 2010 and 2014 than any other commercial group of customers. Apart from medium and small commercial consumers all other groups have not yet reached the pre-recession levels of gas consumption.

\footnotetext{
${ }^{25}$ Czech Statistical Office

${ }^{26}$ IEA

${ }^{27}$ Energy Policies of IEA Countries Czech Republic 2016 Review

${ }^{28}$ ERU Annual Report on the Operation of the Czech Gas System for 2017

${ }^{29}$ ERU Yearly report on the operation of the Czech gas system for 2017

${ }^{30}$ ERU Annual Report on the Operation of the Czech Gas System for 2017
} 

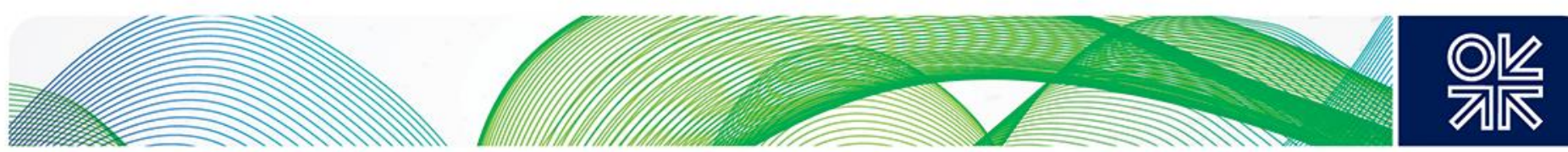

Figure 7: Czech Natural Gas Consumption, by Customer Category 2007-2017

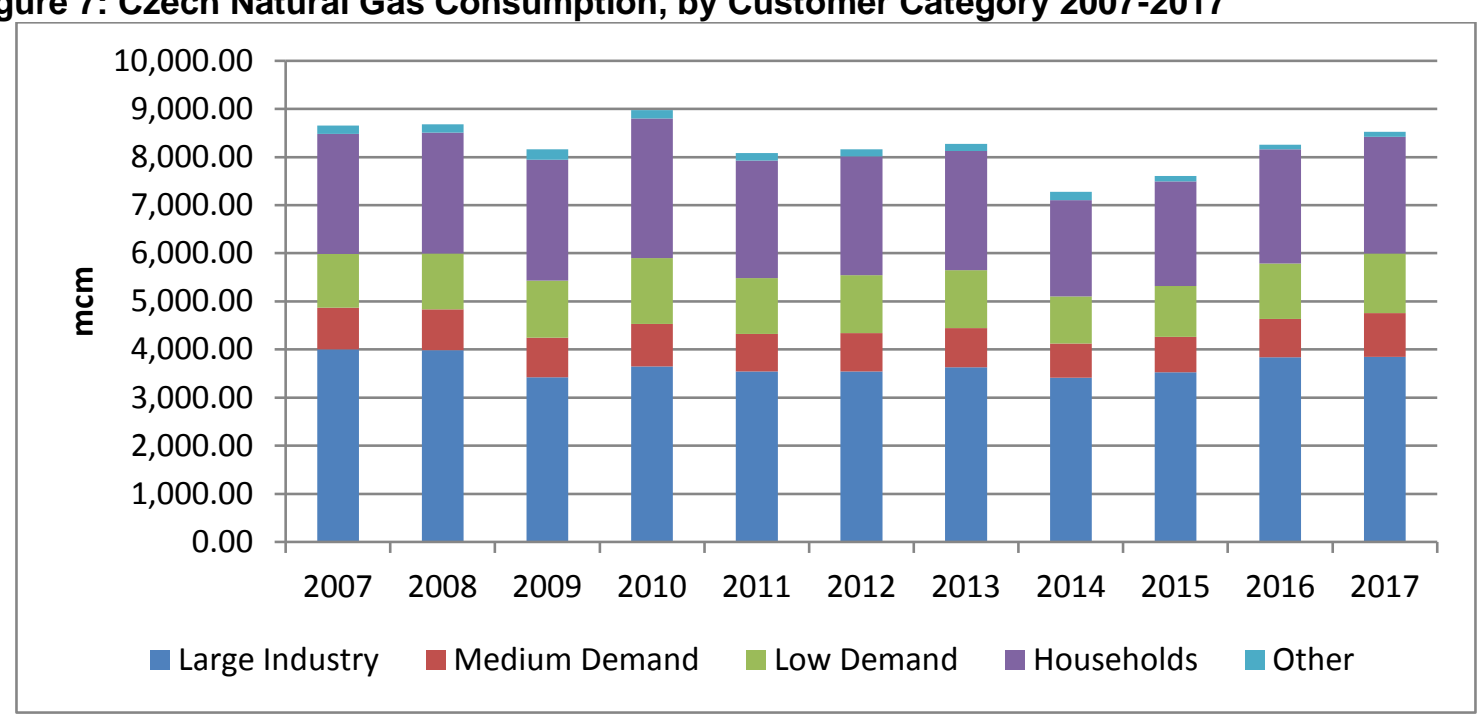

Source: ERU Annual Report on the Operation of the Czech Gas System for 2017

Czech gas policy is incorporated in the State Energy Policy (SEP), approved by the government in August 2015. ${ }^{31}$ The policy was updated in 2017 with a report on the long-term balance of supply of electricity and gas ${ }^{32}$ and a new proposal was submitted on February 4, 2019. ${ }^{33}$ It focuses on diversification of energy sources, improving energy efficiency and increasing use of renewables. The SEP is based on the premise of expanding the country's nuclear energy capacity in order to strengthen energy independence and security of supply. However, the decision on how to finance the construction and operation of the new nuclear plants has yet to be made. More detailed description of SEP is in APPENDIX 2.

\subsection{The Czech Energy Efficiency Progress}

Energy efficiency will be one of the main determining factors influencing industrial growth in future. The Czech Republic has made significant progress in reducing the energy intensity of industrial processes over the last two decades, but energy intensity continues to be twice as high as the average of the EU$28 .{ }^{34}$ One of the main reasons for the high energy intensity is that industry (including the energy sector) accounted for $32.3 \%$ of the country's gross value added in 2016 , the second highest in the EU, and therefore the energy intensity indicators would inevitably be higher than the EU-28 average of $19.3 \%{ }^{35}$ (For instance, the UK's share of industry was a mere 13\% according to Eurostat.) Heavy industry such as metallurgy and engineering account for a large proportion of the industrial sector. Nevertheless there is no doubt that there is a large potential for energy savings in the residential and industrial sectors.

In 2017, KPMG carried out a survey on the attitude of over 2,000 industrial companies on future energy efficiency improvements. ${ }^{36}$ Only $10 \%$ took part in the survey, which showed that $70 \%$ of the respondents

\footnotetext{
${ }^{31} \mathrm{https}: / /$ www.mpo.cz/cz/energetika/statni-energeticka-politika/zprava-o-ocekavane-dlouhodobe-rovnovaze-mezi-nabidkouelektriny-a-plynu-2015--223627/

${ }^{32}$ https://www.mpo.cz/assets/cz/energetika/strategicke-a-koncepcni-dokumenty/2017/8/Zprava-o-ocekavane-dlouhodoberovnovaze-mezi-nabidkou-elektriny-a-plynu- 2016 .pdf

${ }^{33} \mathrm{https}: / /$ www.mpo.cz/cz/energetika/strategicke-a-koncepcni-dokumenty/navrh-vnitrostatniho-planu-v-oblasti-energetiky-aklimatu-ceske-republiky--243377/

${ }^{34}$ Eurostat

${ }^{35} \mathrm{https}: / /$ ec.europa.eu/eurostat/statisticsexplained/index.php?title=File:Energy_intensity_of_the_economy,_in_selected_years, 2006-2016_(kilogram_of_oil_equivalent_per_1_000_EUR).png

${ }^{36}$ https://home.kpmg.com/cz/cs/home/pro-media/tiskove-zpravy/2017/03/cesky-prumysl-dokaze-usporit-14-procentenergie.html
} 

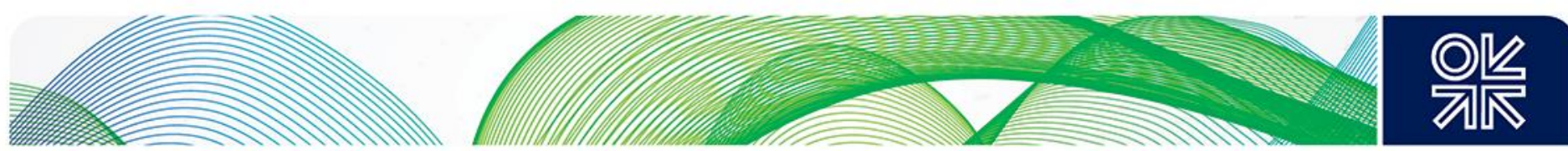

chose to meet the minimum requirements by introducing an energy audit while $30 \%$ had decided to introduce either certification or energy management. The surveyed companies saw the highest potential for saving electricity - up to $14 \%$. The potential for natural gas savings was estimated at up to $10 \%$. The saving potential is largely seen in building insulation (16\%) while improvements in operational technology could yield up to $12 \%$ of savings. The survey illustrates that the major energy savings have already been made and that there is only a limited potential to improve efficiency in the operational technology in the near future.

According to the author's interviews with some large industrial companies, most large companies whose energy represents a significant share of production costs have already pushed through major improvements in energy efficiency, especially since 2013 when prices rocketed. Most energy intensive industrial sectors have exploited at least two thirds of possible energy savings. All the interviewed companies have drawn on EU funds, which cover $50 \%$ of the cost of energy saving technology or emission reducing equipment. Medium and smaller companies had much less access to EU funds and saving measures and the bulk of the potential energy savings in industry is in medium and small companies which continue to run obsolete heating boilers.

Despite increasing energy efficiency, the Czech Republic has the third most energy intensive economy among EU member states, currently more than double the EU average, even though energy intensity has declined at a faster rate than the EU average since 2004. Broken down by sector, industry accounts for the largest share of the economy's energy use, followed by the transport and housing sectors. The energy intensity of industry has been consistently decreasing, and energy consumption in this sector has fallen by $17 \%$ compared to 2004 . See more information on the government policy regarding the improvements in energy efficiency in APPENDIX 3.

Figure 8: Czech \& EU Energy Intensity, 1995-2016

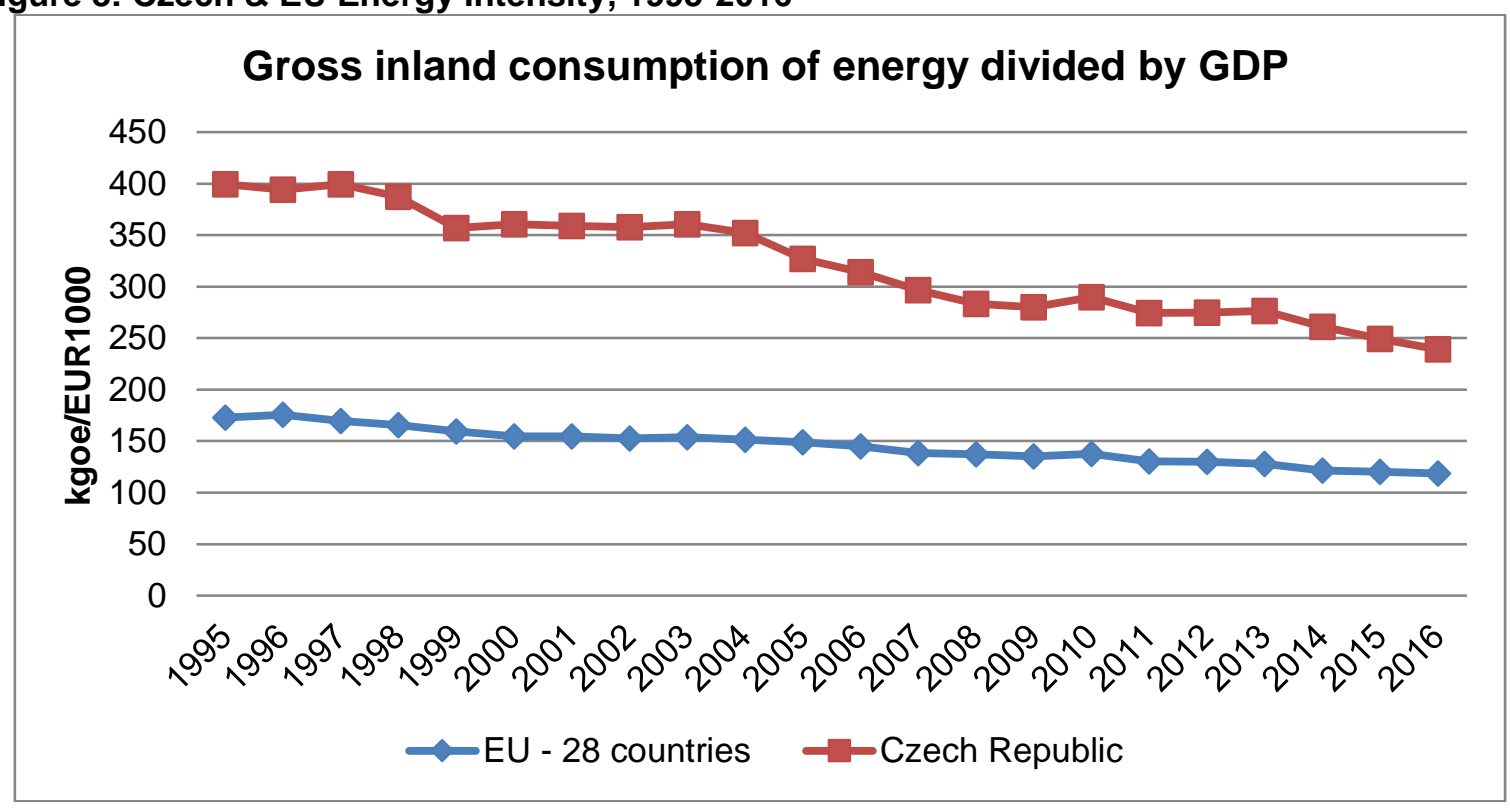

Source: Eurostat

\subsection{Czech Gas Price Developments and Competition from Coal}

Since 1 January 2007, the gas market has been deregulated and all final customers have the right to change their supplier free of charge. The final price of natural gas is composed of a component regulated by the Energy Regulatory Office (ERO) and an unregulated component resulting from the 

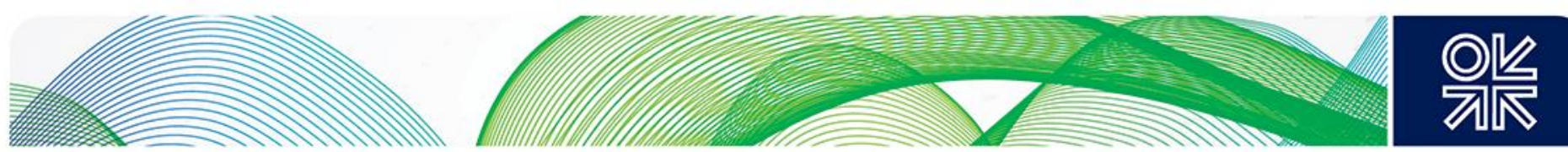

contractual relationship between the supplier and the customer. The regulated component includes the charges for natural gas transmission and distribution. The unregulated component represents the commodity charge and the gas storage charge. ERO sets out regulated prices for gas transmission and distribution, the prices for the market operator's services and the prices of supply of last resort.

Natural gas prices in the Czech Republic are among the lowest in the European OECD states for both household and industry customers. According to Eurostat, Czech gas prices for non-household consumers in the first half of $2018^{37}$ were well below the EU average. ${ }^{38}$ Turkey, Belgium, Hungary, Netherlands and Moldova were the only countries with lower non-household gas prices. ${ }^{39}$

Figure 9: Czech Natural Gas Price for Medium Size Industrial Consumers, Excluding Taxes and Levies, 2012-2018

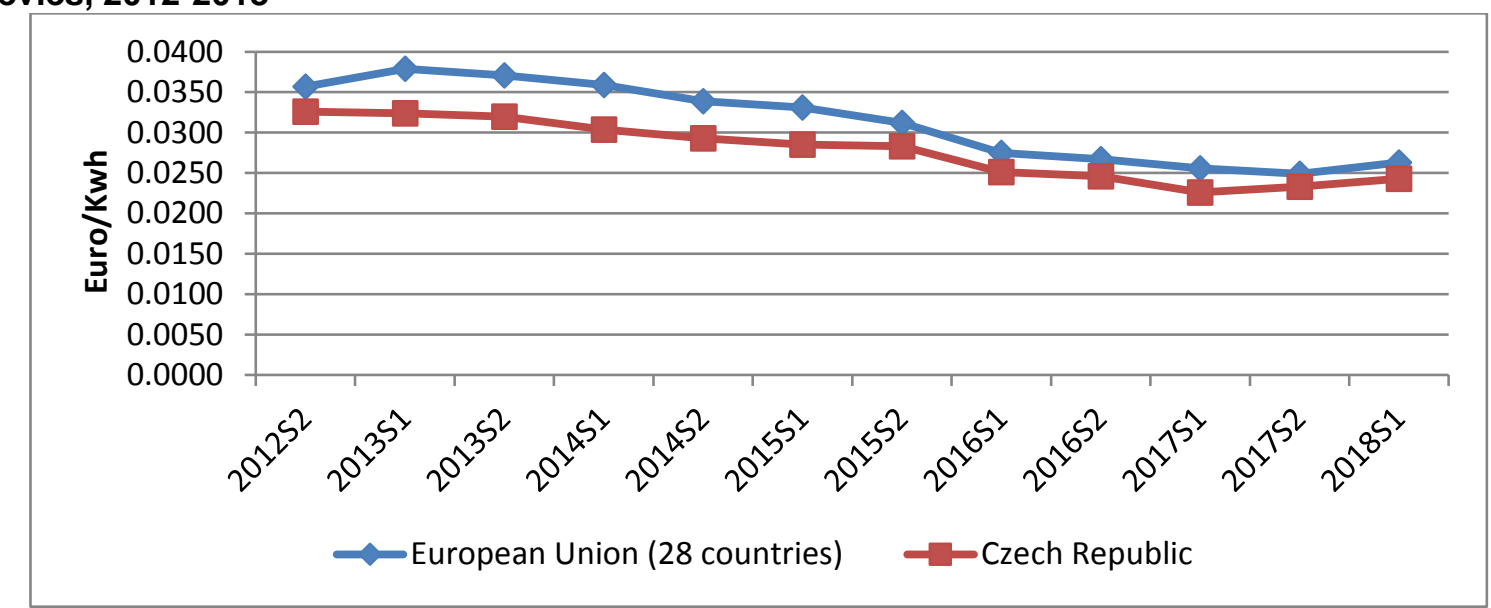

Source: Eurostat

Figure 10: Czech Natural Gas Prices for Medium Size Household, Including Taxes, 2008-2018

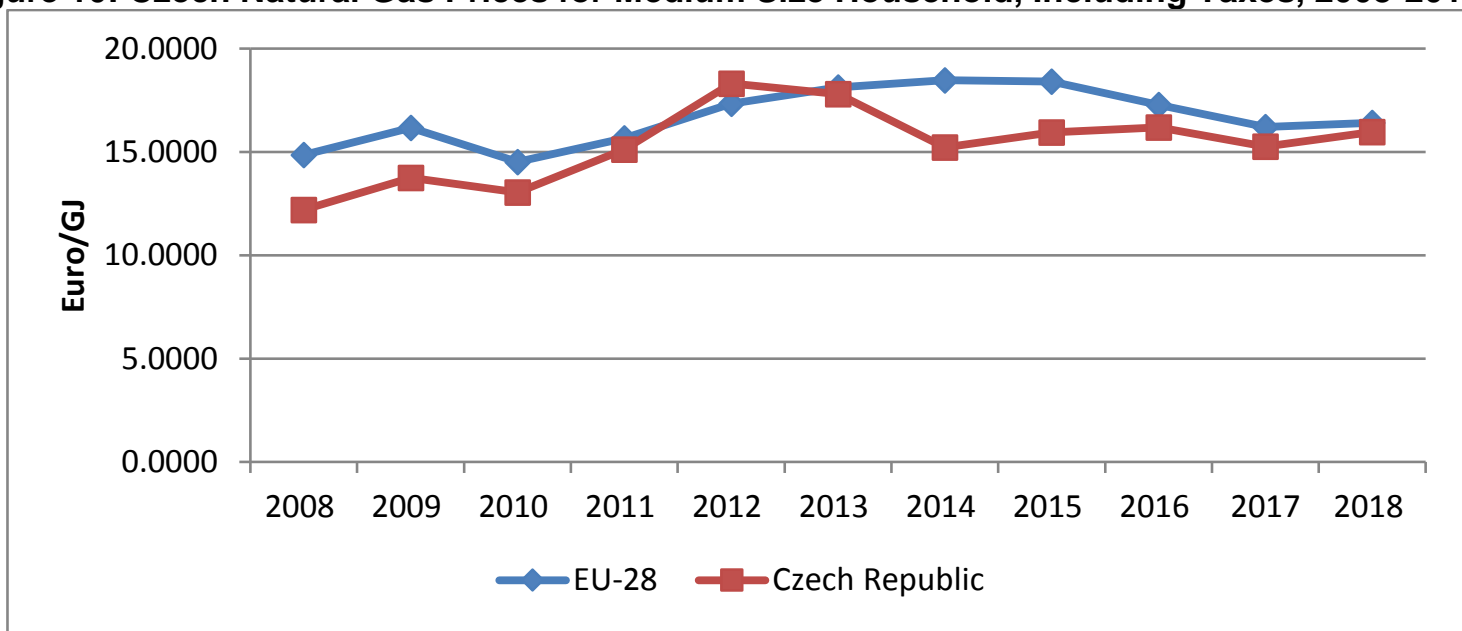

Source: Eurostat

Despite competitive gas prices, natural gas has not been able to compete with coal in electricity generation. Coal is the only significant indigenous energy resource, and historically, the Czech Republic has been a net exporter of coal. Coal has been the main and most affordable source for electricity

${ }^{37}$ EUR $0.0243 / \mathrm{kWh}$ excluding taxes and levies

${ }^{38}$ EUR $0.0263 / \mathrm{kWh}$ excluding taxes and levies

${ }^{39}$ Eurostat 

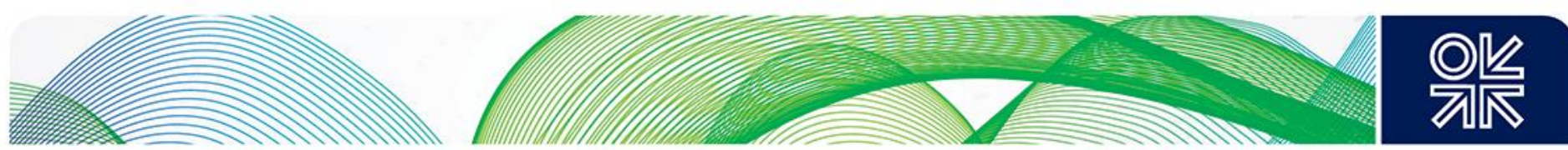

generation for decades and helped the country maintain a lower level of dependence on imported natural gas than many other countries in the region.

Coal prices were gradually declining between 2011 and 2016 but the spike in international coal prices due to the closure of some Chinese coal mines and increased demand from India in 2017 pushed up industrial coal prices in the Czech Republic, which grew throughout the year. In comparison gas prices for industrial customers have continued to decline since 2013, especially in 2016, and the decline continued throughout 2017. The fact that gas price started to be more competitive with coal was shown by the fact that the mothballed gas-fired electricity plant in Pocerady was put back into operation for peak purposes from 2016. However, the growth in international coal prices is not expected to last.

Figure 11: Czech Natural Gas for Medium Industry \& Hard \& Brown Coal Producer Price Indices, 2009-2018

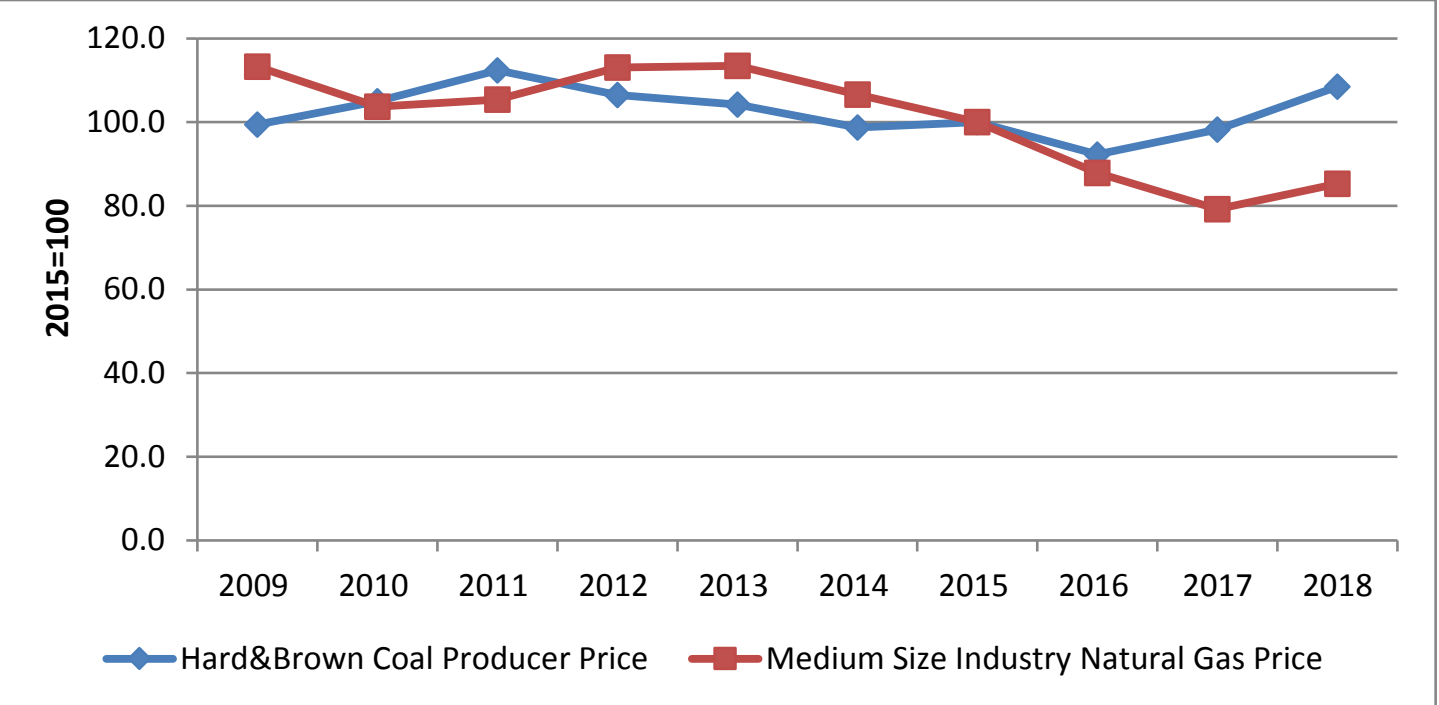

Source: Eurostat, Czech Statistical Office

\subsection{Czech Industrial Natural Gas Demand}

Industrial production in the Czech Republic has a very long tradition and continues to play a crucial role in the Czech economy. Within the EU the Czech Republic belongs to the countries with the highest share of manufacturing industry in gross value added: it represented $29 \%$ of the GDP in 2017.40 Industry employed $26.6 \%$ of all economically active citizens in 2016 . The main pillars of the Czech industry are engineering and machine engineering, mining, petrochemical and foodstuff production, followed by the energy industry, civil engineering and consumer industry. The engineering industry is ranked among the most traditional industrial branches in the Czech Republic.

In 2017 , large industrial consumers represented $45.1 \%$ of total gas consumption.

The most industrialised regions of the country account for the bulk of total demand: Ústecký Region $13.3 \%(1.1 \mathrm{bcm})$, Jihomoravský Region $13.2 \%(1.1 \mathrm{bcm})$, Středočeský Region $12.6 \%(1.1 \mathrm{bcm})$, Moravskoslezský Region 10.7\% (0.9bcm) and Prague 10.7\% (0.9bcm $\left.{ }^{41}\right)$.

\footnotetext{
${ }^{40}$ Czech Statistical Office

${ }^{41}$ ERU Annual Report on the Operation of the Czech Gas System for 2017
} 

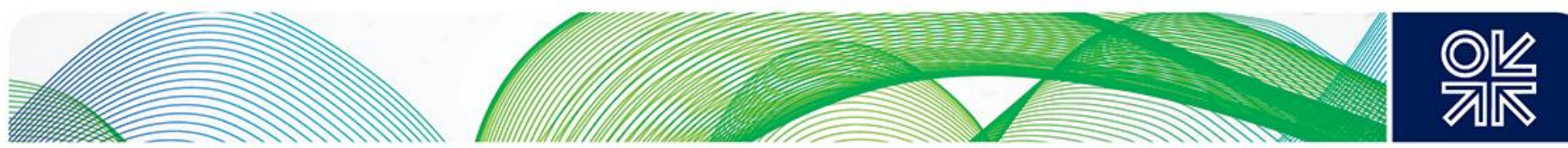

Figure 12: Shares of Czech Gas Demand by Customer, 2017

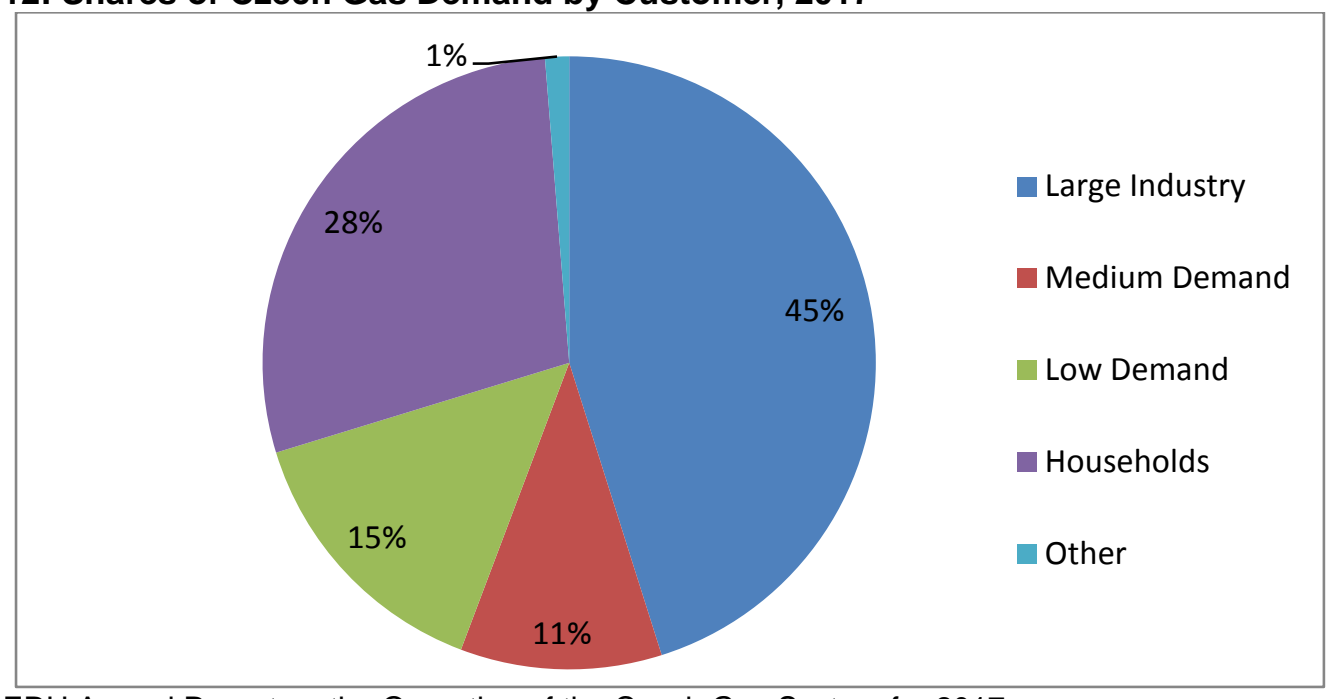

Source: ERU Annual Report on the Operation of the Czech Gas System for 2017

Unlike the electricity sector whose demand for natural gas is highly price-sensitive, the industrial sector is slower in reacting to natural gas price swings. Modern industrial plants are very capital-intensive and take several years to construct. Consequently, industrial plants have limited flexibility when it comes to choosing energy and feedstock sources. Natural gas prices for large industrial customers are close to spot or import prices since they have a regular consumption throughout the year and purchase large volumes of gas. However, in the longer term some industrial sectors will find it difficult to face the increasing competition from markets where energy and raw material prices are substantially lower than in the regulated environment of European markets. In contrast more special and value-added sectors may prosper and see a significant growth in the mid-term future.

In 2017, the Czech mining, industrial, agricultural, and commercial sectors consumed almost $5.2 \mathrm{bcm}$ of natural gas, ${ }^{42}$ of which the largest consumer sectors (non-metallic minerals (glass, cement), metals, chemicals, food, paper and automotive sectors) accounted for over $48 \%$. These sectors will be the driving force behind future natural gas demand and are therefore the focus of this study.

Natural gas demand of the key industries continues to be below the pre-recession 2008 level, but some growth has been evident since 2013. Nevertheless, it is still $4.2 \%$ below 2008 gas demand. The upturn in gas demand since 2013 is due to general economic growth and faster growth of consumer sectors such as automotive and food sectors. However, all the key sectors apart from the paper and pulp industry have seen steady growth over the last five years. The decline or stagnation in gas demand over the last decade is due to the long lasting economic recession and also to increasing efficiency of the Czech economy and energy savings. The period of high natural gas prices has stimulated energy savings and investment in energy efficient technology.

\footnotetext{
${ }^{42}$ Czech Statistical Office
} 

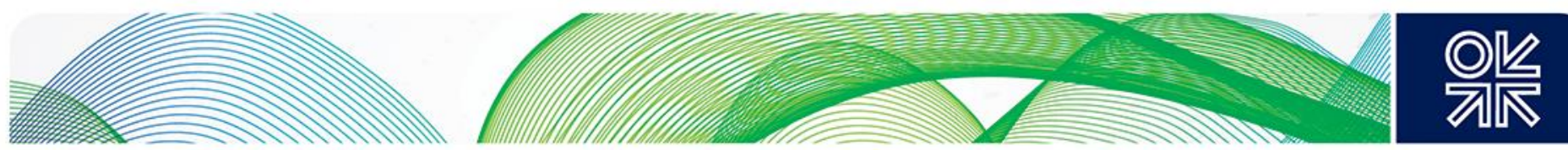

Figure 13: Czech Natural Gas Consumption, by Industry, 2007-2017

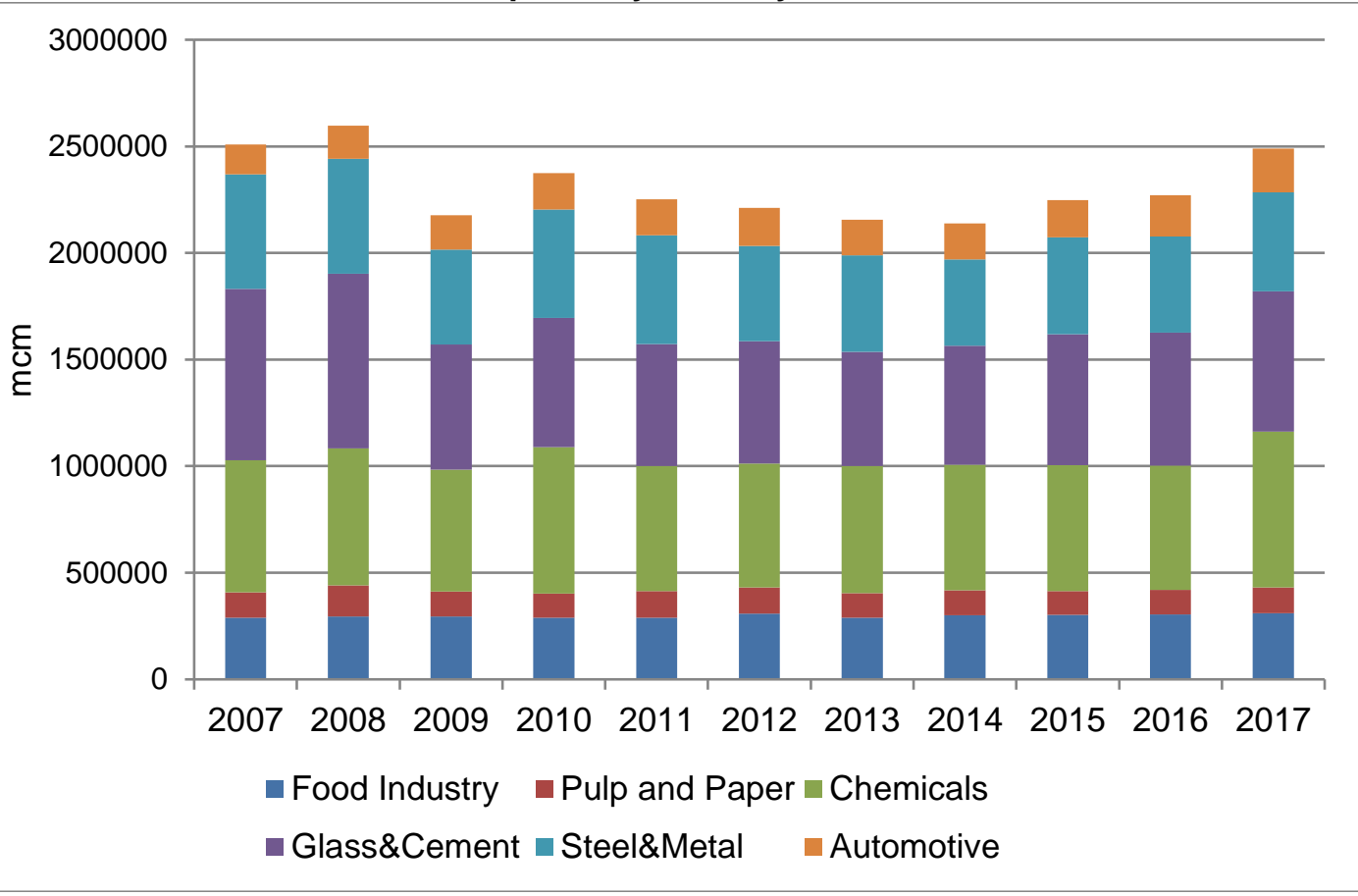

Source: Czech Statistical Office

Other industrial companies reacted to high gas prices immediately and the decline between 2013 and 2015 was much more pronounced. In these sectors gas demand has only started to recover slowly since 2016. Gas demand by electricity and heat plants remained fairly flat throughout the last ten years and strong growth was only seen once the Pocerady gas-fuelled electricity plant came on stream in 2016.

\subsection{Czech Chemical, Fertiliser and Petrochemical Industry}

The Czech chemical industry comprises petroleum refining, chemicals, pharmaceuticals and rubber and plastics processing. ${ }^{43}$ It is the second largest manufacturing industry in the Czech Republic by sales, after automotive, contributes almost $4.5 \%$ to the Czech GDP and employs around 132,000 persons, which represent $2.5 \%$ of the total workforce. ${ }^{44}$ It is also a major exporter and importer but has been increasingly dependent on imports.

The chemical sector is strongly interlinked with other manufacturing industries such as plastics and rubber, textile, electronics, construction, paper and pulp industries and importantly the automotive industry. Manufacture of basic chemicals, fertilisers and nitrogen compounds, plastics and synthetic rubber in primary forms (NACE 20.1) clearly dominates the NACE 20 sector.

The sector is largely dependent on coal (48\%) and natural gas (40\%) while oil, other gases and waste account for the remaining $12 \%$.

Consumption of natural gas by the sector was affected by the recession in 2009 and although gas demand has recovered since 2011 it did reach pre-recession levels till 2016. The industry has seen increasing investment and the major players have now invested in environmental and energy saving technology in order to comply with the EU quotas. Far the most important gas user is the manufacture

\footnotetext{
${ }^{43}$ NACE19 - Manufacture of coke and petrochemicals, NACE 20 - Manufacture of chemicals and chemical products, NACE 21 - Manufacture of pharmaceuticals, NACE 22 - Manufacture of rubber and plastic products

${ }^{44}$ Czech Statistical Office
} 

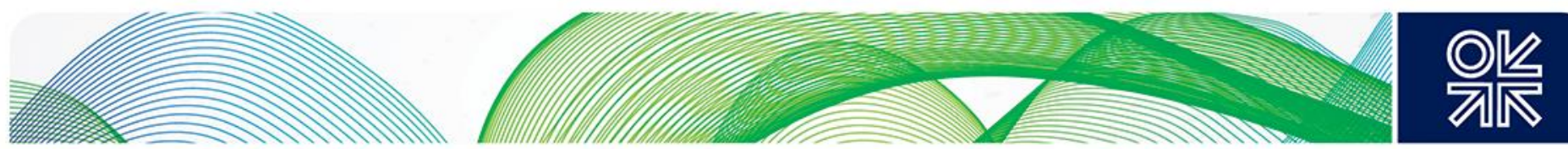

of chemicals (NACE20) which accounts for $66 \%$ of gas demand of this sector, followed by petrochemicals (19\%). The focus of this study will therefore be on these two subsectors.

Figure 14: Czech Chemical Industry Energy Demand, Share by Fuel, 2016

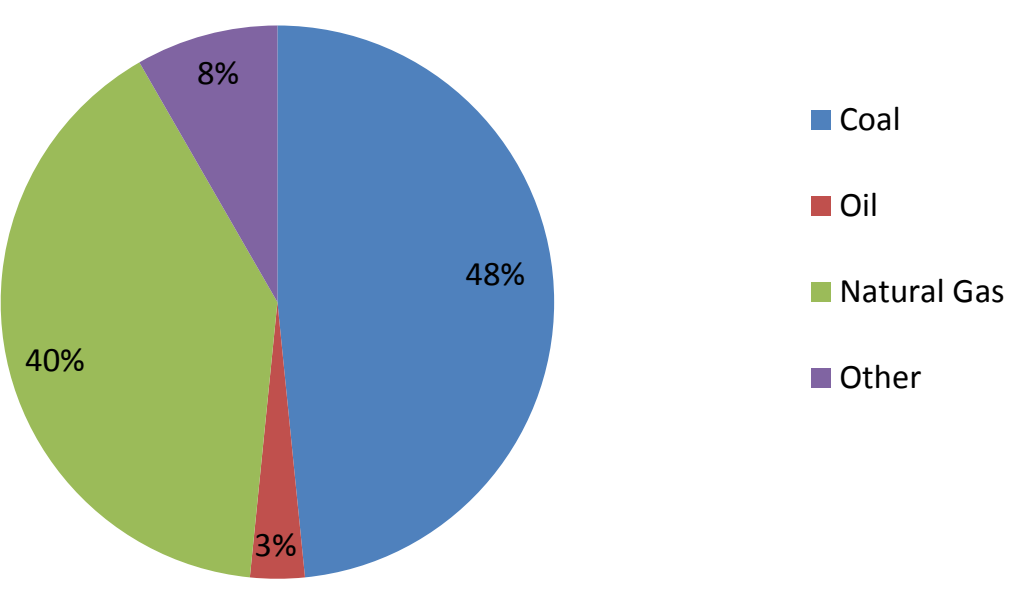

Source: Czech Statistical Office

Figure 15: Czech Natural Gas Demand by NACE $19 \& 20 \& 21 \& 22,2007-2017$

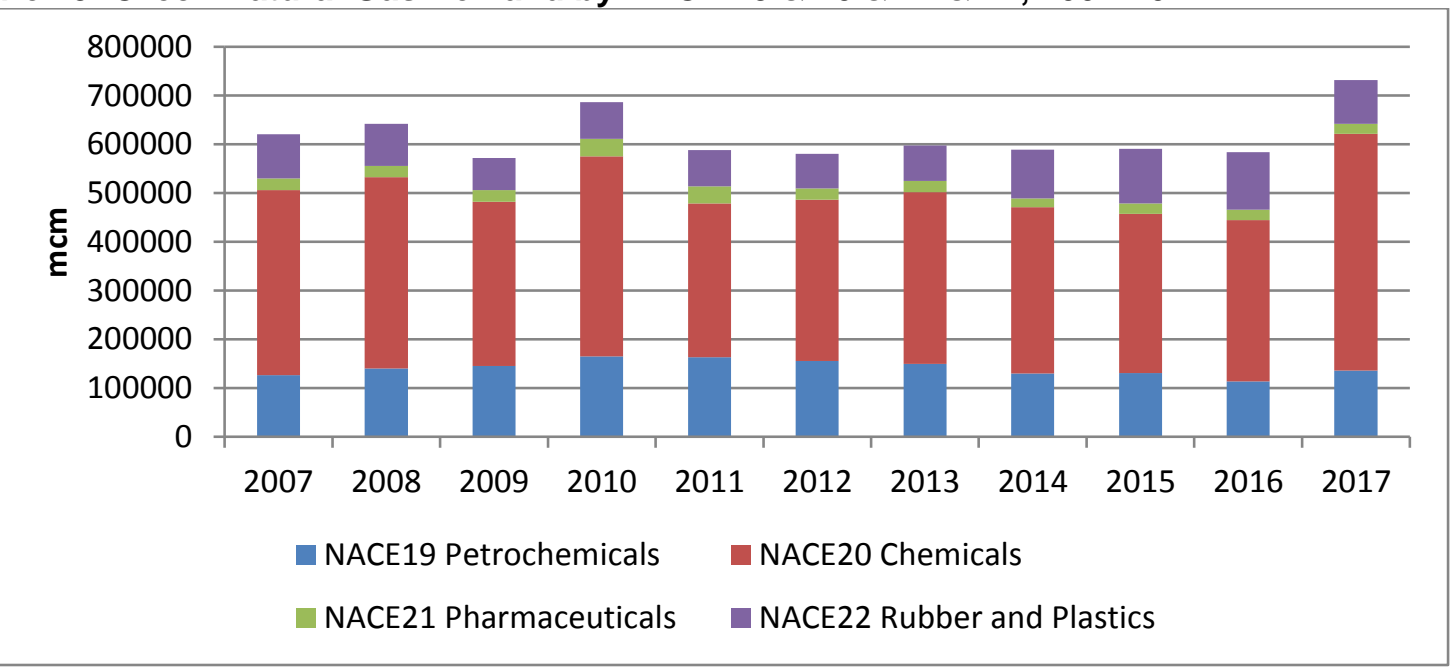

Source: Czech Statistical Office

Chemicals production was correlated to NACE20 natural gas demand till 2010, shown in the table below. Since then energy saving measures have reduced gas demand by the sector, with gas demand declining significantly in 2011 and then plateauing during the period of high natural gas prices while production was increasing. In 2016, the performance of the Czech chemical industry was significantly affected by an accident in August 2015 in the Unipetrol ethylene plant ${ }^{45}$ which was not recommissioned until October 2016.

\footnotetext{
${ }^{45}$ https://www.ogj.com/articles/2015/08/unipetrol-declares-force-majeure-at-czech-ethylene-plant.html
} 

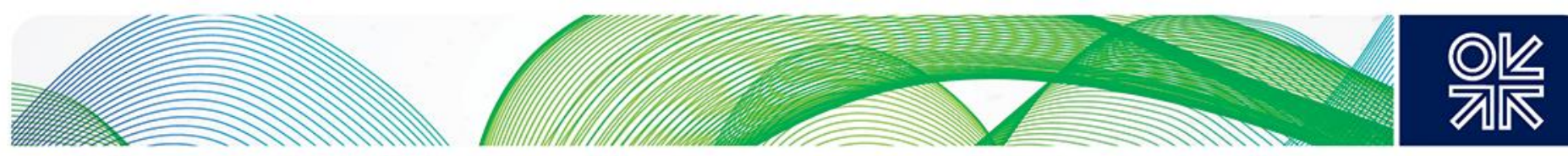

Figure 16: Czech Production \& Gas Demand by NACE20 Indices, 2007-2017

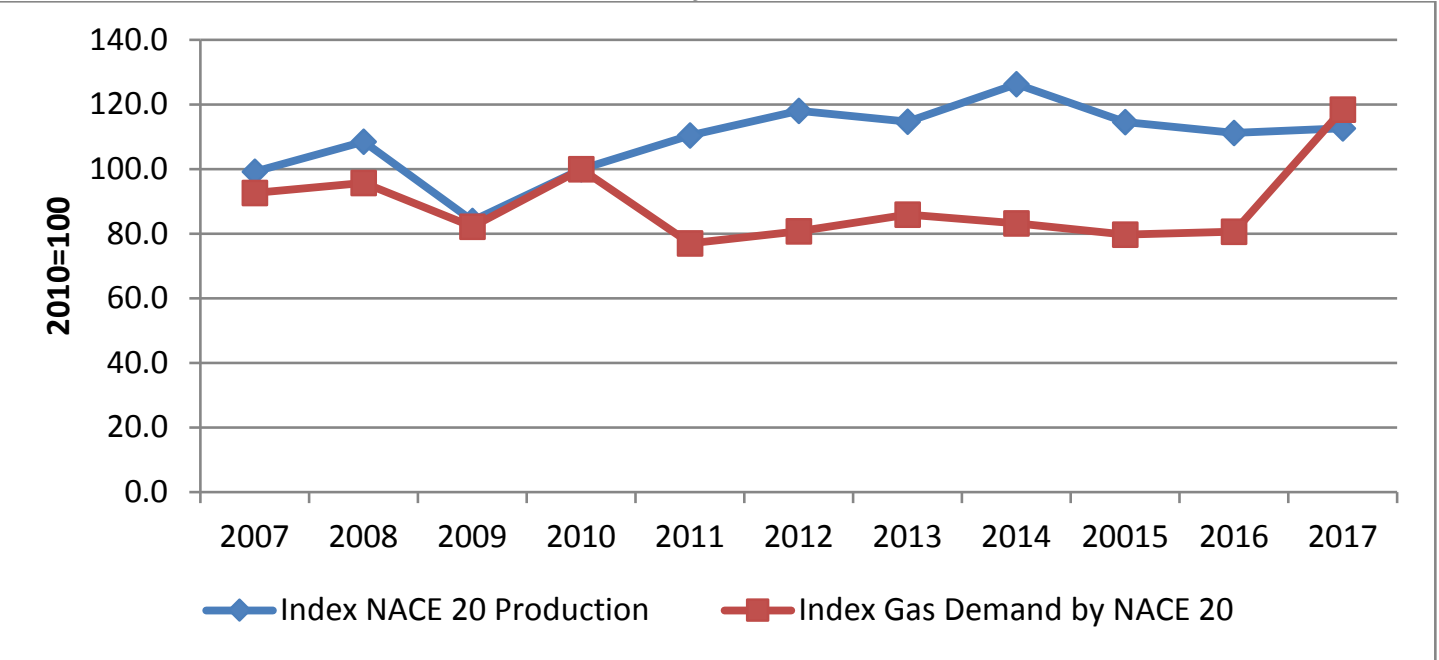

Source: Czech Statistical Office

Fertiliser and petrochemicals are one of the most important sectors of the Czech chemical industry, using natural gas for non-energy purposes as feedstock, but there are no separate statistics for natural gas consumption by the sector. The only statistics available are the IEA annual gas balances, which indicate agglomerated non-energy natural gas use by chemical and petrochemical industry in figure 11 . This clearly shows that the non-energy use is very responsive developments in natural gas prices: it plummeted in years of high gas prices and only started to recover when prices declined. Gas prices for industrial consumers were at the highest in the 2012-2014, which was demonstrated by a sharp decline in the use of feedstock. The turning point was 2015 when prices of natural gas tumbled. However, non-energy use of natural gas is marginal in the overall Czech gas balance. In 2016, it represented $1.4 \%$ of total domestic gas supply according to IEA statistics.

Figure 17: Chemical/Petrochemical Non-Energy Natural Gas Use, 2008-2016

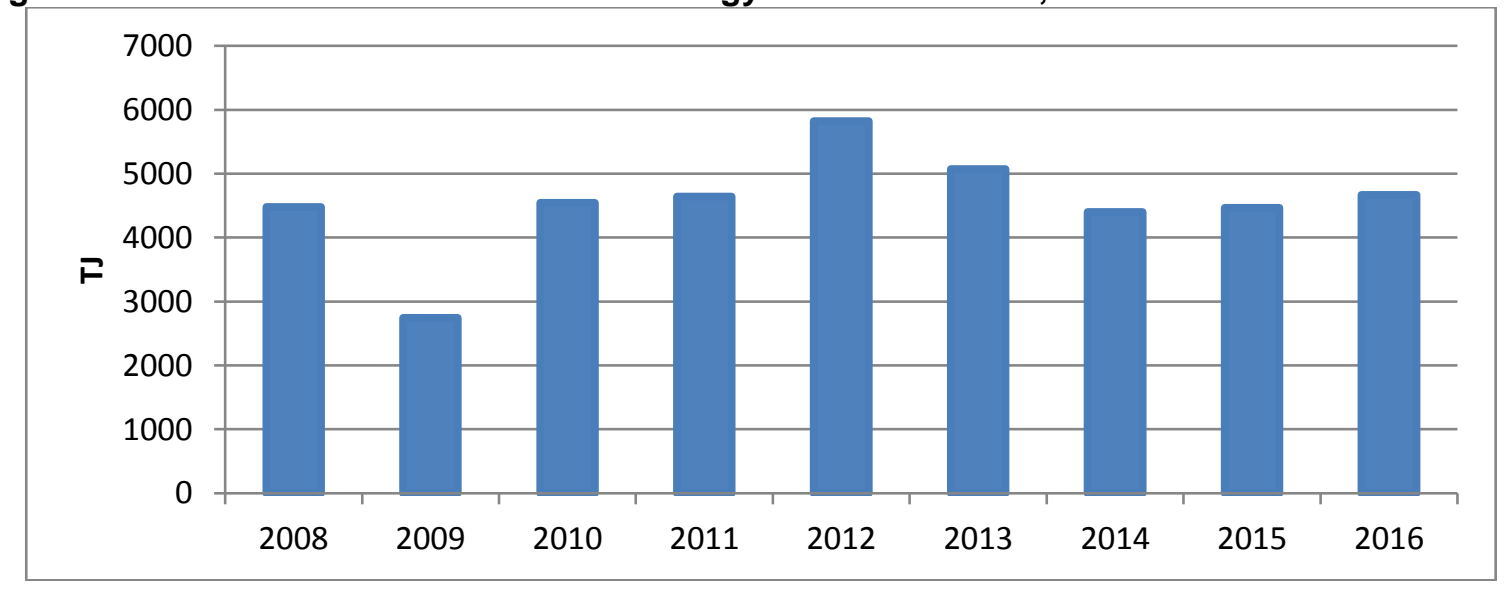

Source: IEA

When indices of nitrogen fertiliser production and non-energy gas use are compared, there is an evident correlation over the last decade, albeit the recovery in production is slower in the years 2014 onwards. The financial accounts of Lovochemie ${ }^{46}$ clearly show a major worsening of the financial health of the company because costs rose due to high gas prices while increasing competition kept the prices of

${ }^{46} \mathrm{http}: / /$ www.lovochemie.cz/sites/default/files/lovochemie/dokumenty/vyrocni_zprava_lovochemie_2017.pdf 

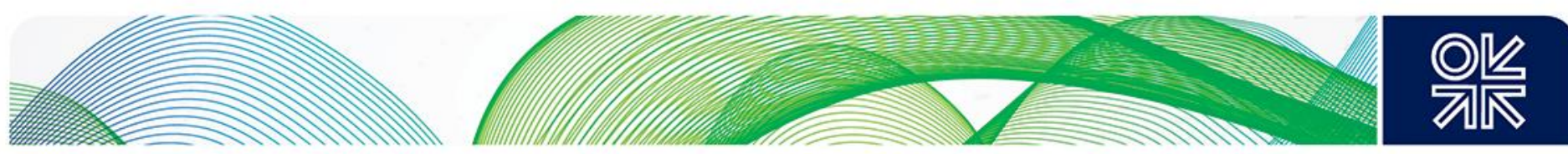

fertilisers low. The company now produces a third of the nitrogen fertilisers compared to 2008 and started to shift to the production of other fertilisers not based on natural gas.

Figure 18: Czech Nitrogen Fertiliser Production \& Feedstock Demand Indices, 2008-2016

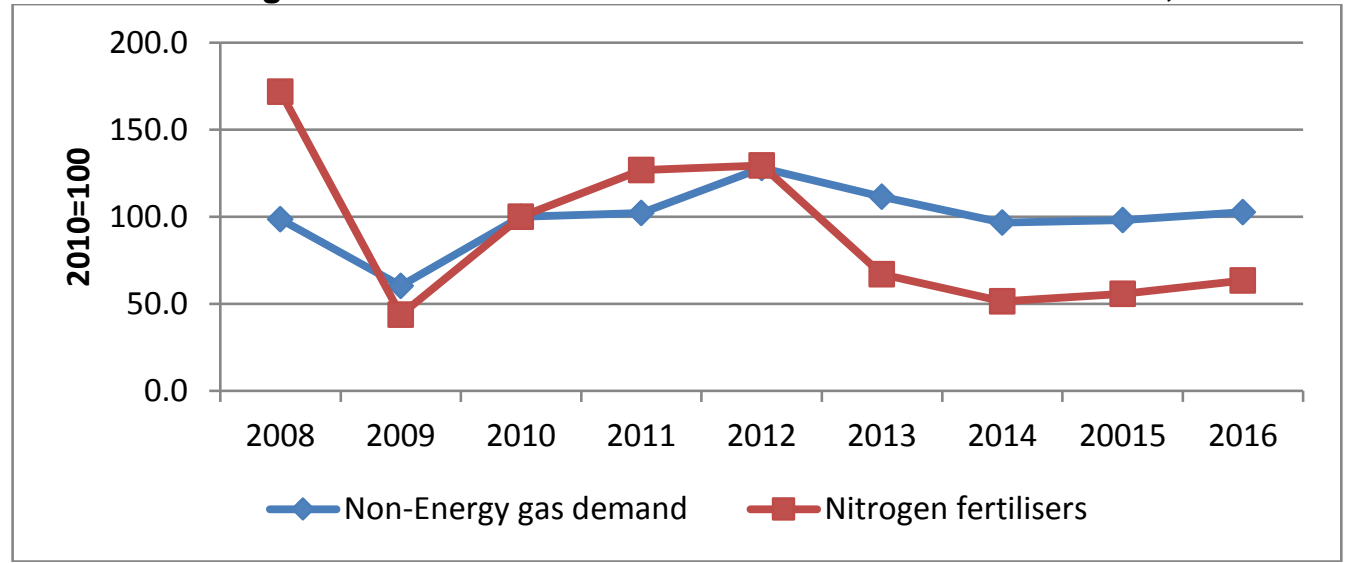

Source: Czech Statistical Office, IEA

\section{Forecast}

\section{Advantages}

The Czech chemical industry remains one of the most important industrial sectors for the stability and growth of the Czech economy. It is well integrated within the Czech industry and its main exports are destined to neighbouring countries; almost half to Germany, Poland and Slovakia. This is a competitive advantage the industry currently holds and with needed investment the sector could retain the regional market.

The current EU chemical industry forecast foresees only a moderate growth of $1 \% / y$, while more than $30 \%$ of jobs are expected to be lost in the European chemical industry by 2030 due to slow growth and productivity gains. 47 Given the competitive advantage, the Czech Republic chemical industry has a potential to show better results than the average EU chemical industry growth.

\section{Challenges to Growth}

The Czech, as well as the rest of the European chemical industry will be facing major challenges in future as value chains increasingly move eastward, drawn by economic growth and market opportunities in the Far East and lately in the USA.48 The EU chemical industry will need to cope with volatile commodity prices and fragile economic conditions. Strategic decisions will be crucial to allow business to thrive in this new competitive environment. The fact that the Czech chemical companies are not dominated by any international corporations may be the decisive factor determining the future of the sector. The local companies may struggle with raising needed investment in R\&D but on the other hand they will be more flexible in adjusting to local market changes.

EU environmental quotas will have a significant impact on Czech chemical companies over the next decade. 49 It will continue to be very energy intensive and international prices of energy and raw materials will be similar to the rest of Europe, which will reduce the competitive advantage of the Czech chemical industry. The Czech Republic enjoys one of the most competitive natural gas prices in Europe

\footnotetext{
${ }^{47}$ Chemical Industry Vision 2030: A European Perspective, ATKearney

48 http://www.atkearney.co.jp/chemicals/ideas-insights/article/-/asset_publisher/LCcgOeS4t85g/content/chemical-industryvision-2030-a-european-

perspective/10192?inheritRedirect=false\&redirect=http\%3A\%2F\%2Fwww.atkearney.co.jp\%2Fchemicals\%2Fideasinsights\%2Farticle\%3Fp p id\%3D101_INSTANCE LCcgOeS4t85g\%26p p lifecycle\%3D0\%26p p state\%3Dnormal\%26p p mode\%3Dview\%26p_p_col_id\%3Dcolumn-2\%26p_p_col_count\%3D1

49 https://ec.europa.eu/clima/policies/strategies/2030 en
} 

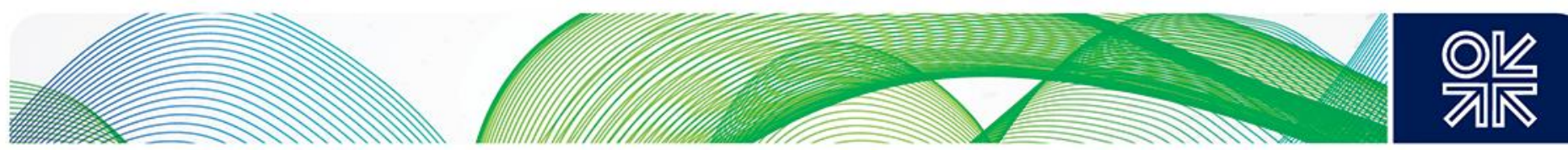

and given its proximity to European hubs and very flexible supply contracts it can be assumed that this situation will last in the mid-term.

For the country the challenge will be to simplify the regulatory framework in order to reduce cumulative regulatory costs and encourage investment.50

\section{Reference Scenario}

Given that current economic forecasts for the Czech Republic and the EU-28 envisage annual growth of $1.5 \%$ to $2 \%$ over the next decade, it can be expected that the Czech chemical industry will do slightly better and grow between $1 \%$ and $2 \% / y$ till 2030 . However, because of its reliance on natural gas as feedstock, the fertiliser and petrochemical industry will struggle due to increasing completion from Central Asia and the USA, where prices of natural gas will be significantly lower than in Central Europe. In a reference scenario non-energy use of natural gas stagnates while the chemical industry in total grows by some $2 \% / y$ till 2020 slowing down to $1.5 \% / y$ and from 2025 to $1 \% / y$. The chemical industries, including non-energy feedstock, are forecast to consume $1 \mathrm{bcm} / \mathrm{y}$ by 2030 . The incremental annual gas demand by the chemical industry is expected to amount to some $0.14 \mathrm{bcm} / \mathrm{y}$ by 2030 .

\section{Figure 19: Czech Reference Chemical Industry Natural Gas Demand Forecast 2016-2030}

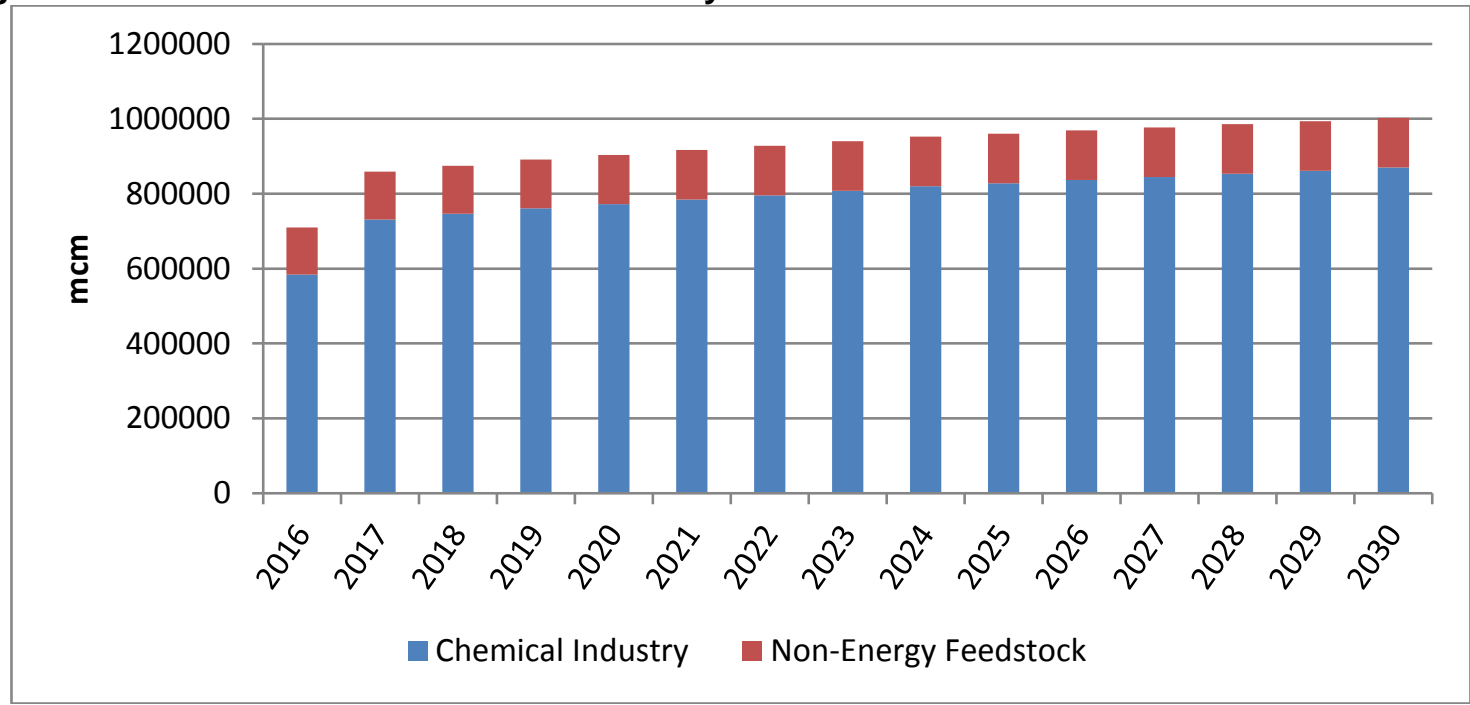

Source: Author's forecast

\section{Optimistic Scenario}

In the event that the Czech chemical industry fares better than the rest of the EU due to buoyant domestic industrial growth, gas demand by the chemical industry will continue to grow on average by some $2 \% / y$ throughout the forecasting period. Even in such a case it will be unlikely that the gas demand for feedstock will increase; it will plateau at the current level at best. The optimistic scenario foresees gas demand by the chemical industry (including feedstock) reaching some $1.1 \mathrm{bcm} / \mathrm{y}$ by 2030 , which represents an incremental increase of $0.22 \mathrm{bcm} / \mathrm{y}$ over 2017.

\footnotetext{
${ }^{50} \mathrm{https}: / /$ ec.europa.eu/growth/sectors/chemicals
} 

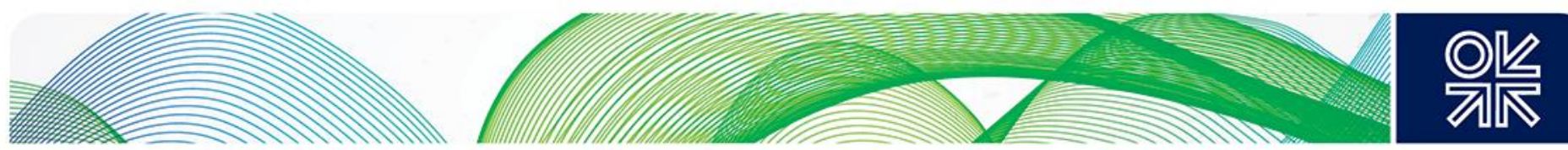

Figure 20: Czech Optimistic Chemical Industry Natural Gas Demand Forecast 2016-2030

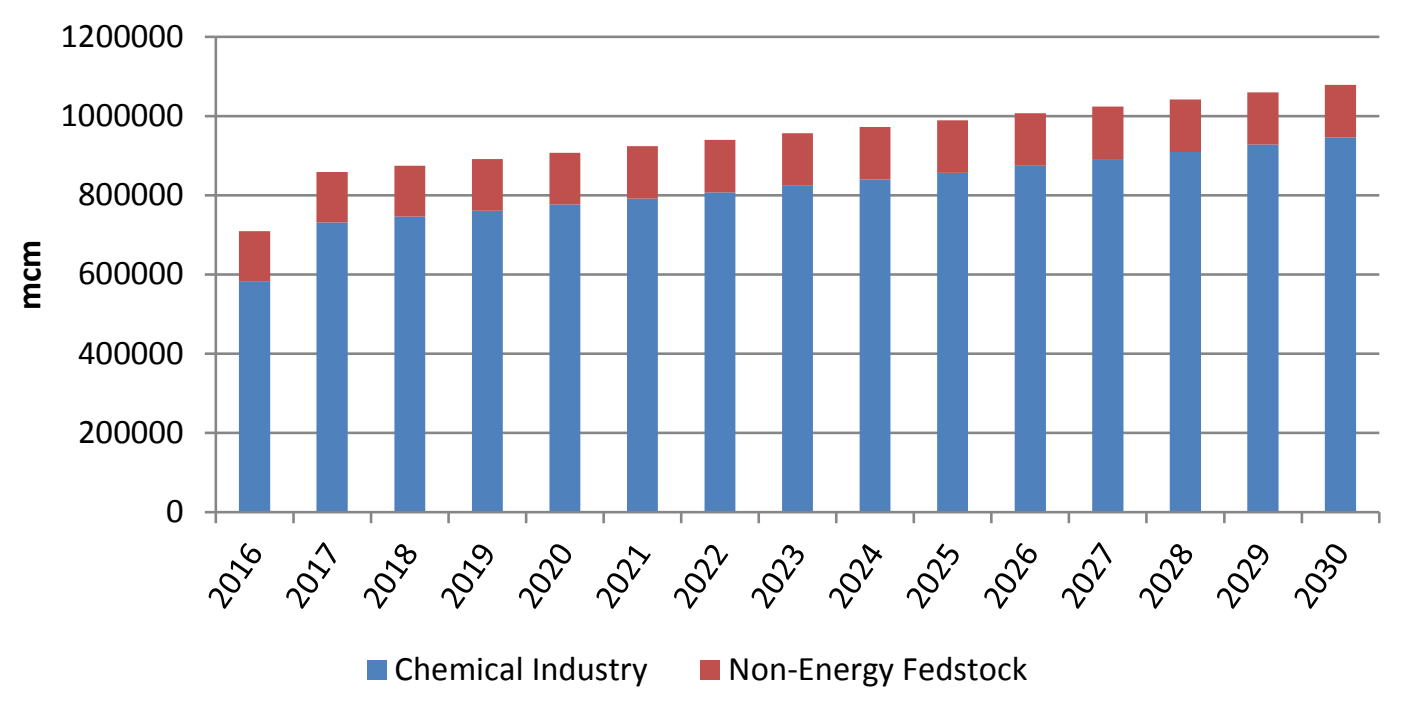

Source: Author's forecast

\subsection{The Czech Steel Industry}

The Czech steel industry in this report includes the NACE 2451 and NACE 2552 sectors. It has traditionally ranked in the top ten EU steel producers and currently employs over 234,212 people, $4.4 \%$ of the total Czech workforce.53 It has been contributing over 5\% of GDP although its contribution has declined to $3.7 \%$ over the last few years as international competition reduced the sector's revenues. It is the main supplier to the Czech engineering industry and other manufacturing sectors and is closely integrated with a wide range of industrial sectors. It is still considered to be the pillar of Czech industry.

Czech metallurgy has been undergoing major structural developments since the global recession. Recently, cheap imports of steel products from countries like China, Russia, South Korea and Ukraine have added further pressure on steel companies and many companies have closed down as a result (e.g. Poldi Kladno, ŽDB Bohumin). Consequently, the surviving companies have become much leaner, energy efficient and have increased productivity.

Almost one-third of Czech-produced metallurgical products are destined for export while two-thirds are used for intermediate consumption. Although most imports and exports of metal products are with EU countries, imports from third countries have been increasing more rapidly. Direct imports from outside the EU to the Czech Republic are part of the problem, but the bigger problem is imports to the EU replacing Czech exports. Over $80 \%$ of imports are directly in competition with Czech metallurgical products. Moreover, a $25 \%$ tariff on all imports of steel products imposed by the USA, effective from 23 March 2018, is having an indirect effect on Czech exports. Iron ore, the core raw material for steel production, is imported.

The steel industry is one of the most energy- and raw material-intensive sectors and for this reason the steel industry is mostly concentrated in the regions with raw material deposits (black coal, limestone). The Czech steel industry is thus largely concentrated in one region - almost $98 \%$ of iron and steel production comes from the Moravian- Silesian Region.

\footnotetext{
${ }^{51}$ Manufacture of Basic Metals, Metallurgy, Casting of Metals

${ }^{52}$ Manufacture of Fabricated Metal Products, except Machinery and Equipment

${ }^{53}$ Czech Statistical Office
} 

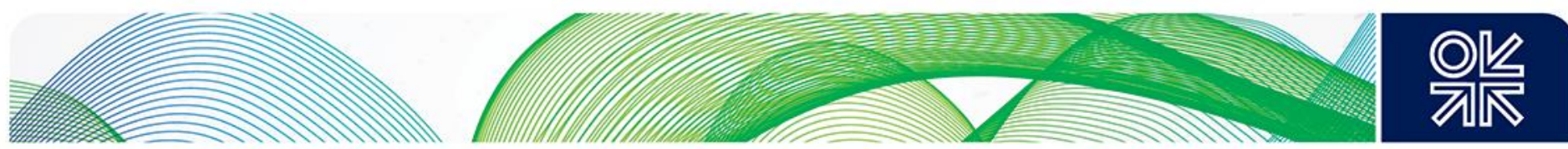

The sector is predominantly dependent on coal (66\%) for fuel while natural gas accounts for $12 \%$ and other industrial gasses $22 \%$.

Figure 21: Czech Iron \& Steel Industry Energy Demand, Share by Fuel, 2016

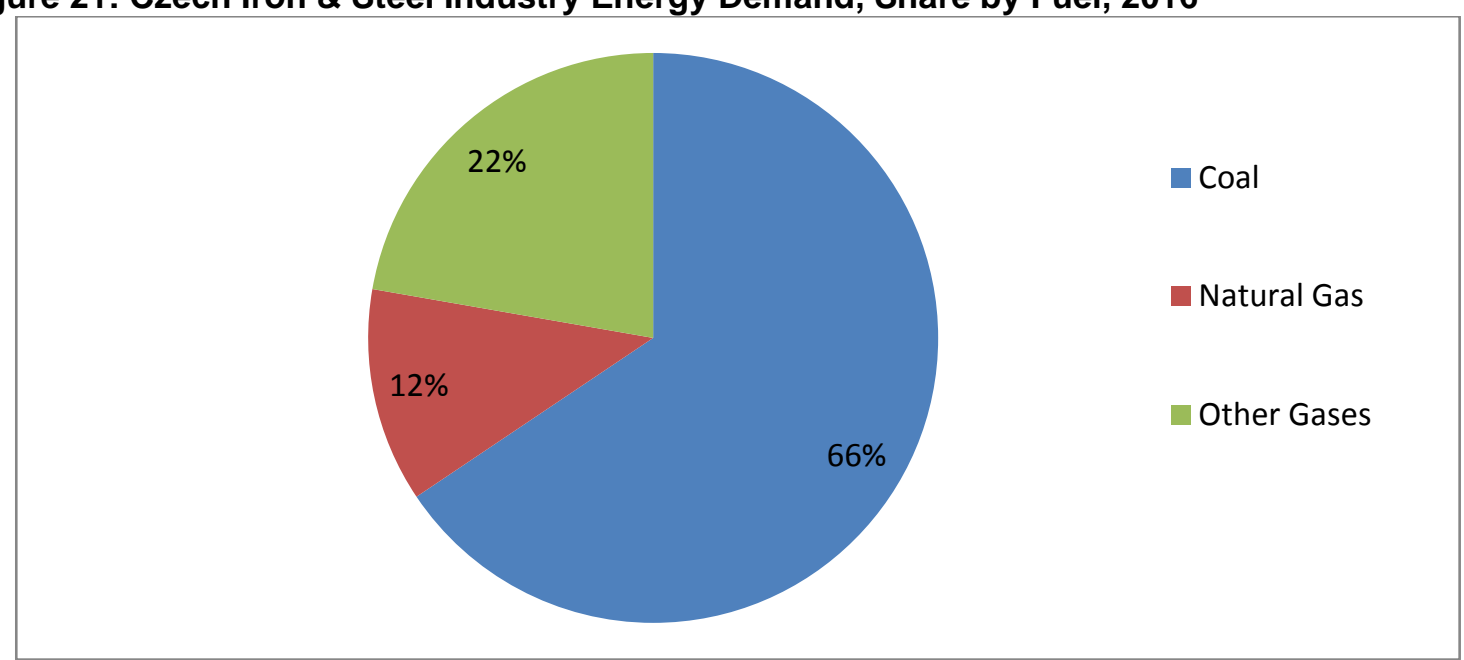

Source: Czech Statistical Office

After the recession and during the time of high natural gas prices between 2012 and 2015 the energy intensity of steel products improved markedly. The energy intensity of pig iron production dropped by almost $20 \%$, partly due to Trínecké železárny installing a new pulverised coal injection technology in 2013 which significantly reduced energy consumption and emissions and overall production costs. ${ }^{54}$ However, energy intensity shot up again in 2017 as steel production declined due to planned reconstruction of ArcelorMittal ${ }^{55}$ and Trinecké železárny. Over the last decade all steel companies introduced energy saving measures and invested heavily in new technologies.

\footnotetext{
${ }^{54}$ https://www.trz.cz/upload/1/files/MS_VZ_2017.pdf

${ }^{55} \mathrm{https}: / /$ corporate.arcelormittal.com/sustainability/reporting-hub/country-reports/czech-republic
} 

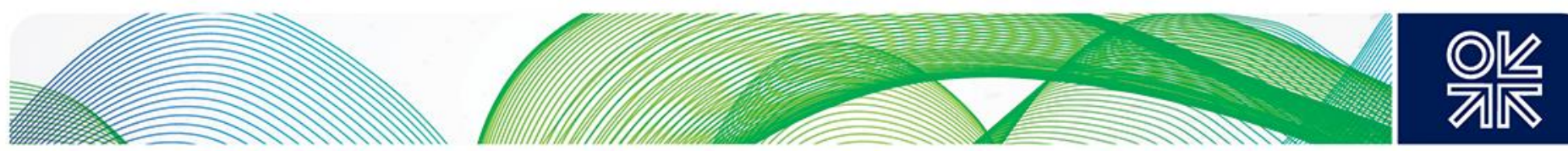

Figure 22: Czech Iron \& Steel Product Energy Intensity, 2005-2017

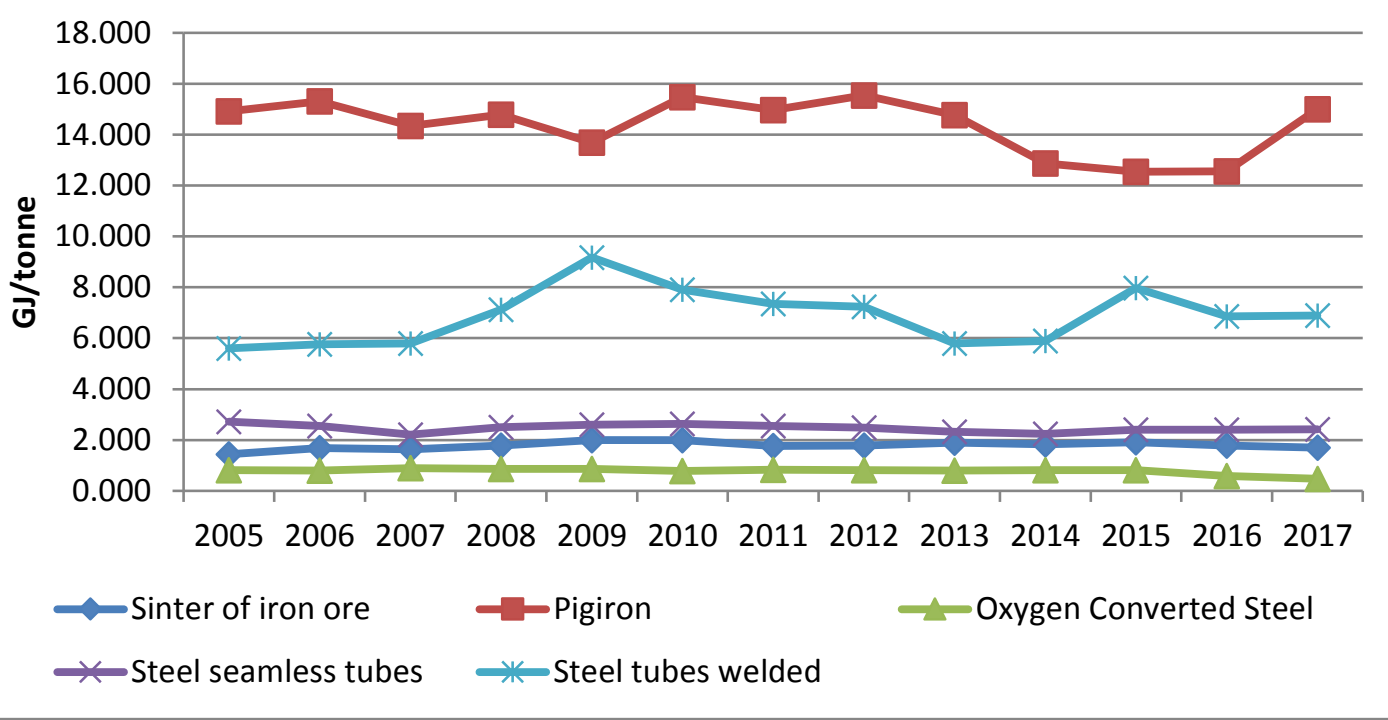

Source: Czech Statistical Office

The sector has been greatly hit by the last recession and is unlikely to restore its production to pre-2007 levels. Over the last decade, there have been periods of growth and decline, but the sector has continuously lost its share in manufacturing industry. Currently, there is about $20 \%$ of overcapacity in the sector.56 Due to the restructuring of the sector and competition from cheap imports, the sector is moving towards higher value added and sophisticated products.

The global recession in the metallurgy sector brought about the biggest drop in profits and revenues in 2009. The second wave of recession in 2012 was moderate while profits posted year-on-year growth, with stagnating employment. Since 2014, all indicators have started to grow with the exception of 2016. Steel product prices followed the development of the sector. A clear trend is evident that the industry managed to post positive growth in sales and value added since 2009, with two exceptions in 2012 and 2016.

Interviews with the leading companies have revealed that most Czech steel and metal companies are turning to value added products and high-pressure casting products. Currently, most companies are preparing or investing in increased production capacities. The industry is increasingly supplying the automotive industry at home and abroad. $90 \%$ of production capacity for iron castings is already used. For aluminium alloy foundries, capacity is completely utilised. 57

Natural gas demand by the steel sector was closely correlated to the development of steel industry output till 2009, but the decline in gas demand since 2010 continued while steel production was recovering. This is largely because steel mills have managed to reduce energy intensity between 2010 and 2015. In 2017, the sector used $0.46 \mathrm{bcm}$ of natural gas, down from the peak of $0.54 \mathrm{bcm}$ in 2008 . In 2017 , the steel industry was responsible for $5.5 \%$ of the country's gas consumption or $16.1 \%$ of manufacturing gas demand.

\footnotetext{
${ }^{56} \mathrm{MPO}$, Panorama of the Manufacturing Industry of the Czech Republic

${ }^{57}$ For instance, in late 2017, Vitkovice Steel, the only producer of sheet piles in the Czech Republic and one of two in the European Union, completed modernization of its rolling mill, which will increase its production capacity by $50 \%$, expand its product portfolio while reducing natural gas consumption by $17 \%$, and NOx emissions from $300 \mathrm{mg} / \mathrm{m}^{3}$ to $200 \mathrm{mg} / \mathrm{m}^{3}$. However the production was suspended between 2015 and 2017, which had a negative impact on the overall performance of the sector over those two years.
} 

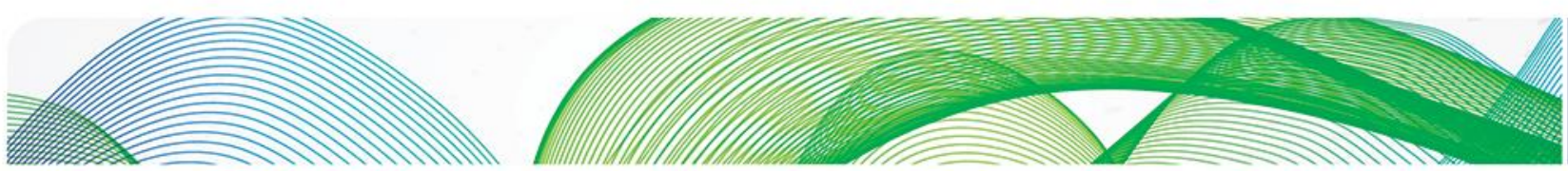

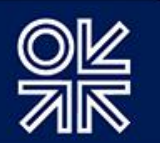

Figure 23: Czech Natural Gas Consumption by Iron \& Steel Industry, 2007-2017

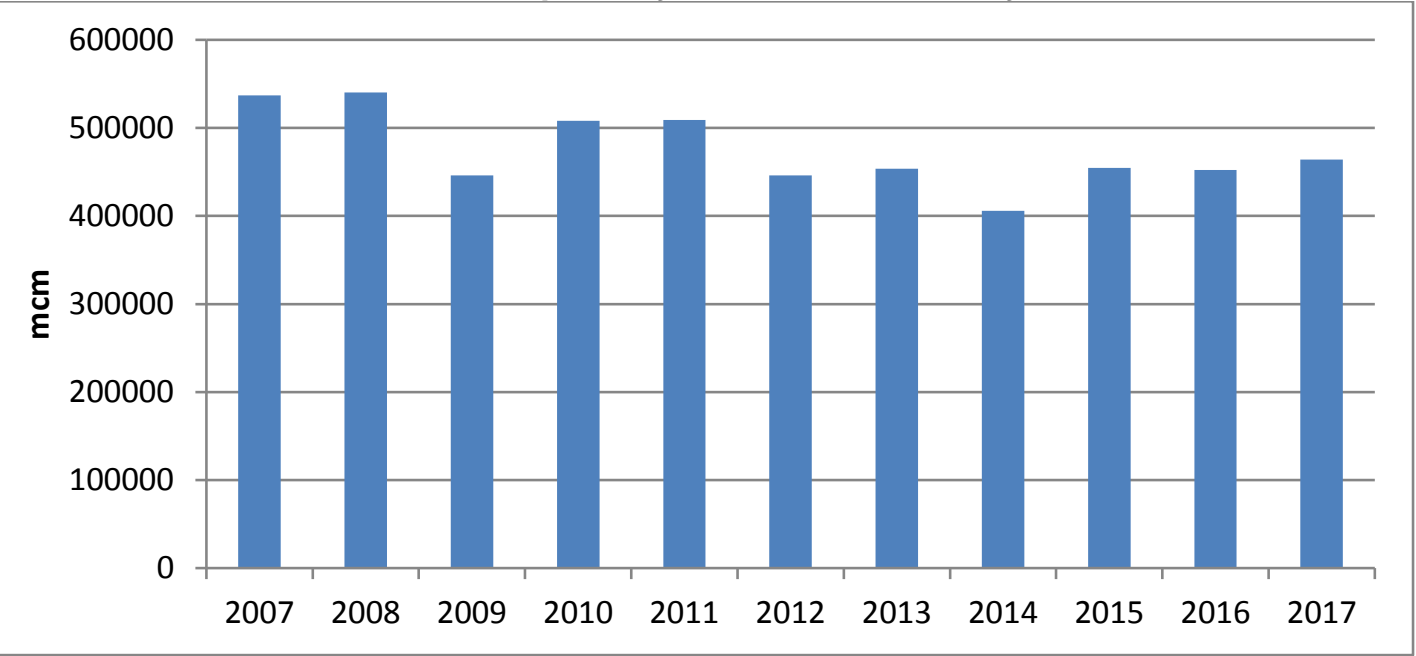

Source: Czech Statistical Office

Figure 24: Czech Steel Production and Gas Demand by Metal Industry Indices, 2007-2017

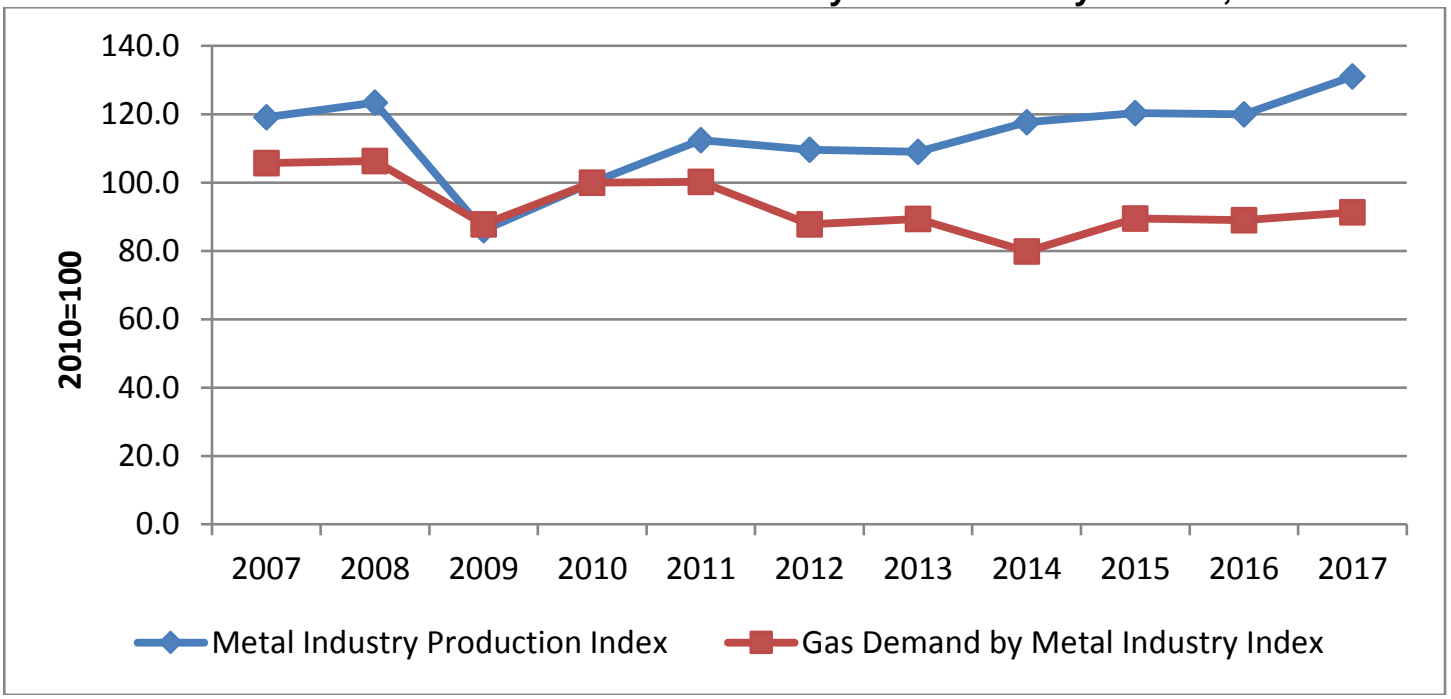

Source: Czech Statistical Office

\section{Forecast}

\section{Advantages}

In comparison with the EU-28 average, the Czech steel industry has fared much better over the last decade. ${ }^{58}$ This is largely due to the fact that the companies which survived the restructuring and the impact of the last recession have modernised and adjusted to global demand for steel products and largely moved to value added products. Despite the decline in 2015-2017, which was partly caused by the shutdown of Vitkovice Steel sheet pile production, ${ }^{59}$ it is evident that the sector has reached a turning point. Given the latest investments and strong economic growth, population growth and increasing demand for steel products in the EU it is expected that the sector will start to recover from 2018 onwards with moderate growth until 2030.

\footnotetext{
${ }^{58} \mathrm{http}: / /$ www.eurofer.org/News\%26Events/PublicationsLinksList/201806-AnnualReport.pdf

${ }^{59} \mathrm{http}: / / \mathrm{www}$.vitkovicesteel.com/en/media/vitkovice-steel-modernizes-equipment
} 

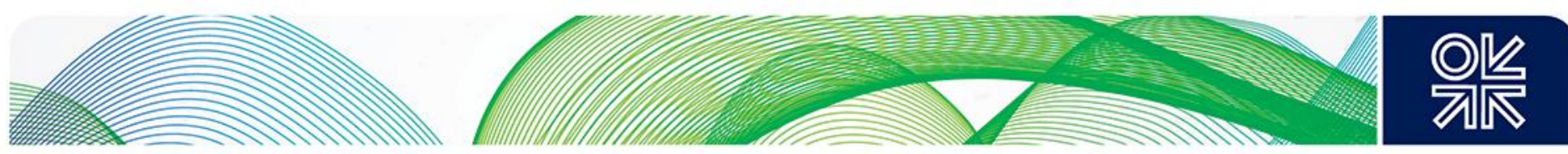

The Czech steel industry is likely to expand at the expense of the West European steel industry because of its geographical proximity to main consuming markets such as Germany, high levels of flexibility and a reliable delivery service, which will give it specific competitive advantages, particularly versus overseas competitors. Competitive gas prices in the Czech Republic and lower labour costs will be a winning card for the local industry over the next decade. The fact that the Czech Republic is a landlocked country will continue to protect the local steel industry from cheap imports arriving at European ports from outside countries. ${ }^{60}$

A large share of the steel industry products is oriented towards the transport sector, which will continue to grow, ${ }^{61}$ and combined with economic growth and increasing population will guarantee healthy growth of the sector. ${ }^{62}$ The Czech Republic alone is one of the biggest manufacturers of vehicles in Europe, and local industry is likely to benefit from this development given the flexibility of the local sector.

\section{Challenges to Growth}

Technology and innovation cycles have become much shorter in recent years. This has been matched by rapid changes to product and market segments. What just a few years ago were still technological niche products with very good margins are now high-volume markets hotly contested by cost leaders. In order for the Czech steel industry to prosper in the mid-term, the industry will need to continue to invest and finance research that remains ahead in innovation and quality. The Czech Republic has shown lower investment levels than Western Europe and it will increasingly become a challenge for the industry to review its product portfolio regularly and align it continuously with shifting markets. If the steel industry does not vertically integrate to raw materials and energy, it will lose its competitive advantage. ${ }^{63}$

The EU measures on anti-dumping and anti-subsidy against imports of metallurgical products from third countries will play a decisive role for the future of the steel industry in the EU in general. The 2030 targets set in the greenhouse gas trading system (EU ETS) by the EU ${ }^{64}$ could put a heavy burden on the sector and could lead to relocation outside the EU to countries and regions with inadequate climate protection policy. However, the Czech steel works have cut emissions and are currently within the EU limit. The largest companies are likely to be able to adjust to new requirements. It will be the smaller companies which are likely to struggle as their access to needed investments is more complicated.

\section{Reference Scenario}

Given the current economic forecasts for the Czech Republic and the EU-28 of a growth level between $1.5 \%$ and $2 \%$ in the next decade, ${ }^{65}$ it is feasible that the Czech steel industry will show an average $1 \% / y$ growth till 2030. The modernised industry will be able to compete within the EU as more metal production capacity will be transferred to the Czech Republic. US tariffs on aluminium and steel will have a dampening effect on all European steel industry, thus the growth rate will be limited. The incremental growth in gas demand will amount to some $0.06 \mathrm{bcm} / \mathrm{y}$ by 2030 .

\footnotetext{
${ }^{60}$ https://www.euro.cz/byznys/ocelova-mesta-v-ohrozeni-vyzene-brusel-tezky-prumysl-z-evropy1328742\#utm medium=selfpromo\&utm source=euro\&utm campaign=copylink

${ }^{61}$ https://eu-smartcities.eu/sites/default/files/2018-03/pwc-five-trends-transforming-the-automotive-industry.compressed.pdf

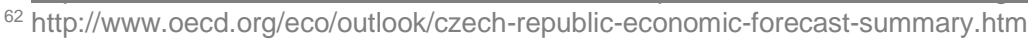

63 http://www.eurofer.org/News\%26Events/PublicationsLinksList/201806-AnnualReport.pdf

64 https://ec.europa.eu/clima/policies/strategies/2030_en

${ }^{65}$ https://www.imf.org/en/Publications/WEO/Issues/2018/09/24/world-economic-outlook-october-2018
} 

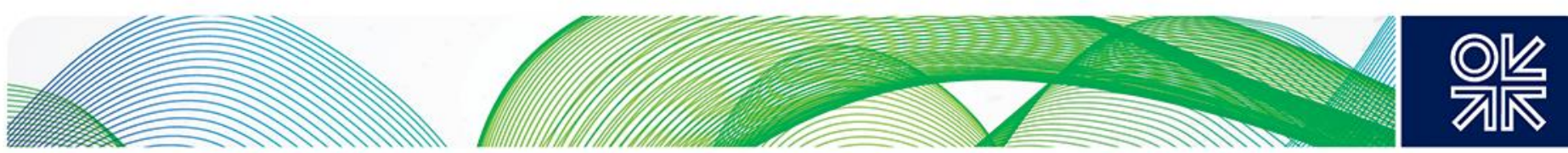

Figure 25: Czech Reference Iron \& Steel Industry Natural Gas Demand Forecast 2016-2030

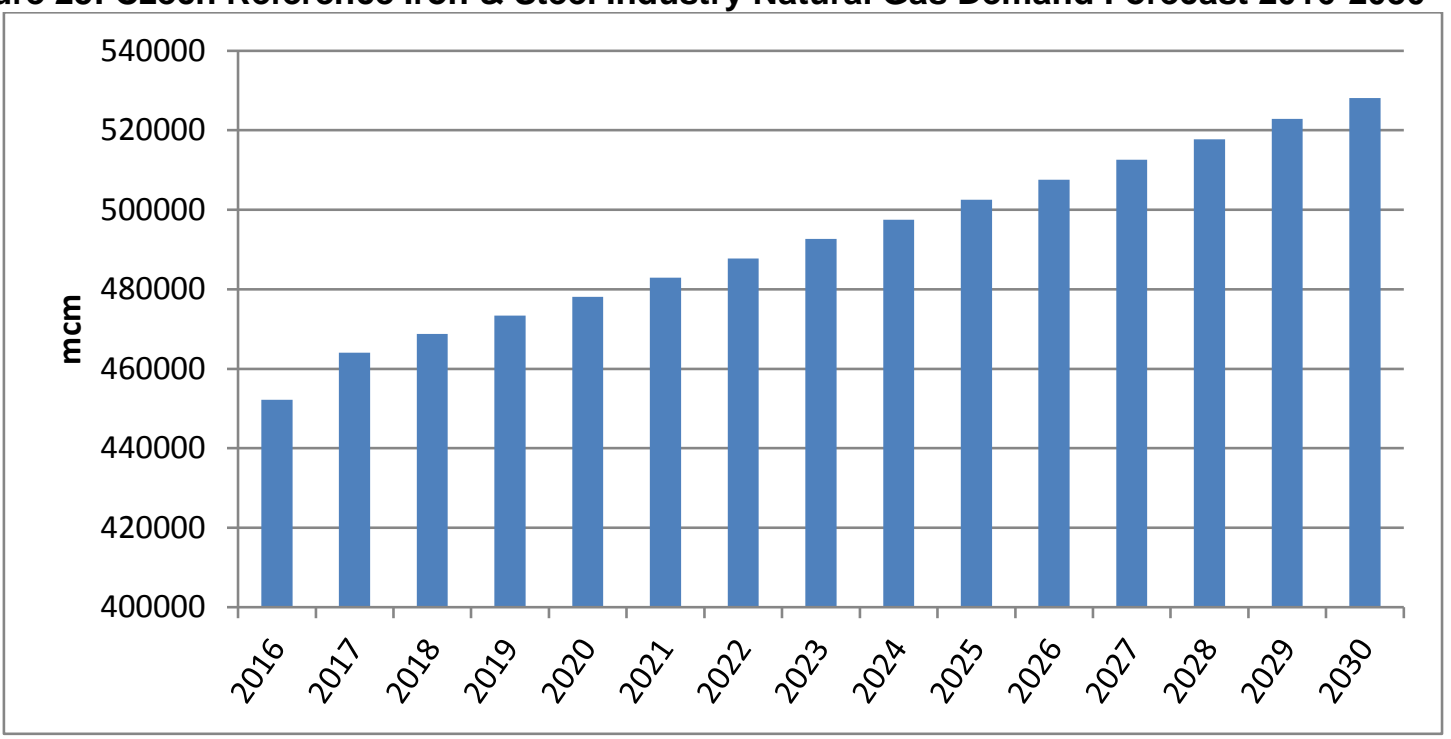

Source: Author's forecast

\section{Optimistic Scenario}

In the event that the Czech steel industry utilises and continues to increase its production capacity, it will see a stronger growth, especially till 2025 (1.5-2\%). It will be able to compete with imported products from outside the EU while increasing exports, mainly to the EU, supplying chiefly the European car industry. In such a case, the forecast would be more optimistic, driving the natural gas demand till 2025 and slowing down towards 2030. Natural gas demand by the sector will reach some $0.56 \mathrm{bcm}$ in 2030 , which represents an increase of $0.09 \mathrm{bcm} / \mathrm{y}$ on 2017.

Figure 26: Czech Optimistic Iron\& Steel Natural Gas Demand Forecast 2016-2030

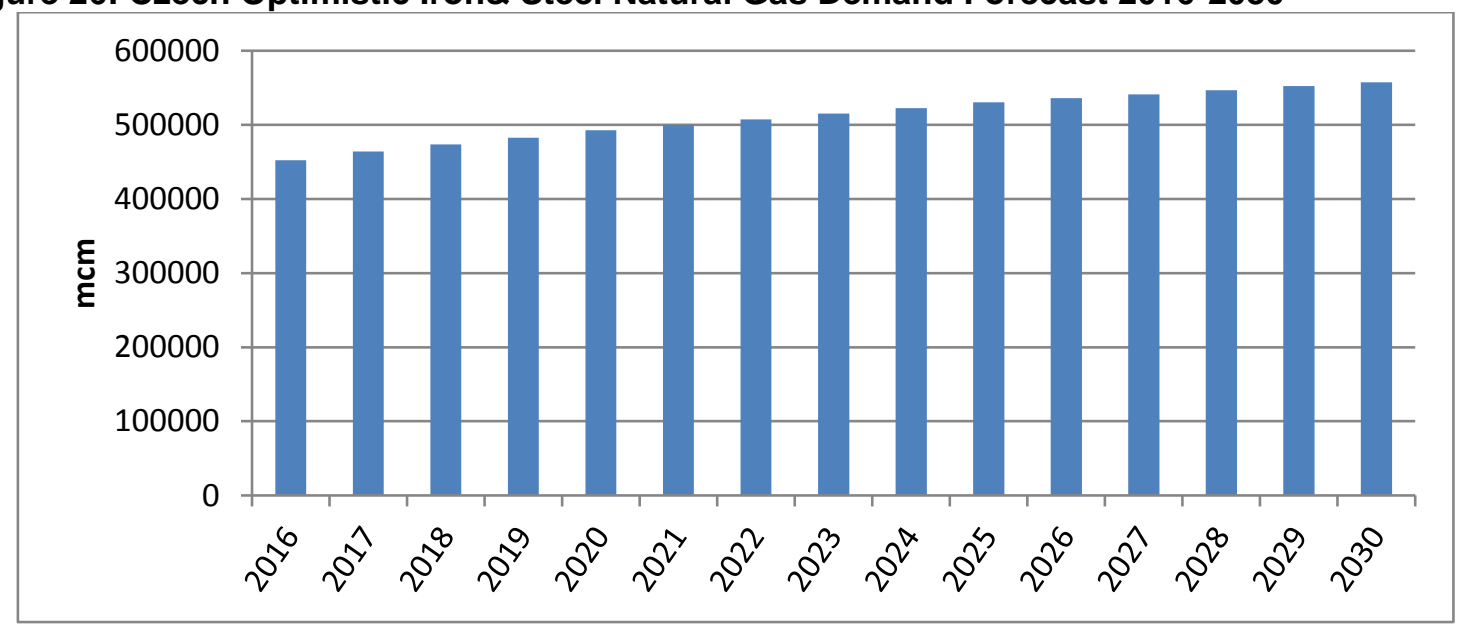

Source: Author's forecast 

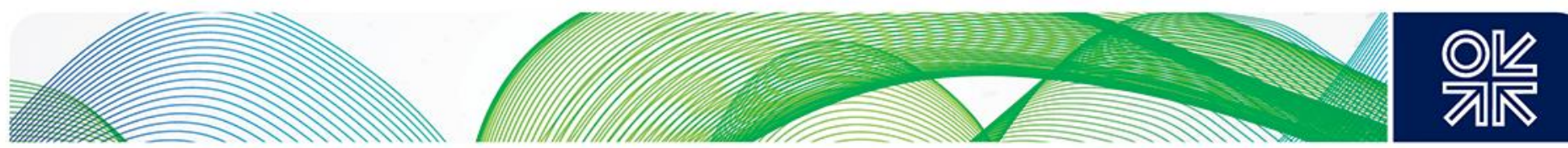

\subsection{The Czech Paper and Pulp Industry}

The Czech paper and pulp industry NACE $17^{66}$ is not a large or key sector in terms of its contribution to the Czech GDP; it is however a traditional sector interconnected with other local manufacturing industry, especially with the booming packaging and printing industry and with the provision of hygienic products. The sector employs around 20,000 people. ${ }^{67}$ The Czech paper industry has been largely modernised and is highly competitive with a good environmental record. About two thirds of domestic paper and cardboard consumption still has to be imported, but exports have been increasing, especially lately. Most of the leading local paper and pulp companies are owned by international firms and as a result they have seen an initial inflow of investment, restructuring and modernisation.

The Czech paper industry has attracted major investments in paper mills which are now both economically and ecologically sound. Currently 830,000 tonnes out of 1 million tonnes of recycled paper collected is exported, because there are no suitable production capacities available in the Czech Republic. Production of fibres and papers based on wood has increased because Mondi has invested in its Štětí plant, which has led to increased wood processing and pulp and paper production and importantly to the energy recovery of all types of bio-waste from this production. ${ }^{68}$

The paper industry is investment- and energy-intensive (electricity, heat), but paper mills now largely recover waste from the production of pulp (bark, sawdust, chips, liquor) or paper. It processes either local wood or recycled paper, creating thus a virtually closed cycle. ${ }^{69}$ It is increasingly dependent on renewable energy, which accounted for $69 \%$ of all energy use in 2016 , followed by natural gas $(23 \%)$ and coal $(8 \%)$ and oil.

Figure 27: Czech Paper Industry Energy Demand, Share by Fuel, 2016

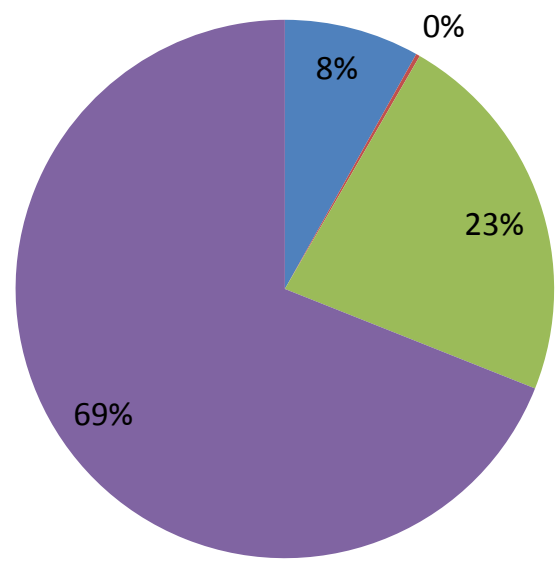

Coal

- Oil

Natural Gas

Renewables

Source: Czech Statistical Office

Although it is energy intensive the industry has made major improvements in energy savings, which have accelerated since 2012. The energy intensity of producing a tonne of paper declined by $27 \%$ between 2009 and 2016 but started to increase again in 2017 due to strong growth in paper production.

\footnotetext{
66 Including manufacture of pulp, paper and paperboard and manufacture of articles of paper and paperboard

${ }^{67}$ MPO, Panorama of the Manufacturing Industry of the Czech Republic 2017

68 https://www.regiony24.cz/47-71037-do-nove-linky-na-vyrobu-papiru-investovala-mondi-steti-47-milionu-eur

${ }^{69}$ MPO, Panorama of the Manufacturing Industry of the Czech Republic 2017
} 

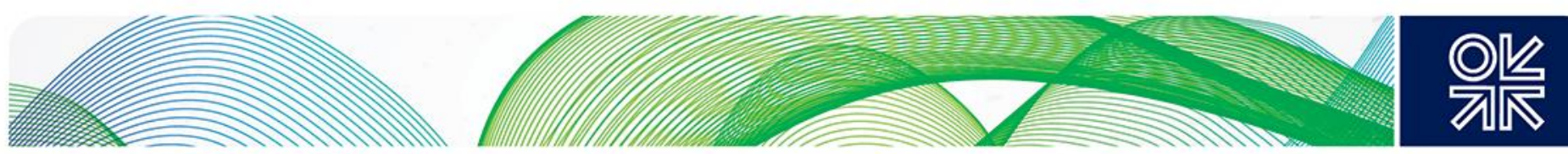

Figure 28: Czech Energy Intensity of Paper Production, 2007-2017

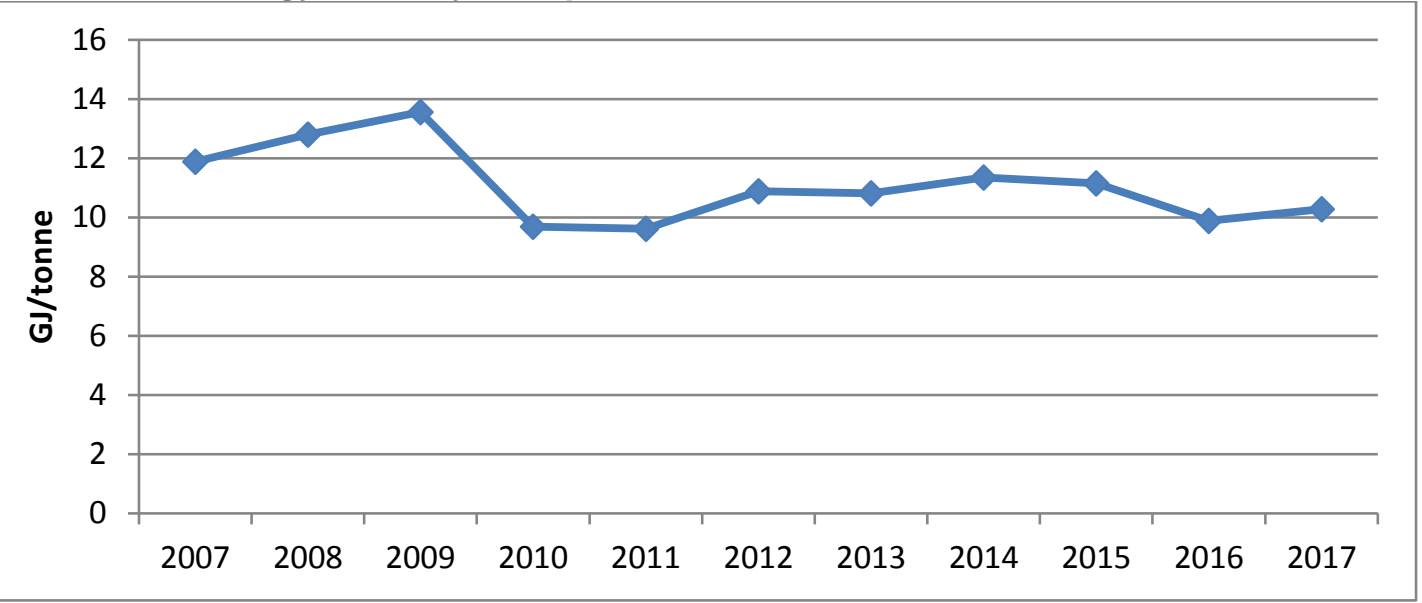

Source: Czech Statistical Office

The NACE 17 industry consumes annually over $0.12 \mathrm{bcm}$ of natural gas, which represented $1.4 \%$ of total gas demand in 2017. Gas consumption reached its peak in 2008 , consuming $0.15 \mathrm{bcm}$ of gas. As with the rest of the Czech economy, the sector was greatly affected by the recession and gas consumption was slashed dramatically in 2009. The second wave of recession in 2012 was not felt as much and gas demand plateaued. High gas prices continued to supress gas demand and bring about investment in energy saving technologies.

Czech paper and pulp production continued to show strong growth over the last decade apart from 2009 and yet the consumption of natural gas plateaued from 2013 as the natural gas price increased. All leading companies have now installed more efficient energy heating systems and switched to renewables, which kept natural gas consumption only marginally above the 2010 level whereas paper and pulp production has grown by more than 35\% since 2010 .

Figure 29: Czech Natural Gas Consumption by Pulp and Paper Industry, 2007-2017

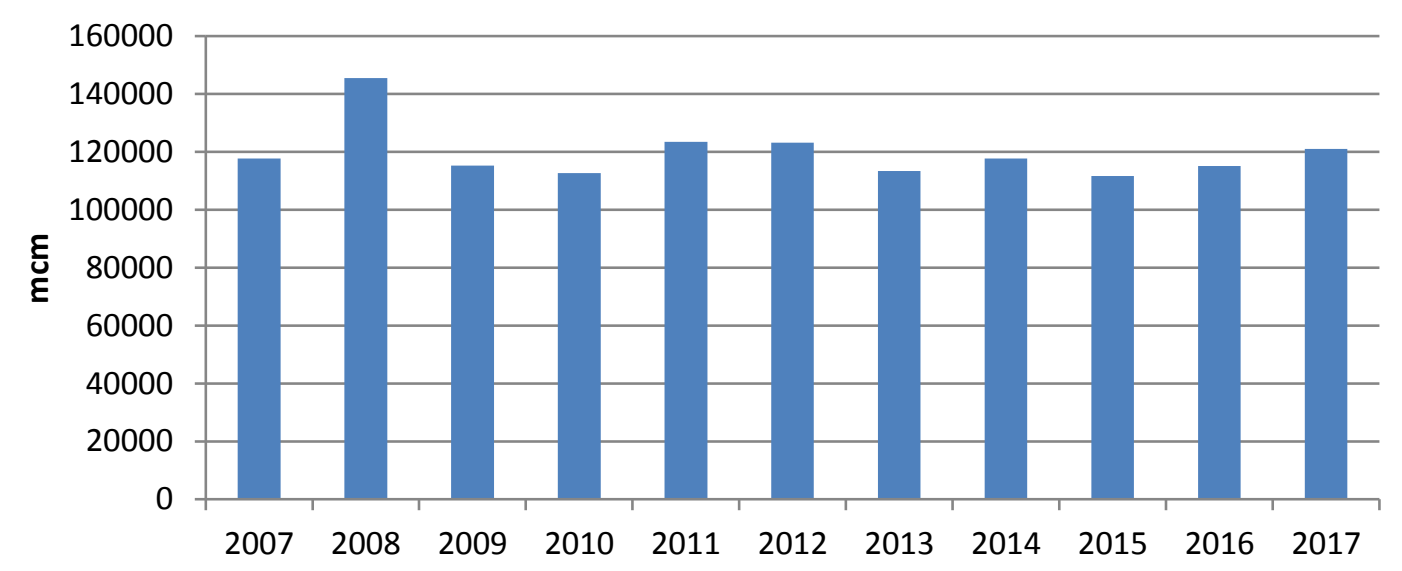

Source: Czech Statistical Office 

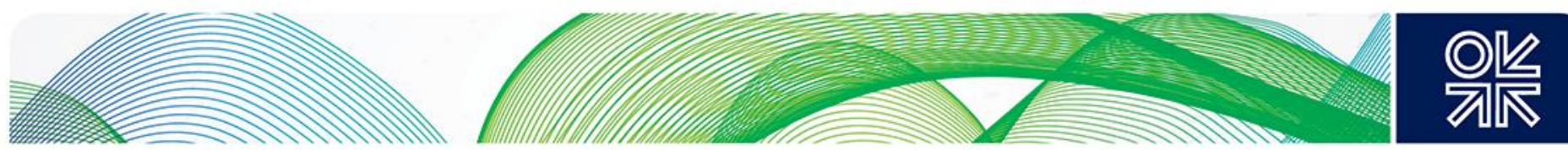

Figure 30: Czech Paper Production \& Natural Gas Consumption Indices, 2007-2017

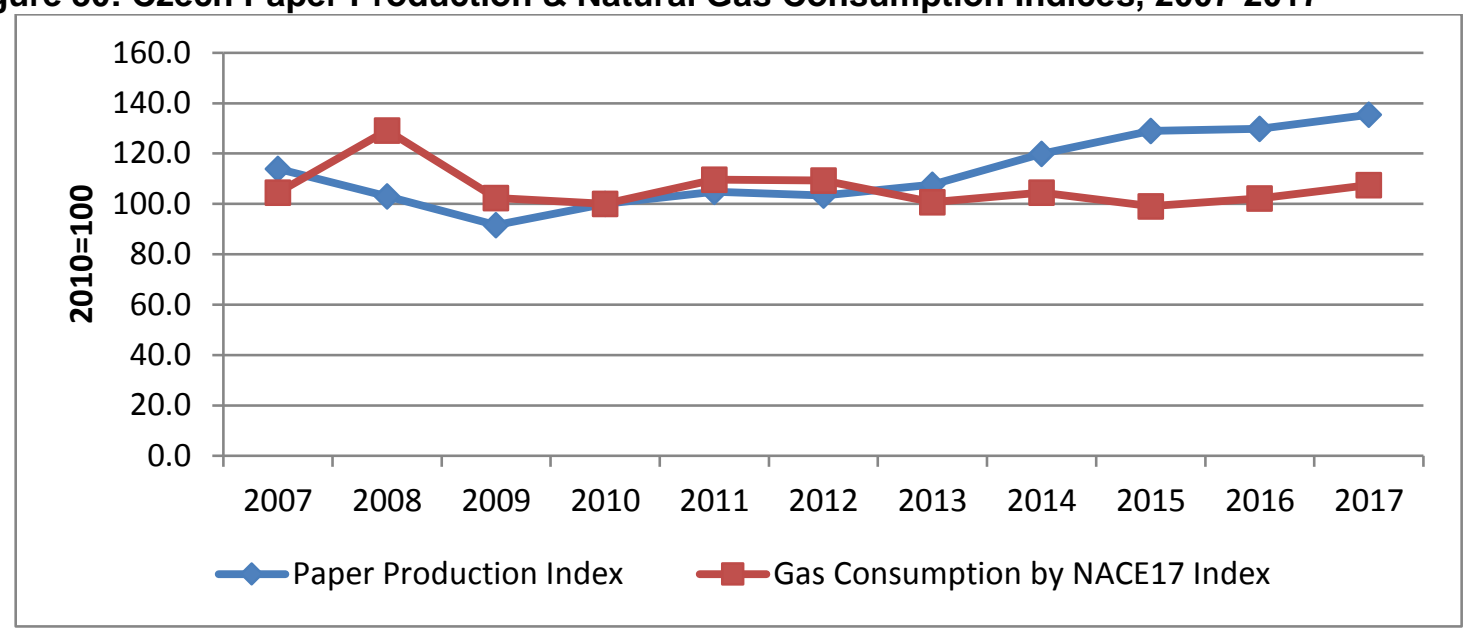

Source: Czech Statistical Office

\section{Forecast}

\section{Advantages}

Despite the dynamic growth in paper and cardboard consumption, the Czech Republic still lags behind the levels of advanced EU countries. Current Czech consumption of paper was $131 \mathrm{~kg}$ per capita while the EU average was $158 \mathrm{~kg}$ per capita in $2016 .{ }^{.0}$ As the living standard is now quickly catching up with the EU average, it can be expected that Czech consumption will reach some $180 \mathrm{~kg}$ per capita by 2035 . This would be equivalent to total domestic consumption of paper and cardboard of approximately 2 million tonnes/year. Since exports to neighbouring countries are growing rapidly, Czech production of paper could almost triple by 2030.

Given the competitive advantage of the Czech paper industry, it is expected that current production capacity will be increased to cover most of the increase in demand for paper. There will be increasing imports of some special products but the bulk of production is likely to be domestically sourced. As the country has a large surplus in recovered paper, which is currently exported, the prospects for the local paper industry look very promising. The optimistic outlook for the paper sector is enhanced by the fact that it is a sector based on renewable sources abundant in the Czech Republic which can be easily recycled and are generally seen as environmentally friendly.

\section{Challenges to Growth}

The sector is dominated by large enterprises controlled by international corporations and there is a danger that they may try to extract maximum profit rather than invest in their plants in the Czech Republic.

For natural gas demand the main limitation is that modern companies are increasingly using renewables rather than more expensive natural gas. The current trend is that modern paper mills install gasification plants which use bark to produce bioenergy and thus are able to cut out fossil fuels altogether, including natural gas. However, these are very costly investments and the modernisation will only happen gradually.

\section{Reference Scenario}

Over the past decade, the Czech paper and pulp industry fared much better than the rest of the EU and increased significantly its exports to the EU. It has good prospects to grow strongly till 2030, and the sector's growth will drive its gas demand, albeit at a slower pace due to further energy savings and a 

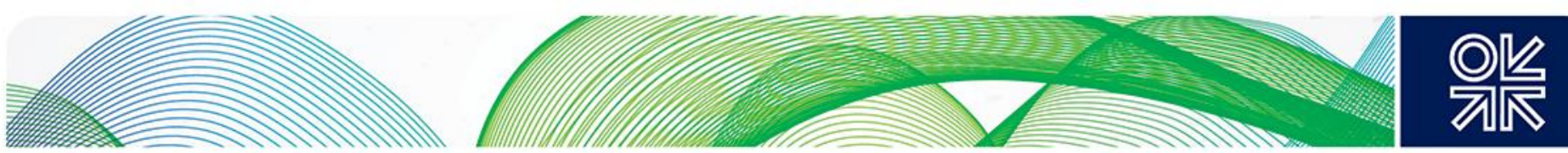

switch to renewables. The reference scenario expects the growth of some $5 \%$ till 2021 which will gradually slow down to $3.5 \%$ a year till 2030 . Natural gas demand by NACE 17 to reach some $0.2 \mathrm{bcm} / \mathrm{y}$ by 2030, which represents an incremental growth of $0.08 \mathrm{bcm} / \mathrm{y}$ in gas demand compared to 2017 .

Figure 31: Czech Reference Paper Industry Gas Demand Forecast 2016-2030

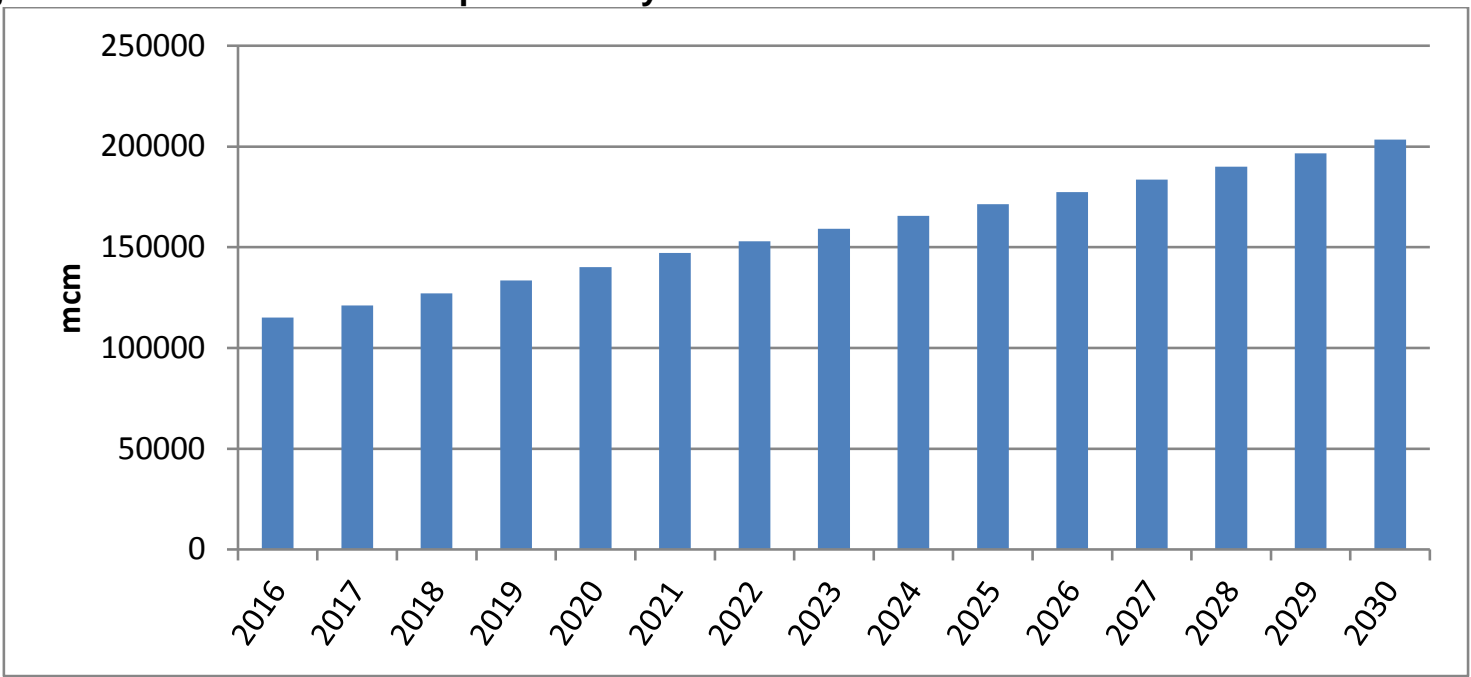

Source: Author's forecast

\section{Optimistic Scenario}

In the event that further major investments flow into enlarging paper mill capacity over the next decade, the sector is likely to show higher rates of growth of between $7 \%$ and $10 \%$ till 2025 and only then it will slow down to $3.5 \%$. The more optimistic scenario thus foresees gas demand by the sector growing from $0.12 \mathrm{bcm}$ in 2017 to $0.27 \mathrm{bcm} / \mathrm{y}$ in 2030 . However, the sector is unlikely to play a major role in future gas demand as it has largely switched to renewable energy and is unlikely to convert back to natural gas.

Figure 32: Czech Optimistic Paper Industry Gas Demand Forecast 2016-2030

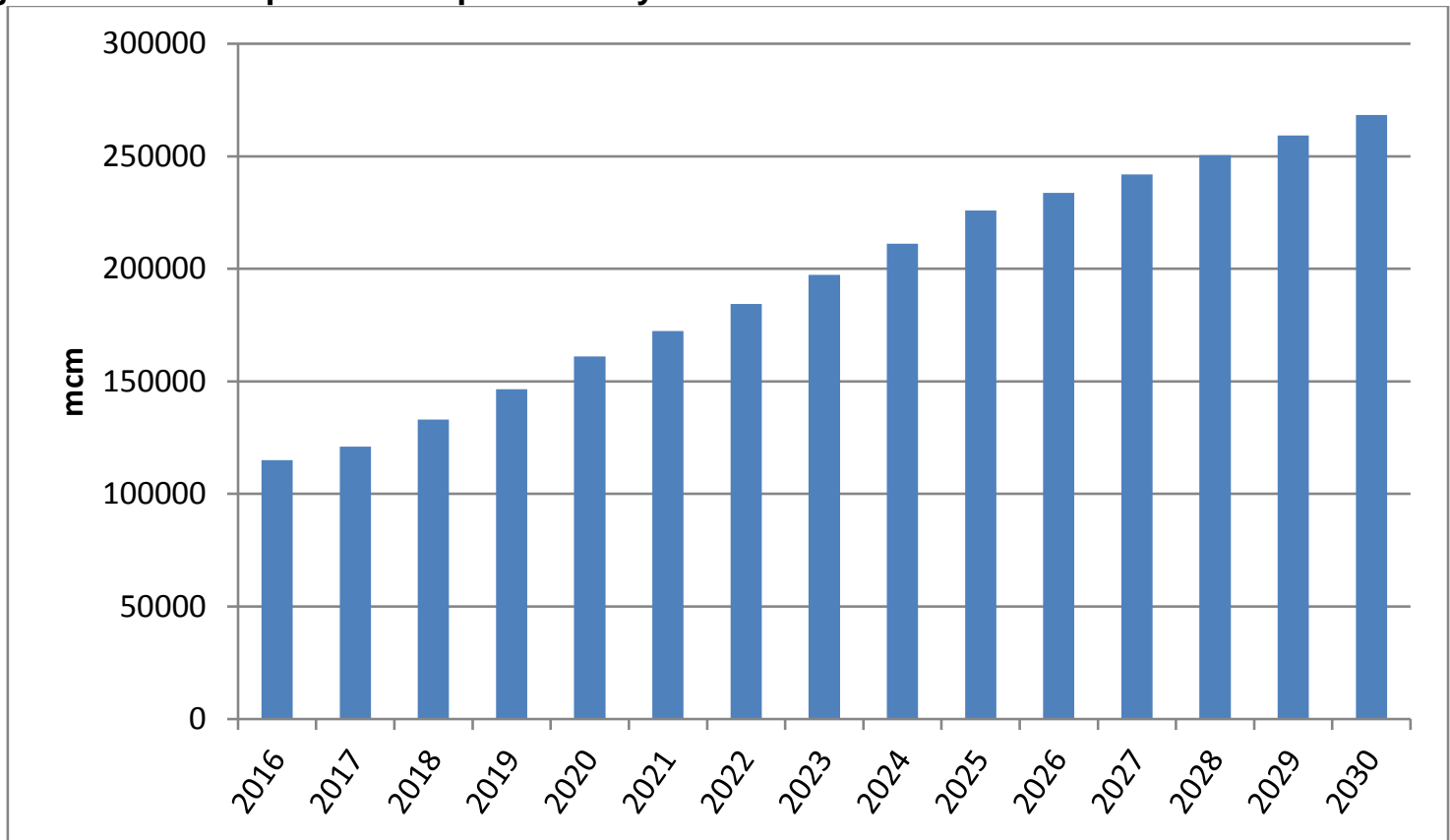

Source: Author's forecast 

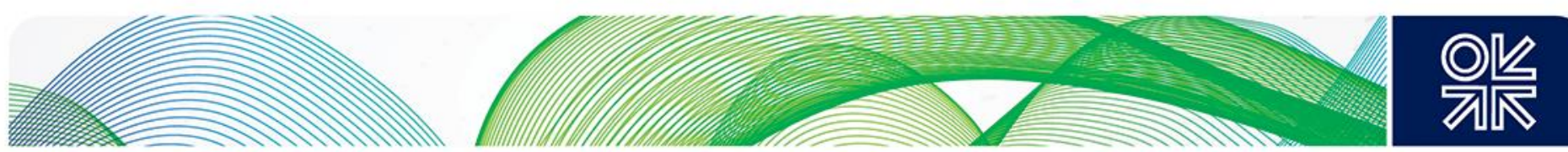

\subsection{The Czech Glass Industry}

The glass industry is classified under NACE23. ${ }^{71}$ The production of glass is the most important subsector for natural gas use. It is a long established traditional industrial sector which remains marginal and contributed less than $0.5 \%$ to the GDP in $2017 . .^{72}$ However, it is a major supplier to the construction and automotive industries, and exports represent almost three quarters of total sales. It benefits from local access to good quality raw materials and the largest companies have been modernised and reorganised.

Although the sector was affected by the recession, revenues have increased by about $5 \% / y$ on average since 2010, and are now reaching pre-crisis levels of CZK43 million. By far the most important sector of the glass and ceramics industry is the manufacture of flat glass for the automotive and construction industries.

Investment in energy saving technologies has varied according to each subsector. Flat glass, which represented almost $44 \%$ of total glass and ceramics revenues in 2016, has attracted the largest investment because this subsector is dominated by one international company, AGC Flat Glass Czech. The hike in energy prices from 2011 prompted investment in energy saving technology. AGC Glass Europe was the first glassmaker in Europe to introduce a combustion method that yields significant energy savings. ${ }^{73}$ This subsector has also attracted large investment in expanding production capacity. The energy intensity of producing $1000 \mathrm{~m}^{2}$ dropped from 9.8 GJ in 2012 to $7.5 \mathrm{GJ}$ in 2016, a significant $25 \%$ drop in just four years. However, a sharp increase in glass production pushed up the energy intensity in 2017.

Figure 33: Czech Energy Intensity of Flat Glass, 2011-2017

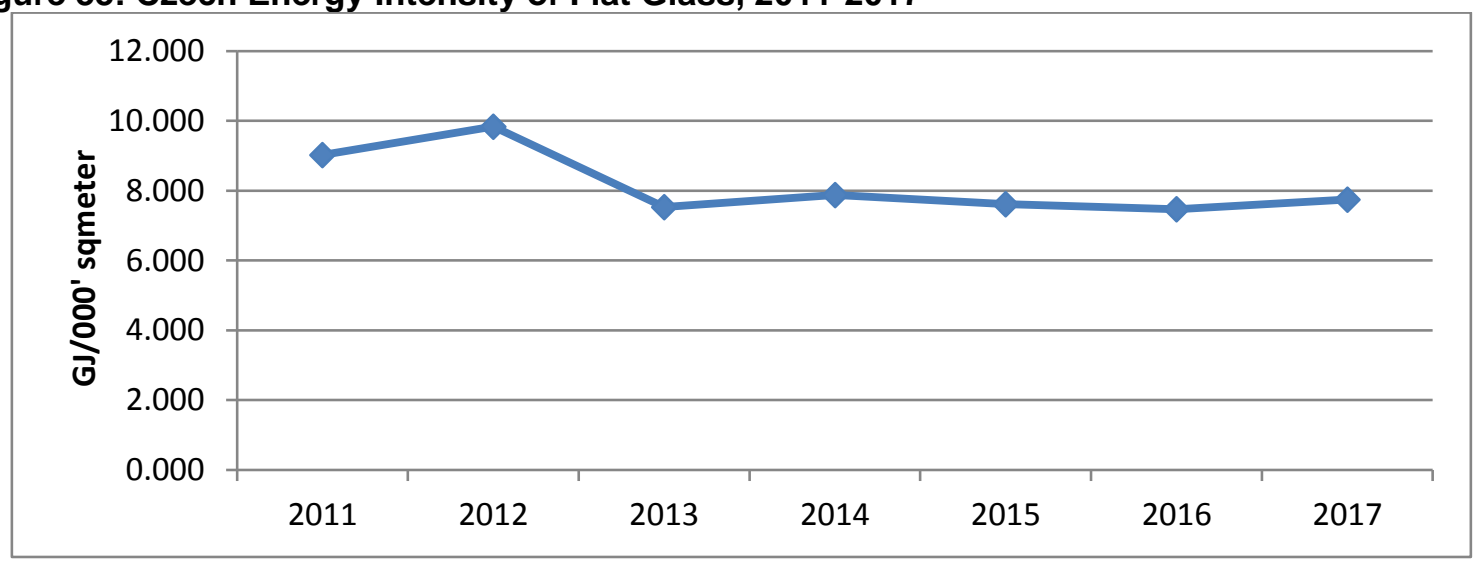

Source: Czech Statistical Office

The glass industry relies largely on natural gas for its technological processes as no other fuel can secure the required quality of glass products. In 2016, natural gas accounted for $57 \%$ of fuel used. However, waste gas is being increasingly used and represented a quarter of all energy used, followed by coal $(16 \%)$.

\footnotetext{
${ }^{71}$ Manufacture of Other Non-metallic Mineral Products

${ }^{73}$ https://www.agc-yourglass.com/agc-glass-europe/gd/en/about/cradle_to_cradle.html
} 

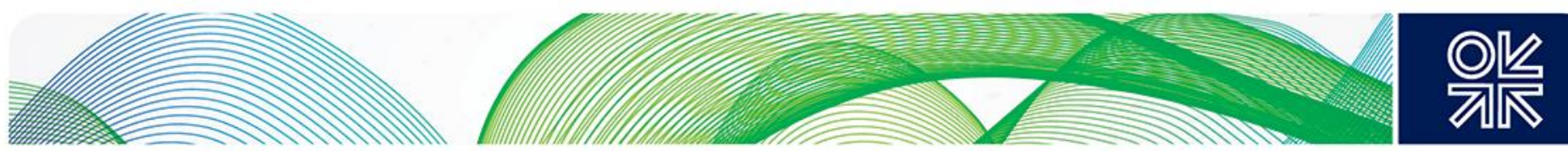

Figure 34: Czech Glass Industry Energy Demand, Share by Fuel, 2016

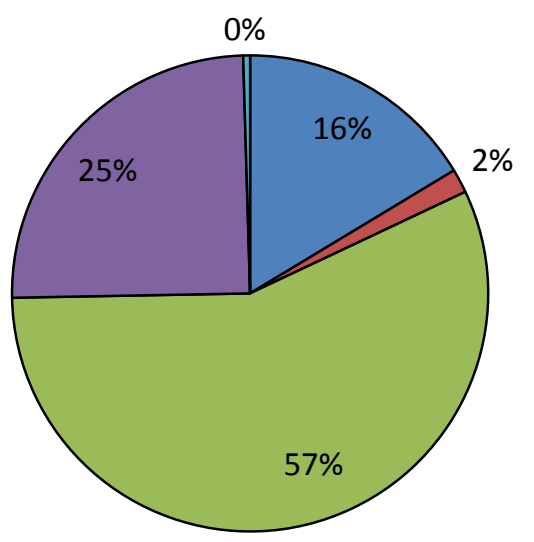

$\square$ Coal

$\square$ Oil

$\square$ Natural Gas

$\square$ Waste

$\square$ Other

Source: Czech Statistical Office

There are no separate statistics available for consumption of natural gas by the glass and cement industries. However, gas demand by other subsectors, especially the cement industry, is negligible and the glass industry accounts for the bulk of natural gas consumption. The figure shows a significant drop in consumption in 2009 due to the recession and a slight recovery since 2014, driven by growing production. The rate of growth in gas consumption is much slower than the growth in production as the energy saving technology makes difference. Natural gas consumption is, however, almost $20 \%$ below the pre-recession level of 2008, while production is now reaching pre-recession levels.

Figure 35: Czech Glass Industry Natural Gas Consumption, 2007-2017

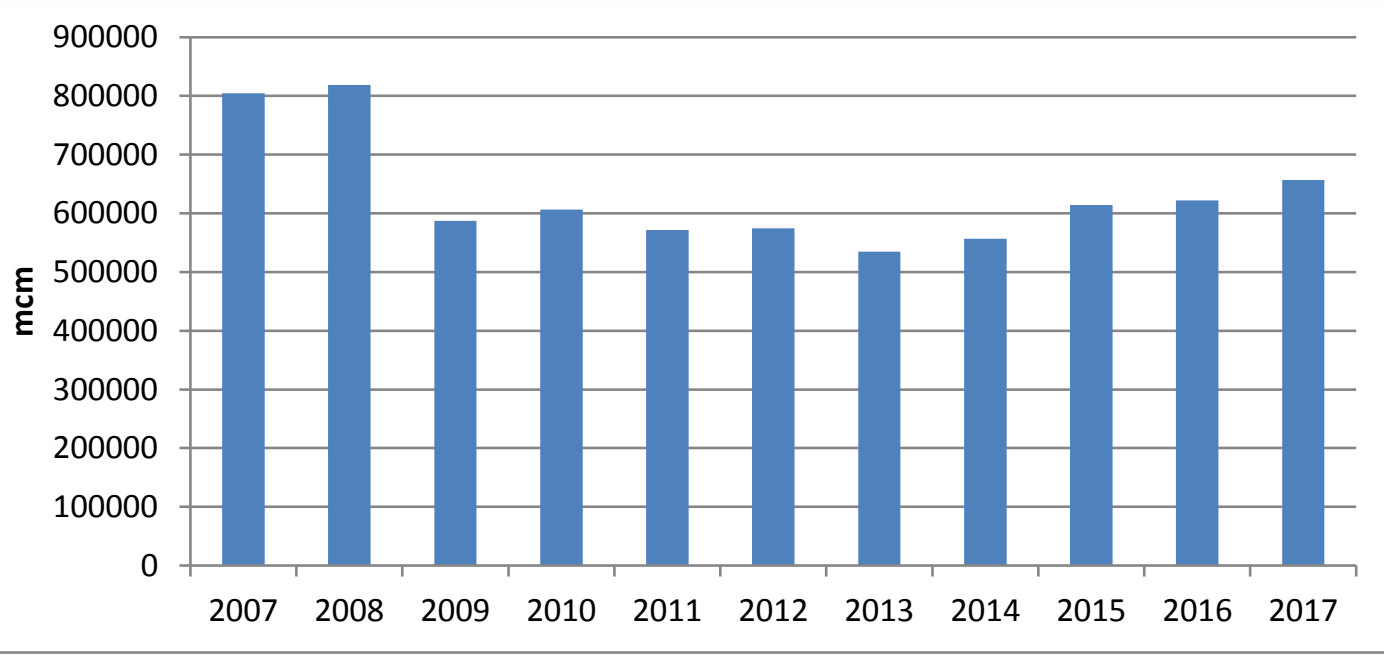

Source: Czech Statistical Office 

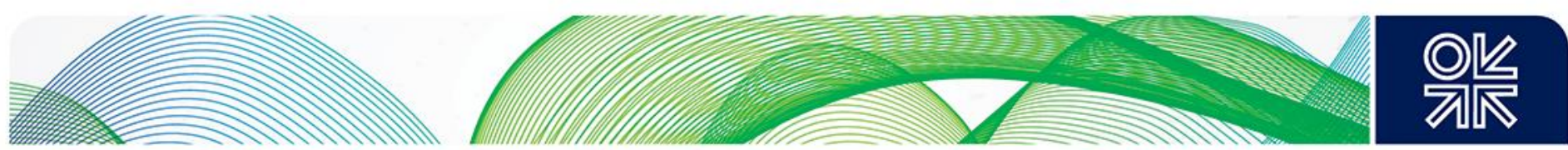

\section{Forecast}

\section{Advantages}

The future of the Czech glass industry looks positive since the industry is very competitive and has access to good quality raw materials and cheap labour. ${ }^{74}$ The industry has been able to compete on international markets and the bulk of production is exported to the EU. ${ }^{75}$ Since 2010 revenues and profits have been improving and there is a potential for further growth.

\section{Challenges to Growth}

The only danger is that the glass industry supplies construction and automotive sectors which are susceptible to recessional pressures, which will therefore be reflected in the glass industry. Future success will also depend on the ability to adjust to ever changing technology and design by the construction and automotive industries. Increasing competition is likely to result in further concentration among manufacturers to enable them to invest in innovation according to the current market needs.

\section{Reference Scenario}

In the past the Czech glass industry fared much better than the rest of the $\mathrm{EU}$ and has been able to increase its exports to the EU. It can be expected that it will grow strongly till 2030, driving future gas demand, albeit at a slower pace due to further energy savings. Growth of around 3\%/y till 2025 will gradually slow down to $1.5 \% / y$ by 2030 . In the reference scenario natural gas demand by NACE 23 will reach some $0.86 \mathrm{bcm} / \mathrm{y}$ by 2030 . The graph below incorporates gas demand by the cement industry, which is marginal as explained in the following chapter and will not make any impact on future NACE 23 gas demand.

\section{Figure 36: Czech Reference Glass Industry Natural Gas Demand Forecast 2016-2030}

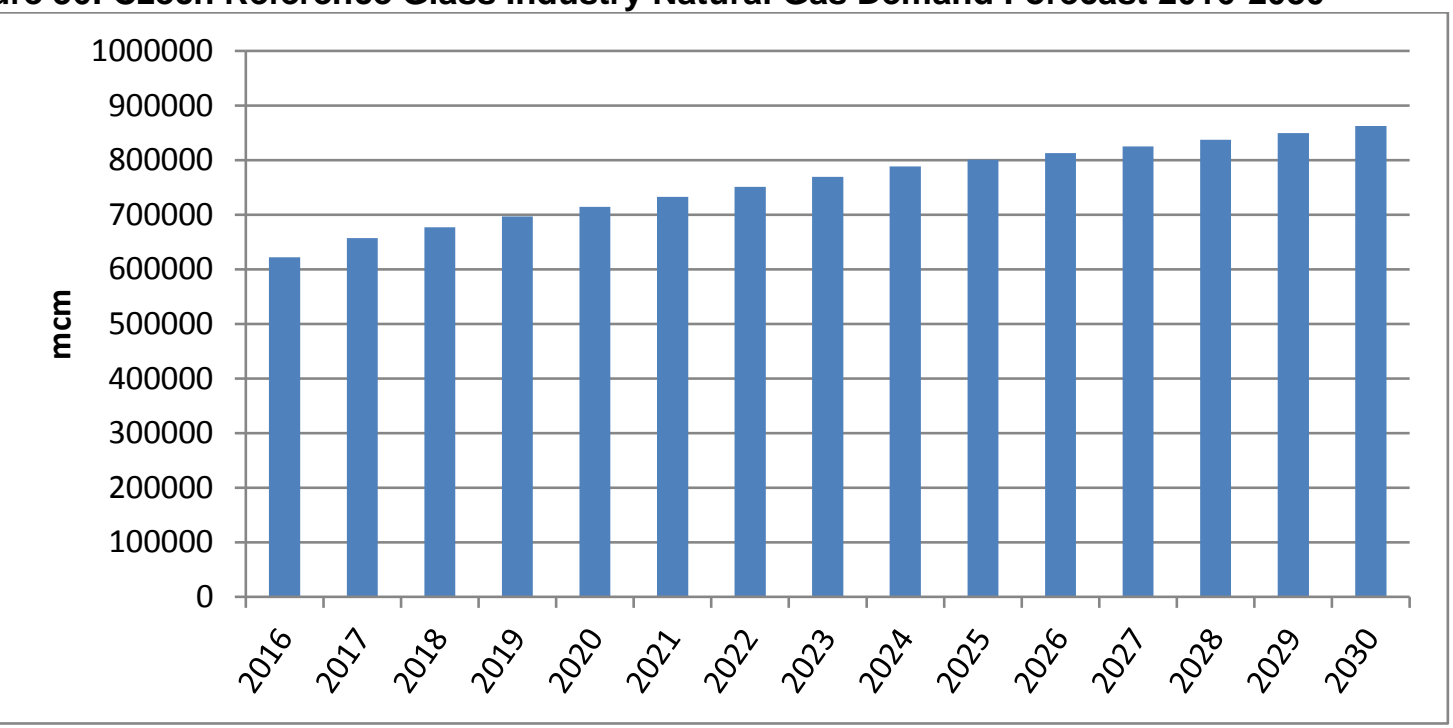

Source: Author's forecast

\section{Optimistic Scenario}

The optimistic scenario for the Czech glass industry could see much greater rates of growth till 2020 gradually slowing down to $2 \% / y$ by 2030 , due to increasing production driven by exports and enlarged investment by the dominant glass producer. In such a case, natural gas consumption is likely to show a healthy growth throughout till 2030. NACE 23 natural gas demand in the optimistic scenario reaches some $0.97 \mathrm{bcm} / \mathrm{y}$ by 2030. This represents an increase in gas demand by $0.32 \mathrm{bcm} / \mathrm{y}$ compared to 2017 .

\footnotetext{
${ }^{74}$ MPO, Panorama of the Manufacturing Industry of the Czech Republic

${ }^{75}$ https://askpcr.cz/file/6617a234b7bc7a8a5c11ab934fce7c2a/731/VZ2017-ASKP-CZ.pdf
} 

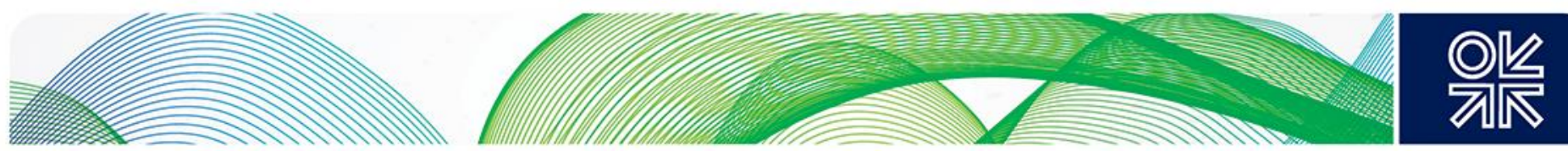

Figure 37: Czech Optimistic Glass Industry Natural Gas Demand Forecast 2016-2030

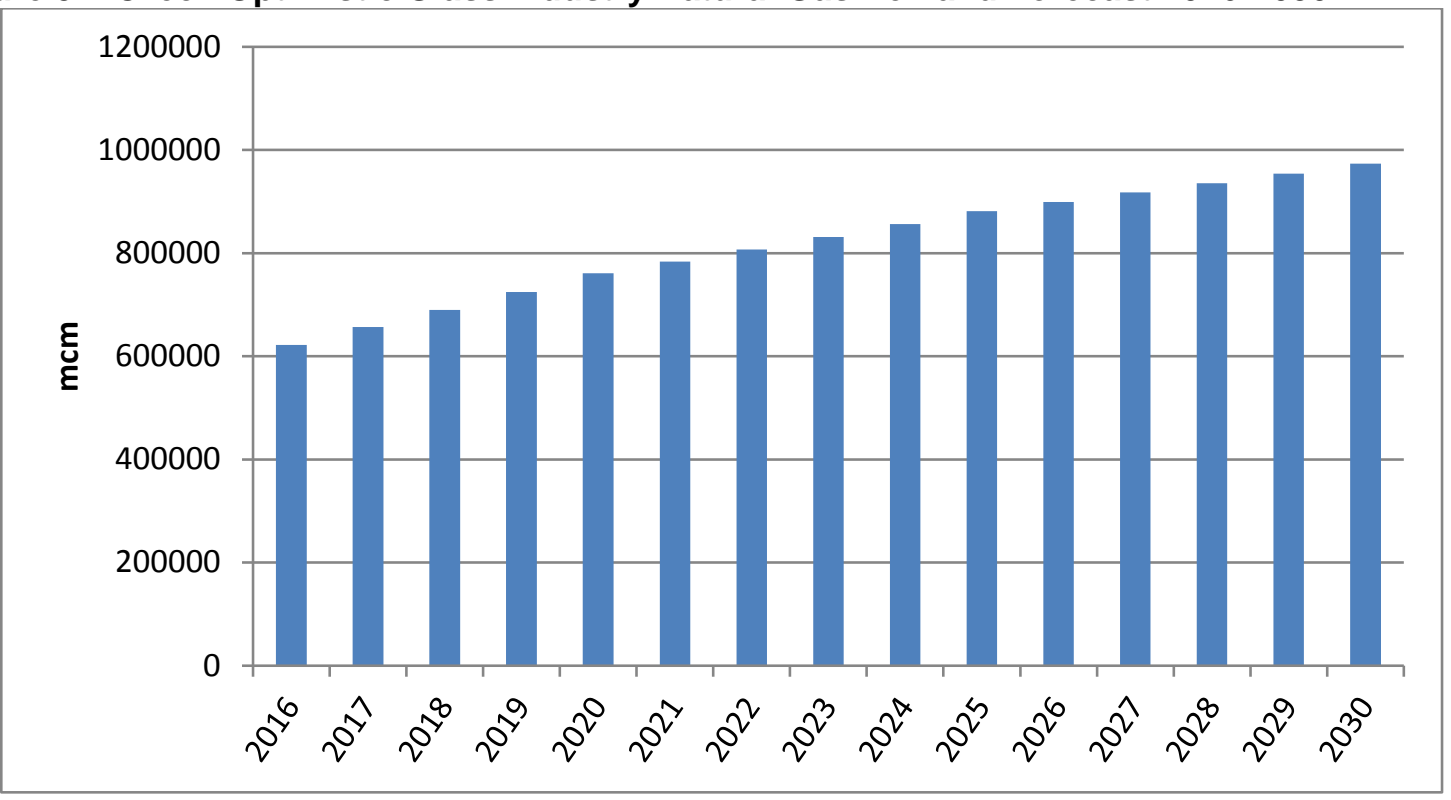

Source: Author's forecast

\subsection{The Czech Cement Industry}

The cement industry belongs to the NACE 23 sector. $^{76}$ Although it is a marginal contributor to the national GDP ( $0.5 \%$ of total GDP), the industry is important in terms of local construction industry. Over the years, it has experienced up and downs due to recessional trends but also due to unresolved glitches in state administration and national legislation. Cement production is mainly destined for local consumption although $9 \%$ of production is exported while $14 \%$ is imported $\left(2017^{77}\right)$.

The cement industry, Is one of the most energy-intensive industries, dependent on an appropriate raw material base. Over the last decade the energy intensity has not improved, apart from the production of cement without clinkers. It has controlled its costs by switching fuels used once energy prices started to increase in the 1990s. In 1990, natural gas represented almost $70 \%$ of fuels used for production of cement, but this dramatically changed by 2000 , when gas use was practically squeezed out, to a mere $0.2 \%$ of all fuels used. Natural gas was largely replaced by cheaper coal $(62 \%)$ and heavy fuel oil $(23 \%)$. The environmental pressures in the 2000s started to put a pressure on fuel consumption and by 2017 biomass represented over a quarter of all fuels used. Natural gas continued to be marginal, representing a mere $1.2 \%$ of fuel consumption while coal use was reduced to $30 \%$ and used tyres and other solid fuels saw a major increase. Currently, the cement industry uses somewhere around $0.005 \mathrm{bcm} / \mathrm{y}$ of gas.

\footnotetext{
${ }^{76}$ - NACE 23.5 Manufacture of cement, lime and plaster and NACE 23.6 Manufacture of articles of concrete, cement and plaster

${ }^{77}$ Svaz výrobců cementu ČR
} 

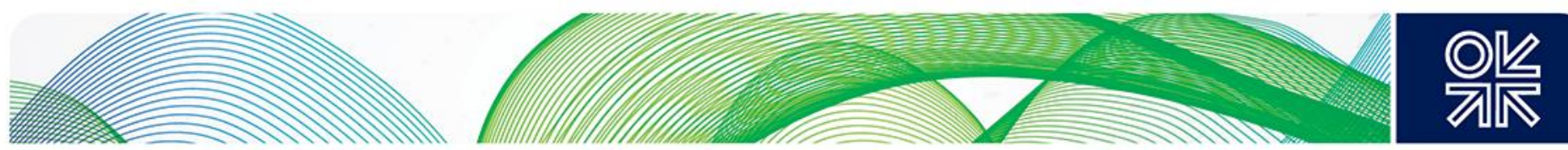

Figure 38: Fuels Used in Czech Cement Production, 1990-2017

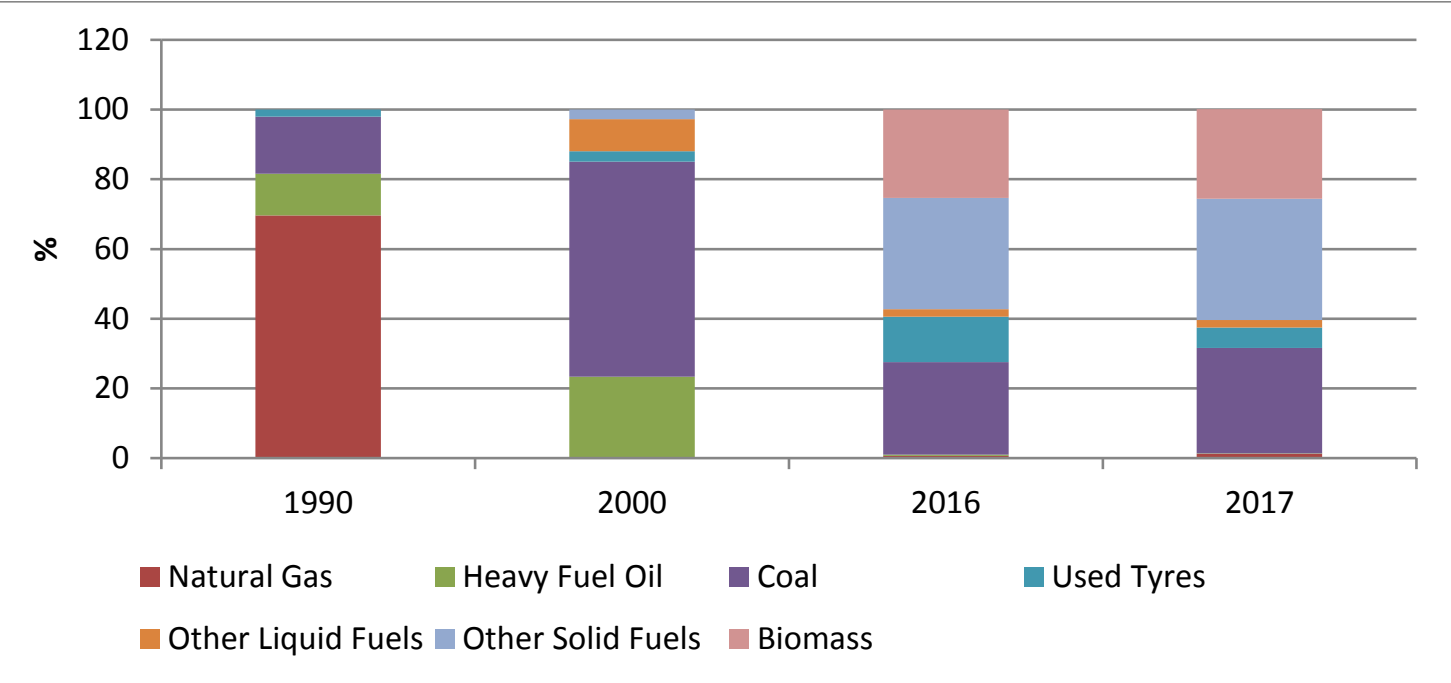

Source: Svaz výrobců cementu ČR

\section{Forecast}

Czech production of building materials is concentrated in a handful of large international companies which are better suited to compete on the European markets and will be able to increase exports of their products to the EU. It can thus can be assumed that the cement industry will see a moderate growth in production till 2030 driven largely by the local economy, construction industry and increasingly exports. However, the largest cement companies are likely to upgrade their technologies and introduce further energy savings, fitting best environmental techniques required in order to reduce greenhouse gas emissions.

The sector would have to introduce and invest in environmental technology in order to reduce its emissions. In future, it is possible that natural gas use will see some growth but since it has been practically squeezed out, it is unlikely that gas will play any major role in future cement production. Since the current natural gas use is a mere $0.005 \mathrm{bcm} / \mathrm{y}$ even a significant switch to natural gas will have no impact on industrial gas demand. In the most optimistic outlook the cement industry could use up to $0.01 \mathrm{bcm} / \mathrm{y}$ by 2030 .

\section{INDUSTRIAL NATURAL GAS DEMAND IN POLAND}

Natural gas plays only a modest role in total primary energy supply due to coal dominance. The industry sector is the largest natural gas consumer, taking over two thirds of total gas demand. Poland has made notable progress in reducing the energy intensity of industrial processes over the last two decades but remains among the countries with highest energy intensity in the EU. It has a big potential to improve its industrial energy efficiency which would provide for significant energy savings. Natural gas prices for Polish industrial users have been moving around the EU average over the last decade although they have hovered above the EU average since 2014 and once the country starts to rely largely on LNG imports from 2022 gas prices are likely to be well above the EU average. Poland has a mixed economic system of private business combined with centralized economic planning and government regulation. Industrial gas demand has been growing continually over the last decade when Poland did not dip into the recession as the rest of Europe. Importantly, one sector, the petrochemical and chemical industry accounts for a half of all industrial gas demand and has shown uninterrupted growth because fertiliser companies receive their gas at discounted prices. Since there is a great potential for Polish industry to make major energy savings, future gas demand will differ between key industry sectors. In the forecast scenarios total industrial and commercial natural gas demand is expected to grow from the current $10.3 \mathrm{bcm}$ to $11.1 \mathrm{bcm}-12.0 \mathrm{bcm}$ in 2030 . 

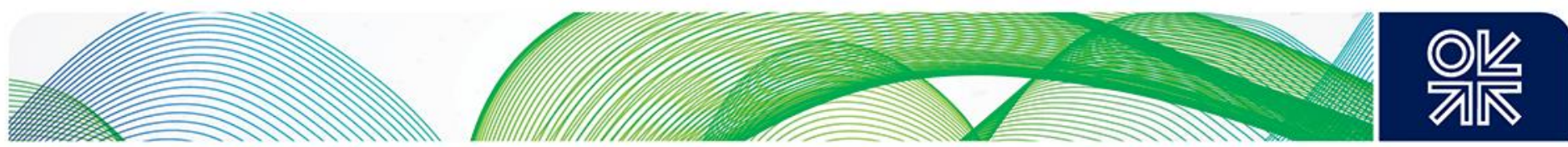

Poland with a population of 38.4 million and an area of $322,575 \mathrm{~km} 2$ is the largest country in Central Europe and the eighth largest economy in the EU. The largest component of its economy is the service sector, followed by industry and agriculture. In 2017, the industry sector made up $40 \%$ of the gross domestic product (GDP), the service and administrative sector contributed $57 \%$ and agriculture $2 \%$. As of 2018, the Polish economy has been growing steadily for the past 27 years, resulting in the country doubling its GDP since 1990. Originally, Poland's industrial base was concentrated in the coal, textile, chemical, machinery, iron, and steel sectors but it has now extended to fertilizers, petrochemicals, machine tools, electrical machinery, electronics, car manufacture and shipbuilding. While the economic growth has been impressive, many large state-owned industrial enterprises, especially the mining sector, have remained resistant to change and to the downsizing required for a competitive free market economy.

\subsection{Main Characteristics of the Polish Gas Market}

Natural gas is the third-largest primary energy source in Poland, after coal and oil, although its share of total primary energy supply (TPES) has been increasing. Over the last ten years, gas demand grew by almost $13 \%$, more steeply than the $2.6 \%$ growth in TPES. ${ }^{78}$ In 2016 , gas share in TPES was $14.7 \%$ while its share in electricity generation was only $4.7 \%$, which is very low compared to the International Energy Agency (IEA) average of 19\%. Coal dominates the Polish power sector, where it is the largest source of greenhouse gas emissions as well as a major employer. Consumption of natural gas is very seasonal. Gas demand in the heating season accounted for approximately $85 \%$ of total annual consumption in 2016, according to the Energy Regulatory Office.

The industry sector is the largest natural gas consumer, with a $67 \%$ share of total demand in 2017 (based on final gas consumption ${ }^{79}$ ). The high seasonality is the result of industry using natural gas predominantly for heating purposes while only a small percentage is used for direct industrial processes. Industry consumption continued to grow throughout the last decade. Poland was the only country in the EU which did not entered into recession post 2007. The largest consuming industries are the chemicals sector (with $35 \%$ of total industry demand), which uses natural gas mainly as feedstock, and petrochemical industries (21\%) and non-metallic mineral products (15\%), which consumes natural gas as a fuel. ${ }^{80}$ The most industrialised regions of the country, which are mainly located in the south, account for the bulk of the total demand.

\footnotetext{
78 IEA Energy Statistics

${ }^{79}$ Central Statistical Office of Poland GUS

${ }^{80}$ Central Statistical Office of Poland GUS
} 

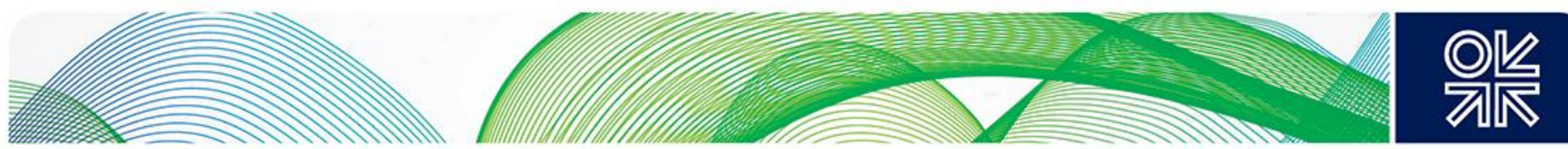

Figure 39: Shares of Polish Gas Demand by Sector, 2017

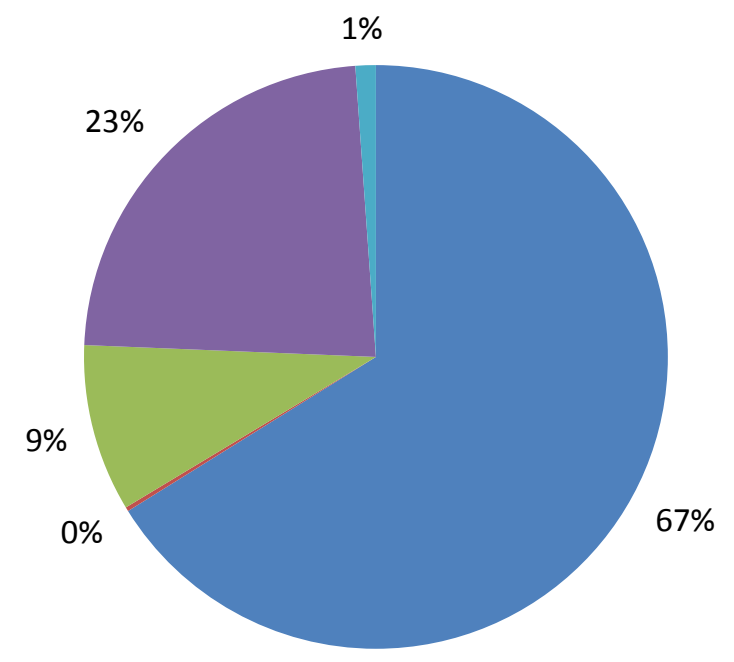

Industry

Agriculture

Services/public

Households

Own use

Source: Annual National Report ERO, 2018

The heat and power sector consumed $11.5 \%$ of natural gas in 2016 , compared with the IEA average of $19 \%$ as a result of the dominance of coal power. The sector has shown small variations in the last decade. In the industry and service sector, natural gas usage is around half of heat and power. The current official forecasts foresee the share of gas increasing. Polish natural gas policy is incorporated in the draft Energy Policy of Poland till 2040 (PEP204081). More detailed description of PEP2040 is in

\section{APPENDIX 4}

The residential sector is the second-largest natural gas user, consuming $23 \%$ of total demand in 2017 . Consumption levels have been less stable, moving between $3.5-3.8 \mathrm{bcm} / \mathrm{y}$. There is only a medium level of gas penetration, around 58\% which is envisaged in PEP2040 to grow to $61 \%$ by 2022 . The number of household consumers has been increasing recently, especially in rural areas, and there has been evident growth in demand by households. The service/public sector ( $9 \%$ ) has had a similar trend in the last decade, with consumption levels moving between $1.8-2.3 \mathrm{bcm} / \mathrm{y} .82$

\subsection{Polish Energy Efficiency Progress}

Energy efficiency is one of the factors affecting the competitiveness of the entire economy, especially industry. Energy efficiency will thus be one of the main determining factors on future industrial growth. Poland has made notable progress in reducing the energy intensity of industrial processes over the last two decades, but still has the fourth highest energy intensity in the EU. One of the main reasons for this is that industry (including the energy sector) accounted for $40.2 \%$ of the GDP, so that energy intensity indicators would inevitably be higher than the EU-28 average: the EU 28-average industry share was $19.3 \%$ in $2016 .{ }^{83}$ Heavy industry such as steel and chemical industries accounts for a large proportion of the Polish industrial sector. There is no doubt that the country has a large potential for energy savings in the industrial and residential sectors, and energy intensity has been growing again since 2015.

\footnotetext{
${ }^{81}$ https://www.gov.pl/web/energia/polityka-energetyczna-polski-do-2040-r-zapraszamy-do-konsultacji

82 Central Statistical Office of Poland GUS

83 https://ec.europa.eu/eurostat/statistics-

explained/index.php?title=File:Energy_intensity_of_the_economy,_in_selected_years,_2006-

2016_(kilogram_of_oil_equivalent_per_1_000_EUR).png
} 

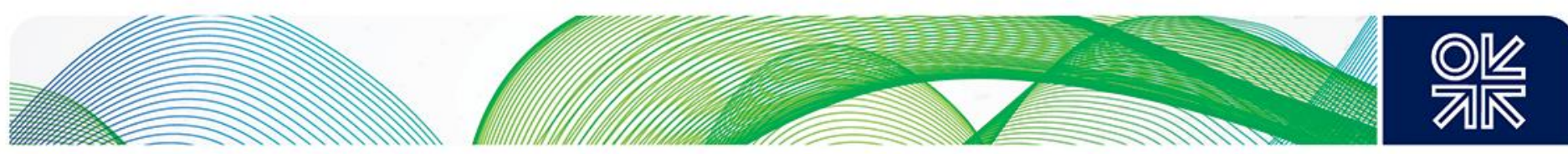

The industry sector accounts for the third largest share of the economy's energy use $(23 \%)$, after housing (30\%) and transport (29\%). Despite the progress Poland's energy intensity still remains twice as high as the EU-28 average. ${ }^{84}$ There is no doubt that it has a large potential to improve its energy efficiency and that would lead to significant energy savings. The country's economy has been growing strongly and growth is expected to continue throughout the next decade, driving energy demand. In future, the growth in energy demand will be much slower than economic growth due to energy savings. For more detailed information see APPENDIX 5.

Figure 40: Polish Energy Intensity, 1995-2016

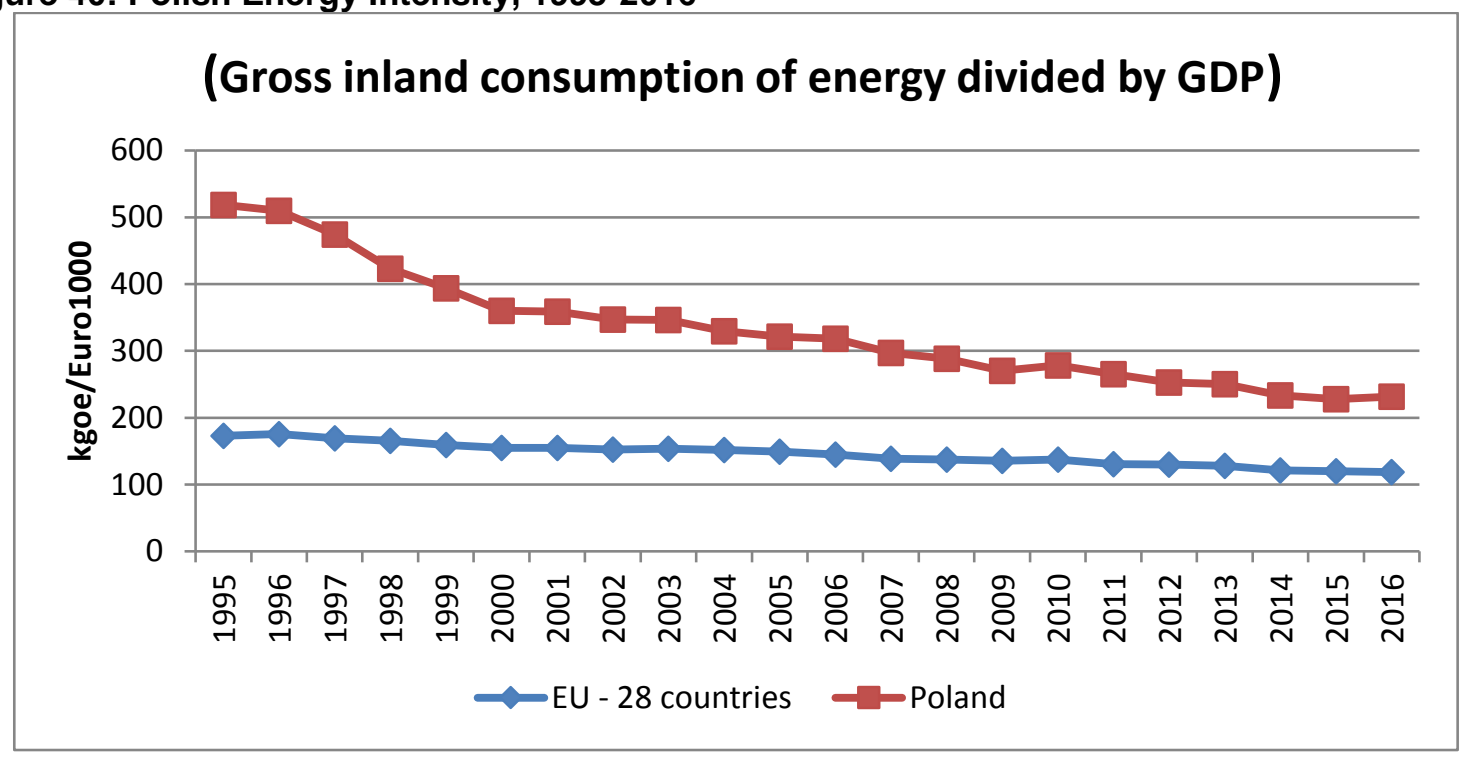

Source: Eurostat

\subsection{Polish Gas Price Developments and Competition from Coal}

Poland has been slow in liberalising its natural gas market and regulated retail prices have been the single biggest challenge to growth. In a ruling on 10 September, 2015, the European Court of Justice confirmed a breach of EU provisions regarding unreasonable use of regulated gas prices for customers other than households. As a result the Polish government amended the Energy Law on 30 November, 2016 with supporting legislation, which has drawn a roadmap for gas price deregulation ${ }^{85}$. As a result the obligation to submit tariffs for EREO approval has been introduced gradually ${ }^{86}$ but the tariff deregulation roadmap can be considered as a step closer to gas market liberalisation. Since 1 January 2018, the gas market has been deregulated apart from household customers and all other final customers have the right to change their supplier free of charge.

Natural gas prices for Polish industrial users have been moving around the EU average over the last decade although they have hovered above the EU average since $2014 .{ }^{87}$

\footnotetext{
${ }^{84} \mathrm{https}: / /$ stat.gov.pl/files/gfx/portalinformacyjny/en/defaultaktualnosci/3304/5/14/1/energy_efficiency_in_poland_in_years_2006_ 2016.pdf

${ }^{85}$ On 1 January 2017, for gas trade (sales) at a virtual point, sales of LNG and CNG and sales by call for tenders, auction or public tender (customers who purchase at least $278 \mathrm{GWh} / \mathrm{y}$ ). From 1 October 2017, for end customers (except for households); from 1 January 2024, for customers in households.

${ }^{86}$ The maximum tariff price mechanism will be in place until the obligation is lifted. If the agreements do not provide for a method of calculating the price of gas after the use of tariff is no longer mandatory, a draft of the revised agreement must be sent to the customer and the customer has the right to terminate the agreement.

${ }^{87}$ In the first half of 2018, natural gas prices for industrial customers were EUR 10.3925/GJ including taxes and levies or 8.2532/GJ excluding taxes and levies, while the EU average was EUR 10.1859/GJ including taxes and levies or 7.2947/GJ excluding taxes and levies.
} 

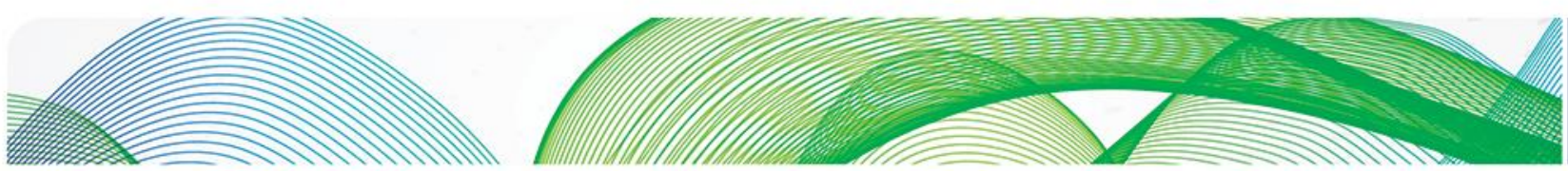
O는

Figure 41: Polish Gas Prices for Medium Size Industries, Excluding Taxes and Levies, 20082018

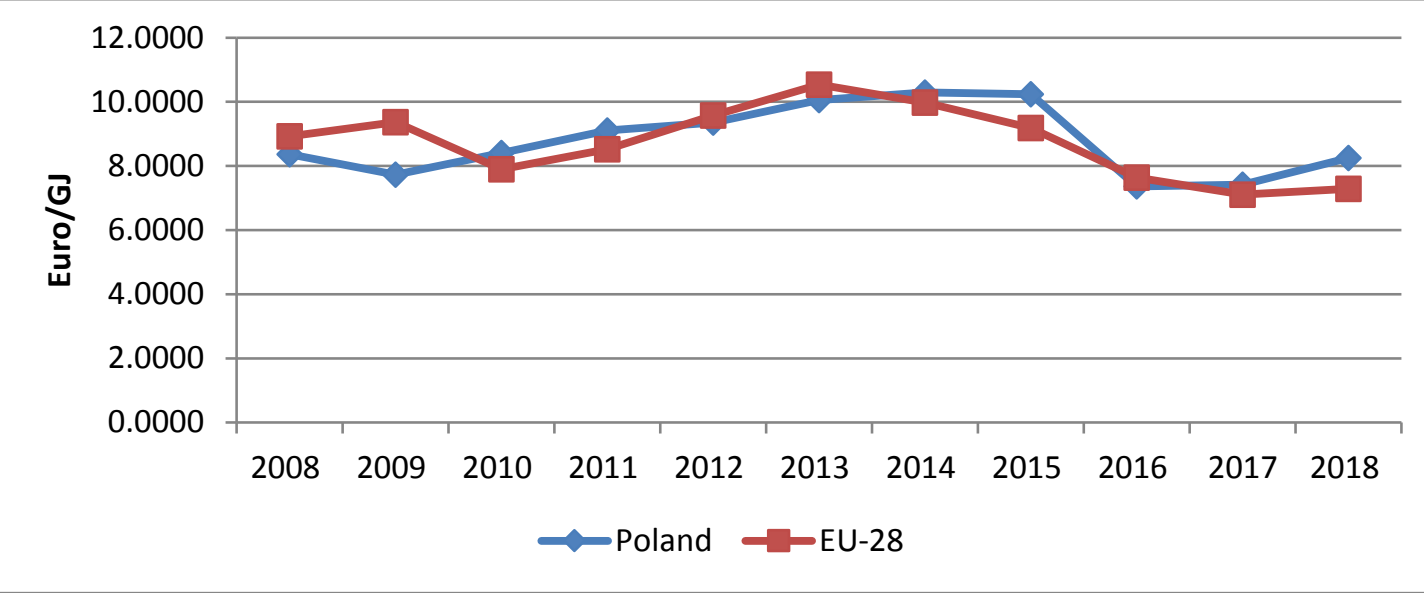

Source: Eurostat

Over the last decade regulated natural gas household prices have been among the lowest in the EU. ${ }^{88}$

Figure 42: Polish Gas Prices for Medium Size Household, Including Taxes, 2008-2018

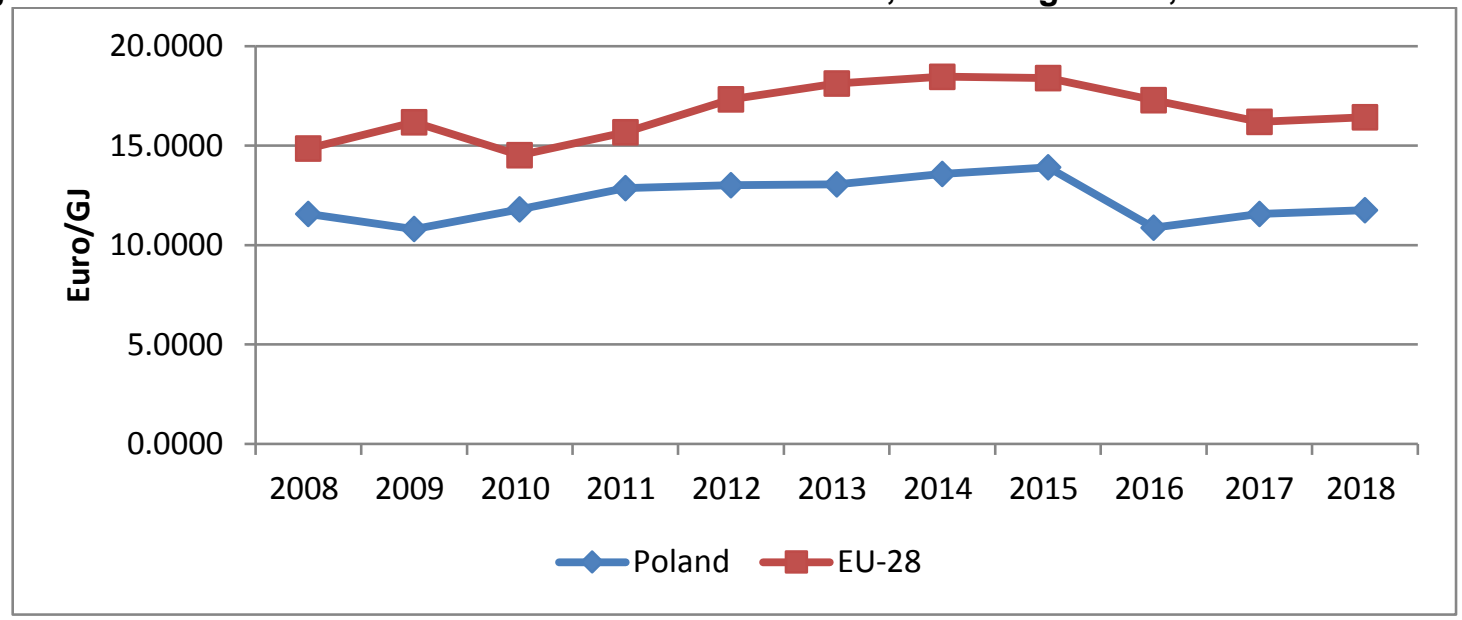

Source: Eurostat

The strong coal lobby and lower coal prices in Poland have protected the dominant position of coal in electricity generation. Coal is the only significant indigenous energy resource in the country. Historically, Poland has been a net exporter of coal. Coal has been the main and most affordable source for electricity generation for decades and helped the country maintain a lower level of dependence on imported natural gas. The security of energy supplies has been the priority concern of the current Polish administration. The spike in international coal prices due to the closure of some Chinese coal mines and increased demand from India in 2017 pushed up industrial coal prices in Poland, which grew throughout 2017 and 2018. In comparison natural gas prices for industrial customers declined in 2015 and 2016 but were still not competitive with coal.

${ }^{88}$ According to Eurostat, retail prices for gas in the first half of 2018 for medium-sized household consumers in Poland (EUR 11.7608/GJ including taxes and levies or 9.5413/GJ excluding taxes and levies) are well below the EU average (EUR 16.4182/GJ including taxes and levies, EUR 11.9757/GJ excluding taxes and levies). 

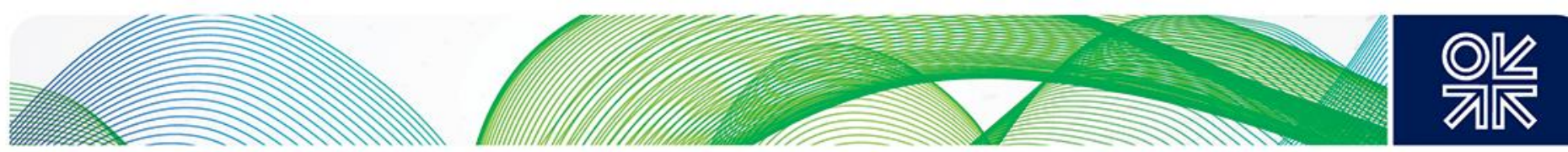

Figure 43: Polish Natural Gas for Medium Industry \& Steam Coal for Electricity Plants Price Indices, 2014-2018

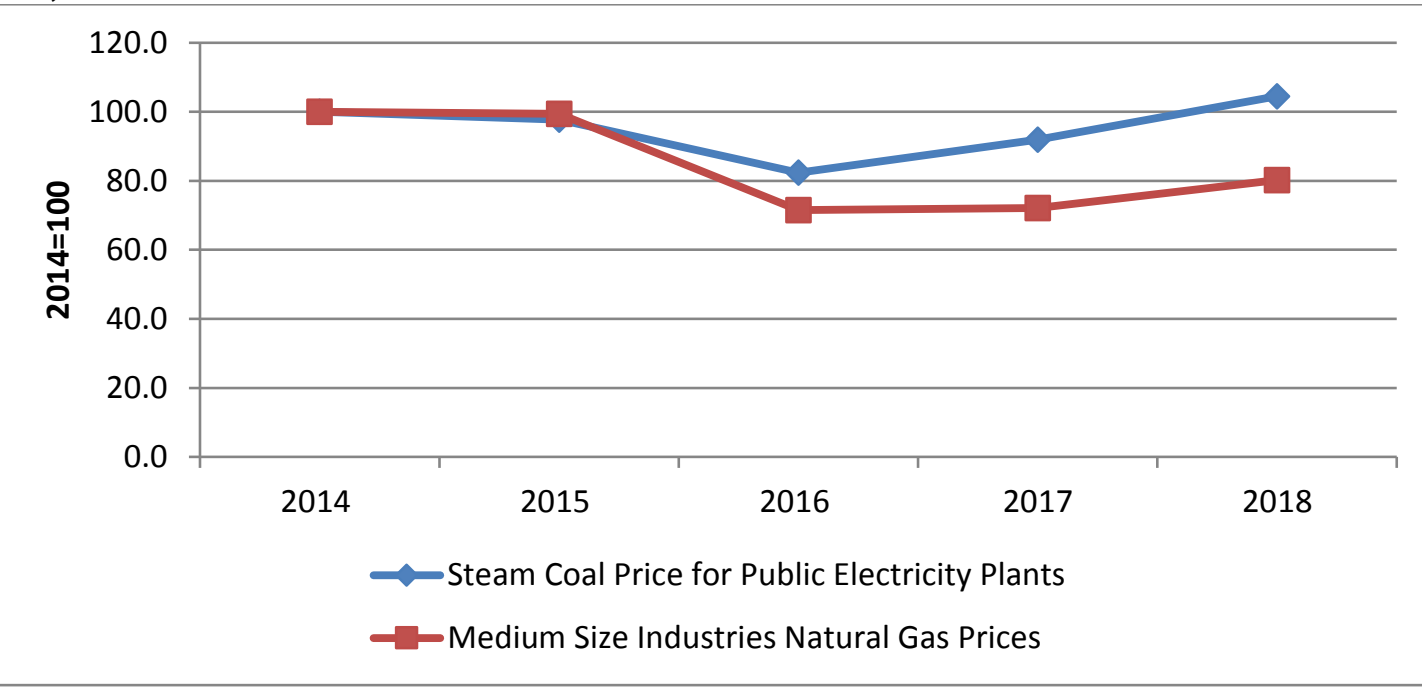

Source: Eurostat, TGE Monthly Report

Given the forecast of depressed international coal prices till 2030 due to declining demand, coal is most likely to continue to be the cheapest fuel for electricity plants in Poland.

\subsection{Polish Industrial Natural Gas Demand}

Industrialisation of today's Poland has been extremely uneven owing to repeated partitioning of the territory over the last 150 years between neighbouring powers with various rates of industrial development. Apart from a small number of industrial centres like Lodz and Warsaw the only area of the country which was industrialised during $19^{\text {th }}$ century European industrialisation was Upper Silesia, which continues till now to be the heartland of Polish industry. Modern industry is now developing in new industrial clusters such as the Polish Aviation Valley - a specialized industrial cluster in the SouthEast of Poland.

Poland has a mixed economic system of private business combined with centralized economic planning and government regulation. Within the EU Poland belongs to the countries with an above average share of the manufacturing industry in gross value added. Manufacturing industry alone represented $20 \%$ of the GDP in $2017 .{ }^{89}$ Employment by the industry is also significant as $31 \%$ of all economically active citizens worked in the industrial sector in 2017. ${ }^{90}$ Currently, the main Polish industries are: production of fertilizers; petrochemicals; car manufacture; machine tools; electrical machinery; electronics; and shipbuilding.

Compared to European standards Polish factories have a very low level of automation. Only $15 \%$ of Polish manufacturers are fully automated, while $76 \%$ have yet to complete the automation process, and $14 \%$ of Poland's manufacturing remains wholly manual. $6 \%$ of manufacturers report making moves towards automated industry. ${ }^{91}$ This suggests that it will take some time for Polish industry to become more efficient.

Industrial customers represent over two thirds of total natural gas consumption in Poland. They use natural gas for a variety of purposes, especially heating; firing boilers for steam needs; CHP facilities for internal factory use; and feedstock for products such as fertilizers, plastics, anti-freeze and fabrics.

\footnotetext{
${ }^{89}$ Central Statistical Office of Poland GUS

${ }^{90}$ Central Statistical Office of Poland GUS

${ }^{91}$ https://www.export.gov/article?id=Poland-Advanced-Manufacturing
} 

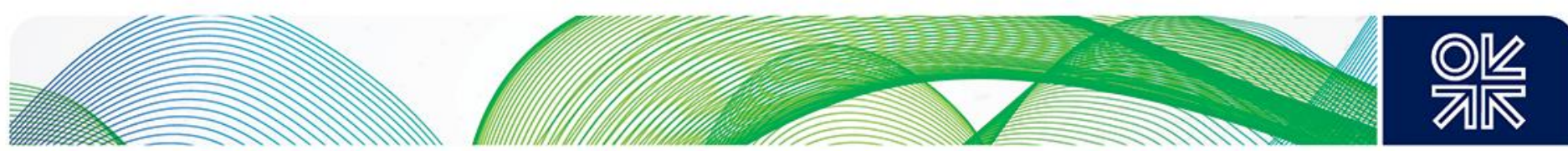

The industrial sector is slower in reacting to natural gas price swings unlike the electricity sector whose demand for natural gas is highly-price sensitive. Modern industrial plants are very capital-intensive and take several years to complete. Consequently, industrial plants have limited flexibility when it comes to choosing energy and feedstock sources.

Natural gas prices for large industrial customers are close to spot or import prices since their consumption is even throughout the year and they purchase the largest volumes of gas. However, in the longer term some industrial sectors will find it increasingly difficult to face tougher competition from markets where energy and raw material prices are substantially lower than in the regulated environment of European markets. In contrast, more specialised and value-added sectors may prosper and see a significant growth in the mid-term future.

In 2017, the Polish industrial sectors in total consumed almost $10.3 \mathrm{bcm}$ of high methane natural gas and $0.4 \mathrm{bcm}$ of low methane gas. ${ }^{92}$ The largest consumer sectors were the chemical industry; the petrochemical industry; non-metallic minerals (glass, cement); production of electricity, steam and air conditioning; metals; and the food industry. These sectors accounted for $88.5 \%$ of the $10.3 \mathrm{bcm}$, will be the driving force behind future natural gas demand and are therefore the focus of this study.

Figure 44: Polish High Methane Gas Final Consumption, 2009-2017

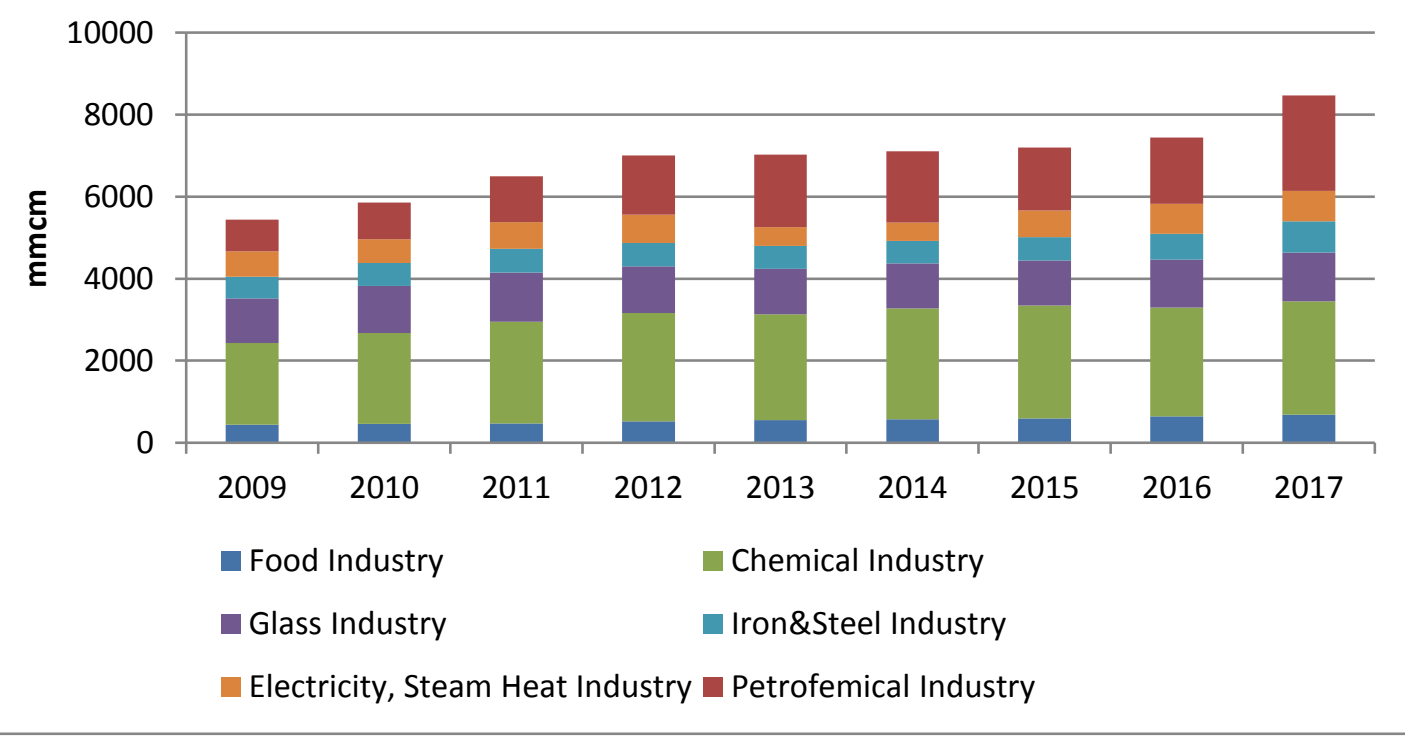

Source: Central Statistical Office of Poland GUS

\subsection{The Polish Chemical, Fertiliser and Petrochemical Industry}

The Polish chemical and petrochemical industry comprises manufacture of coke and refined petroleum products, chemicals, pharmaceuticals and rubber and plastics processing. ${ }^{93}$ It is the largest manufacturing industry by sales, ahead of the automotive and steel industries. It contributes $17 \%$ to the Polish economy and employs around 319,200 persons, who represent $10.7 \%$ of the total workforce. ${ }^{94}$

This sector is the most important consumer of natural gas and consumed $50 \%$ of all industrial gas demand in 2017. ${ }^{95}$ The chemicals industry (NACE 20) is the most significant consumer of natural gas within the Polish chemical industry, consuming $61 \%$ of total chemical industry gas demand. In the energy portfolio, high and low methane gas represented $62.4 \%$, coal $36.4 \%$ and all the other fuels

\footnotetext{
92 Central Statistical Office of Poland GUS

93 NACE 19 - Manufacture of coke and refined petroleum products; NACE 20 - Manufacture of chemicals and chemical products; NACE 21 - Manufacture of pharmaceuticals; and NACE 22 - Manufacture of rubber and plastic products 

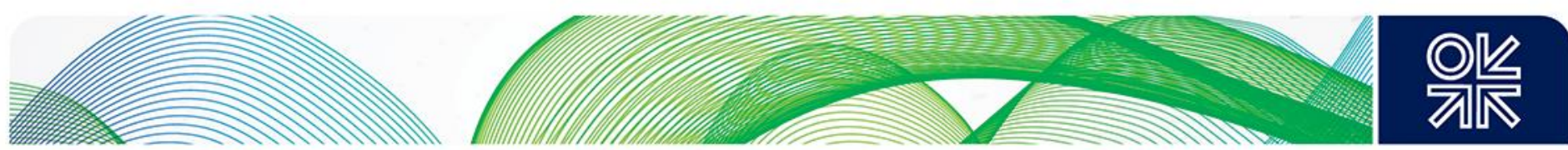

together the remaining $1.2 \%$ in $2017 .{ }^{96}$ This sub-sector is the most energy intensive within the chemical industry.

It is followed by petrochemical refining (NACE 19), which consumes $36 \%$ of total chemical industry gas demand. The two sub-sectors together rely mainly on coal $(62.2 \%)$ and then on gas $(28.7 \%)$, with industrial waste taking the bulk of the rest. ${ }^{97}$

\section{Figure 45: Polish NACE19 \& 20 Energy Demand, by Fuel, 2017}

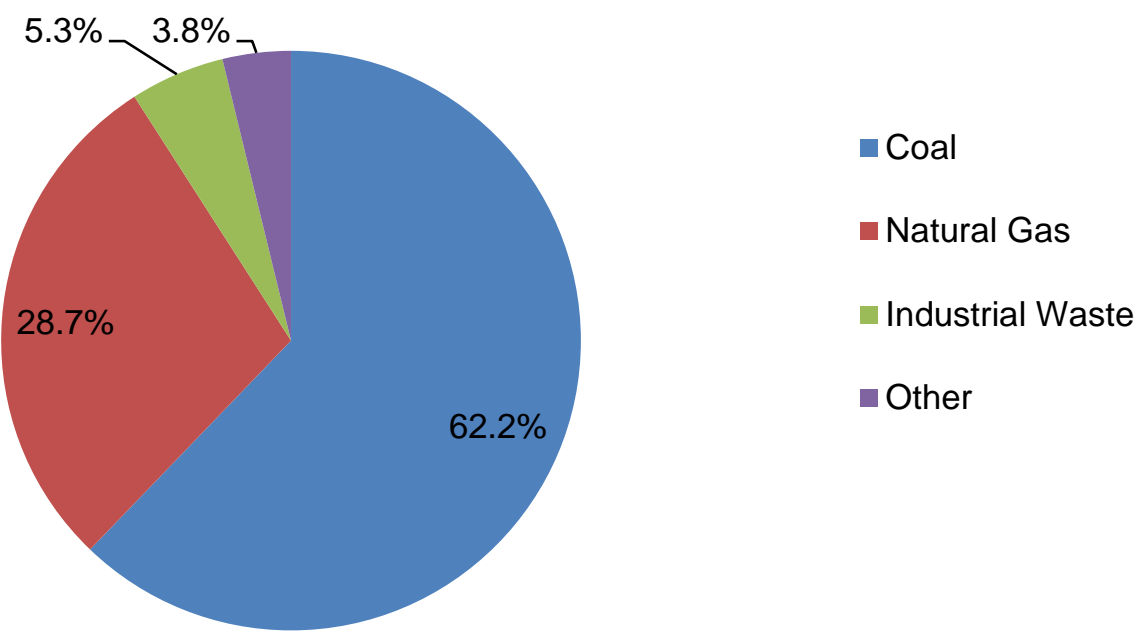

Source: Central Statistical Office of Poland GUS

NACE 21 and NACE 22 are insignificant, consuming together the remaining $3 \%$ of natural gas demand in the chemical and petrochemical sector. For the purpose of this study NACE 19 and NACE 20 will be the focus of further analysis as they represent the bulk of natural gas demand by the chemical and petrochemical sector.

Natural gas demand by the petrochemical industry (NACE19) grew rapidly between 2009 and 2013 but high natural gas prices made an impact on demand in 2014 and 2015 as companies cut costs due to rapidly deteriorating financial results. ${ }^{98}$ However, natural gas demand started to recover from 2016 onwards, and reached $2.3 \mathrm{bcm}$ in 2017 , compared with $0.8 \mathrm{bcm}$ in 2009 , largely due to energy use as refinery throughput increased only by $24 \%$ at the same time.

\footnotetext{
${ }^{96}$ Central Statistical Office of Poland GUS

${ }^{97}$ Central Statistical Office of Poland GUS

${ }^{98} \mathrm{https}$ ://raportzintegrowany2015.orlen.pl/en/financial-results/orlen-in-figures.html
} 

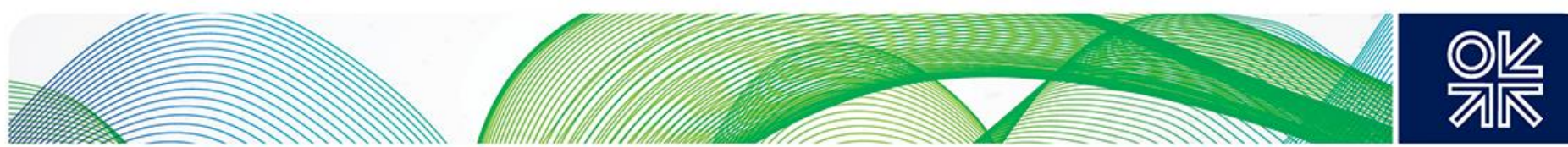

Figure 46: Natural Gas Demand by Polish Chemical and Petrochemical Industry, 2009-2017

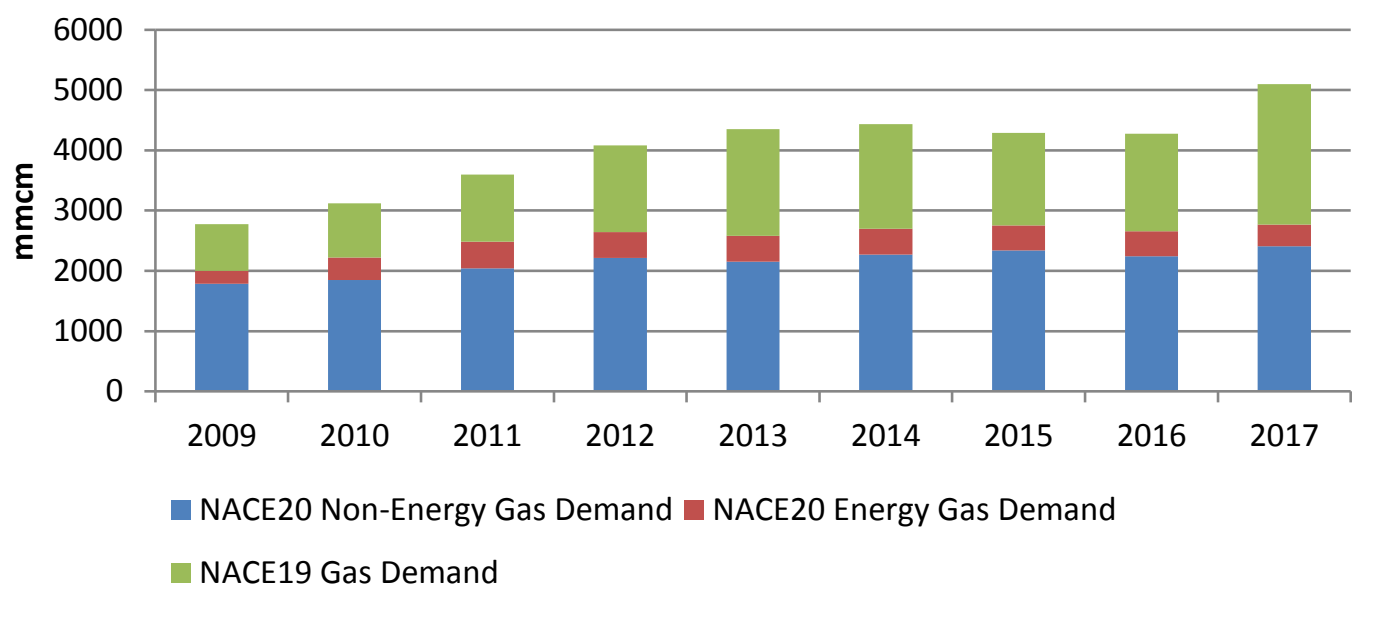

Source: Central Statistical Office of Poland GUS

Figure 47: Natural Gas Demand by Polish Petrochemical Industry, 2009-2017

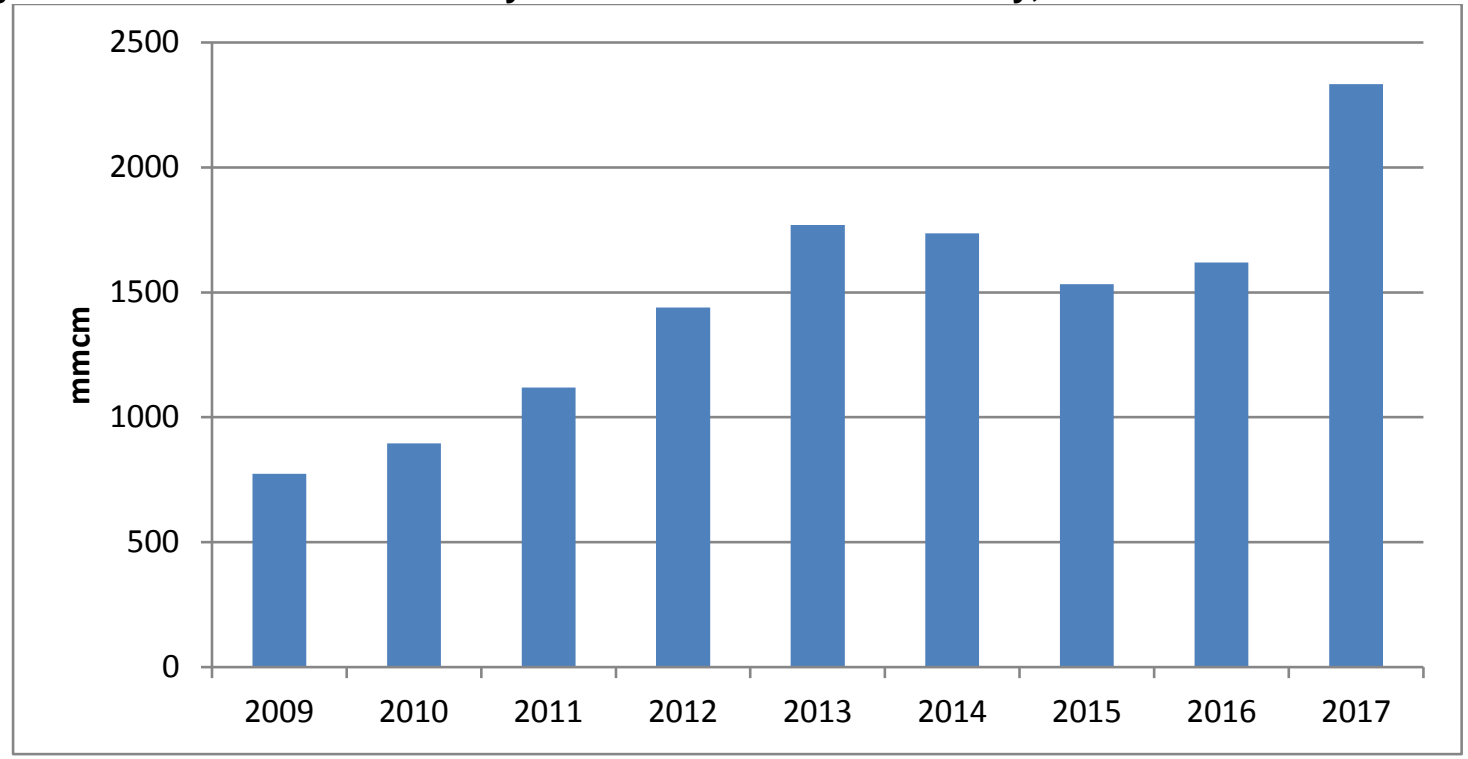

Source: Central Statistical Office of Poland GUS

The NACE20 sector uses natural gas mainly for non-energy purposes as feedstock. Usually, production of fertilisers is highly sensitive to natural gas prices and economic downturns. During the period of high international gas prices in 2012-2014, Polish feedstock gas demand continued to increase regardless of higher gas prices. Non-energy use of natural gas by the fertiliser industry represented $23.5 \%$ of natural gas demand by industry in 2017, according to the Polish statistical office. ${ }^{99}$ This can be explained by the fact that the fertiliser companies receive their gas under long term supply contracts from PGNiG, which reflect the price of domestically produced natural gas rather than international gas prices. Local interviews in Poland suggest that the price of locally extracted natural gas is currently about a third of the price of imported Yamal natural gas. Grupa Azoty, a partly state owned fertiliser company, pays feedstock prices which are based on the price of local gas, which explains the

${ }^{99}$ Central Statistical Office of Poland GUS 

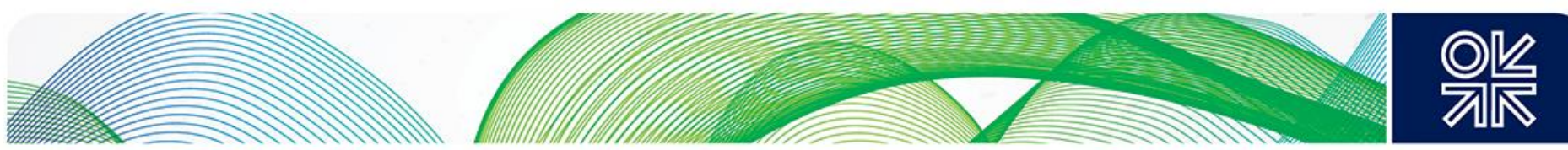

uninterrupted growth in demand over the last decade. The supply contract between PGNiG and Grupa Azoty was signed in June 21, 2017 and will be in operation from October 1, 2018 till September 30, 2020 with a possibility to extend for two more years. ${ }^{100}$ As long as this government stays in power, the special arrangements will prevail.

Figure 48: Polish Crude Oil Processed \& NACE19 Gas Demand Indices, 2009-2017

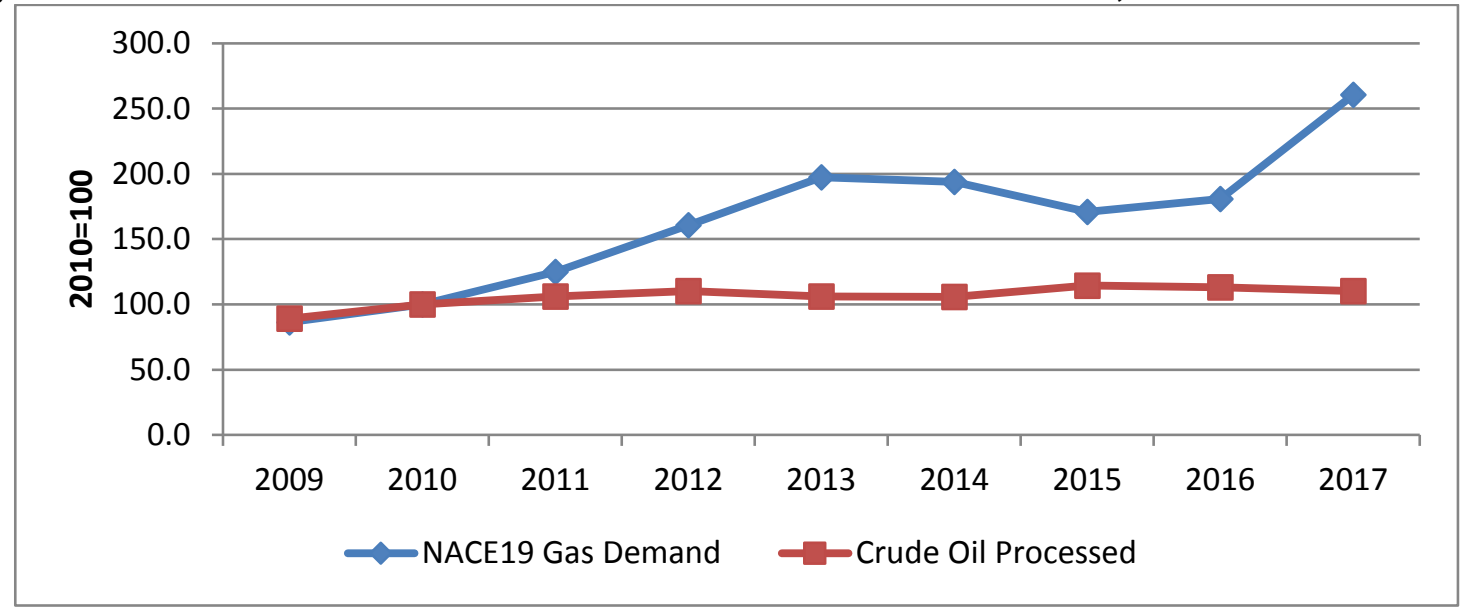

Source: Central Statistical Office of Poland GUS

Figure 49: Polish NACE20 Fertiliser Feedstock Use, 2009-2017

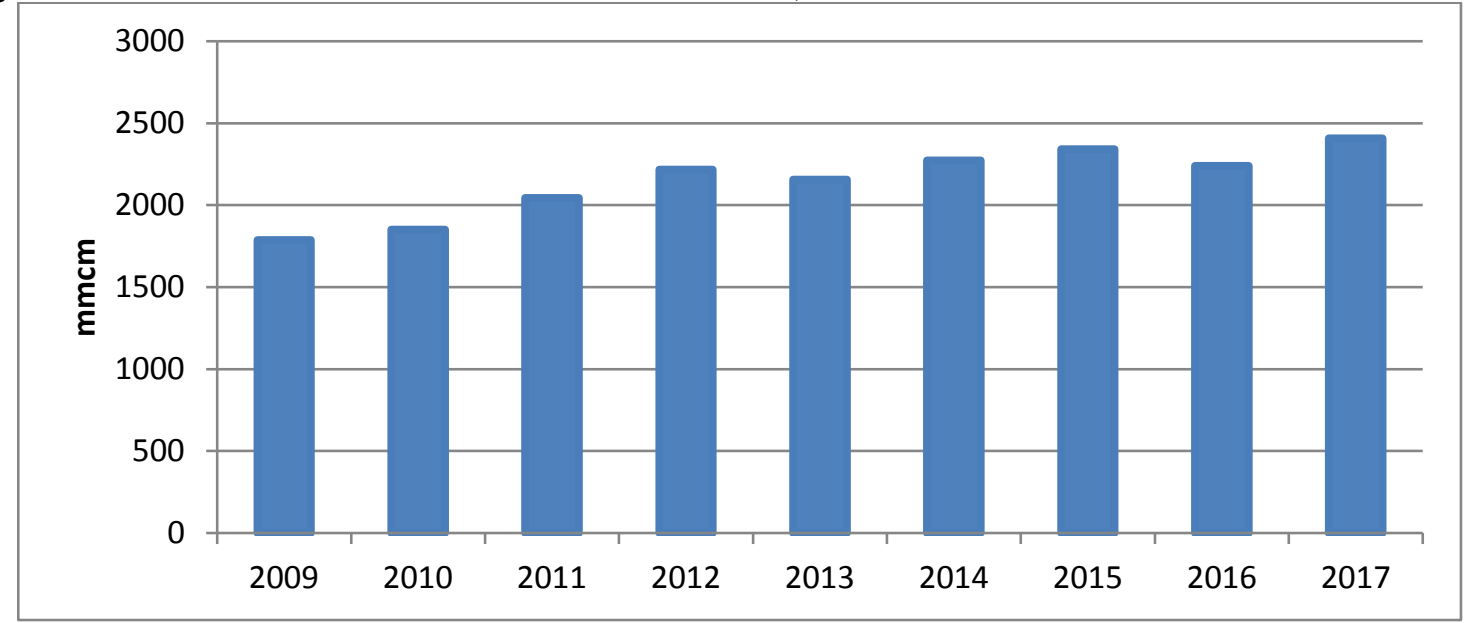

Source: Central Statistical Office of Poland GUS

Consumption of natural gas by NACE20 sector for energy uses is relatively small but it grew rapidly after 2009 till 2011. However, the demand slumped in 2012 and plateaued till 2015 as the sector economised and switched to alternative fuels, largely brown coal.

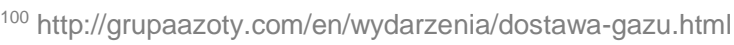



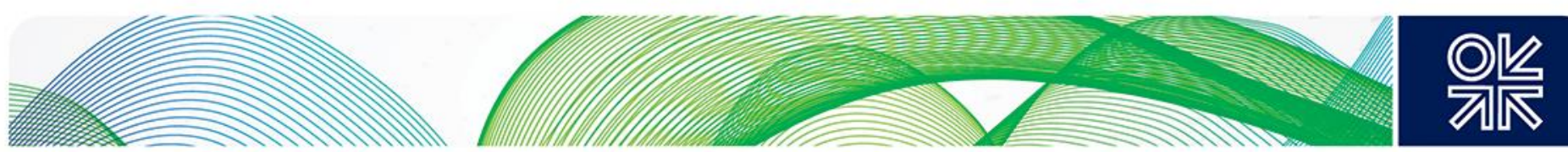

Figure 50: Polish NACE20 Natural Gas Energy Demand, 2009-2017

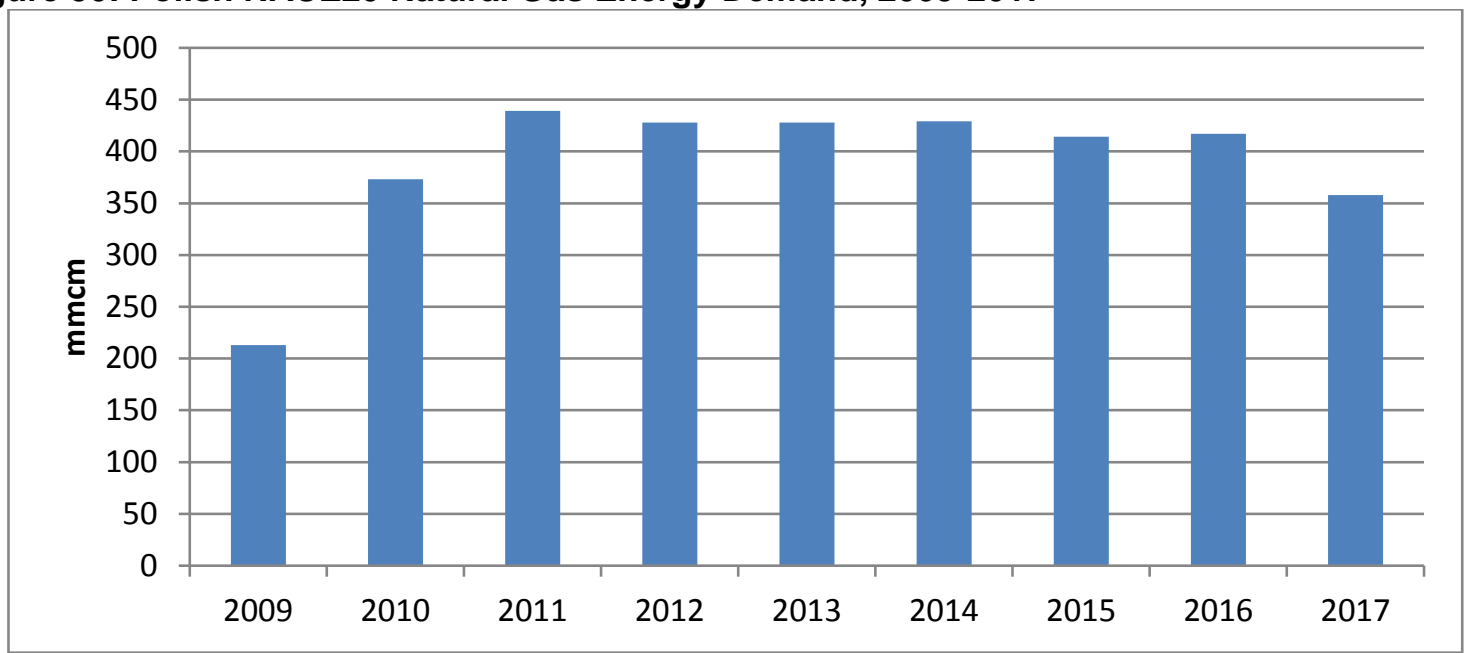

Source: Central Statistical Office of Poland GUS

The index of nitrogen fertiliser production was in full correlation with the index of non-energy gas use over the last decade. Fertiliser production was not impacted by high gas prices and financial results did not deteriorate during that period despite fierce international competition which kept their prices low.

Figure 51: Polish Nitrogen Fertiliser Production \& Non-Energy Gas Demand Indices, 2009-2017

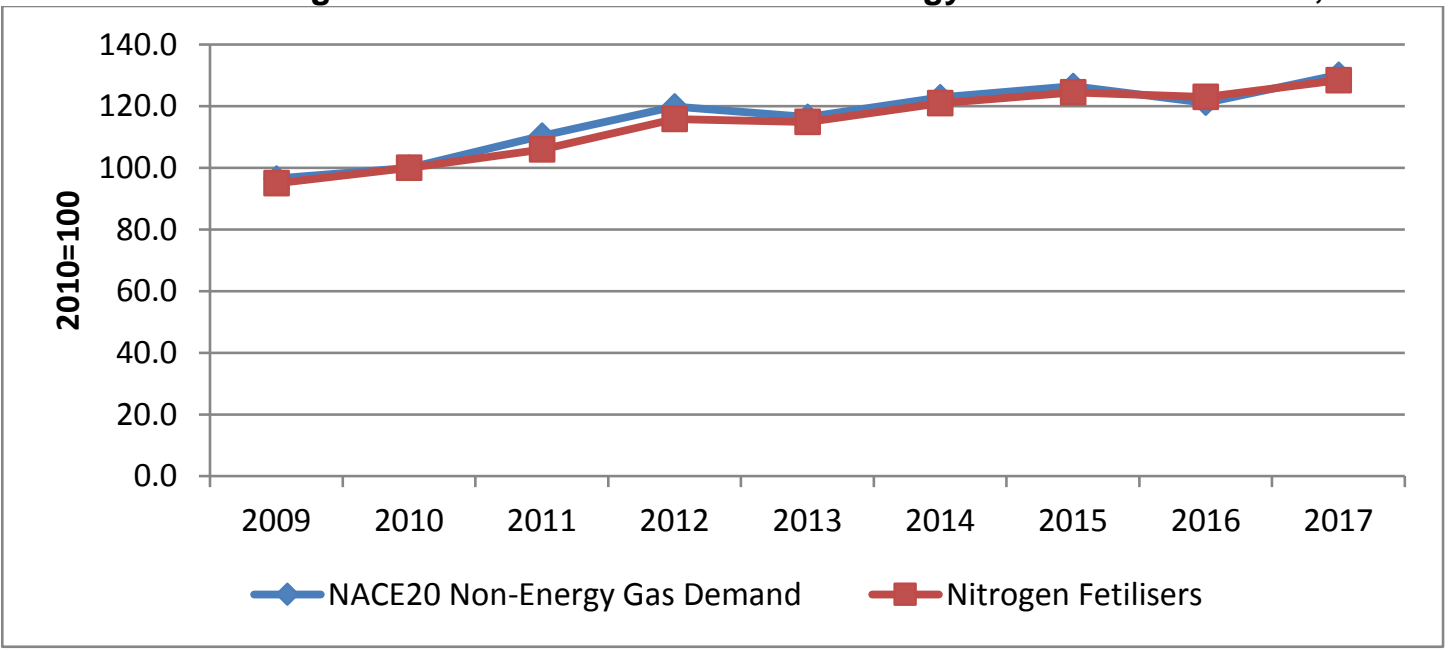

Source: Central Statistical Office of Poland GUS

\section{Forecast}

\section{Advantages}

Poland has fared better economically than most European countries over the last decade and the chemical industry remains one of the most important industrial sectors for the stability and growth of the Polish economy. The sector is one of the most important industrial sectors with high employment and has therefore enjoyed some protection from the government. The preferential pricing of natural gas to the partly state owned company, Grupa Azoty, has helped the sector to keep its competitive advantage. 

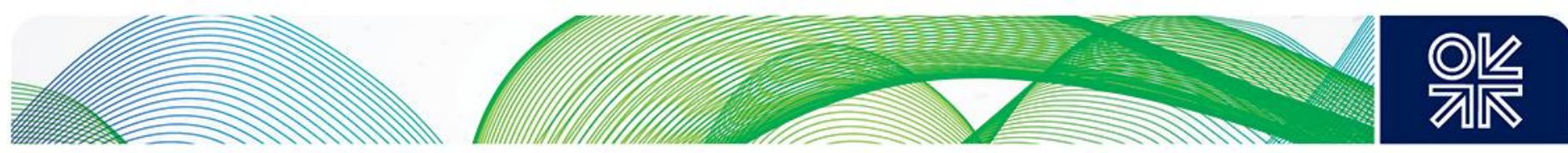

Currently, the EU chemical industry forecast for growth in Europe is expected to be moderate at just $1 \%$, while more than $30 \%$ of jobs will be lost in the European chemical industry by 2030 as a result of slow growth and productivity gains. ${ }^{101}$

\section{Challenges to Growth}

Until now the Polish petrochemical and chemical industry has been sheltered by local policies but progressively the industry will be exposed to similar pressures as the rest of EU as it becomes increasingly dependent on imports of raw materials at international prices. Increasingly, the Polish petrochemical and chemical industry will face major challenges as many chemical companies move eastward, drawn by economic growth and market opportunities in the Far East and the USA. ${ }^{102}$ The industry will have to juggle volatile commodity prices and a delicate economic environment, which will require inventive management as trade flows gradually change direction.

The chemical industry will continue to be a highly energy-intensive industry and international energy and raw material prices will be increasingly similar to those in the rest of Europe. Strategic decisions by the chemical companies will be crucial for thriving business in this new competitive environment. However, to date the Polish industry has showed a lack of flexibility and attracted insufficient investments, partly due to state interference. ${ }^{103}$ This will continue to be a hindrance on the sector's future development. The question is whether the sector will be able to secure the necessary investment in research and innovation to ensure future competitiveness. Poland has a poor record of investment in R\&D. The Polish chemical industry is integrated with local industry but the scope of products is insufficient to cater for domestic demands which have resulted in a rapid increase in dependency on imports. Many local products also struggle to compete on international markets. The question is whether the local industry will be able to maintain its competitiveness even in the domestic market.

Recent indicators show that the sector has been struggling since 2012, showing disappointing financial results. ${ }^{104}$

Another challenge for the chemical sector is the current complex regulatory framework which is increasing cumulative regulatory costs and discourages investment. ${ }^{105}$

In relation to energy and climate change, the conditions for trading in greenhouse gas emissions will have a significant impact on Polish chemical companies and will put weighty financial burden on the sector. ${ }^{106}$

\section{Reference Scenario}

Given the current economic forecasts for Poland and the EU-28 of a growth level between $3.5 \%$ and $2 \%$ in the next decade, ${ }^{107,108}$ it is feasible that the Polish petrochemical and chemical industry will show in average a $0.5 \%$ growth for the next five years and then stagnate for the rest of the decade. Moreover, the fertiliser and petrochemical industry's reliance on natural gas as feedstock will make it struggle in the future to compete with products which will be produced near natural gas fields in Central Asia or the USA where prices of natural gas will be significantly lower than in Central Europe. In the reference scenario it is expected that the non-energy use of natural gas for fertiliser feedstock will not exceed

\footnotetext{
${ }^{101}$ Chemical Industry Vision 2030: A European Perspective, AT Kearney

$102 \mathrm{http}: / /$ www.atkearney.co.jp/chemicals/ideas-insights/article///asset_publisher/LCcgOeS4t85g/content/chemical-industryvision-2030-a-european-

perspective/10192?inheritRedirect=false\&redirect=http\%3A\%2F\%2Fwww.atkearney.co.jp\%2Fchemicals\%2Fideasinsights\%2Farticle\%3Fp_p_id\%3D101_INSTANCE_LCcgOeS4t85g\%26p_p_lifecycle\%3D0\%26p_p_state\%3Dnormal\%26p_p_ mode\%3Dview\%26p_p_col_id\%3Dcolumn-2\%26p_p_col_count\%3D1

${ }^{103} \mathrm{https}: / /$ www.products.pcc.eu/en/blog/chemical-industry-in-poland-what-changes-are-coming/

104 https://raportzintegrowany2015.orlen.pl/en/financial-results/orlen-in-figures.html

${ }^{105}$ https://ec.europa.eu/docsroom/documents/17784/attachments/1/translations/en/.../pdf !

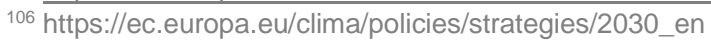

107 https://ec.europa.eu/info/sites/info/files/economy-finance/ip096_en.pdf

$108 \mathrm{https}: / /$ data.oecd.org/gdp/gdp-long-term-forecast.htm
} 

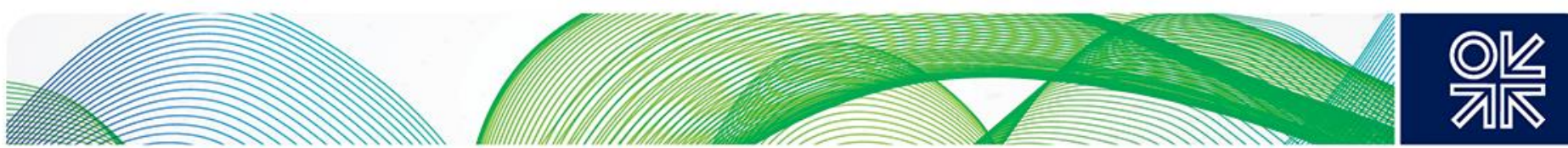

$2.5 \mathrm{bcm} / \mathrm{y}$ and is likely to start to decline from 2025 onwards. It is expected that gas demand by the chemical industry in total will grow marginally till 2023, followed by stagnation and from 2025 onwards by a decline. The chemical and petrochemical industry, including feedstock, is forecast to consume $4.5 \mathrm{bcm} / \mathrm{y}$ by 2030 . Annual gas demand is expected to shrink by some $0.6 \mathrm{bcm} / \mathrm{y}$ by $2030 \mathrm{compared}$ to 2017.

\section{Figure 52: Polish Reference Petrochemical and Chemical Industries Natural Gas Demand} Forecast 2016-2030

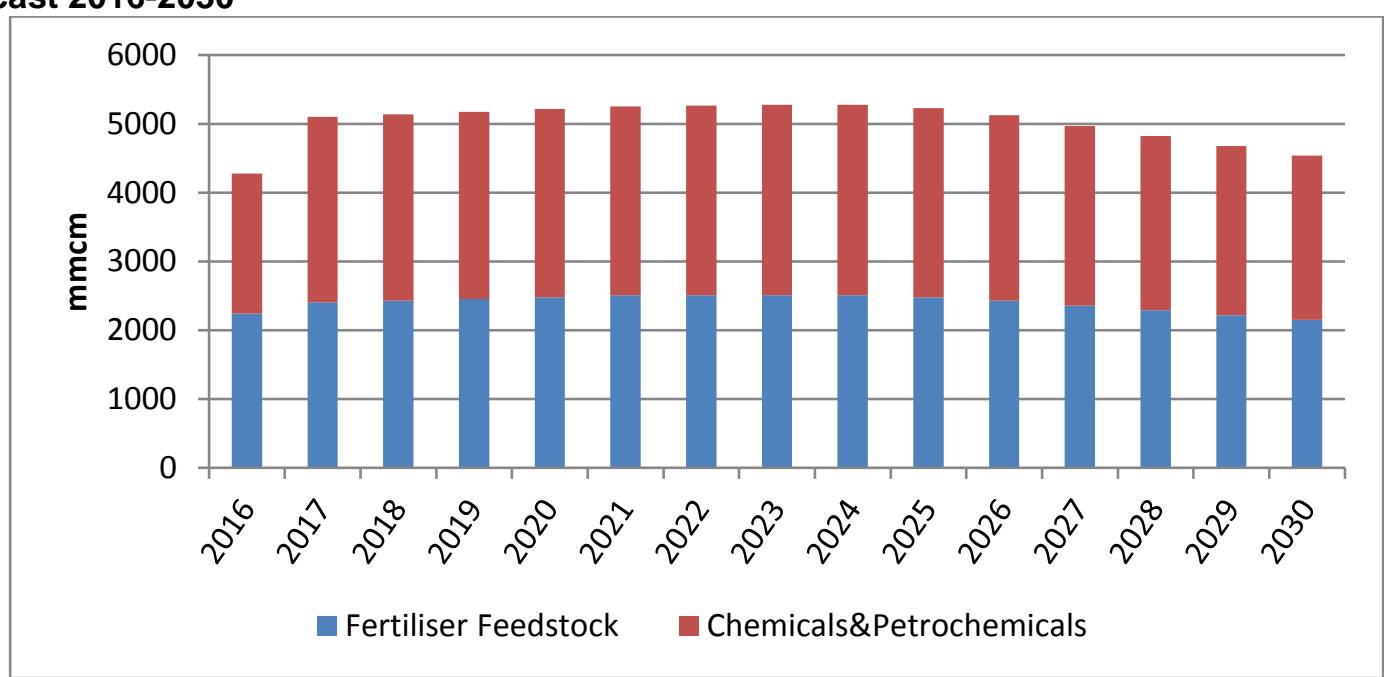

Source: Author's forecast

\section{Optimistic Scenario}

In the event that the Polish petrochemical and chemical industry grows at the same rate as the rest of the EU chemical industry, due to the local support driven by buoyant domestic industrial growth and preferential pricing granted by the Polish regulator, gas demand by the sector will continue to grow on average by some $1 \% / y$ throughout the forecasting period. However, feedstock demand will plateau at the current level in the best case. The optimistic scenario foresees gas demand reaching some $5.5 \mathrm{bcm} / \mathrm{y}$ by 2030, which represents an incremental increase of $0.4 \mathrm{bcm} / \mathrm{y}$ over 2017.

Figure 53: Polish Optimistic Petrochemical and Chemical Industries Natural Gas Demand Forecast, 2016-2030

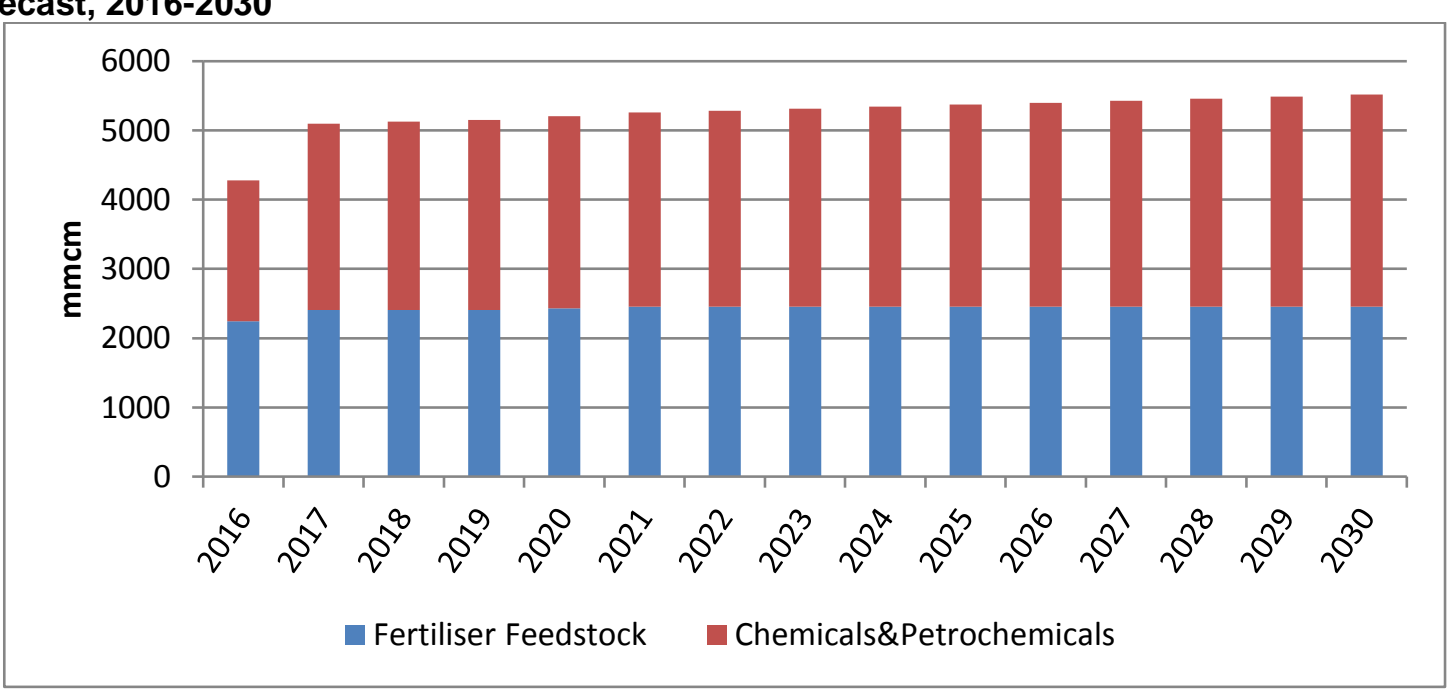

Source: Author's forecast 

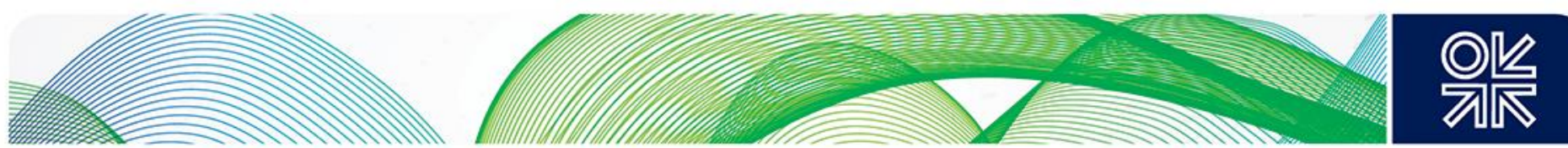

\subsection{The Polish Steel Industry}

The Polish steel industry in this report comprises the NACE 24 and NACE 25 sectors. ${ }^{109}$ It ranks fifth highest of the EU's steel producers. Currently, the sector employs 332,800 people, $12.6 \%$ of the total Polish industrial workforce. ${ }^{110}$ The steel industry is still considered to be the backbone of local industry, accounting for over $10 \%$ of all industry sales. ${ }^{111}$ In 2017 , Polish steelworks produced a total of 10.3 million tonnes of raw steel, which translates into a growth of almost $15 \%$ on 2016 due to the increase in steelworks capacity. Around $44.8 \%$ of crude steel is produced in electric furnaces. ${ }^{112}$ This is significantly much higher proportion than in the Czech and Slovak republics. Poland's steel sector consists of a mix of domestic and foreign owned companies and is concentrated among a handful of producers, with ArcelorMittal alone accounting for over $70 \%$ of Poland's steelmaking capacity. ${ }^{113}$ The future development of the steel industry will thus largely depend on ArcelorMittal's plans.

The steel plants usually produce their own electricity in coal-fired plants, which explains the continuous dependency on coal by this sector. This reliance has grown since 2009 when coal represented $50.7 \%$ of its energy balance while natural gas took the remaining $49.3 \%$. In 2017 , coal's share grew to $53.7 \%$ while gas's share dropped to $46.3 \%$.

Figure 54: Polish Iron and Steel Industry Energy Demand, \% Share by Fuel, 2017

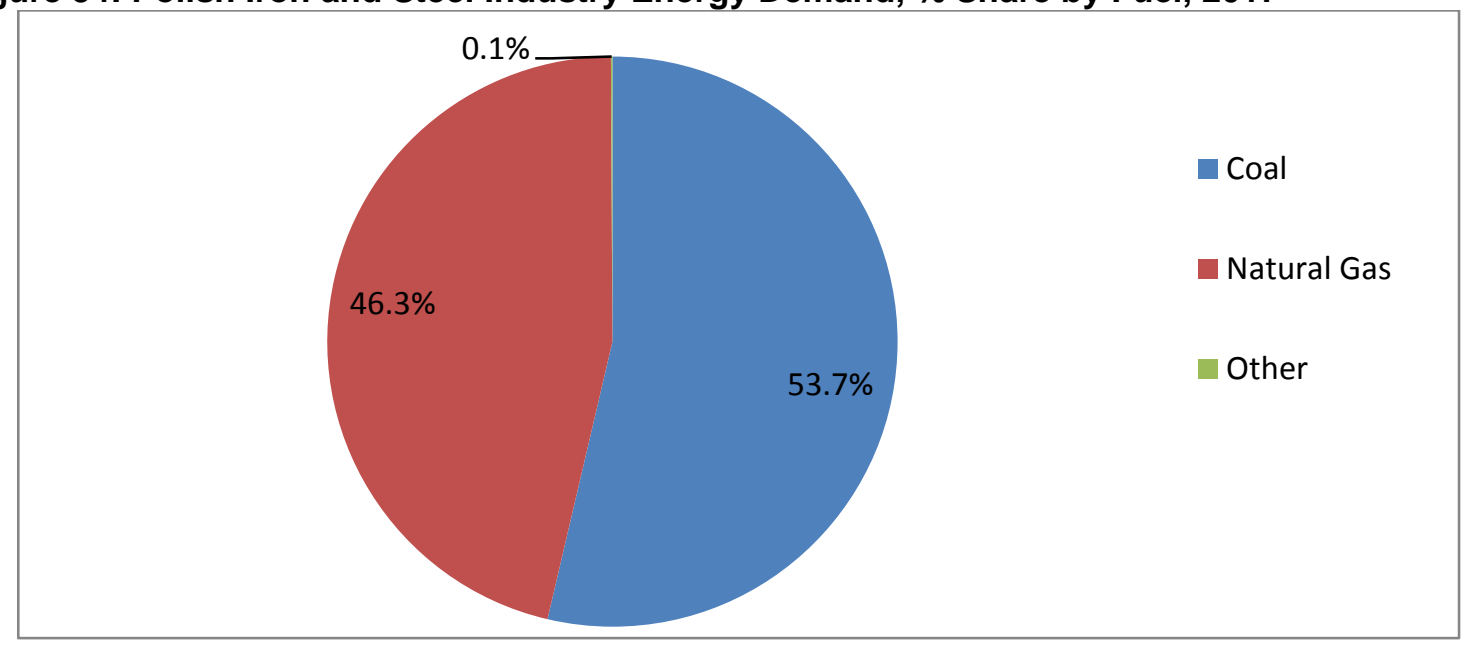

Source: Central Statistical Office of Poland GUS

The energy intensity of crude steel improved markedly between 2006 and 2009, declining by $16.7 \%$. This is largely due to a steep decline in steel production and an even steeper decline in energy consumption due to radical cost cutting during the same period. Crude steel production dropped by $29 \%$. However, in the following years, production of steel started to slowly recover while the energy intensity flattened. Since 2009, there has been no improvement in energy intensity in the production of crude steel which has remained around 0.2 toe/tonne. The primary metals industry as a whole shows similar development.

\footnotetext{
${ }^{109}$ NACE24 - Manufacture of Basic Metals, Metallurgy, and Casting of Metals, NACE 25-Manufacture of Fabricated Metal Products, except Machinery and Equipment.

${ }^{110}$ Central Statistical Office of Poland GUS

111 Central Statistical Office of Poland GUS

112 https://www.worldsteel.org/en/dam/jcr:f9359dff-9546-4d6b-bed0-996201185b12/World+Steel+in+Figures+2018.pdf

$113 \mathrm{https}: / /$ corporate.arcelormittal.com/ /media/Files/A/ArcelorMittal/sdr-2017/poland-sustanibility-report-2017.pdf
} 

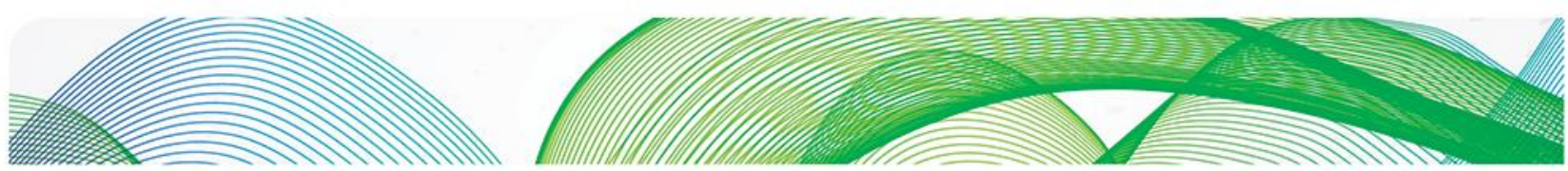

Figure 55: Polish Crude Steel Energy Intensity, 2006-2016

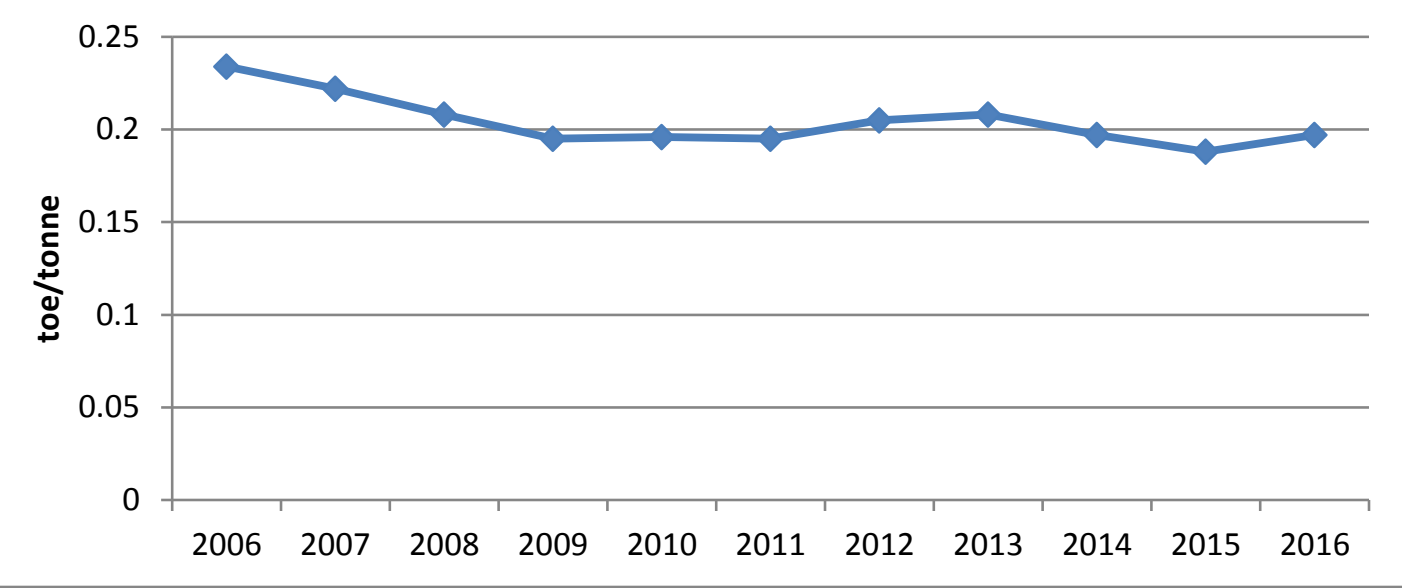

Source: Central Statistical Office of Poland GUS

The sector has been hit by the international recession and only restored its production to pre-2007 levels in 2017. Over the last decade, there have been periods of growth and decline, but the sector has continuously lost share in the manufacturing industry.

The global recession in the metallurgy sector brought about a decline in revenues in 2009. The impact of the second wave of the recession in 2013 was moderate. Since 2014, revenues have been growing. Nevertheless, a clear trend is evident that the industry has managed to show positive growth in sales since 2009, with the one exception of 2013.

Figure 56: Revenues and Profits by Iron and Steel Industry, 2005-2016

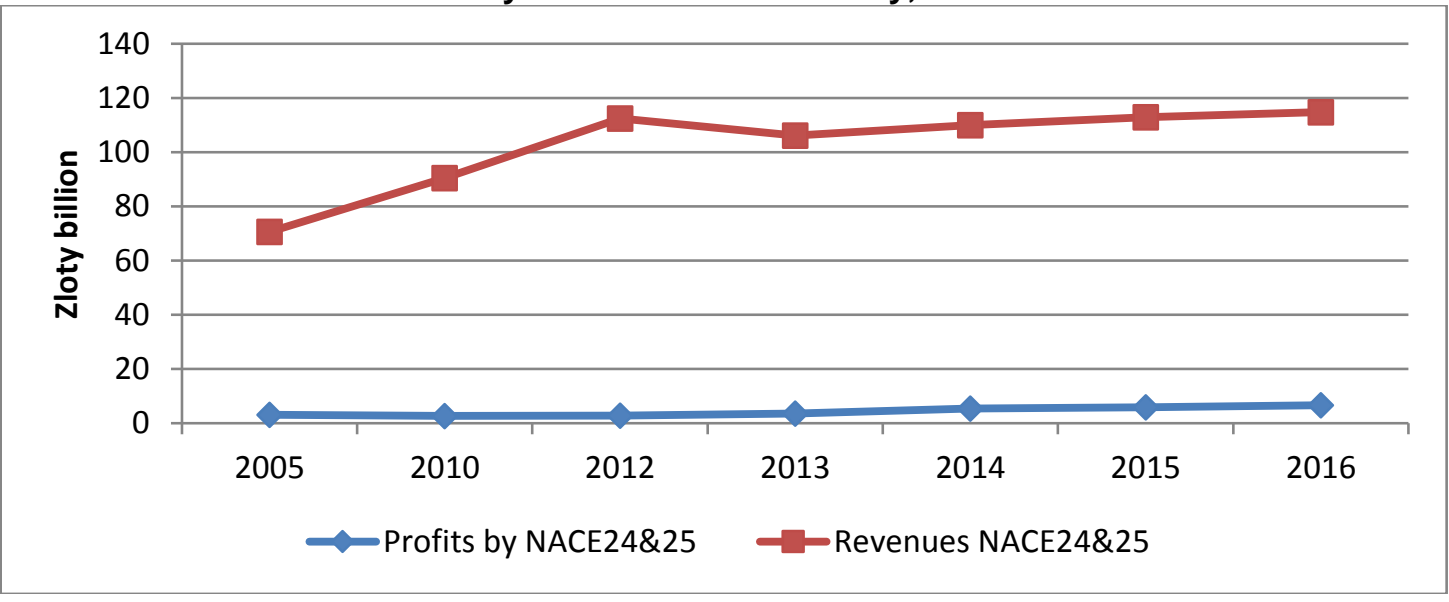

Source: Central Statistical Office of Poland GUS

Profits by NACE24 went into the red post 2010 but started to recover after 2014, due to partial restructuring of the sector. The NACE25 sector has shown higher profitability and gradual improvements till 2015. However, profits dipped in 2016 as competition from imported cheap products hit profitability of the subsector. The profitability of both of the subsectors remains very low. This will lower investment in more efficient technology and R\&D in future, making the sector less competitive. 

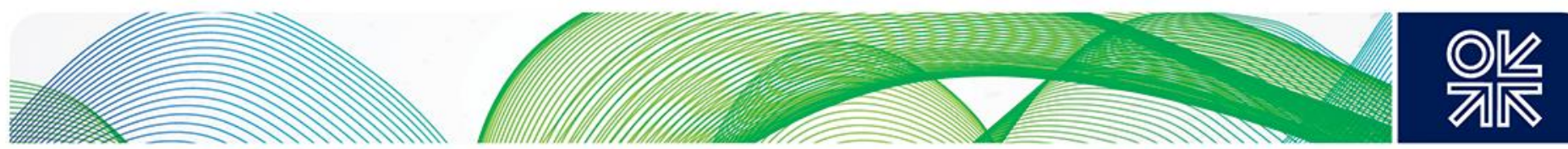

Figure 57: Polish Iron and Steel Industry Profits, 2005-2016

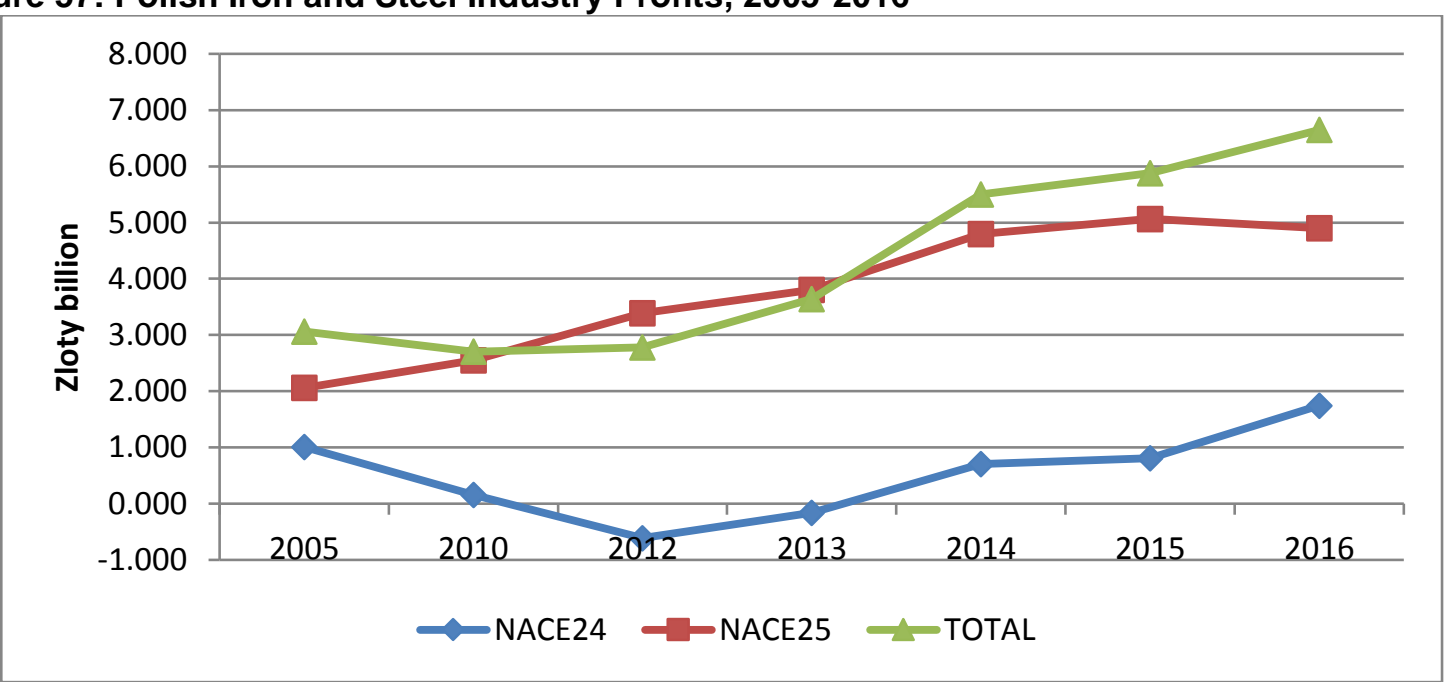

Source: Central Statistical Office of Poland GUS

The Polish steel industry continues to be a major polluter and so far insufficient investment has been channelled into environmental technology as coal continues to be the major fuel. Environmental pressures and charges have, however, started to burden the sector over the last few years. The leading steel producer, ArcelorMittal, has invested over PLN 7 billion ( $\$ 1.9$ billion ${ }^{114}$ ) in the modernization of its plants yet this was largely directed towards increasing production capacity. Unsurprisingly, the company has so far failed to meet environmental requirements. In 2017, some improvements were achieved due to modernisation of the first furnace at the mill in Dabrowa Gornicza. Since then, ArcelorMittal has started a number of other projects which should improve its environmental footprint and move towards building vertically integrated plants. Such developments would lower the cost of the environmental burden on the company and may prompt replacing coal by natural gas.

Natural gas demand by the steel sector was closely correlated to the development of steel industry output till 2013, but gas demand has continued to stagnate since then despite the recovery of steel sector production. This is largely because steel mills do not use natural gas in their production process but only for energy use. In 2017 , the sector used $0.77 \mathrm{bcm}$ of natural gas, up from $0.53 \mathrm{bcm}$ in 2009 . In 2017 , the steel industry was responsible for $4.7 \%$ of the country's direct gas consumption, $7.5 \%$ of total industrial gas demand.

\footnotetext{
114 https://corporate.arcelormittal.com/ /media/Files/A/ArcelorMittal/sdr-2017/poland-sustanibility-report-2017.pdf
} 

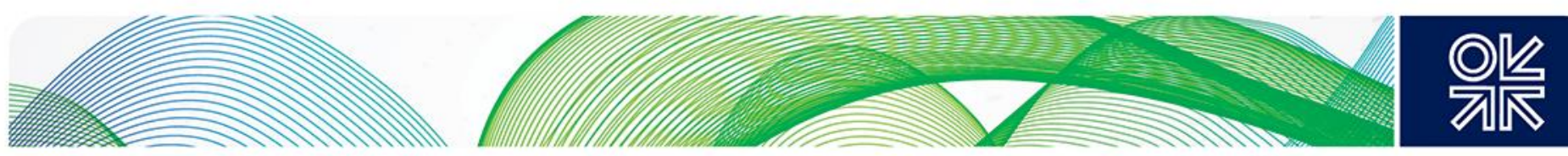

Figure 58: Polish High Methane Gas Consumption by Steel \& Metal Industry, 2009-2017

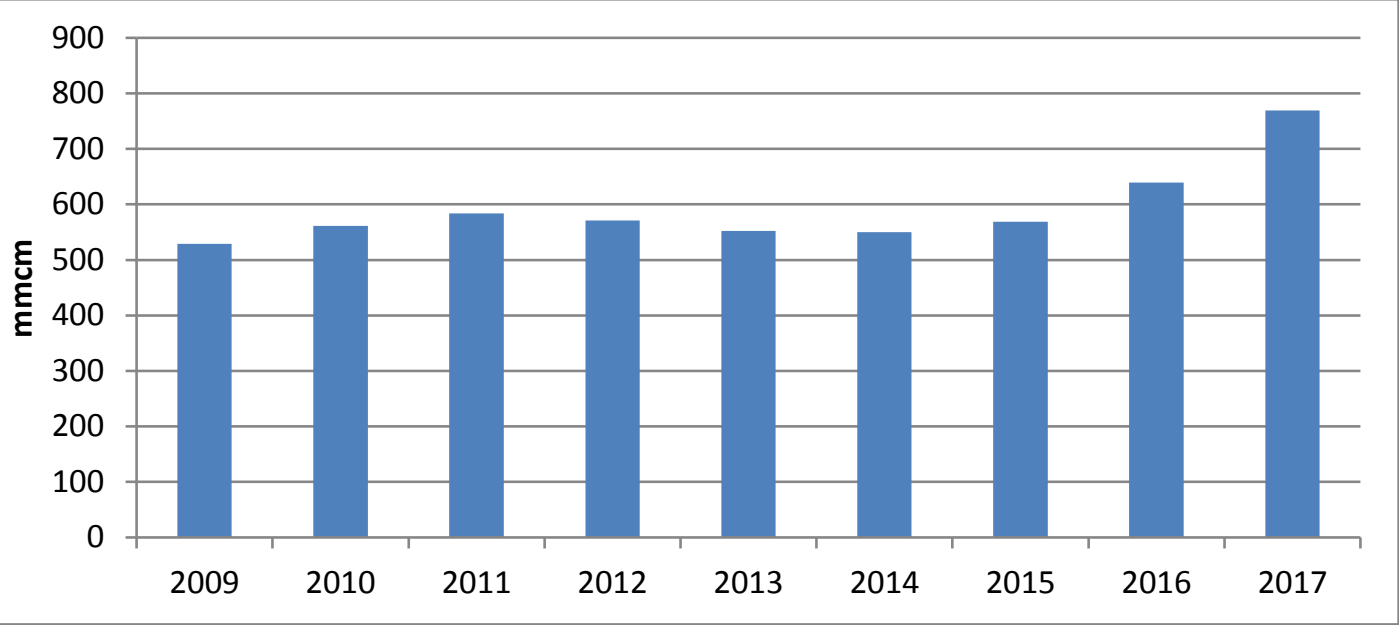

Source: Central Statistical Office of Poland GUS

Figure 59: Polish Steel Production \& NACE24 Gas Demand Indices, 2009-2017

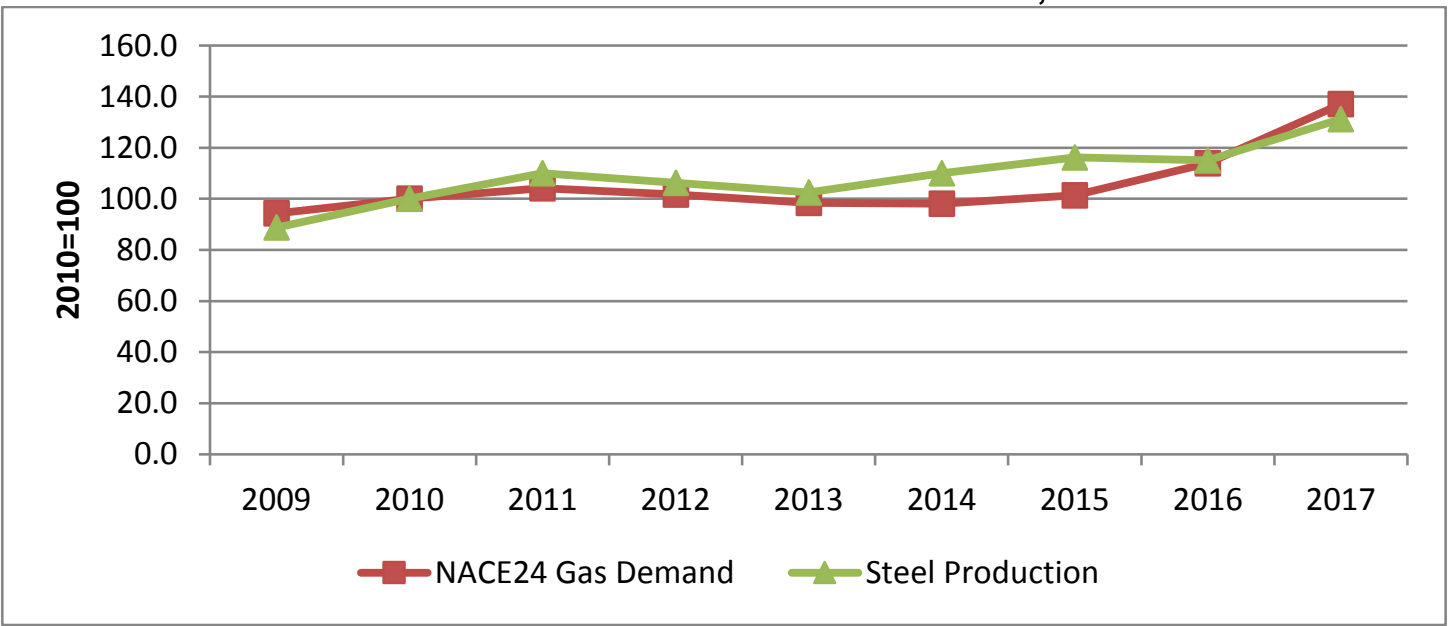

Source: Central Statistical Office of Poland GUS

\section{Forecast}

\section{Advantages}

Compared to the EU-28 average, the Polish steel industry has done better over the last decade. ${ }^{115}$ Since the industry is geared towards supplying the local construction industry, which has been booming, the steel industry has been protected from a steep decline, while the rest of the EU steel industry suffered. Despite the decline in 2012-2013 the Polish steel sector has been recovering. On the positive side, due to latest investments and strong economic growth it is expected to grow in the mid-term. Civil engineering projects, which are planned to continue, ${ }^{116}$ will drive the Polish steel industry through to 2030. Continuous domestic and EU economic growth will also drive demand for steel products. ${ }^{117}$ The transport sector is likewise an important user of Polish steel products, which will show a continuous growth, with the highest increase in 2025 to $2030 .{ }^{118}$

\footnotetext{
115 http://www.eurofer.org/News\%26Events/PublicationsLinksList/201806-AnnualReport.pdf

$116 \mathrm{https} / / /$ ec.europa.eu/regional_policy/en/projects/major

$117 \mathrm{https}: / /$ stats.oecd.org/viewhtml.aspx?datasetcode=EO103_LTB\&lang=en

${ }^{118} \mathrm{https}: / /$ eu-smartcities.eu/sites/default/files/2018-03/pwc-five-trends-transforming-the-automotive-industry.compressed.pdf
} 

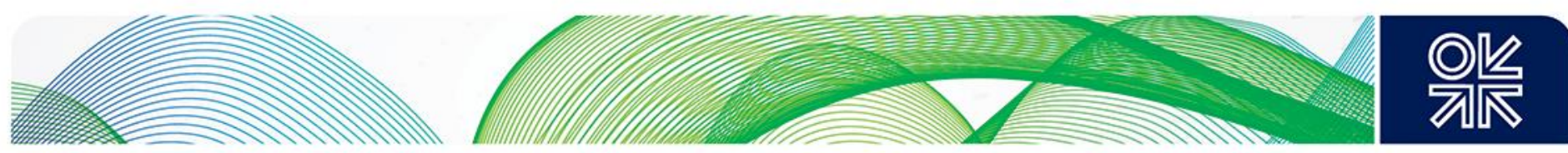

\section{Challenges to Growth}

The Polish steel industry is likely to face increasing competition from cheaper imports from outside the EU unless the industry moves toward value-added steel products. The EU measures on anti-dumping and anti-subsidy against imports of metallurgical products from third countries will play a decisive role in the future of the steel industry in the EU in general.

Companies have yet to invest in environmental technology, which is likely to slow down the expansion of the sector. The 2030 targets set in the greenhouse gas trading system (EU ETS) could put a heavy burden on the steel sector and could lead to relocation outside the EU to countries and regions with inadequate climate protection policy. ${ }^{119}$ The Polish steel industry has not yet cut sufficiently its emission and companies are likely to struggle as they will lack the needed investments.

One of the major challenges for the Polish steel industry will be whether this low profit sector will be able to access finance to sustain investment in research and development and stay ahead in innovation and quality to be able to align its products with shifting markets. The low profitability combined with high energy intensity of the sector is likely to have a dampening effect on the sector's growth.

Higher gas prices, especially after 2022 when Poland diversifies its gas imports towards more expensive sources, are likely to slow down the future growth in gas demand by the steel sector. After 2022, when Poland plans to replace Russian gas with LNG and Norwegian gas imports, ${ }^{120}$ the price of natural gas will be higher than at the European hubs. ${ }^{121}$ Cheaper coal will continue to be the main fuel used by the steel industry for the next decade while natural gas is likely to play a complementary role.

\section{Reference Scenario}

Given the current economic forecasts for Poland and the EU-28 of a growth level between $3.5 \%$ and $2 \% / y$ in the next decade, ${ }^{122123}$ it is feasible that the Polish steel industry will grow on average at $1 \% / y$ till 2030 as some modernised plants will be able to compete within the EU. However, US tariffs on aluminium and steel will have a dampening effect on the whole European steel industry, limiting growth even in Poland. It is expected that the natural gas demand by the steel industry will plateau after 2019 for the following five years and only then will start to grow at a moderate rate of $1 \% / y$ till 2030 . In the reference forecast, it is not expected that the sector will switch quickly to natural gas as the current attempt by ArcelorMittal is to create circular economies, using industrial and by-product gases rather than switching to natural gas within next decade. By 2030 , natural gas consumption by the steel sector could reach $0.82 \mathrm{bcm} / \mathrm{y}$, some $0.05 \mathrm{bcm} / \mathrm{y}$ higher than in 2017 .

\section{Optimistic Scenario}

In case of a political change leading to a willingness to meet environmental quotas, the steel sector would need to gradually switch to natural gas away from coal over the next decade. This would require much higher investment, especially by ArcelorMittal. This scenario also envisages a shift to value added steel products which will make Poland more competitive on international markets, especially in Central Europe. Exports will then drive steel production. In such a case, gas demand by the steel industry will see a continuous growth, which will accelerate from 2025 onwards, reaching some $0.92 \mathrm{bcm}$ in 2030 , $0.15 \mathrm{bcm} / \mathrm{y}$ higher than 2017 .

\footnotetext{
119 https://ec.europa.eu/clima/policies/strategies/2030_en

120 https://www.ft.com/content/6790a1dc-038c-11e9-99df-6183d3002ee1

121 http://en.pgnig.pl/news/-/news-list/id/pgnig-2018-another-year-of-declining-gas-import-volumes-from-russia-and-growing-Ingimports/newsGroupld/1910852

122 https://ec.europa.eu/info/sites/info/files/economy-finance/ip096_en.pdf

${ }^{123} \mathrm{https}: / /$ data.oecd.org/gdp/gdp-long-term-forecast.htm
} 

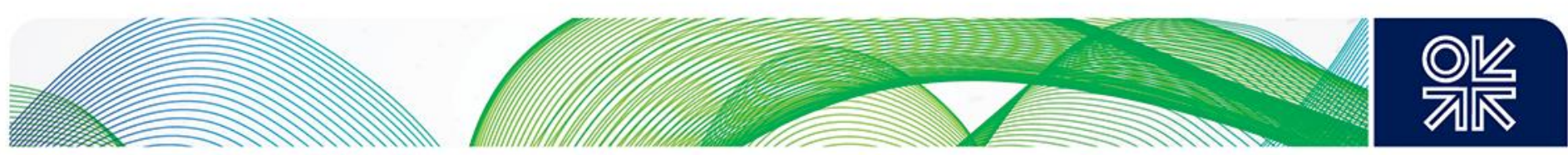

Figure 60: Polish Reference Iron \& Steel Industry Natural Gas Demand Forecast 2016-2030

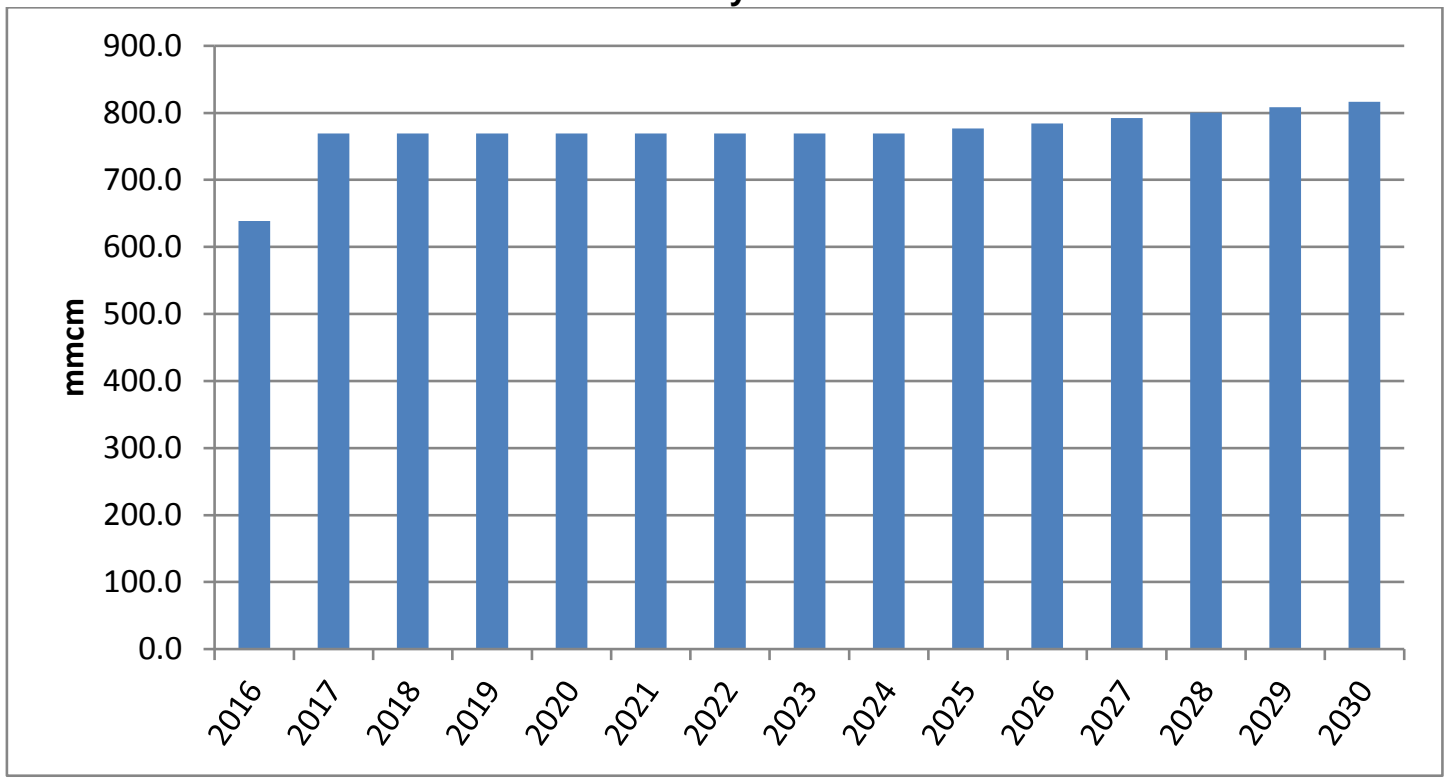

Source: Author's forecast

Figure 61: Polish Optimistic Iron \& Steel Industry Natural Gas Demand Forecast 2016-2030

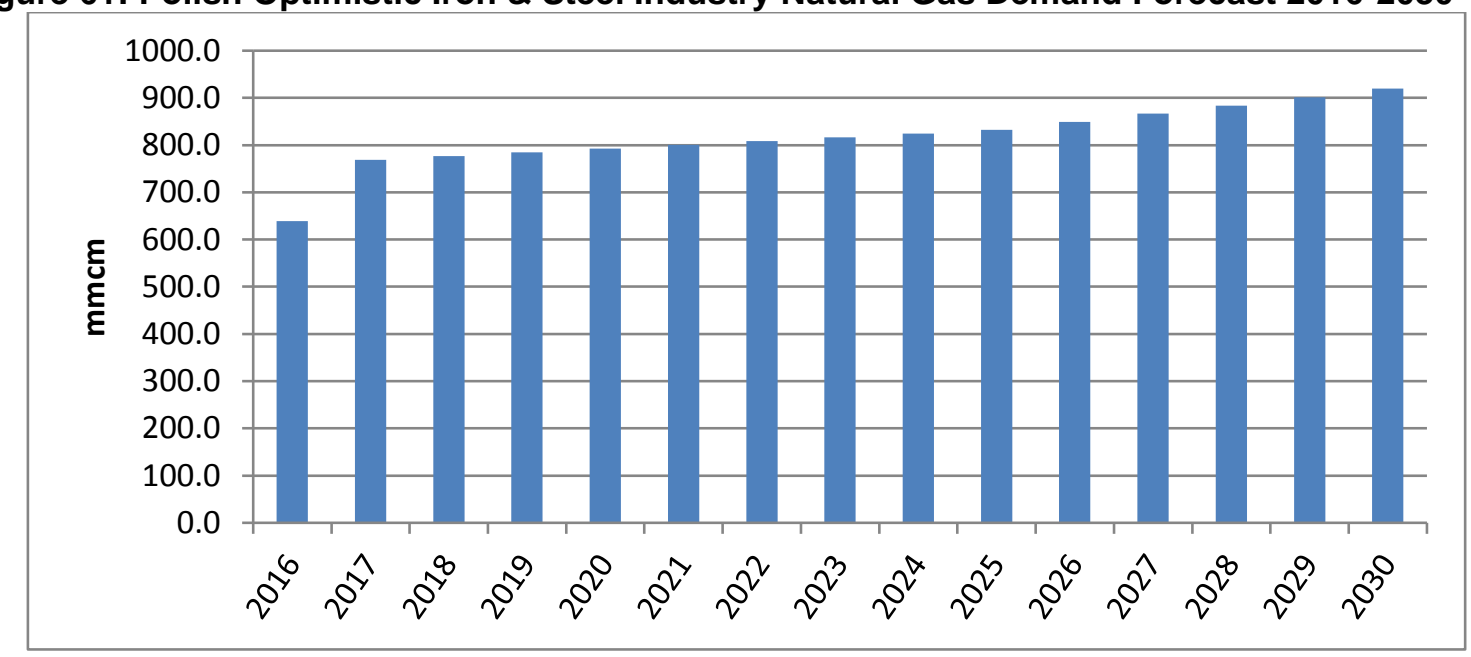

Source: Author's forecast

\subsection{The Polish Paper and Pulp Industry}

The Polish paper and pulp industry (NACE $17^{124}$ ) is not a large or key sector - representing only $2.9 \%$ of total industrial production in 2017 - but it has shown much faster growth than the rest of the industry over the last decade. The sector is interconnected with other local manufacturing industry, especially with the booming packaging and printing industry and with the provision of hygienic products. In 2017, the sector employed 64,300 people ( $0.4 \%$ of total employment). It has enjoyed growing investment from abroad as the sector is dominated by companies with foreign ownership.

The paper industry is investment- and energy-intensive, but paper mills are increasingly recovering waste from the production of pulp (bark, sawdust, chips, and liquor) or paper. In 2017, a third of the energy use by the sector was recovered waste and solid biomass. Natural gas represented $9.7 \%$ and

124 NACE17 includes manufacture of pulp, paper and paperboard and manufacture of articles of paper and paperboard. 

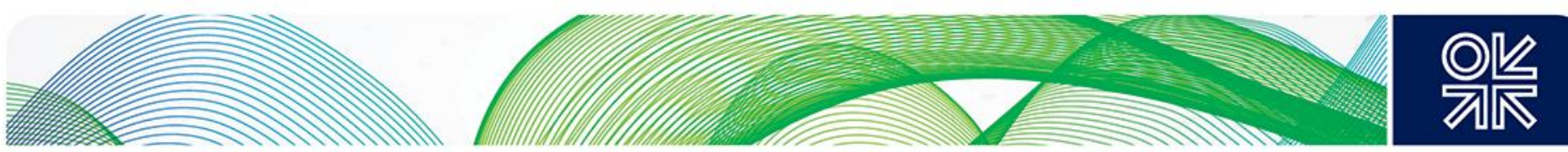

low methane gas $4 \%$ of energy use. The industry has attracted moderate investment but the current paper mills have not been modernised sufficiently and the energy efficiency of producing paper remains high.

Most of the local paper and pulp leading companies are owned by international firms and as a result they have seen an initial inflow of investment, restructuring and modernisation. For instance at Mondi's Świecie mill, the lime kiln was converted to gas from heavy fuel oil in 2015. However, the industry is energy-intensive. Despite some efforts immediately post-2008 the energy intensity of producing a tonne of paper continues to be relatively high. The energy intensity declined between 2008 and 2010 from 0.56 toe/t to 0.44 toe/t as a result of some leading companies introducing energy saving measures and investing in new technologies. However, energy intensity started to climb up again and only dropped in 2014 and 2016 to 0.45 toe/t. This, however, means that the energy intensity of producing paper is twice as high as in the neighbouring Czech Republic.

Figure 62: Polish Paper Energy Intensity, 2006-2016

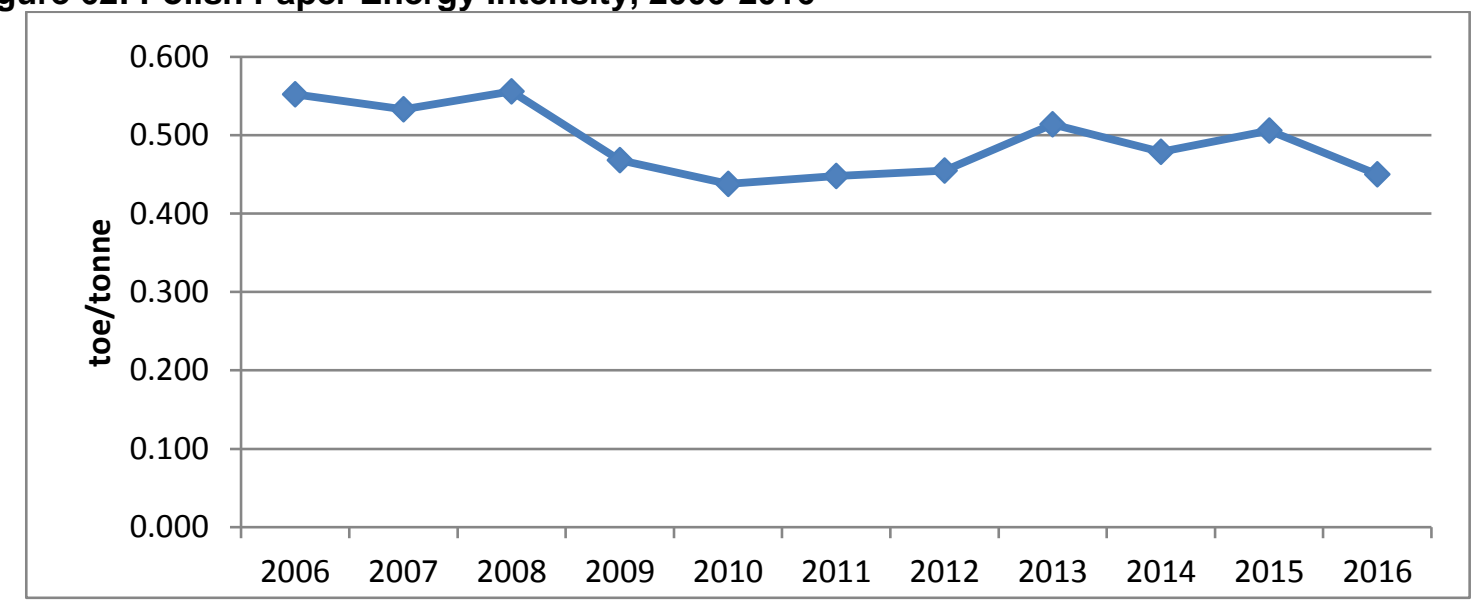

Source: Central Statistical Office of Poland GUS

In 2017, the sector continued to be dependent on biomass (32.8\%), wood (32.2\%), coal (20.1\%), high and low methane gas (13.7\%) and others (1.3\%). It seems that coal has been gradually replaced by wood and biomass while natural gas's share only increased marginally because natural gas continues to be perceived as too expensive by the sector.

Figure 63: Polish Paper Industry Energy Demand, \% Share by Fuel, 2017

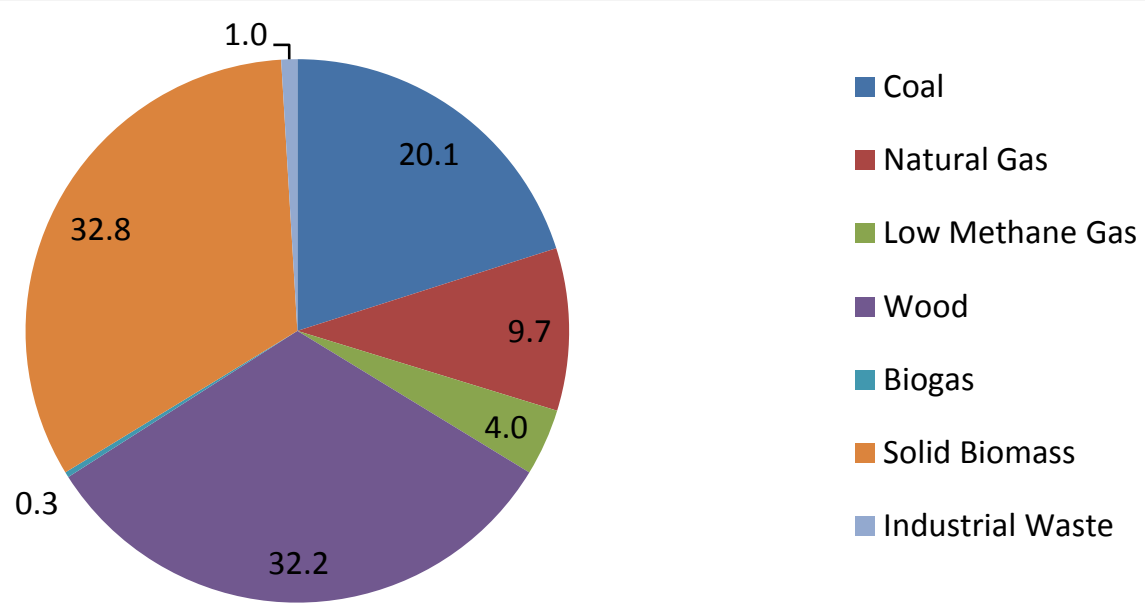

Source: Central Statistical Office of Poland GUS 

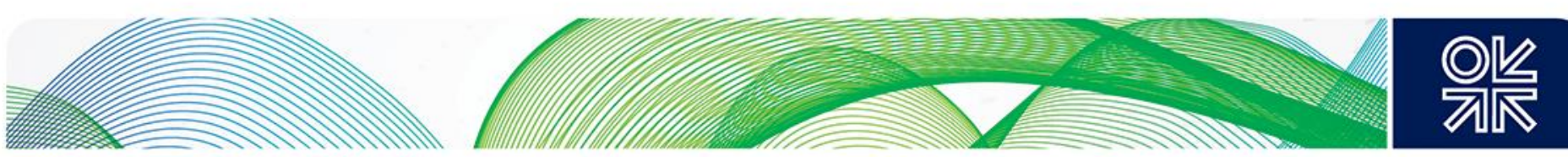

In 2017, the NACE 17 industry consumed 9,491 TJ of high and low methane gas $-0.18 \mathrm{bcm}$ and $0.13 \mathrm{bcm}$ of high and low methane gas respectively. This represented $1.4 \%$ of industrial high methane gas demand and $10 \%$ of low methane gas demand in 2017. With the exception of 2011 gas consumption by NACE17 has shown strong growth ever since 2009, and there is no evidence that high gas prices supressed gas demand. Gas consumption grew, especially after 2015 when the Świecie mill changed from heavy fuel oil to natural gas in the lime kiln.

\section{Figure 64: Polish Paper Industry Gas Demand, 2009-2017}

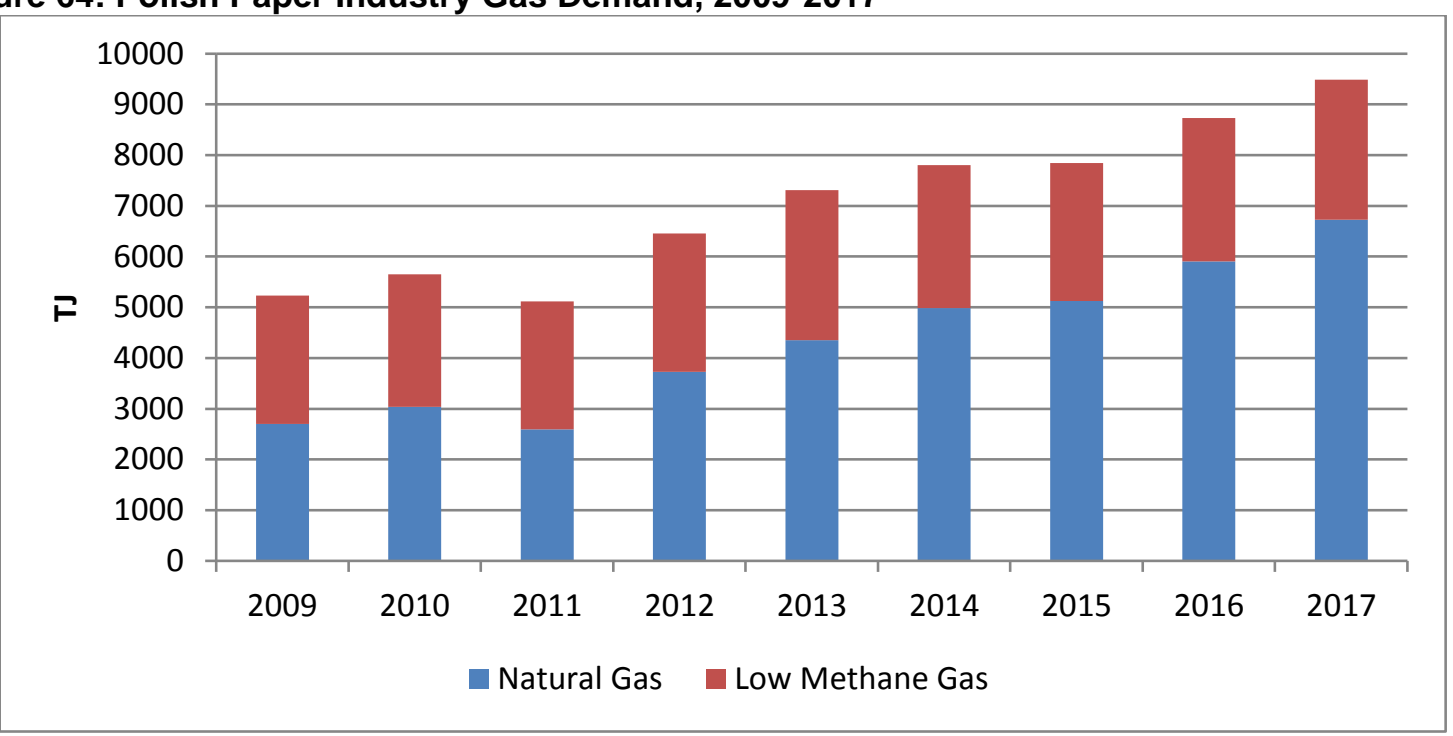

Source: Central Statistical Office of Poland GUS

Polish paper and pulp production continued to show strong growth over the last decade and this was largely copied by the consumption of natural gas. The clear correlation suggests that more efficient energy heating systems have yet to be installed in Poland. In 2016, the index of natural gas consumption was almost identical to the index of paper and pulp production sales.

Figure 65: Polish Paper Production Sales and Gas Consumption by NACE17 Indices, 20092016

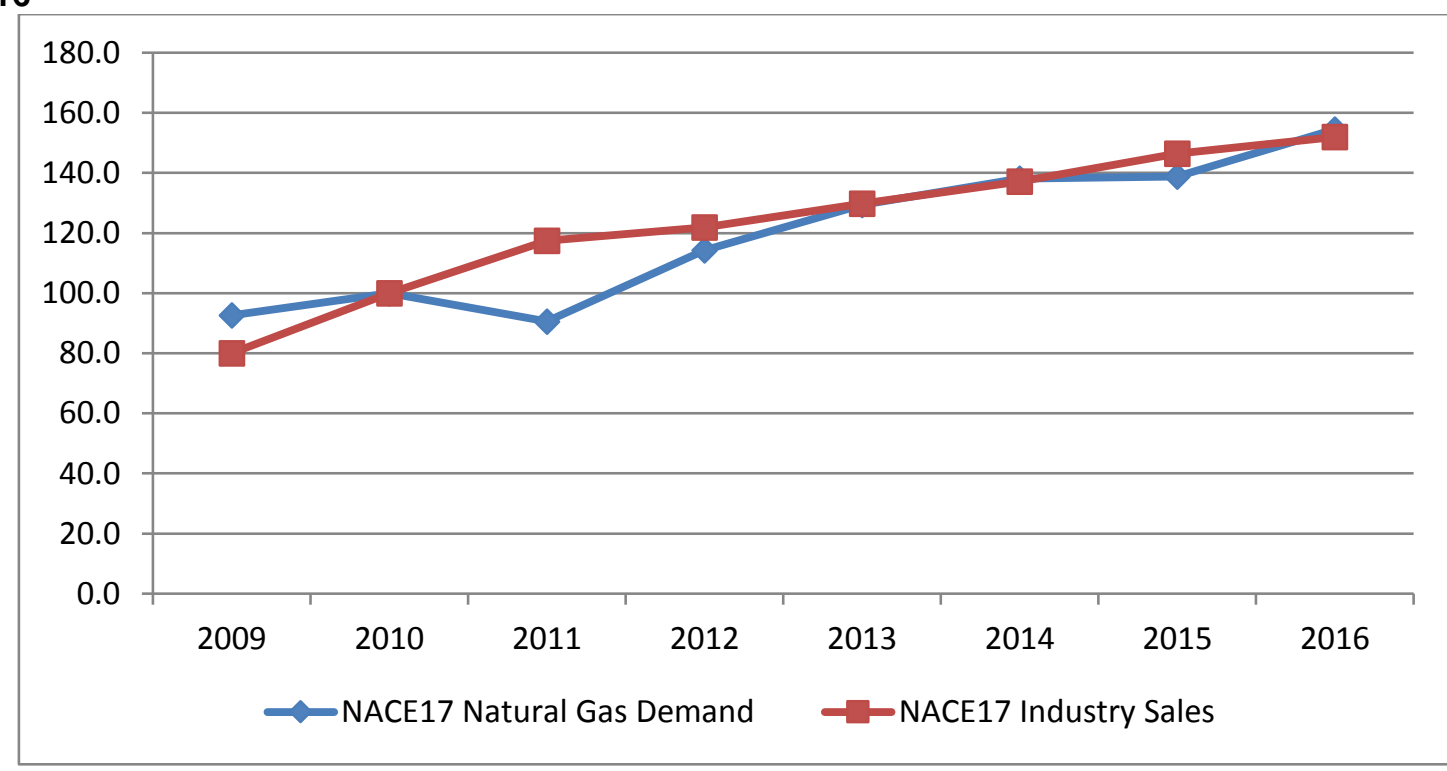

Source: Central Statistical Office of Poland GUS 

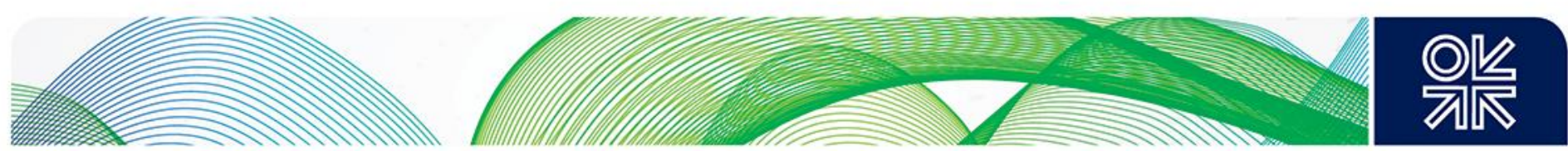

\section{Forecast}

Advantages

Looking at developments in the past decade, the Polish paper and pulp industry fared much better than the EU average. Moreover, the paper industry has also been able to increase its exports to the EU. Despite the dynamic growth in domestic paper and cardboard consumption, Poland still lags behind the levels of advanced EU countries. Polish paper consumption was $130 \mathrm{~kg}$ per capita in 2016 while the EU average was $158 \mathrm{~kg}$ per capita. ${ }^{125}$ As the living standard is now quickly catching up with the EU average, it can be expected that by 2035 Polish consumption will reach at least $170 \mathrm{~kg}$. Given ever increasing exports this would suggest that the production of paper in the country has a potential to almost double by 2030.

The relative competitiveness of the Polish paper industry would suggest that the current production capacity will grow in order to cover most of the growing domestic demand for paper.

\section{Challenges to Growth}

The sector has not made any major advances in energy saving technologies and the energy intensity of producing paper remains very high. With increasing involvement of multinationals it can be expected that new planned capacity will be modern with lower energy intensity, replacing the current obsolete mills and resulting in significant energy savings, including in natural gas.

The 2030 targets set in the greenhouse gas trading system (EU ETS) could also put a heavy burden on the Polish paper industry. ${ }^{126}$

\section{Reference Scenario}

Given the relative competitive advantage of the Polish paper sector, it is feasible that the sector will grow significantly within next decade. However, it will increasingly switch to biomass and convert to circular economy systems while gradually modernising, leading to improvements in energy intensity. It can be thus expected that gas demand by the paper industry will continue to grow for only the next couple of years as a result, albeit at a slower pace than the last couple of years. Due to further energy savings growth will tail off and stagnate after 2022 till 2030. Moreover, high methane gas will be slowly replacing domestically produced low methane gas after 2025. In the reference forecast natural gas demand by NACE 17 reaches some $0.38 \mathrm{bcm} / \mathrm{y}$ by 2030 , an incremental growth of $0.06 \mathrm{bcm} / \mathrm{y}$ in gas demand by 2030 compared to 2017.

\section{Optimistic Scenario}

The more optimistic scenario is built on the assumption that further major investments will flow into the Polish pulp and paper industry over the next decade and that the capacity of Polish paper mills will more than double. As a result the sector will show rates of growth of $7 \%$ till 2019 and between $5 \%$ and $3 \%$ until 2025 and only then it will slow down to $1 \%$. The more optimistic scenario thus foresees gas demand by the sector growing from $0.32 \mathrm{bcm}$ in 2017 to $0.48 \mathrm{bcm}$ in 2030 . However, the sector is unlikely to play a major role in future gas demand as the industry has switched to renewable sources of energy and will not convert back to natural gas in any major way.

\footnotetext{
${ }^{125} \mathrm{https}$ ://www.intechopen.com/books/pulp-and-paper-processing/the-value-and-profitability-of-converting-sawmil-wood-byproducts-to-paper-production-and-energy-ge

${ }^{126} \mathrm{https}: / /$ ec.europa.eu/clima/policies/strategies/2030 en
} 

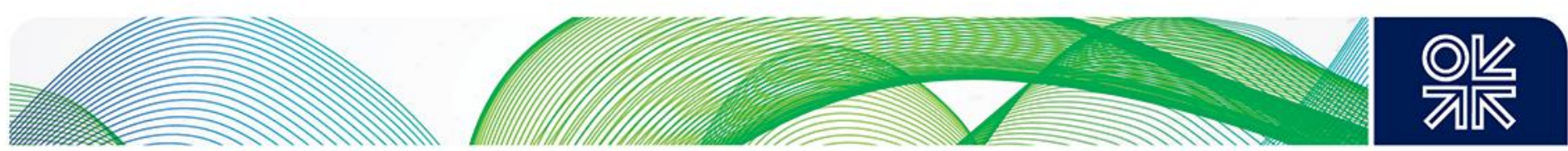

Figure 66: Polish Reference Paper Industry Natural Gas Demand Forecast 2016-2030

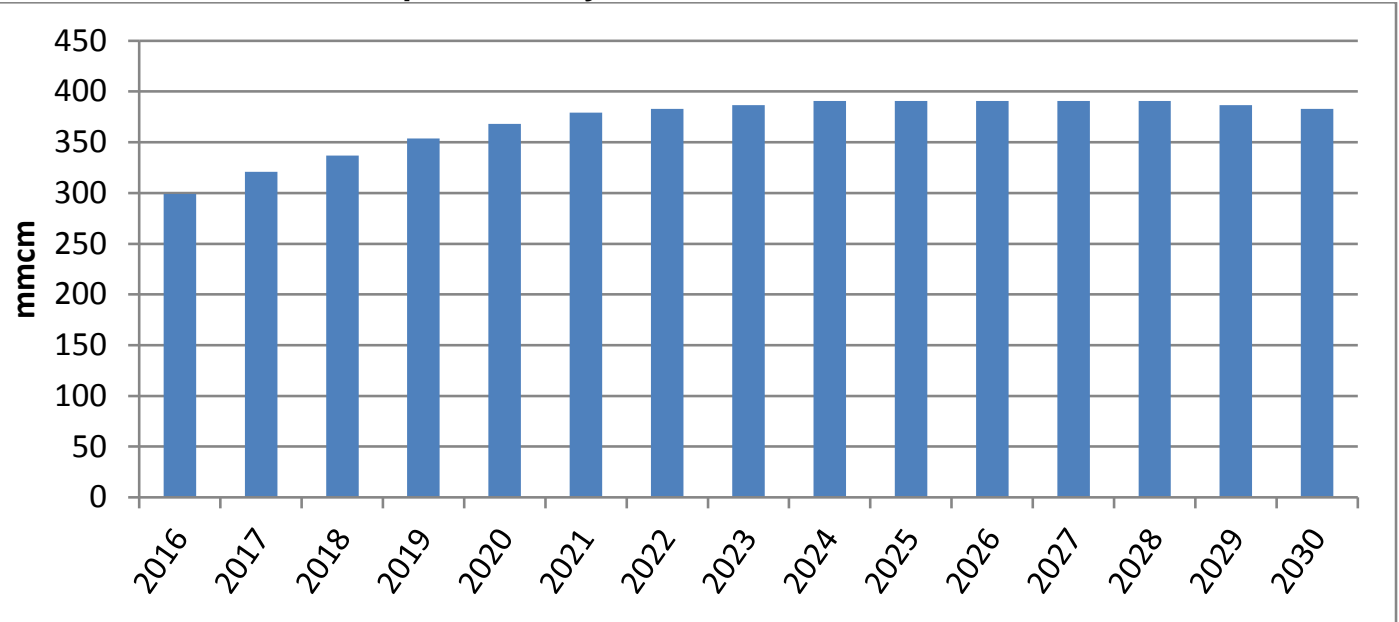

Source: Author's forecast

Figure 67: Polish Optimistic Paper Industry Natural Gas Demand Forecast 2016-2030

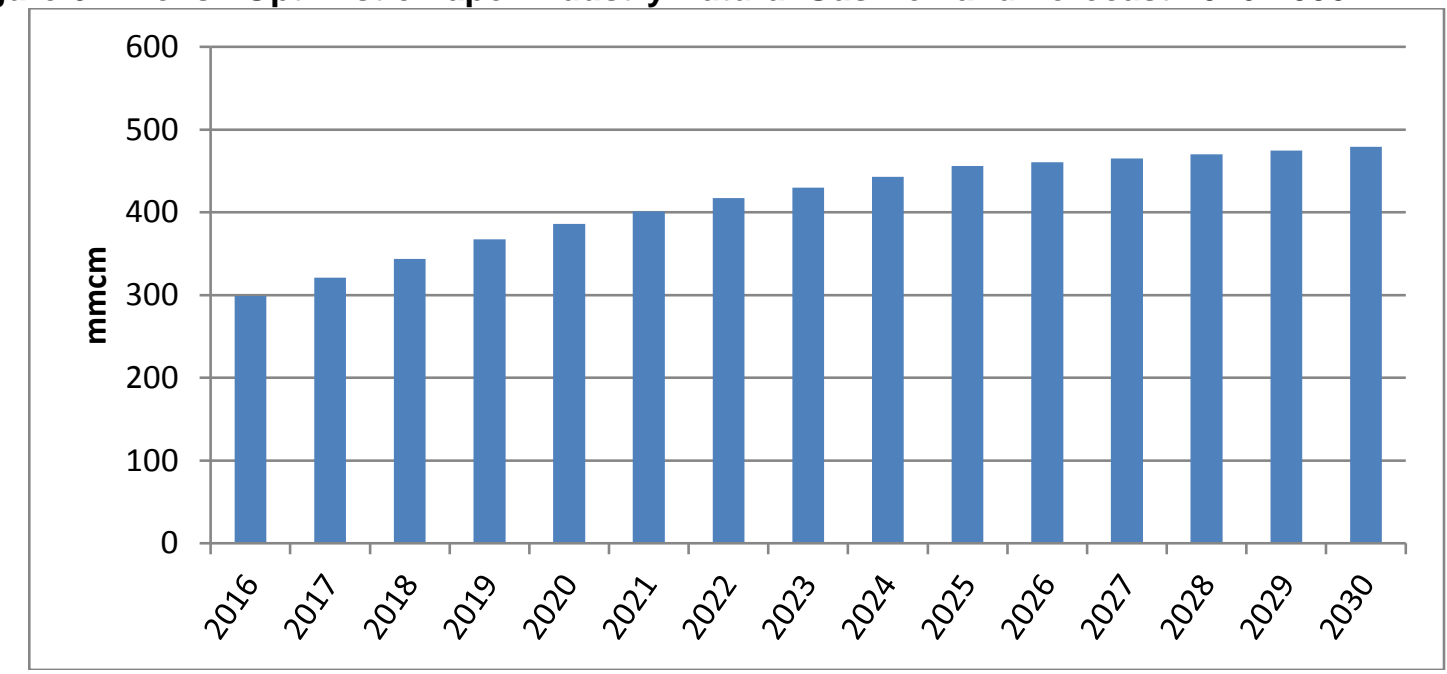

Source: Author's forecast

\subsection{The Polish Glass Industry}

The Polish glass and ceramic industry is a part of NACE23, ${ }^{127}$ which also includes the cement industry. The NACE 23 sector remains small, representing about $4.5 \%$ of total industrial output and its share has declined since 2005, yet the sector has its importance since it is a major supplier to the construction and automotive industries. In 2017, the glass and ceramic industry recorded sales of ZL12.1 billion, which represented $27 \%$ of the NACE 23 sector. It is export-oriented - exports represented $63 \%$ of total sales in 2017.

The glass industry is slowly shifting from dependency on coal to industrial and municipal waste. The share of coal declined from $36 \%$ in 2009 to $23 \%$ in 2017 for NACE23. The share of natural gas in energy demand also declined from $46 \%$ to $44 \%$ in the same period.

\footnotetext{
${ }^{127}$ NACE23 - Manufacture of Other Non-metallic Mineral Products.
} 

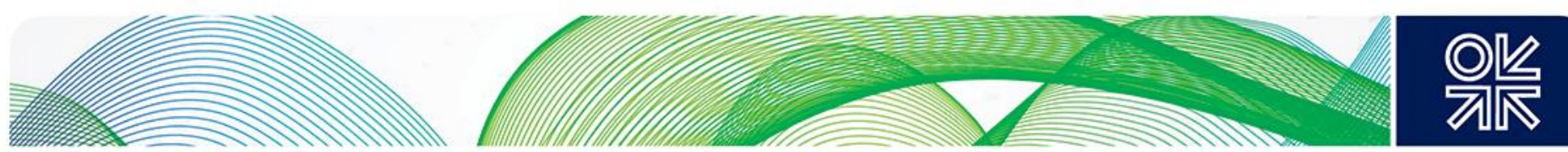

Figure 68: Polish Paper Industry Energy Demand, \% Share by Fuel, 2017

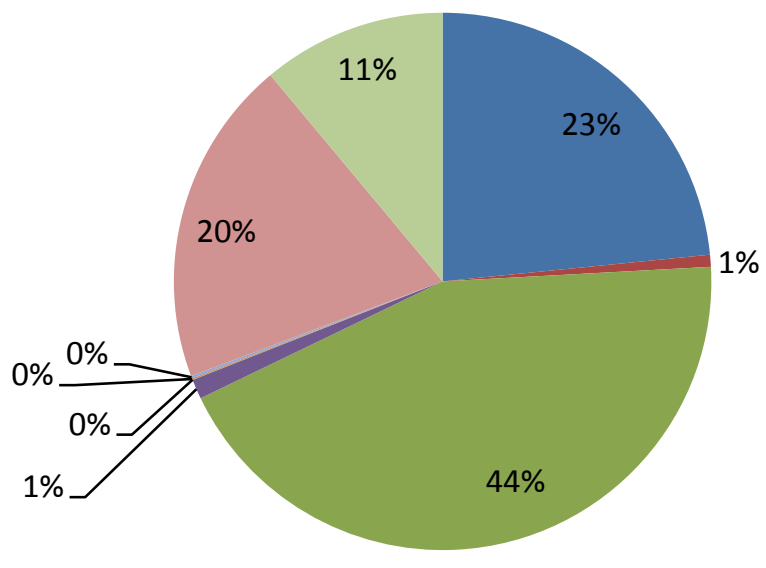
Coal
- Lignite
Natural Gas
- Low Methane Gas
Wood
Biogas
Solid Biomass
Industrial Waste
Municipal Waste

Source: Central Statistical Office of Poland GUS

Investment in energy saving technologies has varied according to each subsector. Flat glass, which represents the bulk of total glass and ceramics revenues, has attracted the largest investment, largely because the subsector is dominated by foreign companies who have modernised their plants in Poland. The hike in energy prices from 2011 resulted in investment in energy saving technology and expanding production capacity. The energy intensity of producing glass (in kWh per 100 Zloty of sold production) dropped from 14.5 in 2013 to 12.9 in 2015, ${ }^{128}$ which represents an $11 \%$ decline within just two years. However, the energy intensity has started to climb again since.

\section{Figure 69: Polish Energy Intensity of Glass Production Industry, 2010-2016}

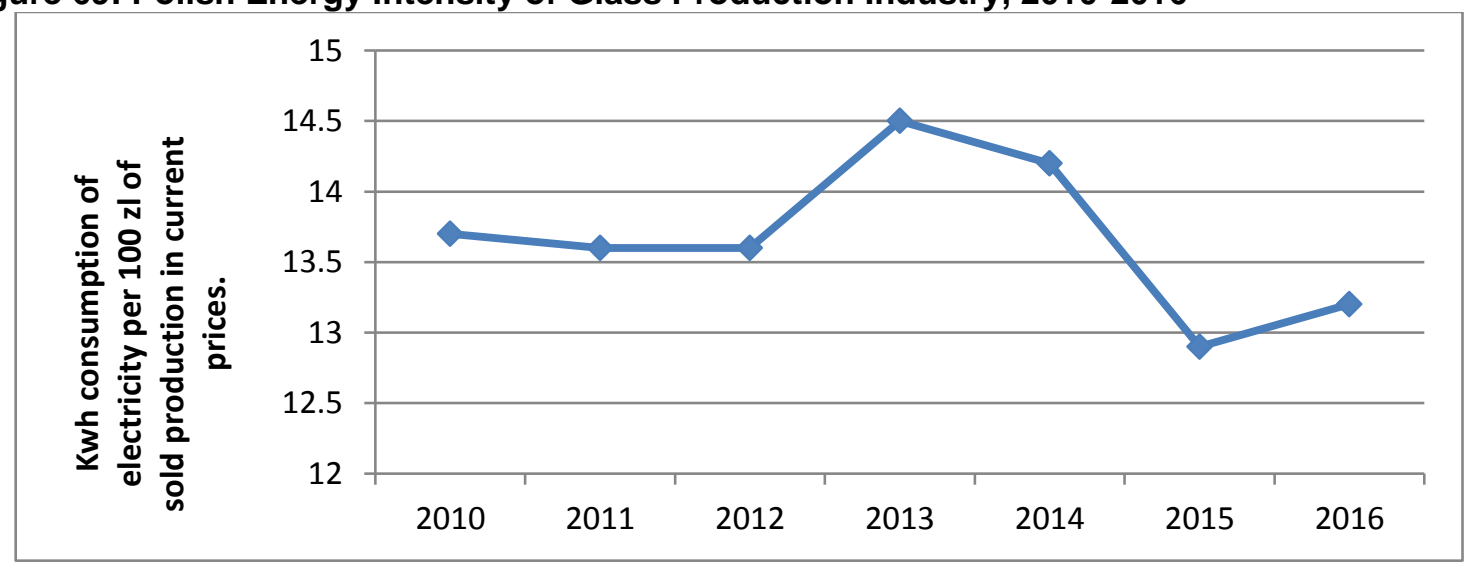

Source: Central Statistical Office of Poland GUS

Although there are no separate statistics available for consumption of natural gas by the subsectors of NACE23, the glass industry is practically solely responsible for consumption of natural gas since the cement industry and other non-metallic industries do not consume gas. NACE23 gas demand showed a significant drop in consumption between 2011 and 2015 as the industry was affected by high gas prices. Demand bounced back as the glassworks in Saint-Gobain's Dobrowa Gornicza switched to use

${ }^{128}$ Central Statistical Office of Poland GUS 

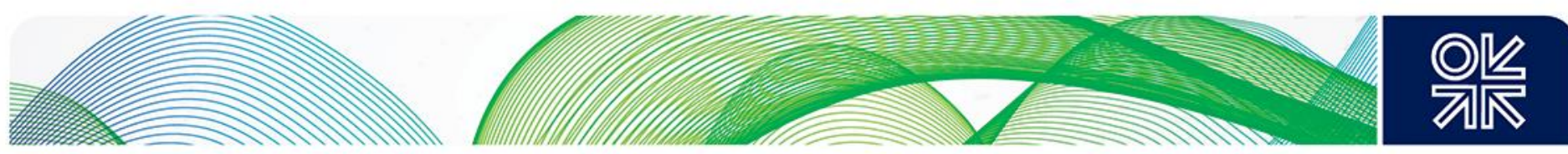

of natural gas in late $2015 .{ }^{129}$ Natural gas consumption is still slightly below the pre-high gas price level of 2011 while production has been continually growing since 2012 .

Figure 70: Polish Natural Gas Demand by NACE23, 2009-2017

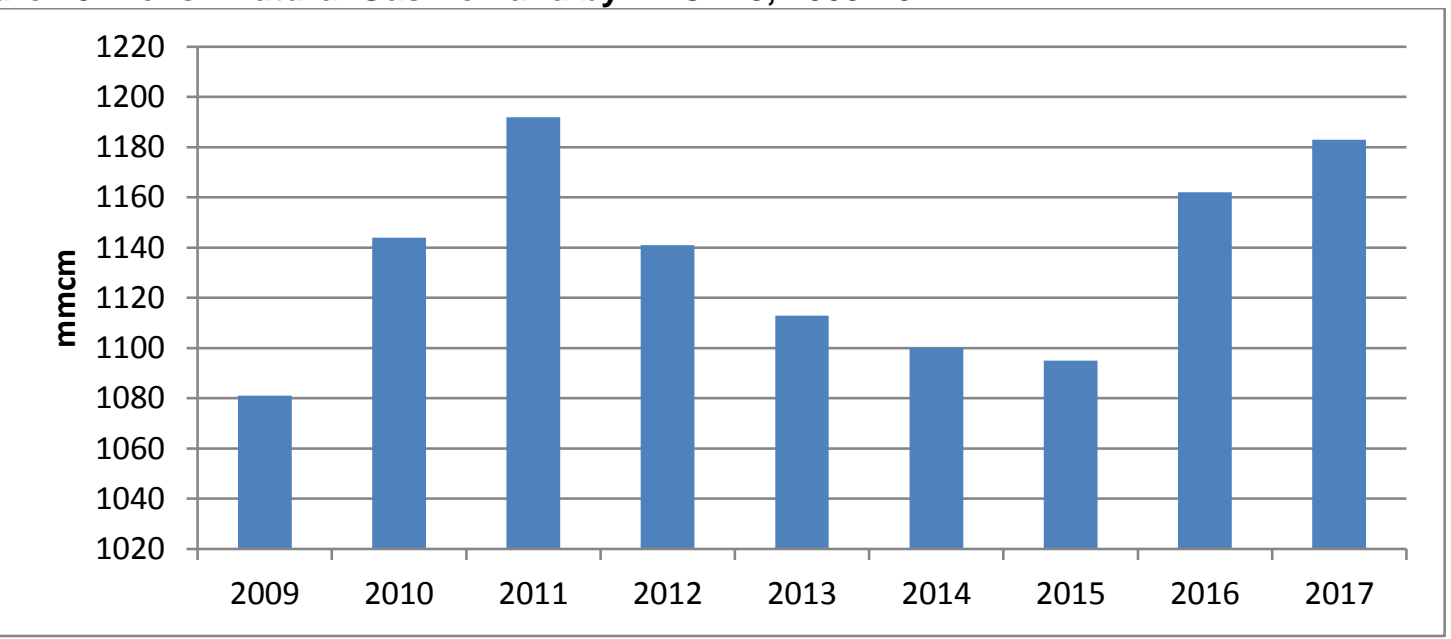

Source: Central Statistical Office of Poland GUS

\section{Forecast}

\section{Advantages}

Within the key heavy energy-dependent industries, the Polish glass and ceramic industry has the highest potential for growth since the industry has become competitive and has the advantage of access to good quality raw materials and cheap labour. This is evident from the ability to export the bulk of the production to the EU. Ever since 2010, the sector has shown improvement in revenues and profits which also suggest a potential for further growth in future. ${ }^{130}$ Considering past developments, the Polish glass and ceramic industry fared better than most EU countries and is likely to grow till 2030.

\section{Challenges to Growth}

However, the success of the sector will also depend on the ability to adjust to ever changing demand in technology and design in the construction and automotive industries. The sector is very dependent on these sectors, which are very sensitive to recessional pressures, and will mirror their development. Increasing competition is likely to result in further concentration among manufacturers in order to be able to invest in innovation according to market needs.

\section{Reference Scenario}

Given the recent strong growth of the sector future development looks promising. Glass production growth will drive gas demand, albeit at a slower pace due to further energy savings. Growth in the next five years will be stronger at around $1.5 \% / y$ and will gradually slow down to $1 \% / y$ for the following five years and plateau just before 2030. Natural gas demand by NACE 23 will reach some $1.34 \mathrm{bcm} / \mathrm{y}$ by 2030 in the reference forecast. The graph below incorporates cement industry gas demand, although it currently does not use natural gas and will not make any impact on future gas demand by NACE 23.

\section{Optimistic Scenario}

The more optimistic scenario for the glass industry could see much higher rates of growth till 2022 due to increased production capacity as new glassworks come on stream. This will require investment inflows especially from the three dominant glass producers. In such a case, natural gas consumption is likely to slow down only between 2022 and 2027 and then grow marginally till 2030 as energy savings

\footnotetext{
${ }^{129}$ https://pl.saint-gobain-building-glass.com/pl

${ }^{130}$ Central Statistical Office of Poland GUS
} 

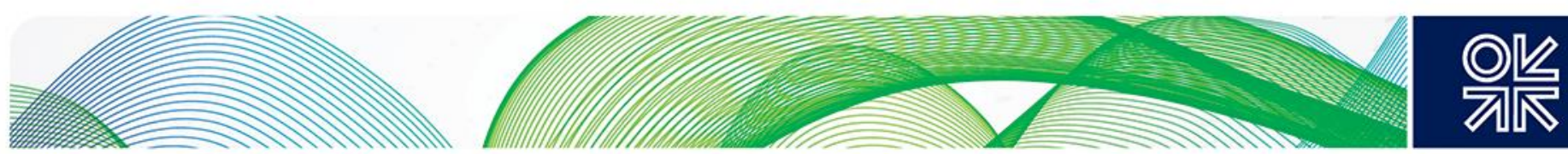

due to new investments start to take effect. NACE 23 natural gas demand reaches some $1.45 \mathrm{bcm} / \mathrm{y}$ by 2030, an increase in gas demand of $0.27 \mathrm{bcm} / \mathrm{y}$ compared to 2017.

Figure 71: Polish Reference NACE23 Natural Gas Demand Forecast 2016-2030

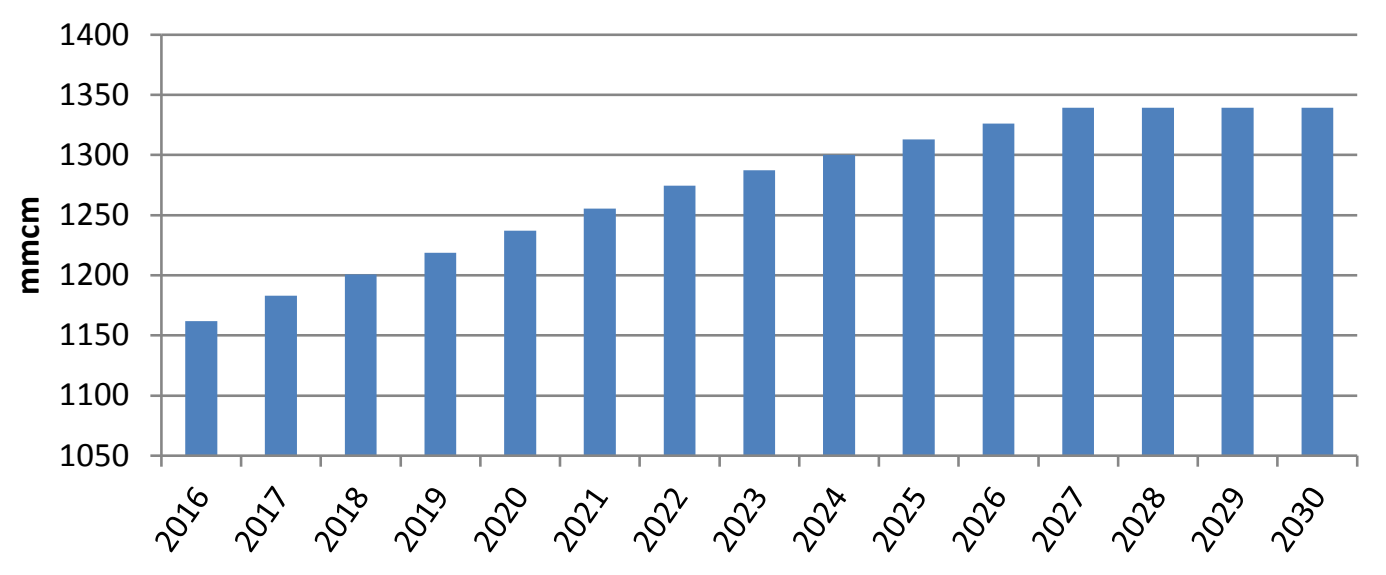

Source: Author's forecast

Figure 72: Polish Optimistic NACE23 Natural Gas Demand Forecast 2016-2030

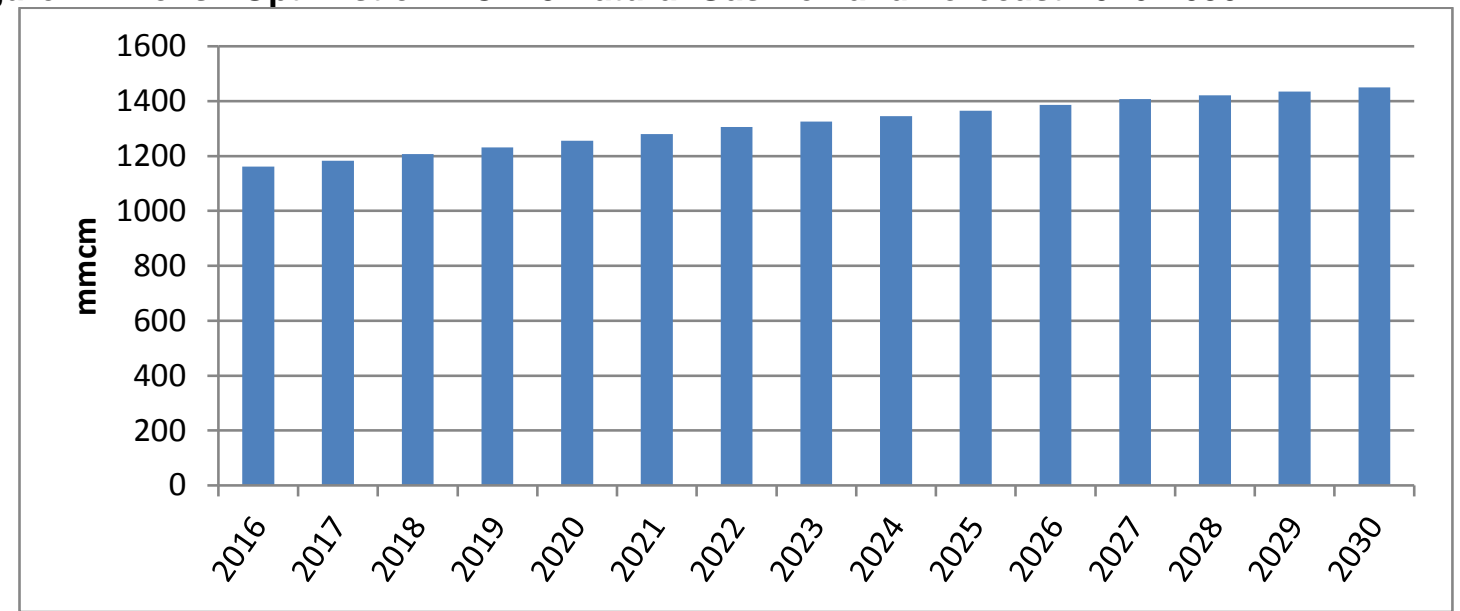

Source: Author's forecast

\subsection{The Polish Cement Industry}

The cement industry belongs to the NACE 23 sector. ${ }^{131}$ Over the years it has experienced ups and downs due to recessional trends. Cement production is mainly destined for local consumption although $2.7 \%$ of production is exported while $5.2 \%$ is imported (2016 ${ }^{132}$ ).

The cement industry is one of the most energy-intensive, and is dependent on an appropriate raw material base. Over the last decade the energy intensity of producing cement has not improved. Emissions came down once the wet method of cement production ceased in the 2000s but $\mathrm{CO}_{2}$ emissions have started to grow again since 2013 once the production of cement bounced back. This indicates a low investment in environmental and energy technology and that the sector uses no natural gas. It is entirely dependent on burning coal and municipal and industrial waste which now represents almost two thirds of fuels used.

${ }^{131}$ NACE 23.5 Manufacture of cement, lime and plaster
${ }^{132}$ Stowarzyszenie Producentów Cementu 

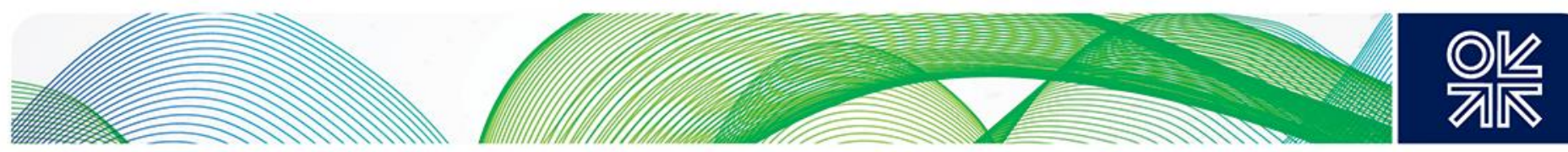

Figure 73: Share of Fuels in Polish Cement Production, 2009, 2015

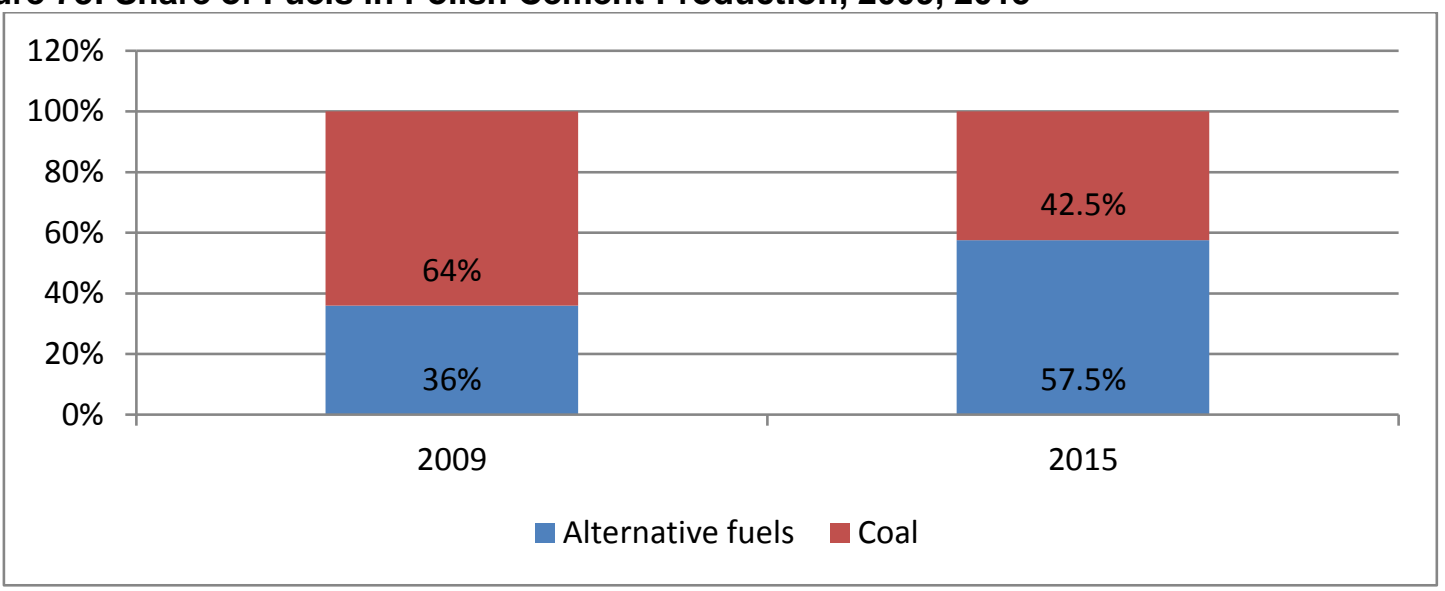

Source: Stowarzyszenie Producentów Cementu

The sector would have to invest in environmental technology in order to reduce emissions after 2020. There may be a possibility that natural gas will be introduced to a small degree in future but it is unlikely that it is going to play any major role in future production of cement. For the purpose of this study we do not expect natural gas to be used by the cement industry before 2030 .

\section{INDUSTRIAL NATURAL GAS DEMAND IN SLOVAKIA}

Natural gas plays an important role in the Slovak total primary energy supply while the industry sector accounts for $42 \%$ of final gas consumption. Slovakia reduced its energy intensity significantly between 1995 and 2016 due to a switch to low-energy industrial production processes. However, it continues to have the seventh highest energy intensity in the EU although it has the lowest energy intensity in Central Europe. The industry still has a potential to increase its energy efficiency although the key companies, apart from the steel industry companies, have mostly implemented efficiency measures. Over the last decade Slovak natural gas prices for industrial customers were largely above the EU-28 average and in 2018 they were the highest. Slovak gas consumption was significantly affected by the recession, falling by more than a third over the last decade. Natural gas demand by the key industries continues to be depressed below the pre-recession 2008 level although some growth has returned since 2016 . The significant decline is due to the long lasting economic recession combined with the increasing efficiency of the Slovak economy, climatic conditions and energy savings. The sectors which were most affected were the paper and glass and cement industries, which switched to alternative fuels once gas prices increased. In the author's scenarios total commercial and industrial gas demand will show only small growth throughout the next decade from 3.3bcm/y in 2017 up to $4.1 \mathrm{bcm} / \mathrm{y}$ in 2030, depending on the future of US Steel Kosice.

Slovakia has a population of 5.4 million and an area of $48,845 \mathrm{~km} 2$. Slovakia became industrialized relatively late, mostly in the second half of the 20th century. Heavy industry (coal mining, steel and heavy machinery) was built for strategic reasons in the communist period. However, after independence in 1993, the importance of industry, and especially of heavy industry, declined. However, Slovakia has been very successful in attracting foreign investment due to its cheap and skilled labour, a $19 \%$ flat tax rate for businesses and individuals, no dividend taxes, a weak labour code, and a favourable geographical location. Automotive, electronics, mechanical and chemical engineering and Information technology are now the main industrial sectors built due to high investment inflows over the last two decades. The automotive sector is among the fastest growing sectors in Slovakia due to the recent 

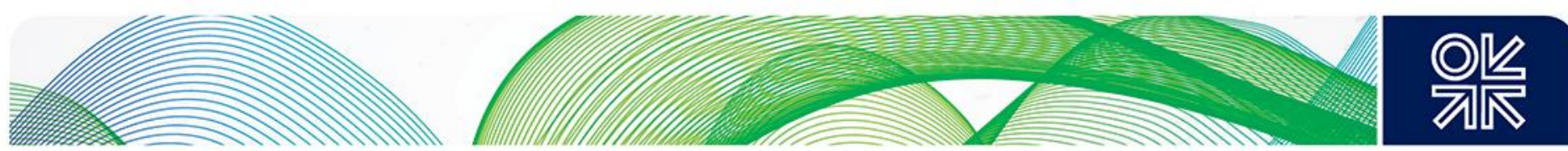

investments by Volkswagen (Bratislava), Peugeot (Trnava), Kia Motors (Žilina) and since 2018 also Jaguar Land Rover in Nitra.

\subsection{Main Characteristics of the Slovak Natural Gas Market}

Natural gas plays an important role in total primary energy supply (TPES). In 2016, the gas share was $23.6 \%$ although its share in electricity generation was only $5.6 \%$. Natural gas is used largely as a fuel in the production of heat. Almost a half (45\%) of heat was produced from natural gas in 2016, according to the IEA. Over the last ten years, gas demand fell by over $27 \%$, more steeply than the $11.5 \%$ decline in TPES over the same period. ${ }^{133}$ Slovakia had a higher share of natural gas in TPES than the EU-28 average till 2015, but it dipped below the EU average of $23.9 \%$ in $2016 .{ }^{134}$

Gross natural gas demand totalled $5.0 \mathrm{bcm}$ in 2017 , showing a slight recovery driven by the buoyant economy. ${ }^{135}$ Slovak gas consumption has been significantly affected by the recession. Over the last ten years, gas demand fell by over a third. The decline in total gas demand in recent years can be attributed to switching to renewables and other alternative fuels, energy savings due to improved insulation, and other energy efficiency measures. The rising average air temperature in the Slovak Republic has also played an important role.

Natural gas is widely used across all the consuming sectors in Slovakia. Industry, the transformation sector and residential users each account for around a quarter of gross natural gas used. The combined cycle power station Elektráreň Malženice with electricity capacity of $284 \mathrm{MW}$ and steam capacity of 152 MW started to operate in 2011 after investment of $€ 400$ million by E.ON Energie AG but the plant has been mothballed since 2013. The planned consumption of the plant is $0.5 \mathrm{bcm} / \mathrm{y} .{ }^{136}$

In 2017 , the industry sector represented $41.5 \%$ of final gas consumption, closely followed by the household sector with $38.5 \%$. The remaining $20 \%$ was consumed by service and other sectors. The share of industry has been growing since 2016 .

\section{Figure 74: Shares of Slovak Final Gas Demand by Sector, 2017}

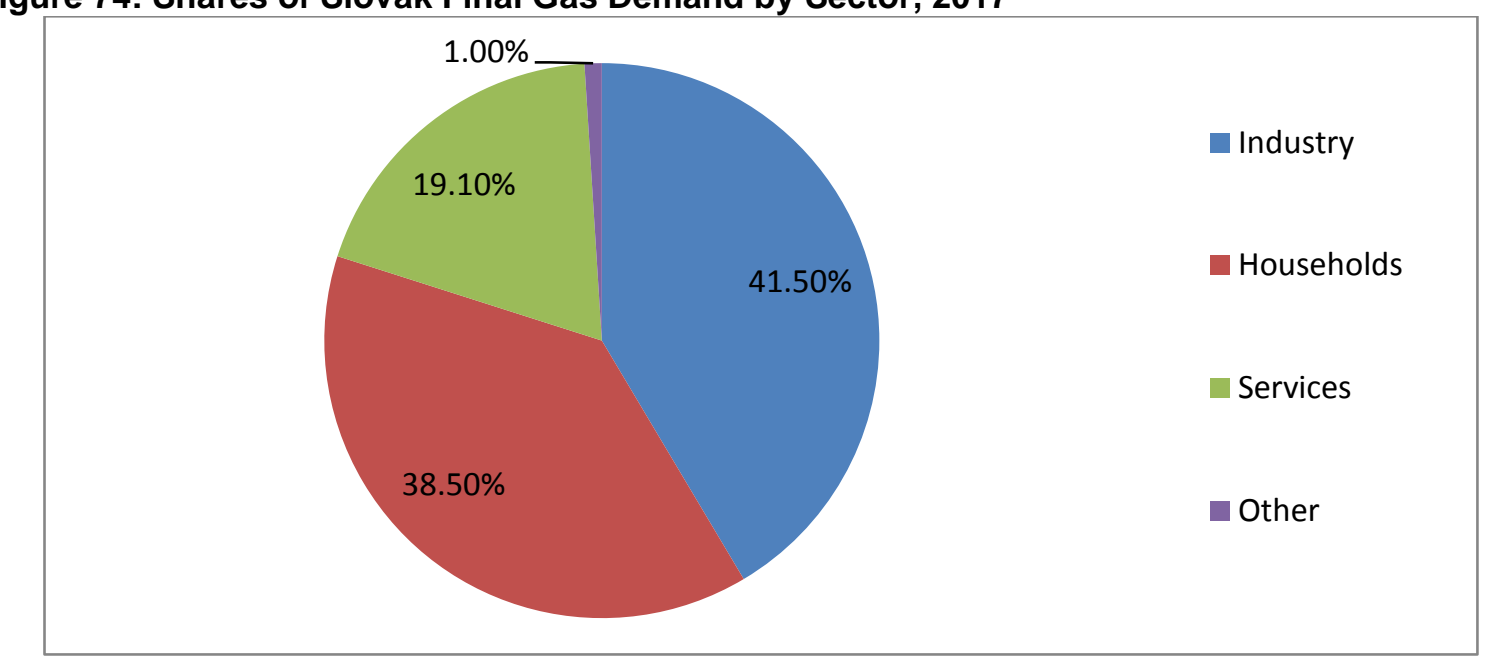

Source: Statistical Office of the Slovak Republic, Energetika

In 2017 , large industrial consumers represented $53.2 \%$ of gross natural gas consumption, followed by households with $28.9 \%$ and other medium and small consumers with $17.9 \% .{ }^{137}$ The strongest growth

\footnotetext{
133 IEA Energy Statistics

134 IEA Energy Statistics

135 Statistical Office of the Slovak Republic, Energetika

136 https://spectator.sme.sk/c/20047637/e-on-to-halt-production-at-malzenice-steam-gas-power-plant-in-october.html

137 URSO Annual Report 2017
} 

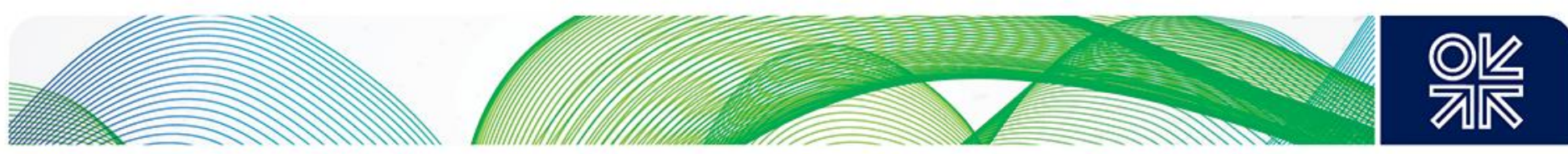

in 2017 was in the large customer segment. Natural gas demand was affected by the last international recession, especially during the second phase after 2010, although different groups of consumers registered decline differently. Industrial demand has been declining since 2011 but the decline stopped in 2015 and it has been recovering, although 2017 demand was still 14\% below the 2008 level. Household consumers demand declined rapidly in 2011 and 2012, then stagnated until small growth since 2015. Commercial customers saw a rapid decline after 2009, apart from 2010 and 2013, with its demand halving. ${ }^{138}$

Slovakia has one of the highest gas connectivities in Europe, with over three quarters of households being connected to the gas grid. Presently, $77 \%$ of Slovak municipalities are connected to the gas distribution network, covering $94 \%$ of Slovakia's population. ${ }^{139}$ However, due to the increase in gas prices after 2010 some of the households switched away from gas to alternative fuels.

In October 2014 the Slovak Ministry of Economy published a new Energy Policy, defining the energy sector's primary objectives and priorities to 2035 with a view to $2050 .{ }^{140}$ Its reference scenario envisages a significant increase in nuclear electricity consumption with the start-up of new nuclear reactors. A decline in coal consumption is expected, balanced by increase in nuclear electricity, natural gas and RES. The share of natural gas should remain at the current level. See APPENDIX 6 for more detail on the Energy Policy.

\subsection{Slovak Energy Efficiency Progress}

Energy efficiency is one of the factors affecting the competitiveness of the entire economy, especially industry and is thus one of the main determining factors for future industrial growth. Slovakia has made significant progress in reducing its energy intensity in industrial processes over the last two decades. According to Eurostat, Slovakia reduced its energy intensity by 2.4 times between 1995 and 2016 . Between 2008 and 2016 alone, energy intensity contracted by more than $22 \%$. This positive trend can be attributed to successful industry restructuring, a switch to low-energy industrial production processes, improvements in building insulation, and replacement of older appliances with efficient ones. Nevertheless, Slovakia continues to have the seventh highest energy intensity in the EU. ${ }^{141}$ Moreover, the limits to decreasing the country's energy consumption were clearly visible in the last two years as energy intensity started to grow again.

One of the main reasons behind the high energy intensity is that industry (including the energy sector) accounted for $25.4 \%$ of the country's gross value added, making it inevitable that Slovak energy intensity will be higher than the EU-28 average of $19.6 \%$ in $2017 . .^{142}$ In Slovakia, heavy industry such as metallurgy, engineering, manufacture of rubber and plastics account for a large proportion of the industrial sector. In 2016, Slovakia had the fourth largest industrial share in gross value added within the EU. ${ }^{143}$ However, there is no doubt that the country has a large potential for energy savings in both the industrial and residential sectors.

Interviews with a number of large industrial companies revealed that most of them had already implemented major improvements in energy efficiency, especially since 2013 when energy prices rocketed, and had exploited at least two thirds of possible improvements. All the interviewed companies have drawn on EU funds, which cover $50 \%$ of the cost of energy saving technology or emission reducing equipment. In fact energy savings in the industry have been achieved ahead of targets unlike other sectors. Energy efficiency measures in the industry sector have focused on supporting innovation, technology transfers and energy savings in industrial processes on a company level, recommended by

\footnotetext{
${ }^{38}$ Statistical Office of the Slovak Republic, Energetika

139 https://www.spp.sk/en/all-segments/about-us/

140 http://www.economy.gov.sk/uploads/files/47NgRIPQ.pdf

141 Eurostat

${ }^{142} \mathrm{https}$ ://ec.europa.eu/eurostat/statisticsexplained/index.php?title=File:Energy intensity of the economy, in selected years,

2006-2016_(kilogram_of_oil_equivalent_per_1_000_EUR).png

143 Eurostat
} 

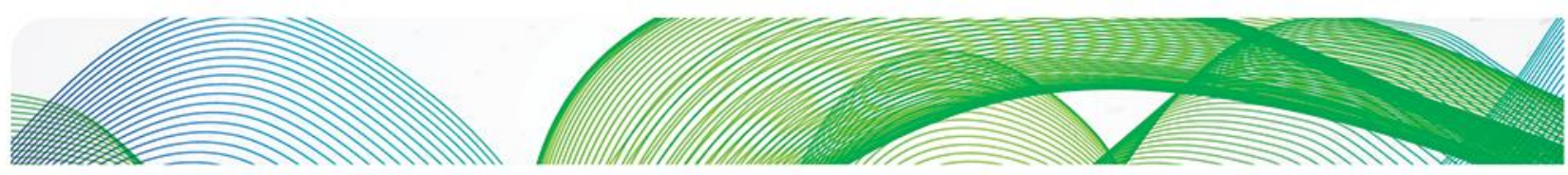
O진

compulsory energy audits. For more detailed information on the energy efficiency progress see APPENDIX 7.

The energy intensity of the Slovak economy is currently $76 \%$ higher than the EU average despite declining at a faster rate than the EU average since 2001. ${ }^{144}$ Broken down by sector, industry accounts for the largest share of the economy's energy demand (44\% compared to the EU average of $25 \%$ ). Consumption by industry remained more or less constant in the past few years, after undergoing a gradual decrease from 2005 to 2009. It is followed by energy consumption in transport (22\%), households, and trade and services. Consumption has decreased by the most in the residential sector $(-22 \%)$ followed by the trade and services sector (-13\%). ${ }^{145}$ Apart from the impact of growing industrial output the transport sector has been expanding strongly, which also contributed to the growing energy consumption in later years.

\section{Figure 75: Slovak Energy Intensity, 1995-2016}

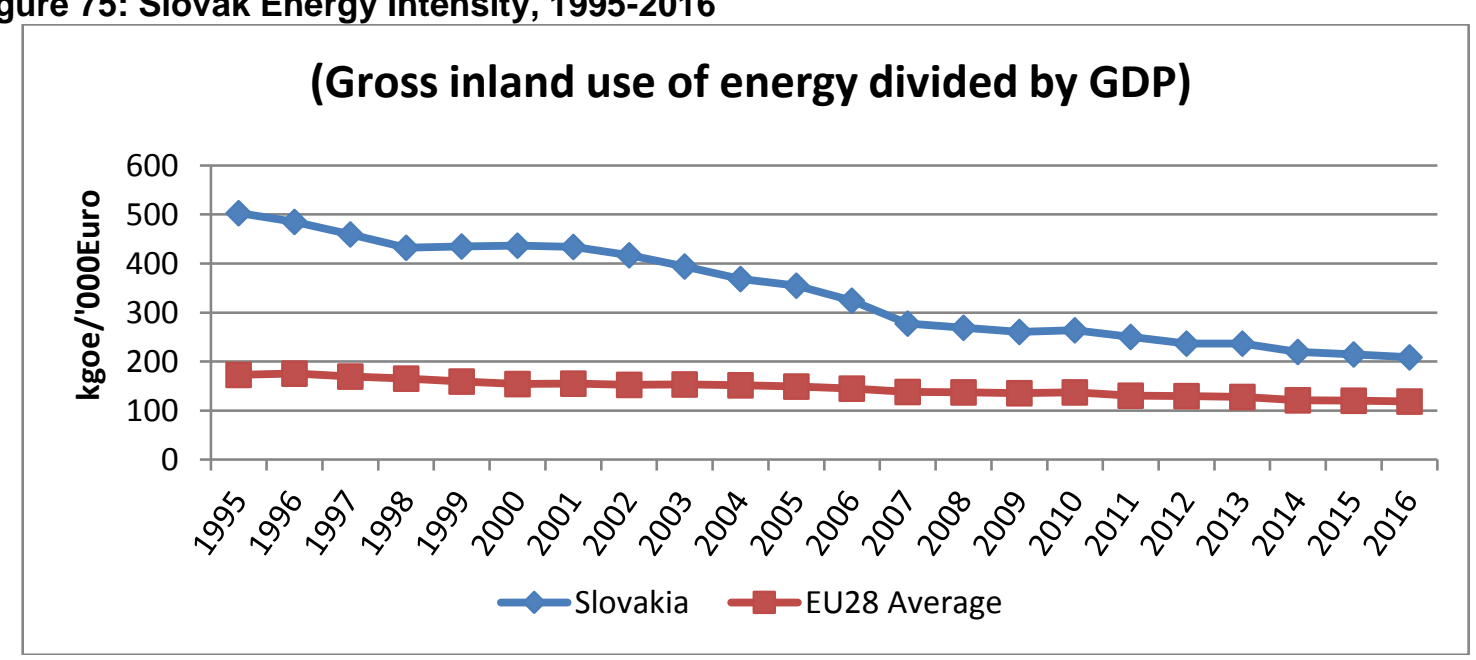

Source: Eurostat

\subsection{Slovak Gas Price Developments and Competition from Coal}

Since 2013, the Slovak gas market has been deregulated and all final customers have the right to change their supplier free of charge. Retail prices are still regulated through "price caps" for all households, small industrial users and for district heating companies that produce heat for households. They are regulated by the Regulatory Office for Network Industries (RONI). Gas tariffs for other consumers are not regulated. There are no "social" gas tariffs for vulnerable customers. The final wholesale price of natural gas includes a component regulated by the regulator and an unregulated component resulting from the contractual relationship between the supplier and the customer. The regulated component includes charges for natural gas transmission and distribution. The unregulated component represents the commodity charge and the gas storage charge.

Compared with many IEA countries, natural gas prices for households in the Slovak Republic are low, both pre-tax and the final tariffs including tax. Over the last decade Slovak natural gas prices for industrial customers were largely above the EU-28 average and were one of the highest among the EU countries in 2018. ${ }^{146}$

\footnotetext{
${ }^{144}$ Eurostat

${ }^{145}$ Commission Staff Working Document; Energy Union Factsheet Slovak Republic, Third Report on the State of the Energy Union, Brussels, 23.11.2017

${ }^{146}$ According to Eurostat, gas prices for medium size industrial customers in Slovakia in the first half of 2018 (2.76€cent/kWh excluding taxes and levies) were almost $5 \%$ higher than the EU average (2.63€cent/kWh excluding taxes and levies) and they were $13.6 \%$ higher than in the neighbouring Czech Republic.
} 

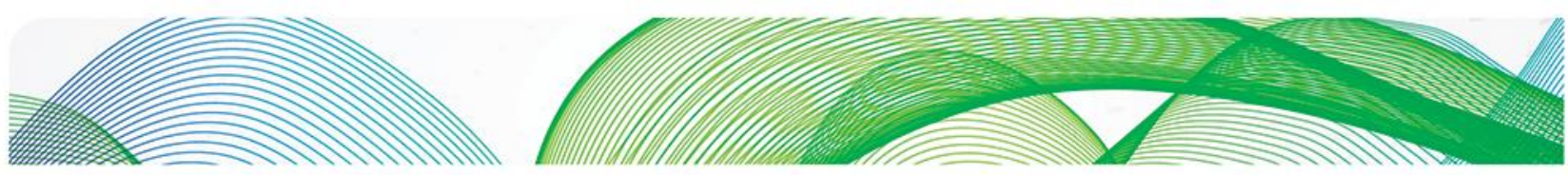

Figure 76: Slovak Gas Prices for Medium Size Industries, Excluding Taxes, 2008-2018

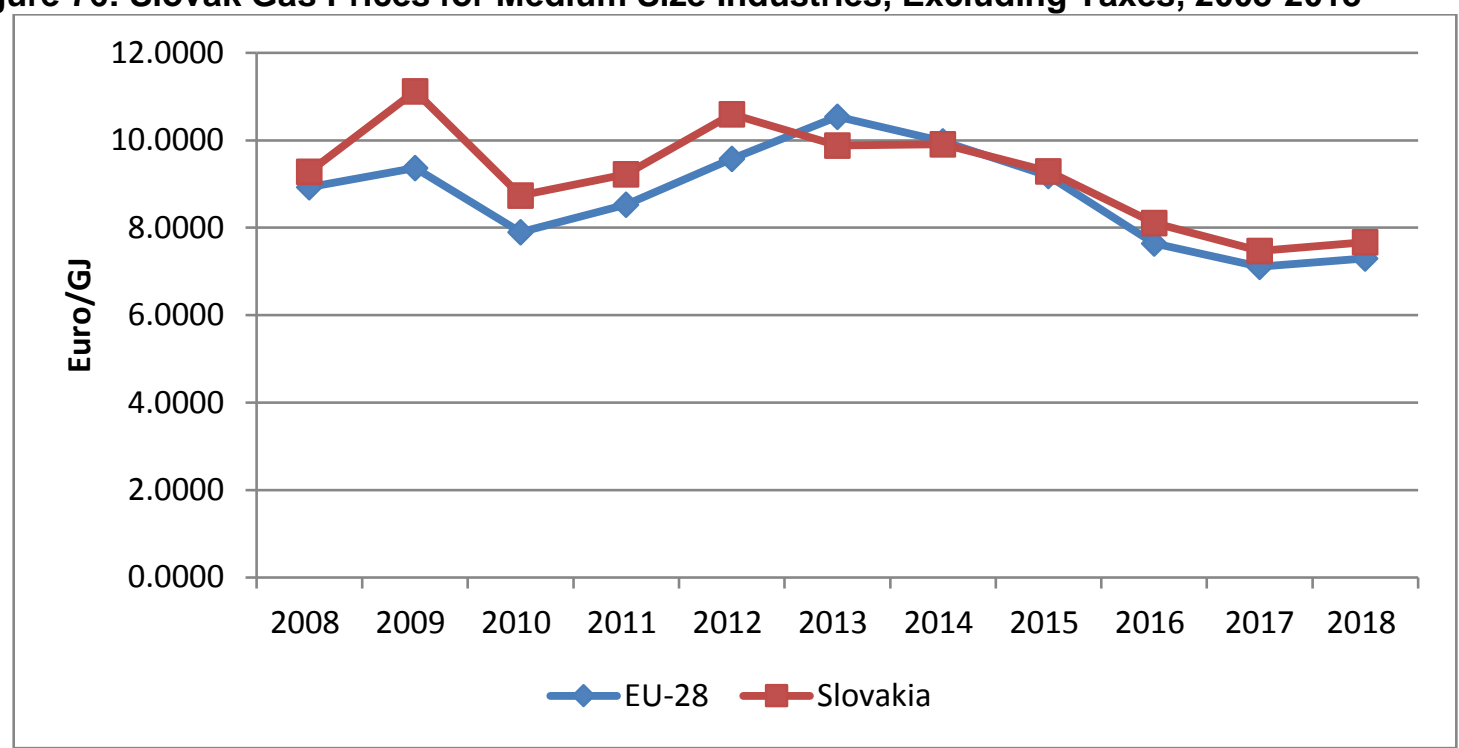

Source: Eurostat

Since the Slovak regulator continues to regulate household prices, they continue to be well below the EU-28 average over the last decade. Household natural gas prices inclusive of all taxes are therefore among the lowest within the EU, and in the first half of 2018 were $38.3 \%$ lower that the EU-28 average. Moreover, the difference between the EU-28 average and Slovak household natural gas prices is getting progressively bigger.

Figure 77: Slovak Gas Prices for Medium Size Household, Including Taxes, 2008-2018

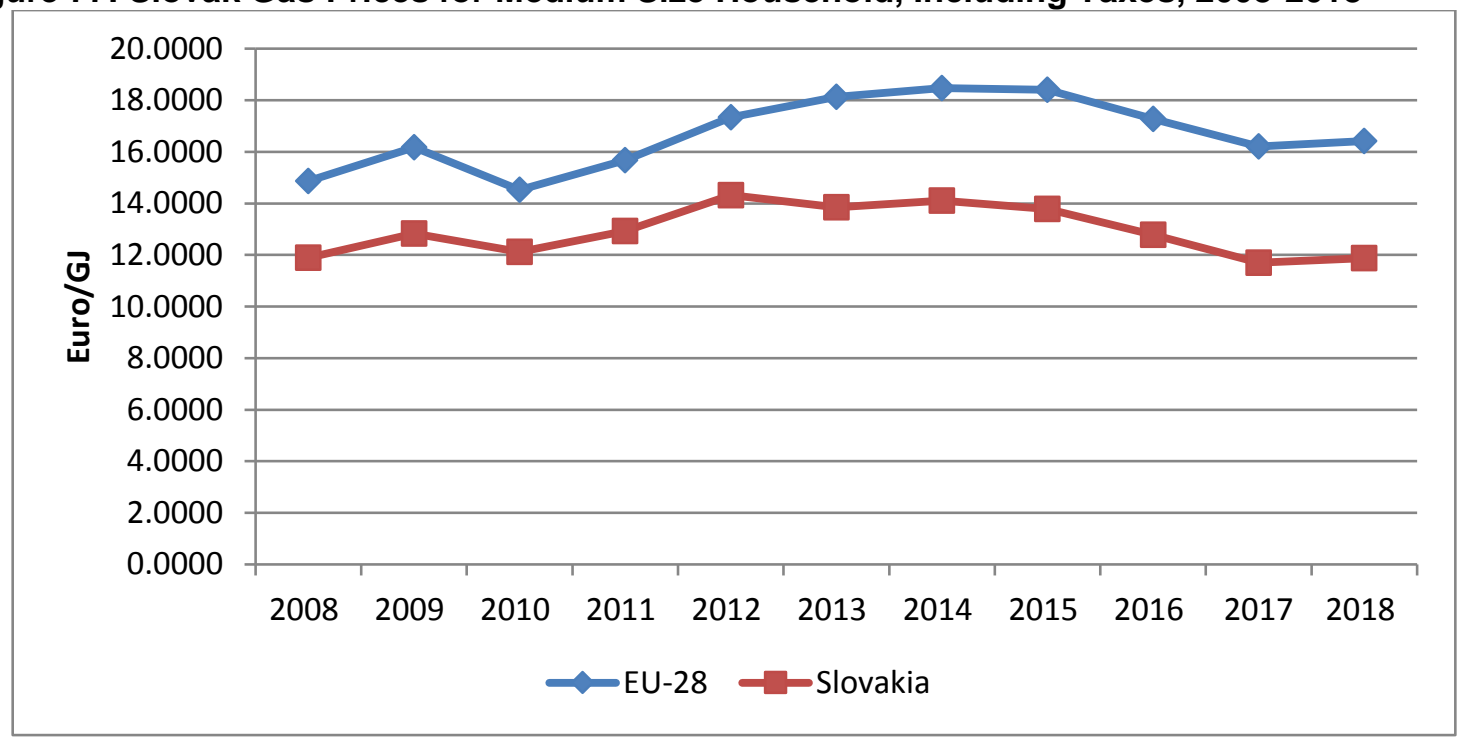

Source: Eurostat

The high industrial gas prices in Slovakia have not been able to compete with coal prices, especially in electricity generation. Lignite is the only significant fossil fuel indigenous to Slovakia and therefore has been the main and most affordable source for electricity generation for decades. The dependence on 

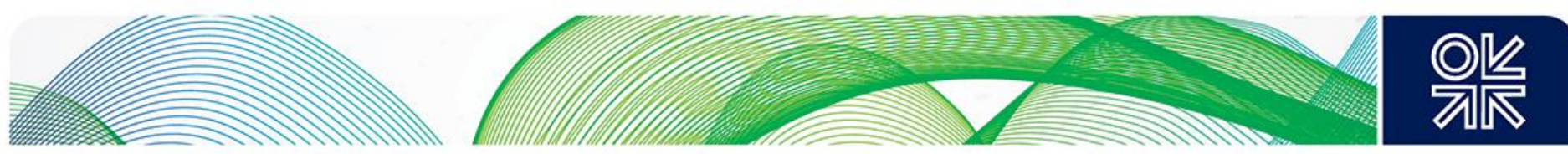

local lignite helped the country maintain a lower level of dependence on imported natural gas than many other countries in the region. Hornonitrianske bane Prievidza (HBP), ${ }^{147}$ is the only coal miner in the country, after recent mine acquisitions, employing circa 4,200 employees. However, Slovakia has been trying to reduce the domestic production of low quality lignite. The regional authorities in Upper Nitra have recently started to prepare the phase-out of coal mining and qualified for the EU pilot programme to support the transformation of coal mining regions at the end of 2017. ${ }^{148}$ Power generation is the largest coal-consuming sector, using around $30 \%$ of total coal supply and generating $40 \%$ of gross electricity. This direct use of coal has been the main polluter in the country.

Coal prices gradually declined between 2011 and 2016, in line with North West Europe steam coal prices. However, the spike in international coal prices due to the closure of some Chinese coal mines and increased demand from India in 2017 also pushed up industrial coal prices in Slovakia, which grew throughout the year. Gas prices for industrial customers fell between 2013 and 2017.

However, gas prices did not fall low enough to put the mothballed gas-fired electricity plant Elektráreň Malženice back into operation. Given the forecast of depressed international coal prices till 2030 due to declining demand, coal is most likely to continue to be the cheapest fuel for Slovak electricity plants. Slovak energy policy envisages a very low rate of decommissioning of coal-fired power plants and shift towards gas power plants in the medium term. We assume that apart from small CHP plants and boilers Slovak electricity production will continue to be dependent on coal rather than gas till 2030, despite the fact that the country would have to import more coal, especially after 2023.

Figure 78: Slovak Natural Gas and Steam Coal Price Indices, 2008-2017

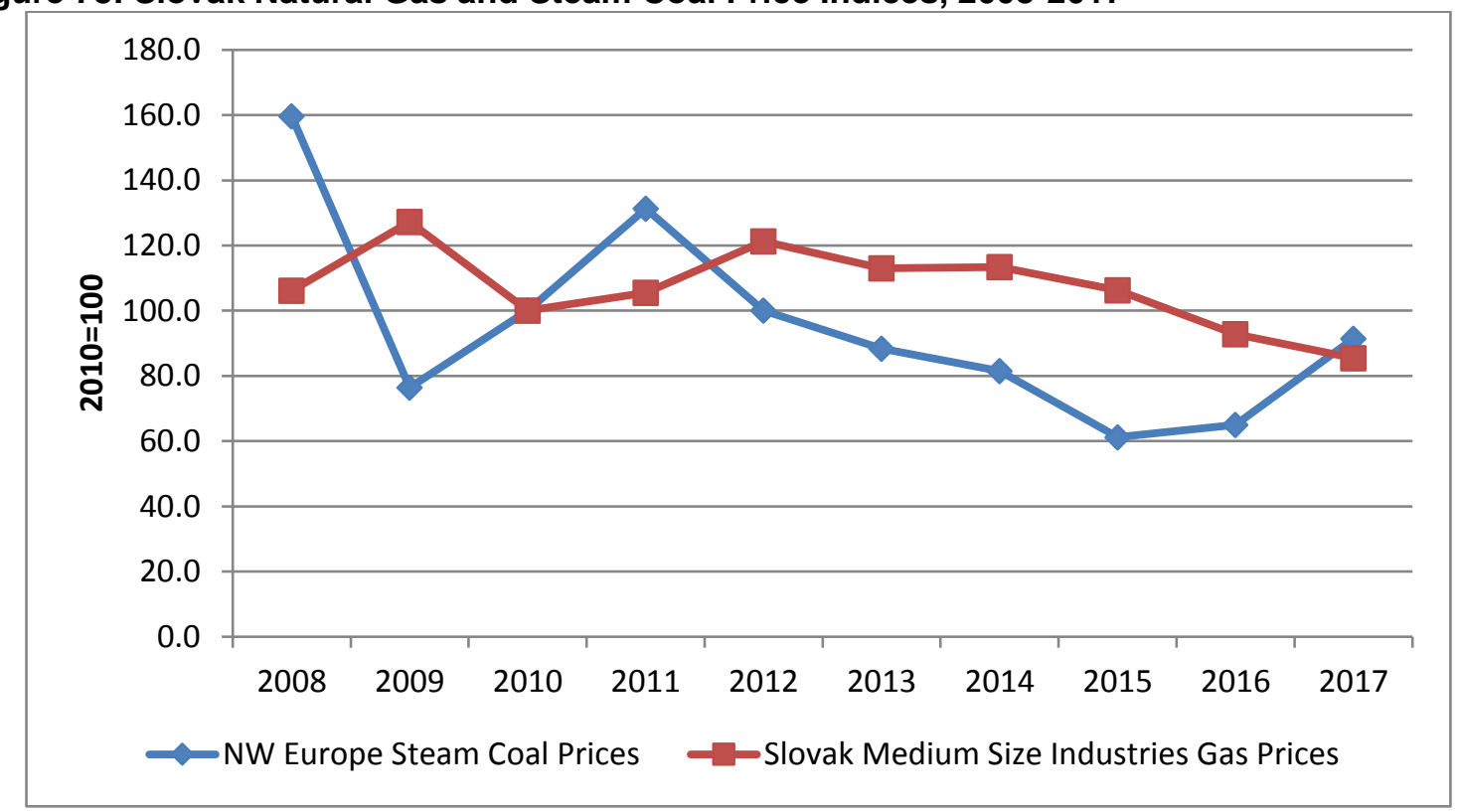

Source: Eurostat, BP

\subsection{Slovak Industrial Natural Gas Demand}

The Slovak economy is characterised by a rapidly growing manufacturing sector while the country has low domestic resources. As a result, the country is highly dependent on external markets for both imports of raw materials and exports of manufactured goods. Slovak industry is almost entirely dependent on imported gas, mainly from Russia. Industrial production only took off after the Second World War but has since gained an important place in the Slovak economy. Automotive, electronics,

\footnotetext{
147 http://www.hbp.sk/

148 https://www.euractiv.com/section/energy/opinion/will-slovak-coal-giant-benefit-from-eus-clean-energy-transition-efforts/
} 

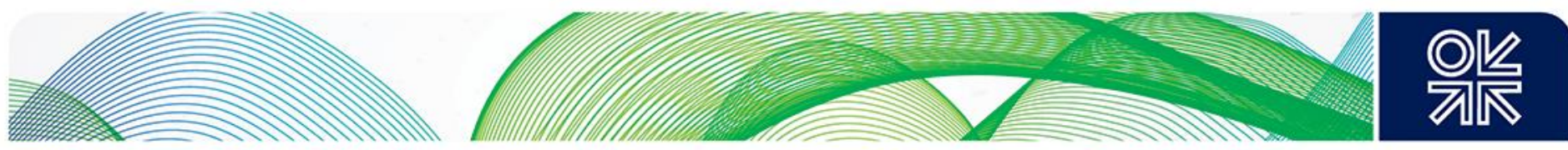

mechanical and chemical engineering and information technology are now the main industrial sectors, due to high investment inflows over the last two decades. The automotive sector is among the fastest growing sectors due to the recent investments by Volkswagen (Bratislava), Peugeot (Trnava), Kia Motors (Žilina) and since 2018 also Jaguar Land Rover in Nitra. In 2017, the industry sector accounted for $24 \%$ of GDP while the service sector contributed $65.5 \%$, construction $7.4 \%$ and agriculture $3.1 \%$. 149 Employment by the industry is also significant: $27.4 \%$ of all economically active citizens worked in the industrial sector in the last quarter of $2017 . .^{150}$

In 2017, industrial gas demand was $49.5 \%$ of gross Slovak natural gas demand. The largest consumer sectors were chemicals, metals, non-metallic minerals (glass, cement), food, paper and automotive, which together accounted for around $57.6 \%$ of total industrial gas demand of $2.5 \mathrm{bcm}$. The most industrialised regions of the country account for the bulk of the total demand: Bratislavský kraj $28 \%$ $(0.7 \mathrm{bcm})$, Nitriansky kraj $24 \%(0.6 \mathrm{bcm})$, Košický kraj $11 \%(0.3 \mathrm{bcm})$, and Trenčiansky kraj $10 \%$ $(0.3 \mathrm{bcm}) .{ }^{151}$ These are the regions with the largest concentration of industry. The key sectors will be the driving force behind the future natural gas demand in the country and are therefore the focus of this study.

Natural gas is the most important fuel for individual boiler heating and has the highest share in total heat consumption. In 2017 natural gas accounted for $44 \%$ of heat production, followed by coal (24\%) and biomass (16\%). ${ }^{152}$ According to Eurostat, derived heat is used for heating in approximately $22.1 \%$ of households while $52.6 \%$ were heated by natural gas directly in $2016 .{ }^{153}$ In the industry and service sector, natural gas represents over two thirds of heating. The current official forecast scenarios foresee the dominant share of gas remaining at the same level, apart from a small number of self-producers who may switch from natural gas burned in boilers to the use of syngas/small cogeneration or gas heat pumps. ${ }^{154}$

Natural gas demand by the key industries continues to be depressed below the pre-recession 2008 level. It is now at $60 \%$ of the peak industrial consumption in 1996. In 2017, industrial gas demand was $14 \%$ below the 2008 level. ${ }^{155}$ In 2016, there was the first sign of stabilisation due to economic growth, which was reflected in a growing gas demand in consumer sectors such as automotive and food. In 2017, most key industrial sectors showed a recovery. The significant decline in gas demand over the last decade is due to the long-lasting economic recession and to increasing efficiency in the Slovak economy, climatic conditions and energy savings. ${ }^{156}$ The period of high natural gas prices has encouraged energy savings and investment in energy efficient technology. The recession was followed by a period of high gas prices which prompted major energy efficiency savings as companies tried to cut their costs or switch away from gas altogether. The key industries' gas demand remained comparatively flat as they have less flexibility to switch fuels. Electricity and heat demand was much more responsive to high gas prices and demand slumped between 2012 and 2014 . While the gas demand has struggled, especially since 2011, Slovak industry has been growing strongly since 2014 and industrial output in 2017 is almost 37\% higher than in 2010.

\footnotetext{
Statistical Office of the Slovak Republic

50 Statistical Office of the Slovak Republic

${ }^{151}$ Statistical Office of the Slovak Republic, Energetika

${ }^{152}$ Statistical Office of the Slovak Republic, Energetika

${ }^{153}$ IEA Statistics

154 http://www.economy.gov.sk/uploads/files/47NgRIPQ.pdf

155 Statistical Office of the Slovak Republic, Energetika

${ }^{156}$ URSO Annual Report 2017
} 

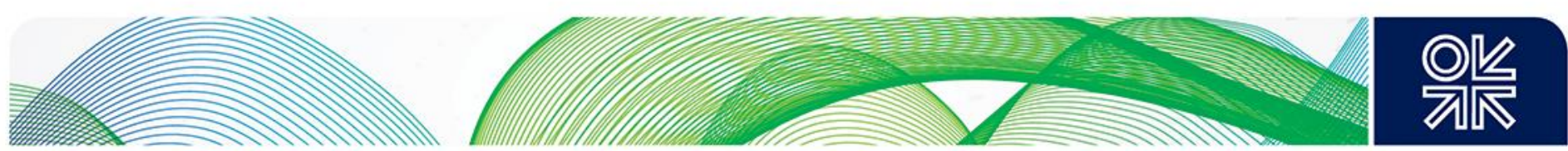

Figure 79: Slovak Industrial Natural Gas Consumption by Sector, 2008-2017

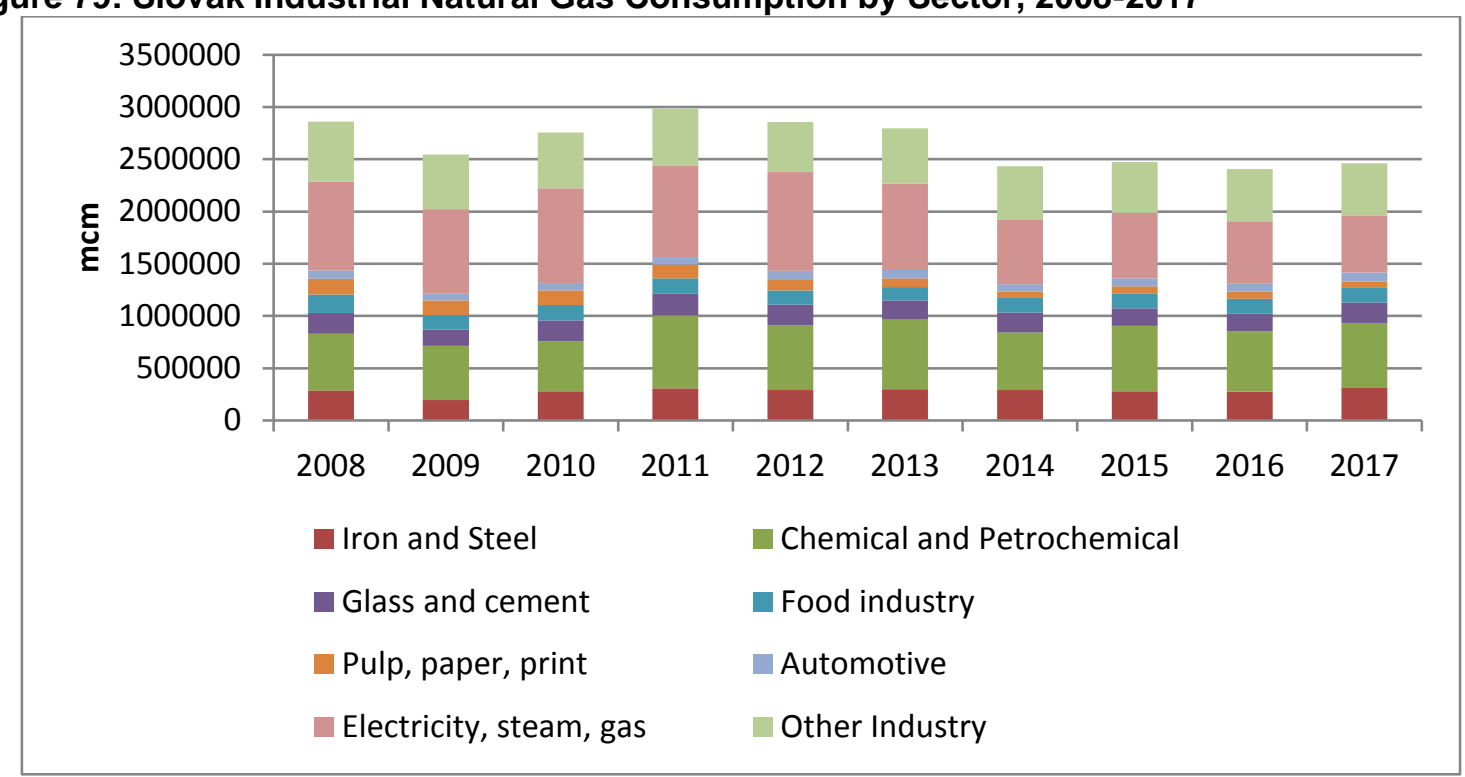

Source: Statistical Office of the Slovak Republic, Energetika

A quarter of total industrial gas demand is used for production of electricity, heat and steam rather than industrial processes. The chemical and petrochemical sector is the largest industrial consumer of natural gas in Slovakia and accounted for $25 \%$ of total industrial gas demand in 2017 , when its demand was almost 15\% above the 2008 level. The metal and steel sector is the second largest industrial consumer with $13 \%$ in 2017 . However, metal and steel gas demand fell below the 2008 level and steadily declined between 2013 and 2016 . The glass and cement industry (8\%) is the third largest gas consumer. Gas demand declined between 2008 and 2016 but bounced back in 2017. The pulp and paper industry saw the most significant decline as gas demand by the sector dropped by $60 \%$ between 2008 and 2017.

\subsection{The Slovak Chemical, Fertiliser and Petrochemical Industry}

The Slovak chemical industry comprises manufacture of coke and refined petroleum products, chemicals, pharmaceuticals and rubber and plastics processing. ${ }^{157} \mathrm{It}$ is closely connected to the Slovak automotive industry and electronics production. Turnover of many enterprises in the chemical industry is significantly tied to the development of crude oil prices and raw materials on world markets.

The chemical industry is an important manufacturing industry in Slovakia, contributing $13.3 \%$ to the Slovak industry revenues and employing around 44,640 persons, which represent $1.8 \%$ of the total workforce. ${ }^{158}$ Slovakia's economy is export-oriented and the chemical industry is no exception as it is a major exporter and importer. Nevertheless, the Slovak chemical industry has been increasingly dependent on imports of chemicals.

The sector was significantly impacted by the last recession with both revenues and profits declining to their lowest point in 2010. Growth returned in 2011 but was followed by ups and downs. However, the overall trend in gross value added by the chemical industry has been upward since 2009.

\footnotetext{
${ }^{157}$ NACE 19 - Manufacture of coke and refined petroleum products, NACE 20 - Manufacture of chemicals and chemical products, NACE 21 - Manufacture of pharmaceuticals, NACE 22 - Manufacture of rubber and plastic products

${ }^{158}$ Statistical Office of the Slovak Republic
} 

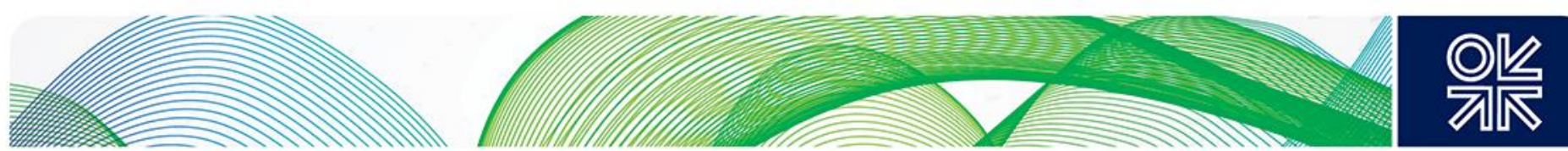

The chemical sectors are the most important natural gas consumers, accounting for over a quarter of all industrial gas demand in 2017. ${ }^{159}$

Figure 80: Natural Gas Demand by Slovak Chemical \& Petrochemical Industry, 2008-2017

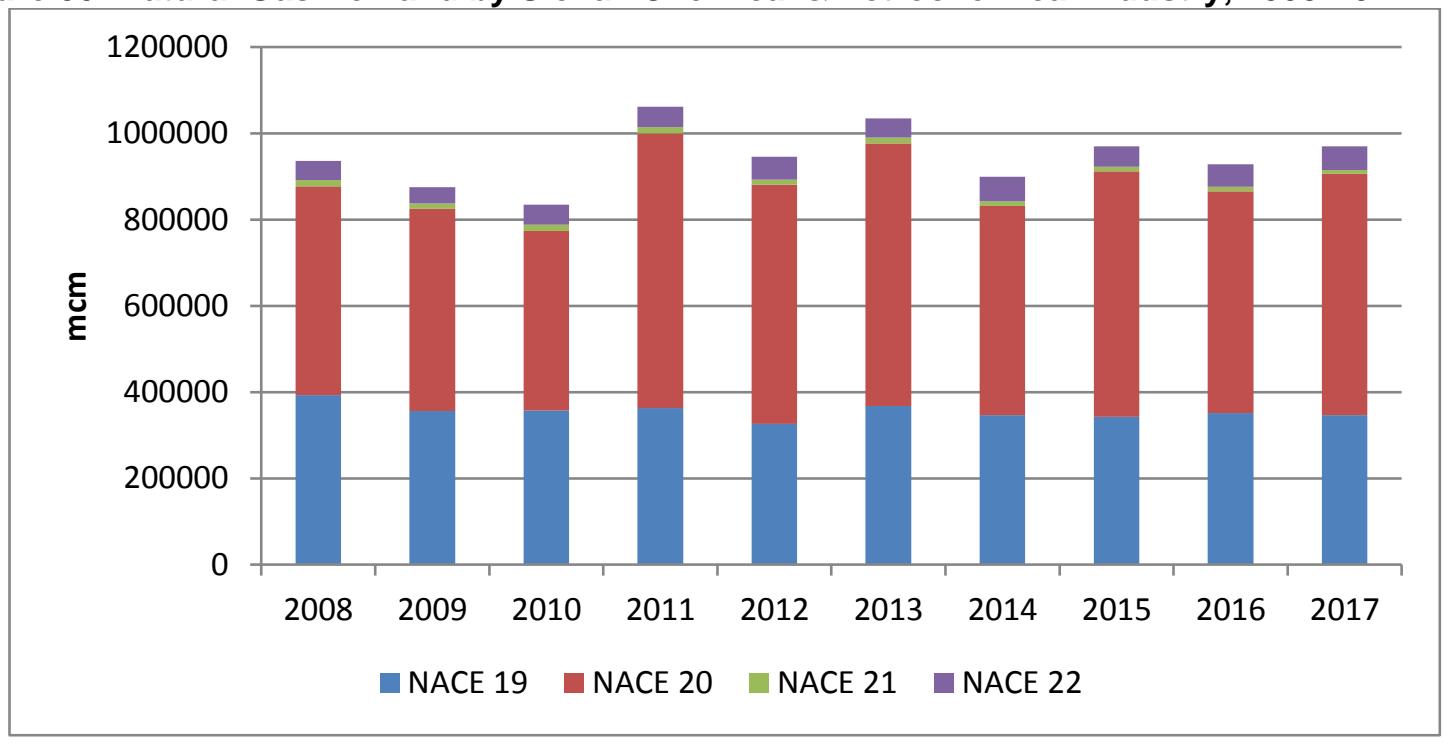

Source: Statistical Office of the Slovak Republic, Energetika

The chemicals industry (NACE 20) is the most significant consumer of natural gas within the Slovak chemical industry, consuming $58 \%$ of total chemical industry gas demand and is the most energy intensive subsector. It is followed by the petrochemical refining (NACE 19), which consumes $36 \%$ of total chemical industry gas demand. NACE 21 and NACE 22 are insignificant when it comes to natural gas demand and jointly account for the remaining $6 \%$ of the chemical industry gas demand. For the purpose of this study NACE 19 and NACE 20 will be the focus of a further analysis as they represent $94 \%$ of natural gas demand by the chemical sector.

The chemical industry depends largely on natural gas. In 2017 , coal represented $81 \%$ of energy consumed while industrial waste accounted for $19 \%$ and wood represented less than $1 \%$.

Figure 81: Slovak NACE 19\&NACE 20 Energy Demand, 2017

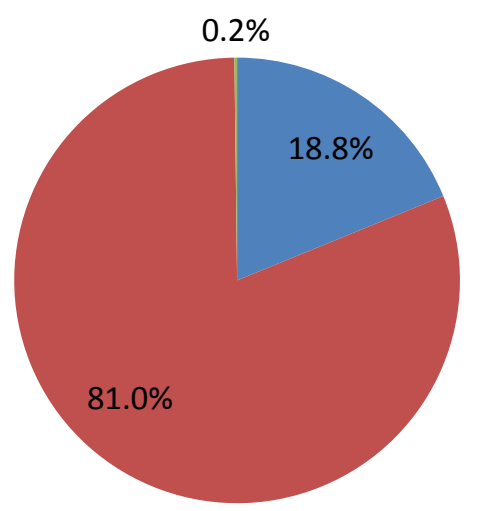

Industrial Waste

Natural Gas

Wood

Source: Statistical Office of the Slovak Republic, Energetika

\footnotetext{
${ }^{159}$ Statistical Office of the Slovak Republic, Energetika
} 

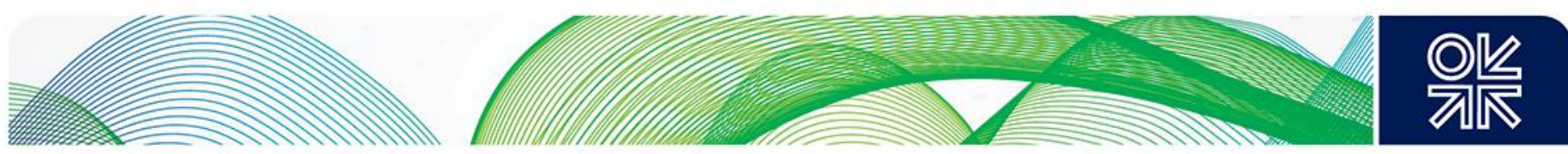

Petrochemical and fertiliser industries are one of the most important subsectors of the Slovak chemical industry. Slovnaft is the only refinery in Slovakia, which has been restructured and modernised and has a high level of conversion and flexibility. It is among the most modern refineries in Europe. Until the end of 2017, the production of electricity and heat in the Slovnaft Group was delivered by its subsidiary, CM European Power Slovakia, but at the beginning of 2018 this company was incorporated into Slovnaft. 160

The production of fertilisers in Slovakia is dominated by one company, Duslo, which has grown into an important European producer of fertilisers. It invested Euro 310 million in the new ammonia production unit in the existing plant in Sal'a, which was commissioned in the first quarter of 2018 and has increased the company's ammonia production capacity by $23 \%$ from 1,300t/y to $1,600 t / y$. According to press statements the new ammonia production unit uses the most modern technology in Europe ${ }^{161}$ and incorporates the most advanced engineering and technological solutions for minimum energy consumption and reduction of pollutant emissions.

The petrochemical and fertiliser industries use natural gas for non-energy purposes as feedstock and also for energy uses. There are no available separate statistics of non-energy natural gas consumption: the only statistics available are agglomerated non-energy natural gas use in the graph below. Nonenergy use is responsive to the development of natural gas prices and economic downturns and plummeted during the global recession and the period of high international gas prices of 2012-2014. The downturn post 2005 is also due to modernisation of the Slovnaft refinery. Non-energy use of natural gas is relatively small in the overall Slovak gas balance. In 2017, it represented $13 \%$ of domestic final gas consumption, according to the Slovak statistical office. ${ }^{162}$ However, the share and importance of feedstock gas demand has been increasing since 2008 when its share stood at $8.7 \%$.

\section{Figure 82: Slovak Non Energy Fertiliser/Petrochemical Feedstock Demand, 2001-2017}

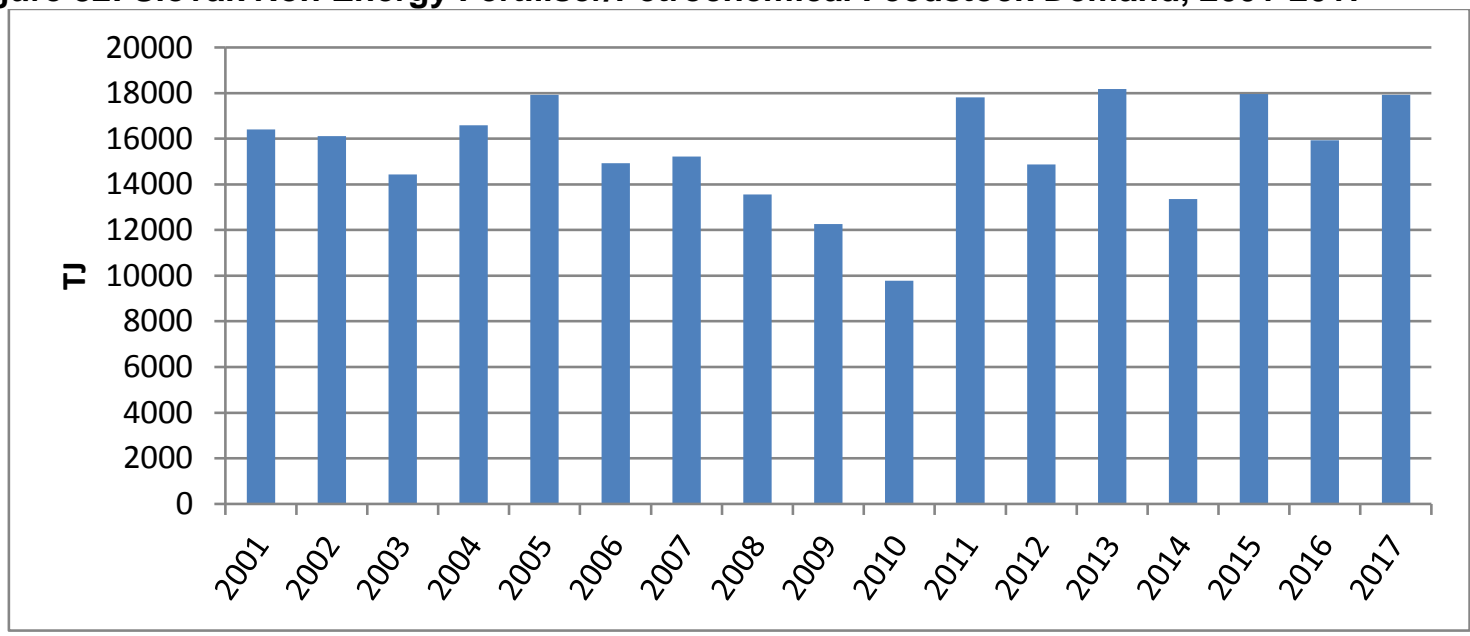

Source: Statistical Office of the Slovak Republic, Energetika, IEA

Gas demand for energy by the petrochemical industry has been relatively flat since 2009 with little deviation, regardless of the recession and the period of the high international gas prices. The bulk of NACE 19 energy gas demand is used by the Slovnaft refinery: other companies in this subsector are marginal. Apart from 2012, gas demand levelled at around $0.35 \mathrm{bcm} / \mathrm{y}$. This is because the refinery continued to operate nonstop. Since the refinery was modernised there was no evidence of noticeable

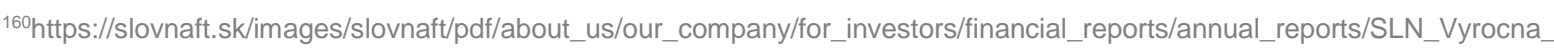
Sprava_2017_EN_Web.pdf

${ }^{161}$ https://www.technipfmc.com/en/media/news/2018/10/new-ammonia-production-plant-starting-up-in-slovakia

162 Statistical Office of the Slovak Republic, Energetika,
} 

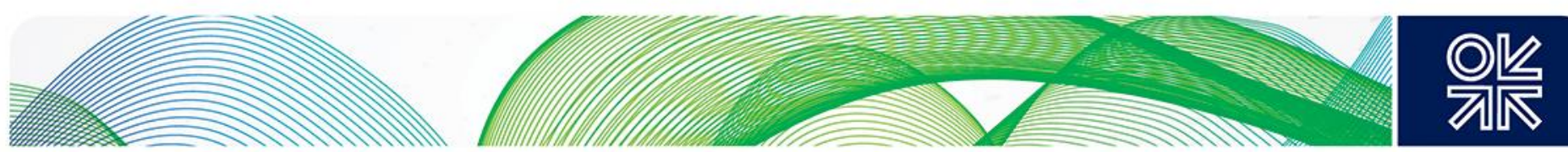

energy savings as the current technology is one of the most up to date in Europe. ${ }^{163}$ It seems that petrochemical production has not been impacted by high gas prices because prices of petrochemical products increased in line with mounting costs.

Figure 83: Slovak Petrochemical Industry Energy Natural Gas Demand, 2008-2017

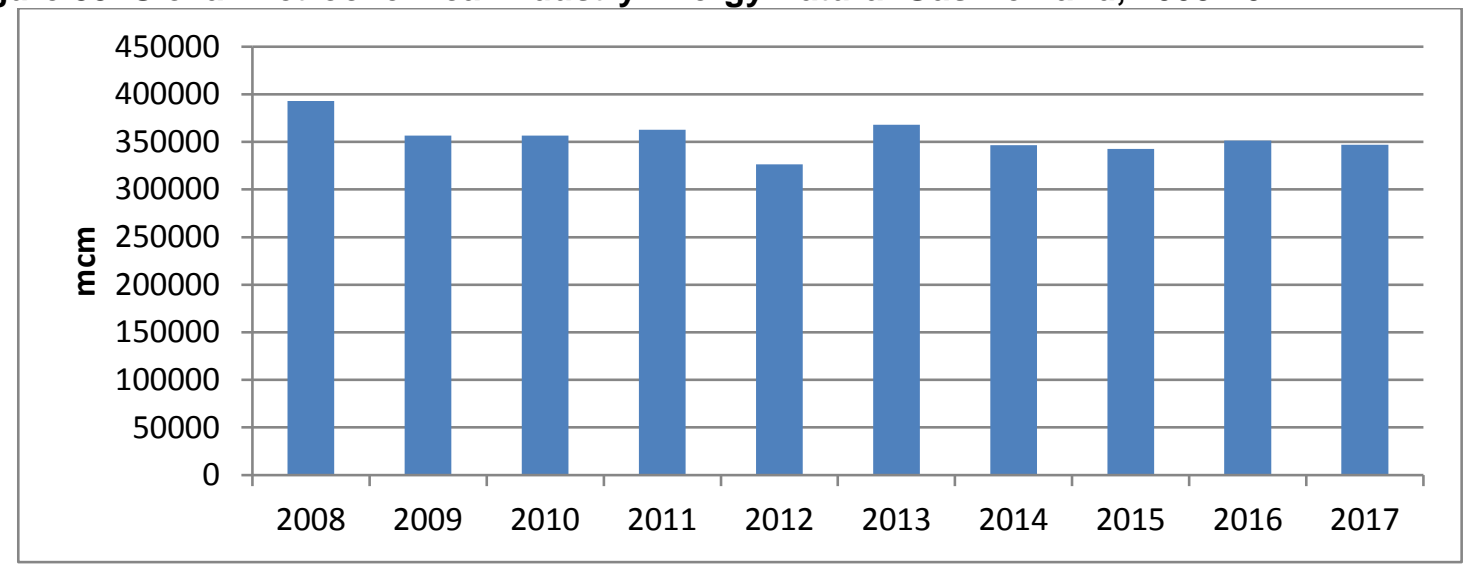

Source: Statistical Office of the Slovak Republic, Energetika

The situation is very different in the fertiliser subsector, which has continued to face fierce international competition that kept prices low. Duslo's accounts clearly show a major worsening of the financial health of the company as a result. From 2012 to 2016 the company's revenues shrunk by almost a quarter and its operating profits just managed to remain in the black. In 2017 revenues recovered but operating profits continued to decline. ${ }^{164}$

The energy gas demand by NACE20 has shown higher sensitivity to variation in international gas prices and gas demand slumped between 2011 and 2014. This subsector is the most natural gas intensive, which means gas represents a substantial share of production costs. Gas demand by NACE20 dropped from $0.64 \mathrm{bcm}$ in 2011 to $0.51 \mathrm{bcm}$ in 2016 , only slightly recovering in 2017 to $0.56 \mathrm{bcm}$.

Figure 84: Slovak NACE20 Natural Gas Demand, 2008-2017

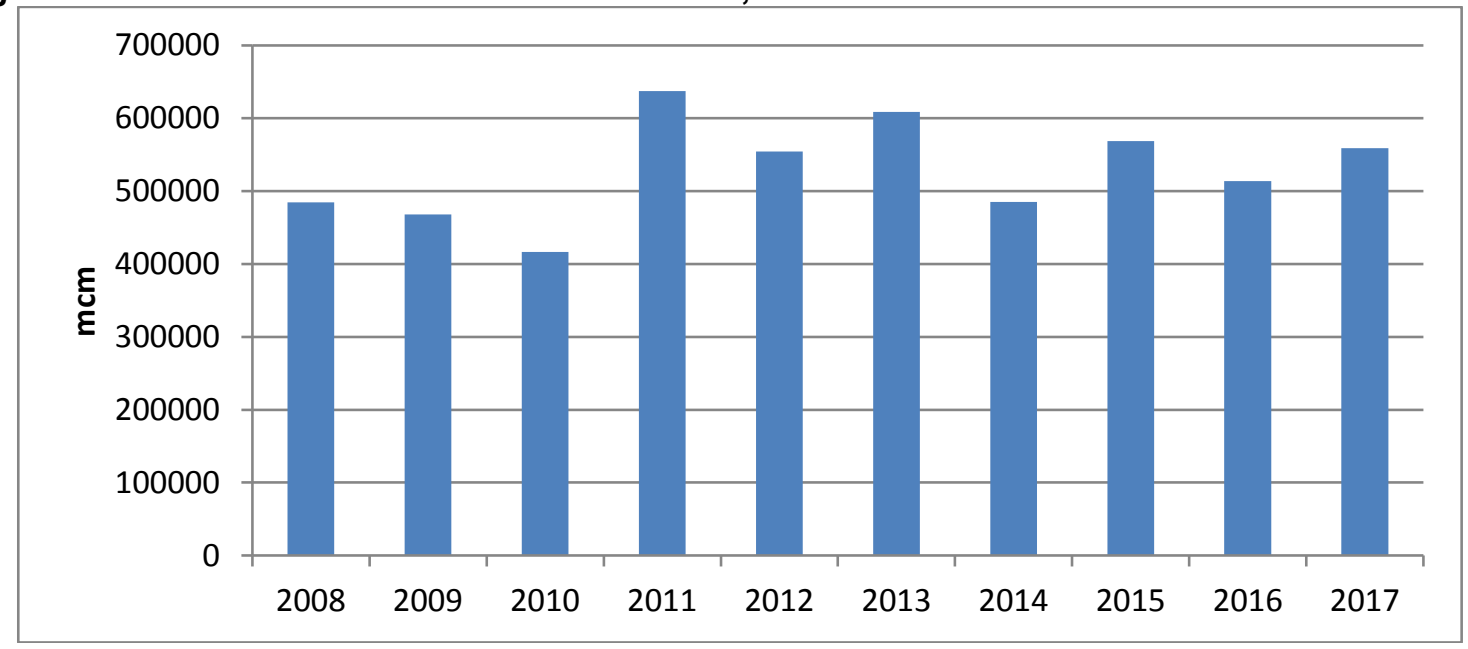

Source: Statistical Office of the Slovak Republic, Energetika

\footnotetext{
${ }^{163} \mathrm{https}: / /$ slovnaft.sk/images/slovnaft/pdf/about_us/our_company/for_investors/financial_reports/annual_reports/SLN_Vyrocna_ Sprava_2017_EN_Web.pdf

${ }^{164}$ https://www.duslo.sk/userfiles/downloads/vlrocanl sprlva k 31122017 s uz1.pdf
} 

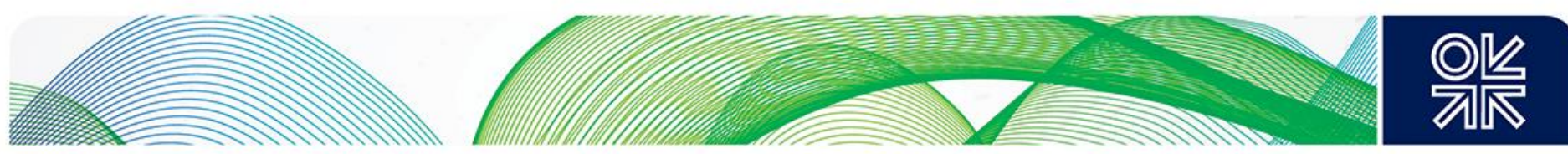

Comparison of the indices of gross value added and the indices of gas demand for NACE20 shows a loose correlation over the last decade. Clearly high international gas prices in 2011-2014 prompted a reduction in gas demand. However, gas demand followed the trend of gross value added, which would suggest that no tangible energy savings were achieved by the chemicals industry during the same period.

Figure 85: Slovak Indices of Gross Value Added and Natural Gas Demand by NACE20, 20082017

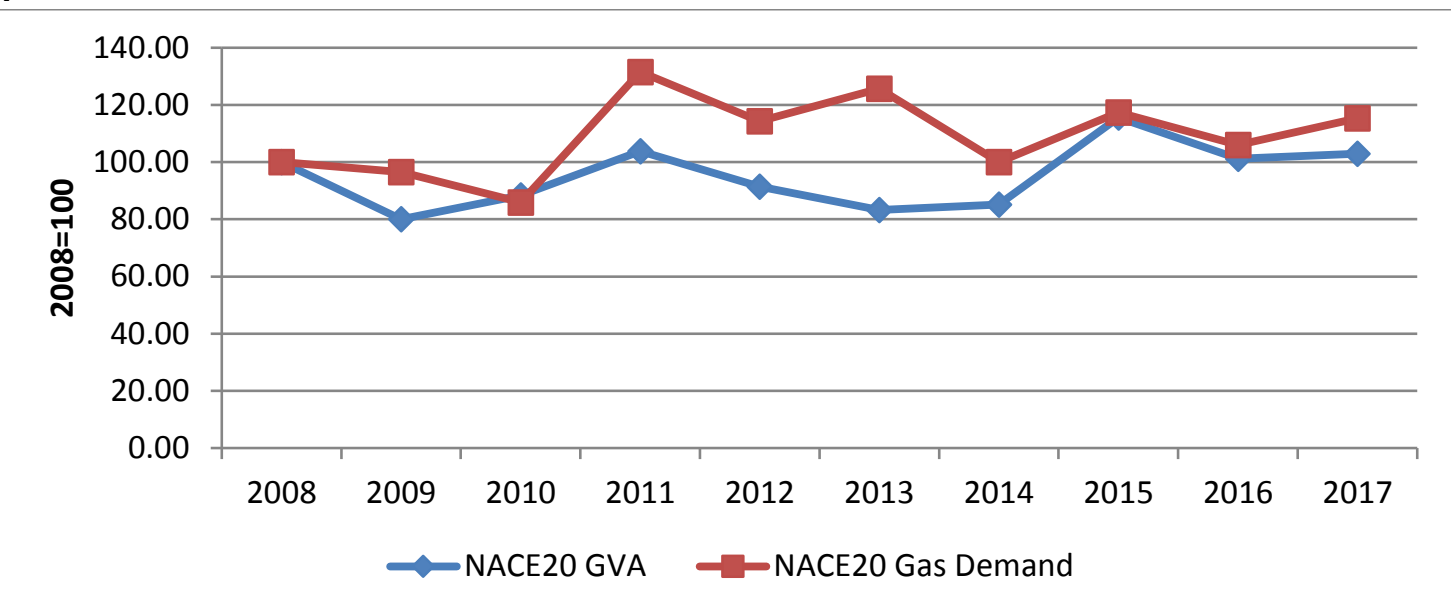

Source: Statistical Office of the Slovak Republic, Energetika

\section{Forecast}

Advantages

The Slovak chemical industry remains one of the most important industrial sectors of the Slovak economy. It is well integrated with Slovak industry and its main exports are destined to neighbouring countries.

The proximity to its main export markets is its competitive advantage and if the industry continues to invest in research, development and innovation it should be able to retain its domestic and export markets. The chemical companies are largely controlled by foreign investors who have invested heavily in the Slovak chemical sector, which means the leading companies are equipped with the most modern technology.

\section{Challenges to Growth}

In future, the Slovak chemical industry will increasingly face a more competitive environment as value chains gradually move eastward, drawn by economic growth and market opportunities in the Far East and lately the USA. ${ }^{165}$ The industry has to handle volatile commodity prices and fragile economic conditions, which will require inventive management as trade flows gradually change direction. Strategic decisions by chemical companies will be crucial for the health of business in this new competitive environment. Currently, the EU chemical industry expects a moderate growth of just $1 \% / y$, while more than $30 \%$ of jobs will be lost by 2030 as a result of slow growth and productivity gains. ${ }^{166}$

The Slovak chemical industry is unlikely to be an exception, because it is equally dependent on imports of raw materials at international prices. Since the industry is not labour-intensive, Slovakia's cheap

\footnotetext{
165 http://www.atkearney.co.jp/chemicals/ideas-insights/article/-/asset_publisher/LCcgOeS4t85g/content/chemical-industryvision-2030-a-european-

perspective/10192?inheritRedirect=false\&redirect=http\%3A\%2F\%2Fwww.atkearney.co.jp\%2Fchemicals\%2Fideasinsights\%2Farticle\%3Fp_p_id\%3D101_INSTANCE_LCcgOeS4t85g\%26p_p_lifecycle\%3D0\%26p_p_state\%3Dnormal\%26p_p mode\%3Dview\%26p_p_col_id\%3Dcolumn-2\%26p_p_col_count\%3D1

${ }^{166}$ Chemical Industry Vision 2030: A European Perspective, AT Kearney
} 

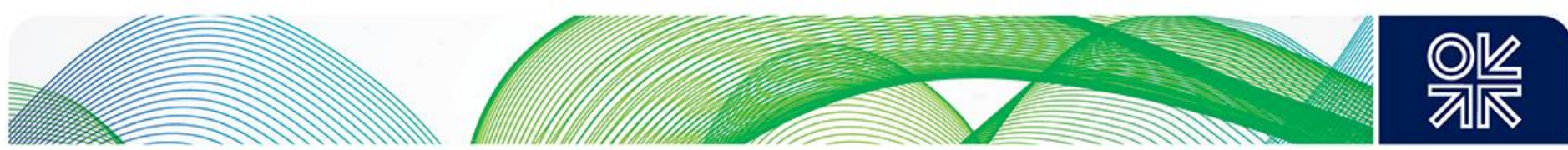

labour will not be an important advantage as it is in more labour-intensive industries. The chemical industry will continue to be very energy-intensive industry and international prices of energy and raw materials will be similar to the rest of Europe.

In relation to energy and climate change, the conditions for trading in greenhouse gas emissions will have a significant impact on Slovak chemical companies in the next decade. ${ }^{167}$

Since the chemical companies are largely controlled by foreign investors it can be argued that funding R\&D in Slovakia may not be always their priority.

\section{Reference Scenario}

Slovakia's economic growth is projected to strengthen in 2019 and 2021 on the back of an upswing in investment and more positive contributions of net trade, with growth between $3.5 \%$ and $4 \% / y$ till 2020 and slowing down to $3.0 \%-3.5 \% / y$ till 2025,168 with further deceleration to $3 \% / y$ between 2025 and $2030 .{ }^{169}$ Given the current buoyant economic forecasts for Slovakia and the EU-28 growth level of $1.5 \%-2.0 \% / y$ in the next decade, it is feasible that the Slovak chemical industry will grow by around $2 \% / y$ till 2020 and slow down to 1\%/y between 2021 and 2030. The exception is NACE 22, which is irrelevant to natural gas consumption, is inseparably linked to the car industry and will post higher rates of growth.

The fertiliser and petrochemical industry is however reliant on natural gas as feedstock and will struggle in the future to compete with products which will be produced near natural gas fields in Central Asia or the USA, where prices of natural gas will be significantly lower than in Central Europe. ${ }^{170} \mathrm{It}$ is expected that the non-energy use of natural gas will decline from $0.5 \mathrm{bcm}$ in 2017 to $0.3 \mathrm{bcm}$ in 2030 .

In contrast, it is expected that the chemical industry's energy gas demand will grow by some $2 \% / y$ till 2020 and then slow down to some $1 \% / y$, given that some energy savings are still to be introduced. The chemical industry in total, including non-energy feedstock, is forecast to consume $1.5 \mathrm{bcm} / \mathrm{y}$ by 2030 . Incremental annual gas demand by the chemical industry will be some $0.03 \mathrm{bcm} / \mathrm{y}$ by $2030 \mathrm{compared}$ to 2017.

\footnotetext{
167 https://ec.europa.eu/clima/policies/strategies/2030_en

168 https://ec.europa.eu/info/sites/info/files/economy-finance/ip096_en.pdf

169 https://data.oecd.org/gdp/gdp-long-term-forecast.htm

170 http://www.atkearney.co.jp/chemicals/ideas-insights/article/-/asset_publisher/LCcgOeS4t85g/content/chemical-industryvision-2030-a-european-

perspective/10192?inheritRedirect=false\&redirect=http\%3A\%2F\%2Fwww.atkearney.co.jp\%2Fchemicals\%2Fideasinsights\%2Farticle\%3Fp_p_id\%3D101_INSTANCE_LCcgOeS4t85g\%26p_p_lifecycle\%3D0\%26p_p_state\%3Dnormal\%26p_p mode\%3Dview\%26p_p_col_id\%3Dcolumn-2\%26p_p_col_count\%3D1
} 

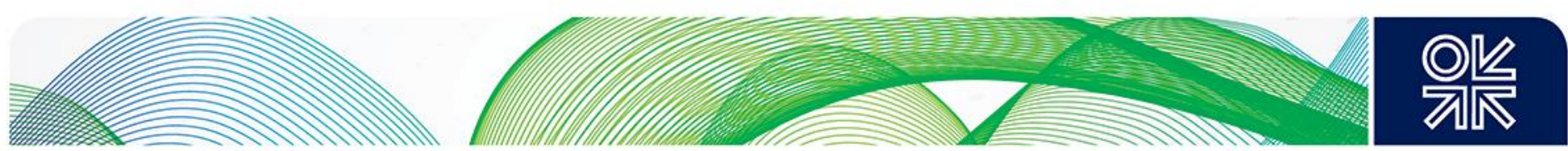

Figure 86: Slovak Reference Natural Gas Demand Forecast by Chemical Industry 2015-2030

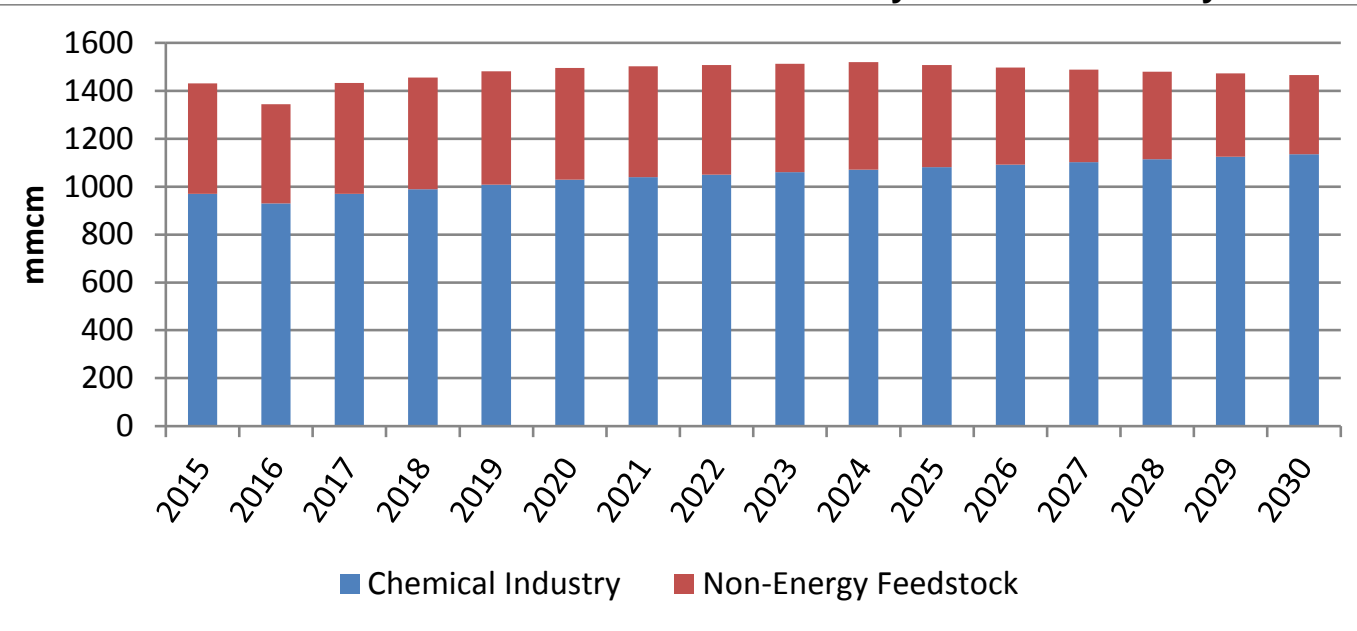

Source: Author's forecast

\section{Optimistic Scenario}

In the event that the Slovak chemical industry fares better than the rest of the EU industry due to local support driven by buoyant domestic industrial growth, gas demand by the chemical industry will continue to grow on average by some $2 \% / y$ throughout the forecast period. Even in such a case it will be unlikely that gas demand for feedstock will increase; it will plateau at the current level in the best case. The optimistic scenario foresees gas demand by the chemical industry (including feedstock) reaching some $1.7 \mathrm{bcm} / \mathrm{y}$ by 2030, which represents an incremental increase of $0.29 \mathrm{bcm} / \mathrm{y}$ over 2017 .

Figure 87: Slovak Optimistic Natural Gas Demand Forecast by Chemical Industry 2015-2030

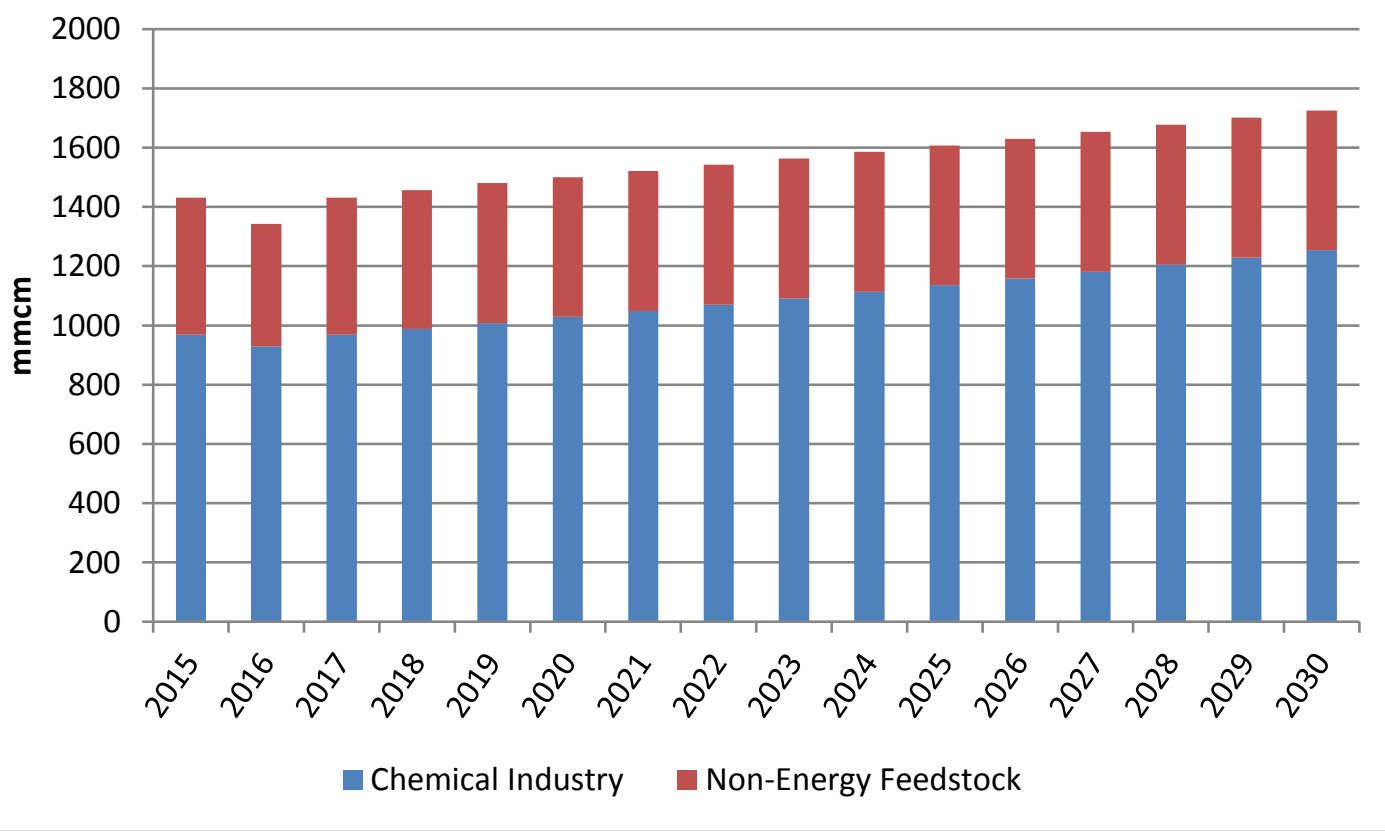

Source: Author's forecast 

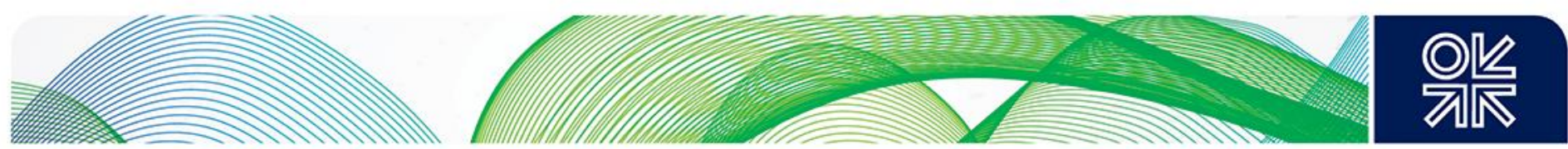

\subsection{The Slovak Steel Industry}

The Slovak steel industry in this report comprises the NACE $24{ }^{171}$ and NACE $25^{172}$ sectors. It traditionally ranked within the top ten EU producers of steel and currently employs over 58,387 people, $2.3 \%$ of the total Slovak workforce, which has grown from 52,401 in $2011 .{ }^{173}$ The Slovak metal sector used to contribute around $10 \%$ to GDP but its contribution has been declining. In 2017 it contributed $4.5 \%$ to gross value added, as international competition reduced the sector's revenues. The steel industry is the main supplier to the Slovak engineering industry and other manufacturing sectors. It is still considered to be the backbone of local industry.

At present, there are only two companies in Slovakia with full metallurgical cycle from the manufacture of iron through the production of steel to the production of semi-finished products and rolled products U. S. Steel Košice and Železiarne Podbrezová. U.S. Steel Kosice accounts for 4.5 million tonnes/year of Slovakia's production, $90 \%$ of the country's steel production. ${ }^{174}$ The Slovak steel industry is thus largely concentrated in one region, Eastern Slovakia. Iron ore, the core raw material for steel production, is imported.

The Slovak steel industry is very vulnerable since it is almost entirely reliant on one company, U. S. Steel Košice (owned by United States Steel Corporation) which is one of the largest integrated producers of flat-rolled steel products in Central Europe. Currently, the company employs almost 12,000 people.

Crude steel production has fluctuated between 2009 and 2017 but the overall trend has been increasing. Production has outpaced apparent consumption for the entire period and has often been double domestic demand, so the sector is export-oriented. However, since 2014 imports of cheaper steel products mainly from outside the EU have made inroads. In 2017, there was an improvement in the trade balance as EU tariffs on metal products from outside the EU made an impact. Direct imports from outside the EU to Slovakia are only one part of the problem, more important are imports to the EU where they replace Slovak exports. The EU is the major market for the Slovak metallurgical industry but Slovak steel is increasingly supplying automotive industry at home and abroad.

Slovakia has the seventh highest energy intensity in the EU. Although the period of high natural gas prices between 2012 and 2015 prompted companies to introduce energy saving measures and to invest in new technologies, energy efficiency deteriorated due to the recession and the fact that factories did not operate at full capacity and were thus less efficient. The steel industry is responsible for over a half of industrial energy consumption. Moreover, the energy intensity in steel production increased between 2007 and 2012. Some savings were introduced since then but the current energy intensity is very high. Comparing total energy consumption by the iron and steel industry between 2012 and 2017 to the tonnage of steel produced it seems that energy intensity has declined by almost $11 \%$ over the last five years. ${ }^{175}$ Official statistics are not published because of the dominance of one company.

\footnotetext{
${ }^{171}$ Manufacture of Basic Metals, Metallurgy, and Casting of Metals

172 Manufacture of Fabricated Metal Products, except Machinery and Equipment

173 Statistical Office of the Slovak Republic

174 https://www.usske.sk/en/about-us/corporate-info/financial-statements

175 Statistical Office of the Slovak Republic, Energetika
} 

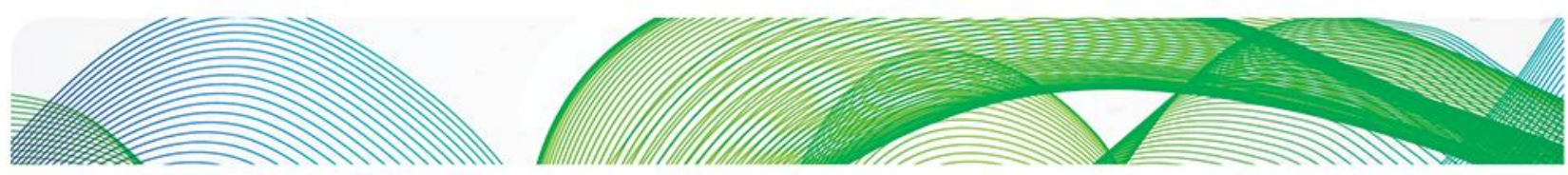
애잔

Figure 88: Slovak Energy Used per Tonne of Steel, 2000-2012

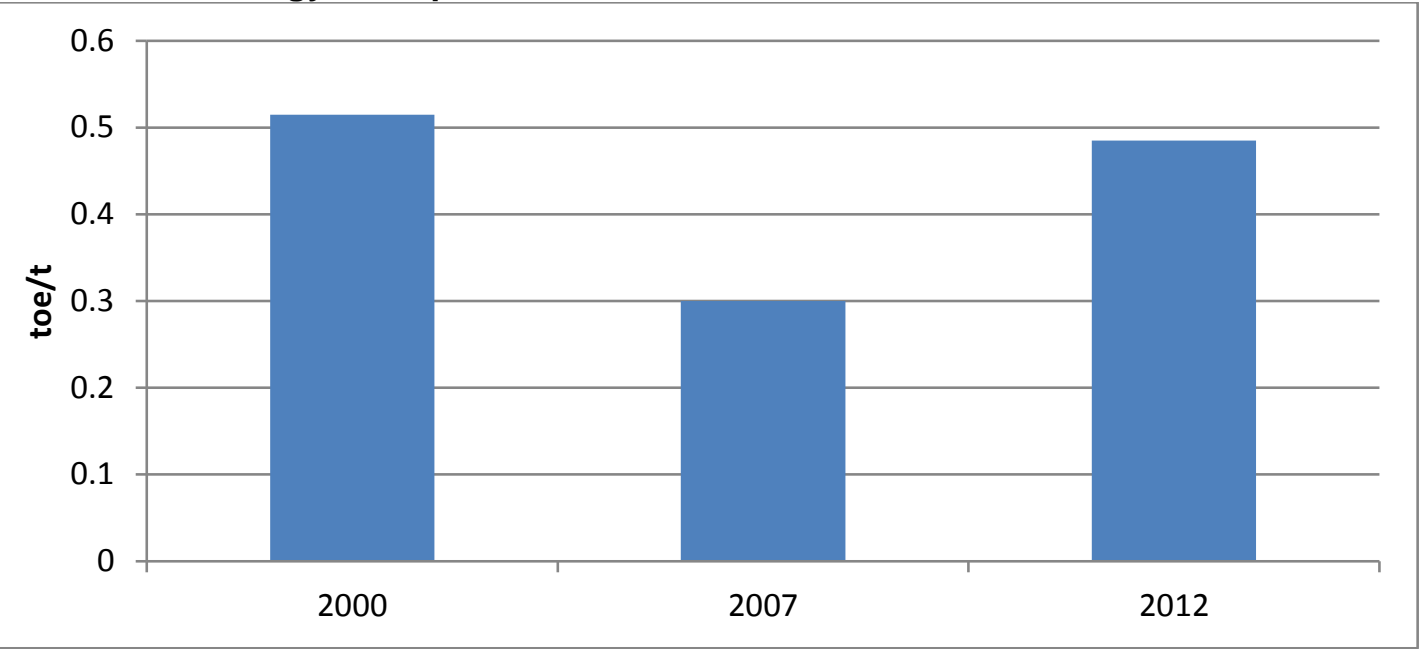

Source: Energy Efficiency Trends in Industry in the EU May 2015

Although the sector was hit by the last recession, steel production has quickly rebounded and is now well above the 2008 level. Over the last decade, there have been periods of growth and decline, but the overall trend has shown slowly growing progress in steel production. Due to some restructuring of the sector and external competition from cheap imports, the sector is moving towards higher value added products. A clear trend is evident that the steel industry has managed to post positive growth in sales and profits since 2009, with the one exception of 2012. However, once the figures from the dominant steel producer US Steel Košice are taken into account it is clear that the positive growth is entirely driven by the manufacture of fabricated metal products. U. S. Steel Košice's profits were in the red for a few years after 2009, but since 2014 the company has reported positive figures albeit the profitability is still very low. ${ }^{176}$

Figure 89: US Steel Košice Revenues and Operating Profits, 2007-2017

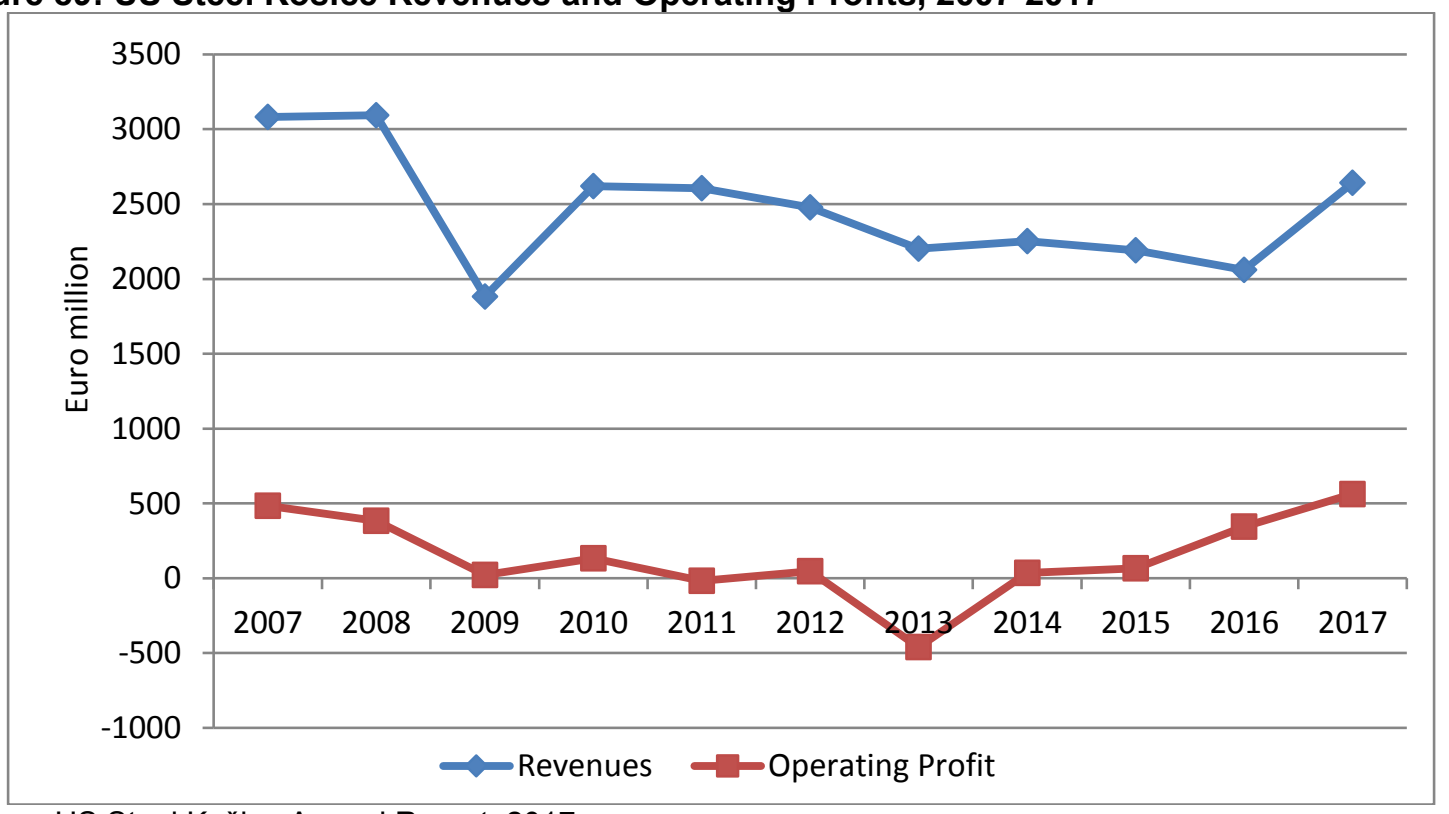

Source: US Steel Košice Annual Report, 2017

\footnotetext{
176 https://www.usske.sk/en/about-us/corporate-info/financial-statements
} 

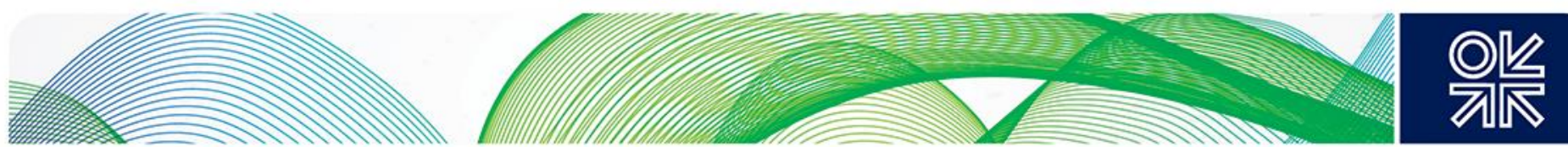

The iron and steel sector continues to depend heavily on coal. In 2017, coal consumed almost $59 \%$ of energy consumed followed by natural gas $(40 \%)$ and wood (1\%). The Slovak steel mills are still solely dependent on coal and coke furnace gas. There is currently no natural gas furnace in Slovakia. Natural gas is solely used for heating purposes.

Figure 90: Slovak Iron \& Steel Industry Energy Demand, Share by fuel, 2017

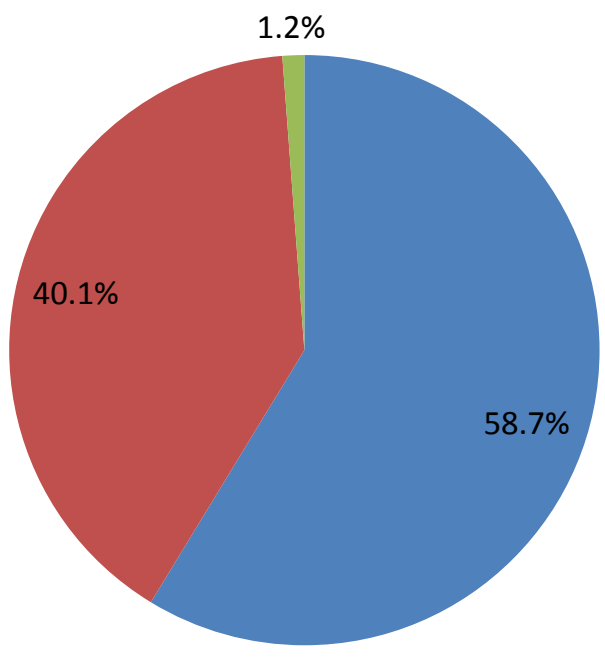

- Coal

natural Gas

Wood

Source: Statistical Office of the Slovak Republic, Energetika

The iron and steel industry accounts for $13 \%$ of industrial natural gas demand. Over the last decade, natural gas consumption by the sector has seen ups and downs which were largely predisposed by the volumes of produced steel. In 2017 natural gas use recovered strongly after three years of decline. This was due to much colder January weather and strongly growing steel production.

Figure 91: Slovak Natural Gas Demand by Iron and Steel Industry, 2008-2017

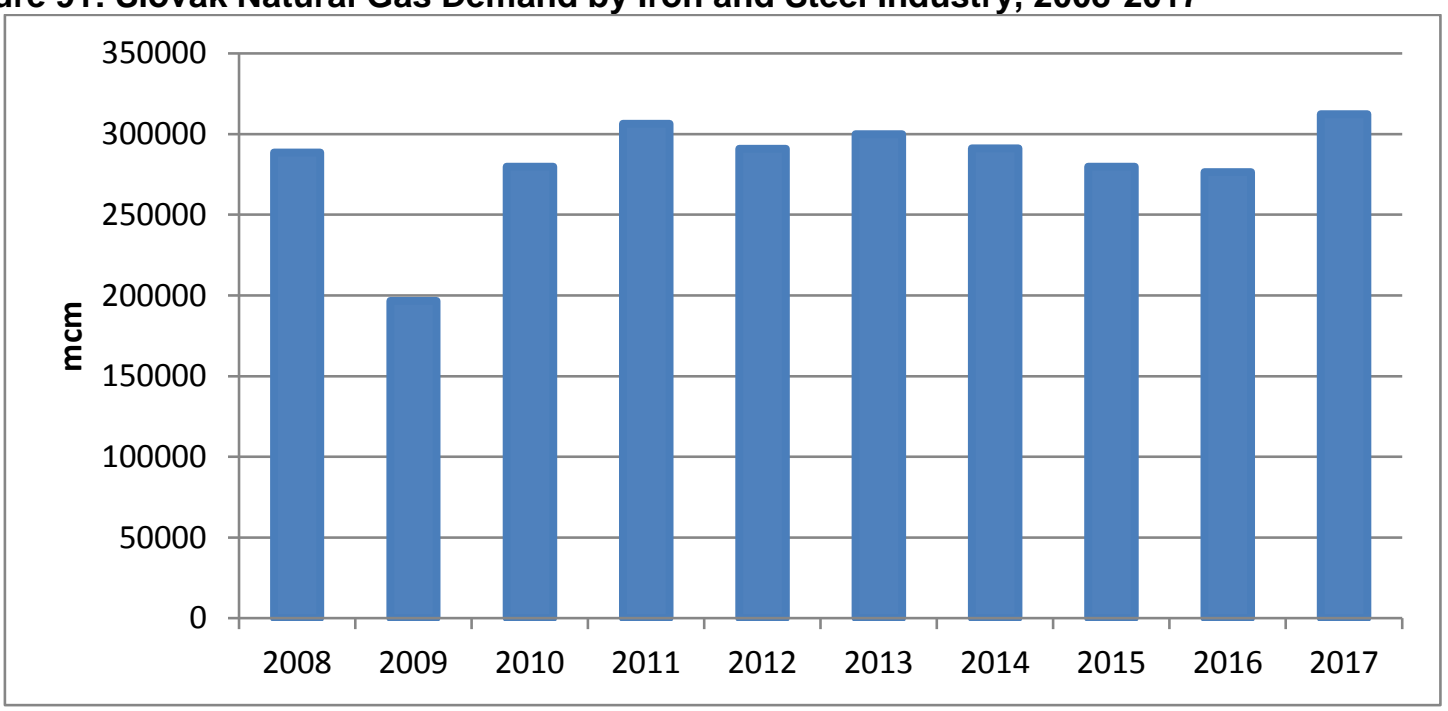

Source: Statistical Office of the Slovak Republic, Energetika

Natural gas demand by the steel sector was closely correlated to the development of steel industry output until 2010. However, the steel production declined sharply in 2011 while gas demand continued to grow. It is only since 2013 that major gas demand declined despite the recovery in steel production. This is largely because steel mills have managed to reduce energy intensity and higher utilisation rates. 

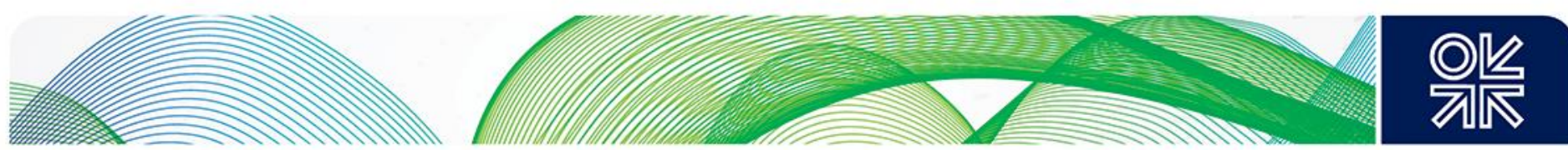

In 2017, the trend was reversed and both steel production and gas demand grew strongly, as the sector used $0.31 \mathrm{bcm}$ of natural gas exceeding the previous peak of 2011 .

Figure 92: Slovak Steel Production and Gas Demand by Steel Industry Indices, 2008-2017

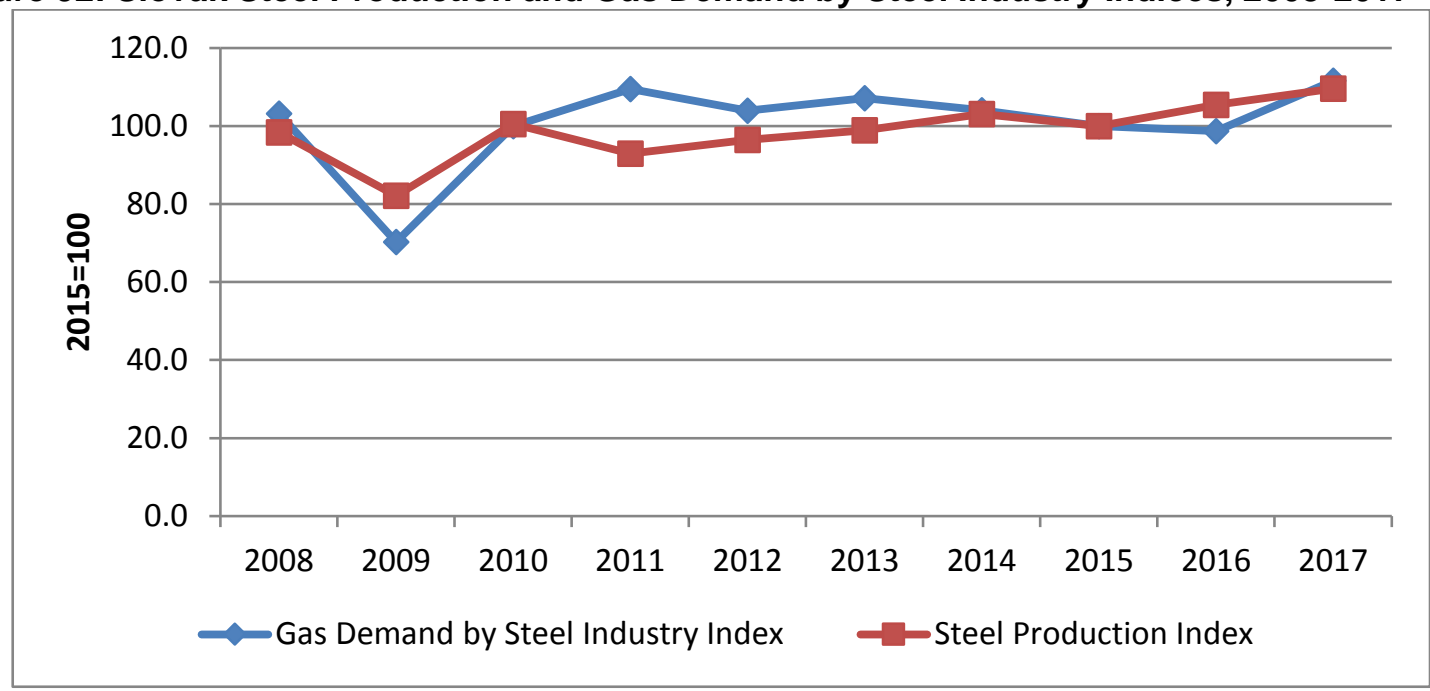

Source: Statistical Office of the Slovak Republic, Eurofer

\section{Forecast}

\section{Advantages}

On the positive side, Slovak steel production has fared better than the EU-28 average and Slovak steel output has recovered from the slump and is now well above the pre-recession levels. ${ }^{177}$ Given recent investment and strong Slovak economic growth it is expected that the sector will remain stable for the next couple of years. ${ }^{178}$ This will be driven by the stronger domestic and EU economic growth, population growth and increasing EU demand for steel products. The Slovak steel industry can also offer its geographical proximity to main consuming markets such as Germany.

A large share of Slovak steel industry products is oriented towards the transport sector which will show continuous growth, with the highest increase in 2025 to $2030,{ }^{179}$ driven by developments in economic activity, growth in autonomous vehicles and increasing population. Slovakia alone is one of the biggest manufacturers of vehicles in Europe. However, a question is whether the Slovak steel industry can provide high enough quality products and flexibility for the local car industry to benefit from this development.

Competitive gas prices in Slovakia, lower labour costs and an advantageous tax regime are likely to ensure the survival of the steel industry in Slovakia over the next decade. The fact that Slovakia is a landlocked country will continue to protect the local steel industry from cheap imports arriving at European ports from third countries. ${ }^{180}$

\section{Challenges to Growth}

The major weakness of the Slovak steel sector is that the industry is dominated by one producer which is struggling with increasing competition. The situation has started to improve since 2016 due to lower raw material and energy costs and better operating efficiencies from running at higher utilisation rates, partially offset by lower average realized prices. Nevertheless it is difficult to see a rosy future for the

\footnotetext{
177 http://www.eurofer.org/News\%26Events/PublicationsLinksList/201806-AnnualReport.pdf

178 https://www.usske.sk/en/about-us/corporate-info/financial-statements

179 https://eu-smartcities.eu/sites/default/files/2018-03/pwc-five-trends-transforming-the-automotive-industry.compressed.pdf

180 https://www.euro.cz/byznys/ocelova-mesta-v-ohrozeni-vyzene-brusel-tezky-prumysl-z-evropy-

1328742 \#utm medium=selfpromo\&utm source=euro\&utm campaign=copylink
} 

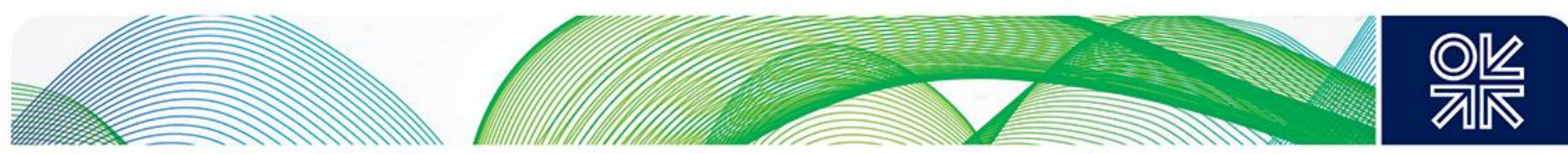

Slovak steel industry. The outdated technology of the US Steel Košice plant already struggles to supply sheet steel to the high quality standards required by the automotive industry. Its galvanising line, necessary for production of high-quality added-value steel, is almost 10 years old and does not fully meet the requirements of carmakers any more. ${ }^{181}$ The US Steel Group has been trying to sell the company for a number of years but no agreement has so far been signed. The Chinese He-Steel Group was most frequently mentioned among its potential buyers but no deal has been signed and currently there is no deal on the table. In May 2018, the parent company US Steel announced that it will retain the ownership of the Slovak plant. US Steel Kosice is currently hiring more people and has invested $€ 250$ million in new technologies over the past three years, which seems to indicate that the U.S. investor's intention is to stay in Košice for the time being. ${ }^{182}$

Since 2000, the company has invested more than $\$ 610$ million in dozens of environmental projects and is in compliance with all the EU current environmental requirements. However, after 2020 stricter EU $\mathrm{CO}_{2}$ emission requirements will increase the company's costs as it will be required to purchase emission allowances. This could result in restriction of production after 2020. Moreover, the Košice plant suffers from a shortfall in investment, stemming from significant cuts by its American parent company following the financial crisis in 2009. As a consequence, the technology at the plant has become outdated and the quality of its products is unable to compete with other steelmakers. It is estimated that investments totalling at least $€ 1$ billion would be required to support ongoing production. Steel industry experts have also estimated that an additional $€ 1$ billion is needed to bring the plant up to a level at which it can compete with top European producers like Voestalpine or ArcelorMittal. ${ }^{183}$ Given the financial difficulties of the US Steel, it is not expected that the Košice plant will receive the needed investment.

In the longer term, the future of US Steel Kosice is unpredictable since the parent company is in financial difficulties and will not be able to fully modernise the plant. Technology and innovation cycles have become much shorter in recent years, as is demonstrated by rapid changes in product and market segments. Without investment in research and new technology steel plants will find it difficult to compete with cost leaders. Even in the best scenario where the Kosice plant is bought by a new owner with the intention to modernise the plant, it is difficult to see that the Slovak steel industry will continue to prosper in the mid-term as the industry is unlikely to invest and finance research that would keep it ahead in innovation and quality in coming years.

The Slovak steel industry is likely to face increasing competition and will find it difficult to compete in the higher quality value added products niche. Although it can offer its geographical proximity to main consuming markets, it is currently unable to provide enough flexibility and a reliable delivery service and without further investment it may gradually lose its domestic market.

The EU measures on anti-dumping and anti-subsidy against imports of metallurgical products from third countries will also play a decisive role in the future of the steel industry in the EU in general.

The targets set for 2030 by the EU in the greenhouse gas trading system (EU ETS) could put a heavy burden on the sector and could lead to relocation outside the EU to countries and regions with inadequate climate protection policy. ${ }^{184}$ However, Slovak steel works have cut their emissions and are currently within the EU limit. Nevertheless, after 2020 compliance with $\mathrm{EU} \mathrm{CO}_{2}$ emission requirements for the sector may involve further costs for purchasing emission allowances, and could result in restriction of production.

\footnotetext{
${ }^{11}$ https://spectator.sme.sk/c/20449178/u-s-steel-will-they-stay-or-will-they-go.html

$182 \mathrm{https://spectator.sme.sk/c/20818323/ussk-remains-in-kosice-for-now.html}$

$183 \mathrm{https}: / /$ spectator.sme.sk/c/20449178/u-s-steel-will-they-stay-or-will-they-go.html

184 https://ec.europa.eu/clima/policies/strategies/2030_en
} 

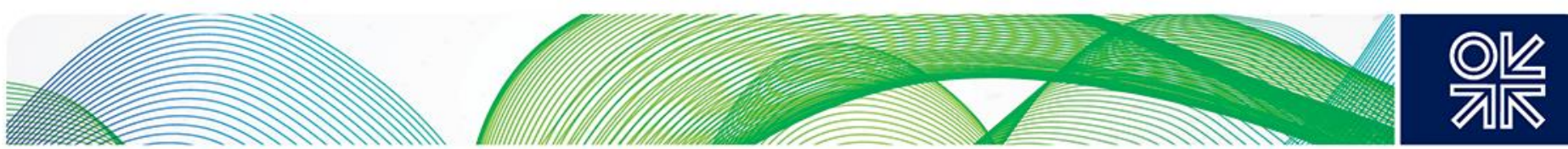

\section{Reference Scenario}

Slovakia's economic growth is projected to strengthen in 2019 and 2020 on the back of an upswing in investment and more positive contributions of net trade, with growth between $4 \%$ and $3.5 \% / y$ till 2020185 slowing down to $3.5 \%-3.0 \% / y$ till $2025^{186}$ and further decelerating to 3\%/y between 2025 and 2030 . Given the current economic growth forecasts for Slovakia and the EU-28 of 1.5\%-2.0\%/y in the next decade, it is feasible that the Slovak steel industry will continue to survive, supported by domestic demand and will show only a 1\%/y average decline till 2025 and 5\%/y between 2025 and 2030 . The output by the dominant producer will be constrained by outdated technology and will increasingly lose share to the EU steel industry. Moreover, US tariffs on aluminium and steel will have a dampening effect on the whole European steel industry and thus the growth rate will be limited. It is expected that the gas demand by the steel industry will plateau till 2020 and then start to decline at a moderate rate of $1 \% / y$ till 2025 and 5\%/y between 2025 and 2030. The incremental reduction in gas demand will amount to $0.08 \mathrm{bcm} / \mathrm{y}$ over the next decade.

\section{Optimistic Scenario}

In the unlikely event that a new investor willing to spend $€ 2$ billion on modernising the Košice steel mill could be found, Slovakia would be in a position to increase its steel exports, supplying chiefly the European car industry, and to escalate supply to the domestic market due to demand from rising production in the export-oriented automotive sector. In such a case, the forecast would be much more positive, driving natural gas demand from 2025 onwards to reach some $0.44 \mathrm{bcm}$ in 2030 , which represents an increase of $0.13 \mathrm{bcm} / \mathrm{y}$ on 2017.

Figure 93: Slovak Reference Steel and Metal Industry Natural Gas Demand Forecast 2015-2030

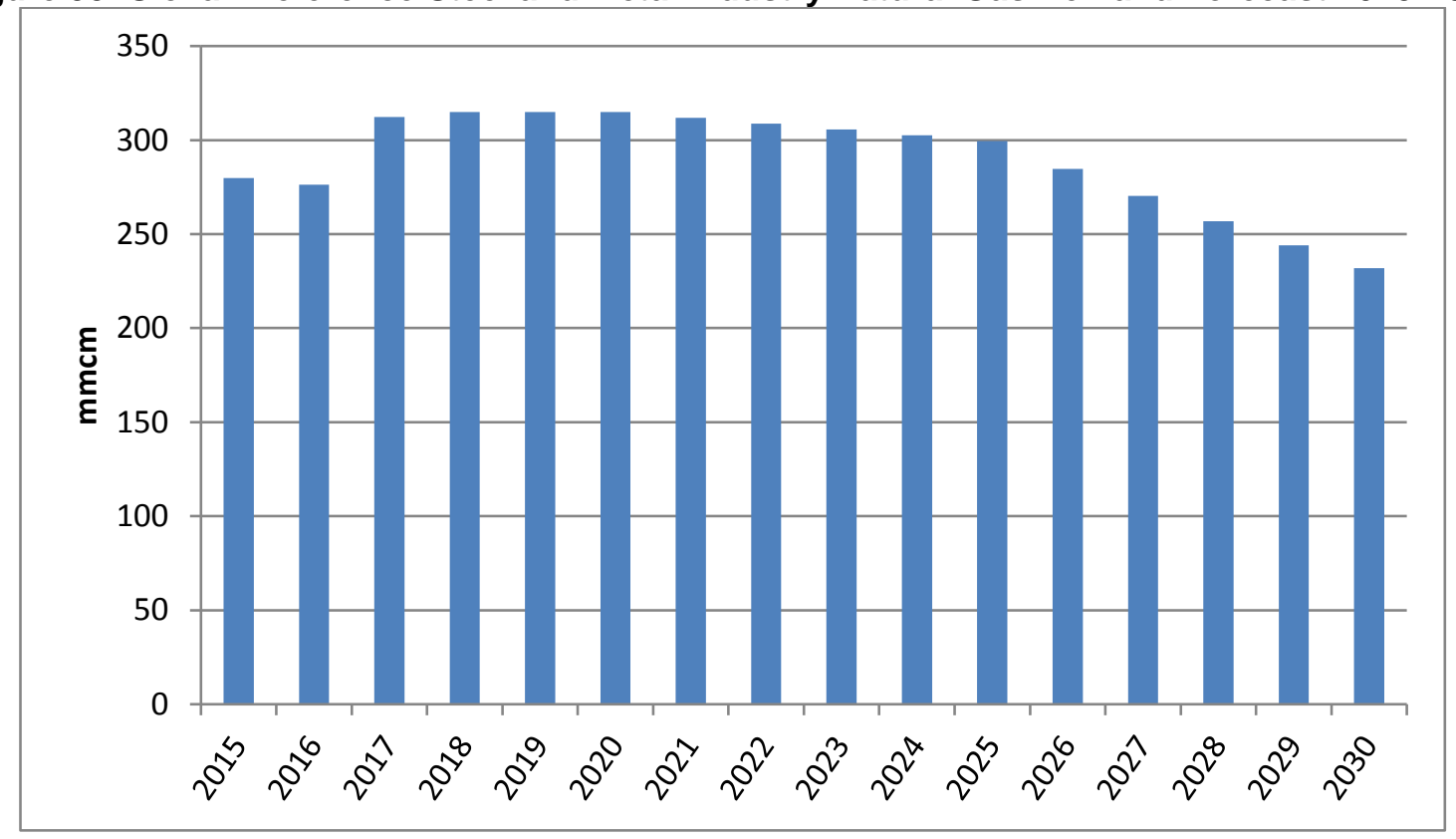

Source: Author's forecast

\footnotetext{
185 https://ec.europa.eu/info/sites/info/files/economy-finance/ip096 en.pdf

${ }^{186}$ https://www.imf.org/en/Publications/WEO/Issues/2018/09/24/world-economic-outlook-october-2018
} 

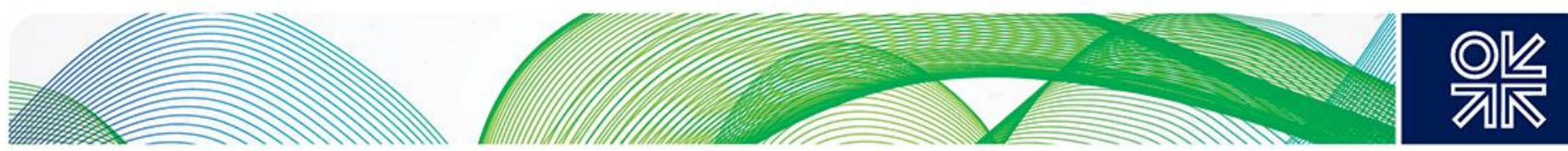

Figure 94: Slovak Optimistic Iron \& Steel Industry Natural Gas Demand Forecast 2015-2030

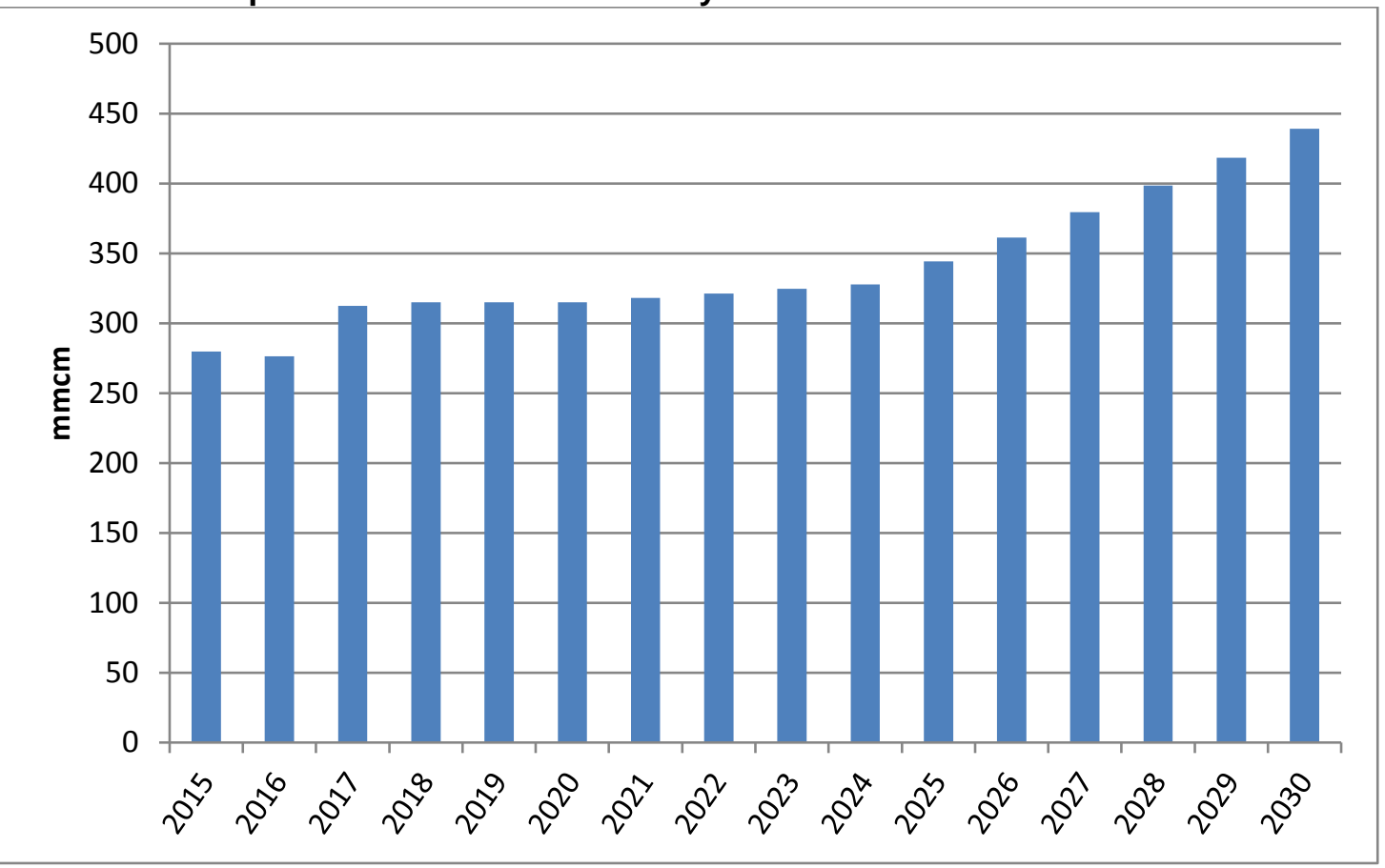

Source: Author's forecast

\subsection{The Slovak Paper and Pulp Industry}

The Slovak paper and pulp industry (NACE $17^{187}$ ) is not a big sector in terms of its contribution to Slovak industry but the sector is interconnected with other local manufacturing industry, especially with the growing packaging and printing industry. It employs just fewer than 6,500 people. In 2017, the paper industry contributed $1.9 \%$ to the total gross value of Slovak manufacturing, but the sector is slowly losing its share as total industry outperforms the sector. The Slovak paper industry has not been fully restructured but has now attracted foreign investment, which should help to modernise the sector. There are 45 companies operating in this sector. The value of paper exports has consistently exceeded the value of imports, but since 2015 the faster growth in exports has improved the foreign trade surplus. ${ }^{188}$ The bulk of domestic paper and cardboard consumption still has to be covered by imports.

The paper industry is investment- and energy-intensive (electricity, heat), but the paper mills increasingly recover waste from the production of pulp (bark, sawdust, chips, liquor) or paper. After years of stagnating investment, Mondi is now investing in its Ružomberok plant, which should not only lead to increased wood processing and pulp and paper production, but also to the energy recovery of all types of bio-waste from this production. ${ }^{189}$

Between 2008 and 2016, with the exception of 2013, gross value added by the paper and pulp industry grew moderately but declined sharply in $2017 .{ }^{190}$ Due to tough competition, paper product prices stagnated over the reference period while prices of basic raw materials (mainly pulp) showed an increasing trend. This had a negative effect on paper companies' margins over the last decade and thus reduces funds for future investment.

\footnotetext{
187 Including manufacture of pulp, paper and paperboard and manufacture of articles of paper and paperboard

188 Statistical Office of the Slovak Republic

189 https://www.euwid-paper.com/news/singlenews/Artikel/mondi-proceeds-with-containerboard-investment-project-inslovakia.html

190 Statistical Office of the Slovak Republic
} 

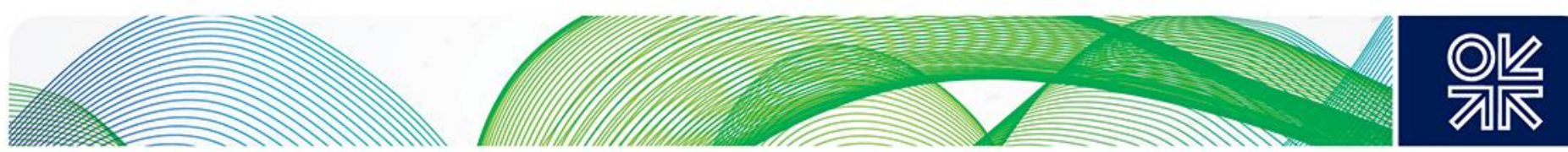

In 2017, the paper industry was largely dependent on wood (87\%) and natural gas (13\%).

Figure 95: Slovak Paper Industry Energy Demand, \% Share by Fuel, 2017

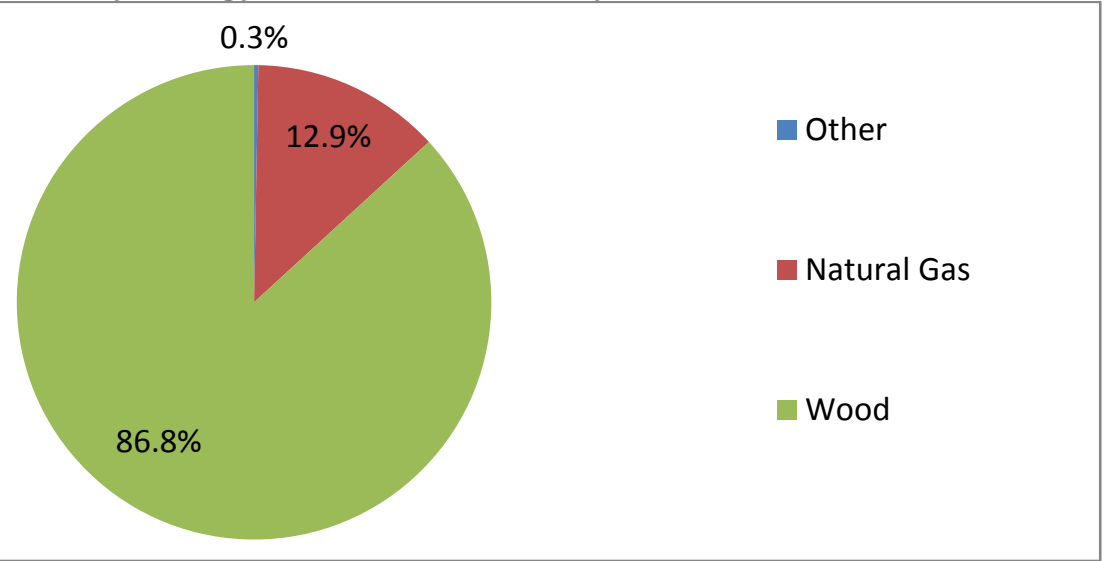

Source: Statistical Office of the Slovak Republic, Energetika

The paper and pulp industry is energy-intensive, but has made major improvements in energy savings, which have accelerated since 2013 since Mondi SCP switched to renewable energy. ${ }^{191}$ Natural gas demand slumped quickly after 2008 and accelerated after 2011 when international gas prices rose sharply. Natural gas demand dropped by $60 \%$ between 2008 and 2017, and the energy intensity of producing a tonne of paper declined, (although figures are not available). This is the result of all leading companies in the sector introducing energy saving measures and investing in new technologies or switching to alternative energy sources. The NACE17 industry consumed $0.06 \mathrm{bcm}$ of natural gas in 2017 , which represented $2.8 \%$ of total industrial gas demand. The gas consumption reached its peak in 2008 , when it consumed $0.15 \mathrm{bcm}$ of gas.

Figure 96: Slovak Natural Gas Demand by Paper Industry, 2008-2017

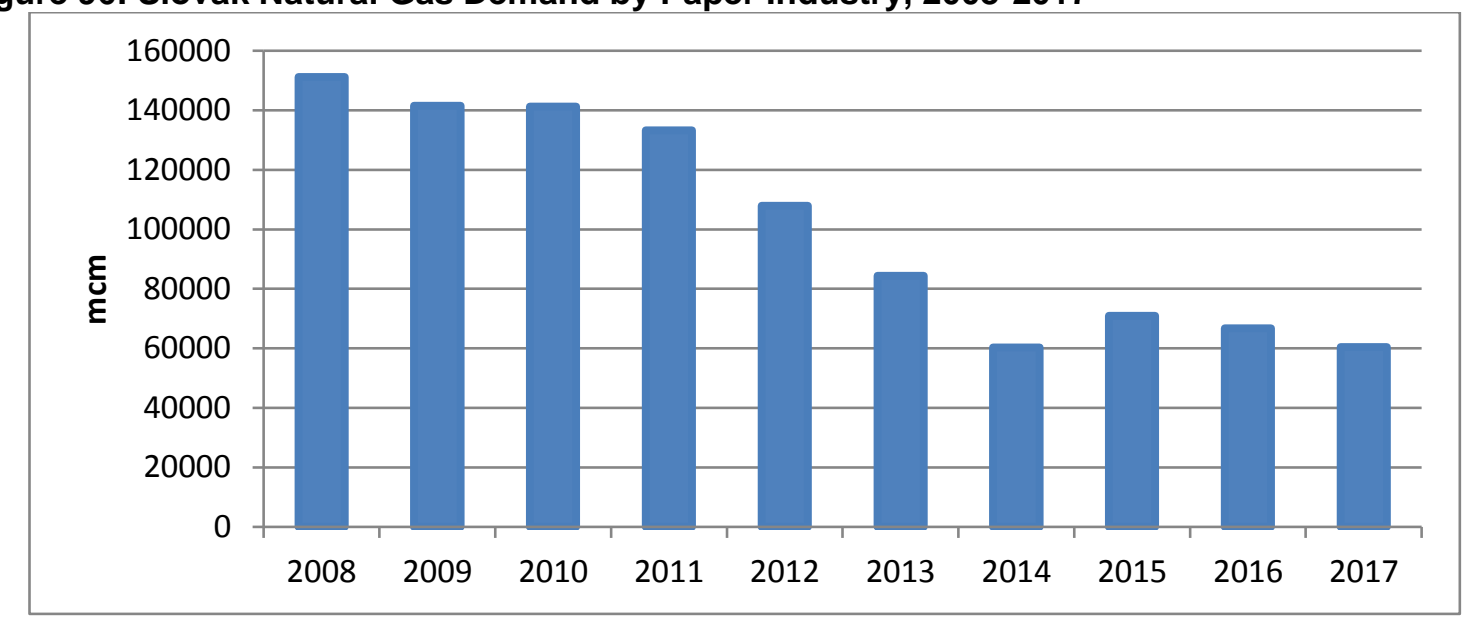

Source: Statistical Office of the Slovak Republic, Energetika

Comparing the indices of gas demand and gross value added by the paper industry, it is clear that while gross value added recovered after 2014, gas demand continued to decline ever since 2008, with the decline accelerating between 2011 and 2014 during the period of high international gas prices. It shows

\footnotetext{
191 https://www.mondigroup.com/en/newsroom/media-centre/press-releases/2012/mondi-scp-invests-128-million-in-greenenergy-projects-at-its-mill-in-ru\%C5\%BEomberok-slovakia/
} 

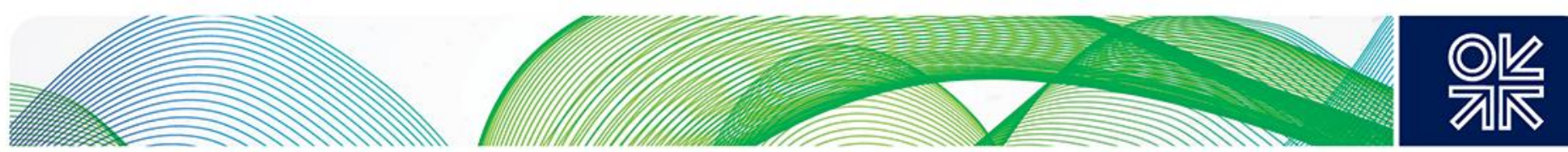

that industry has quickly switched to alternative energy and introduced energy saving technologies. Since 2015, when international gas prices fell, gas demand by the sector has stabilised.

Figure 97: Slovak Gas Demand and Gross Value Added by NACE17 Indices, 2008-2017

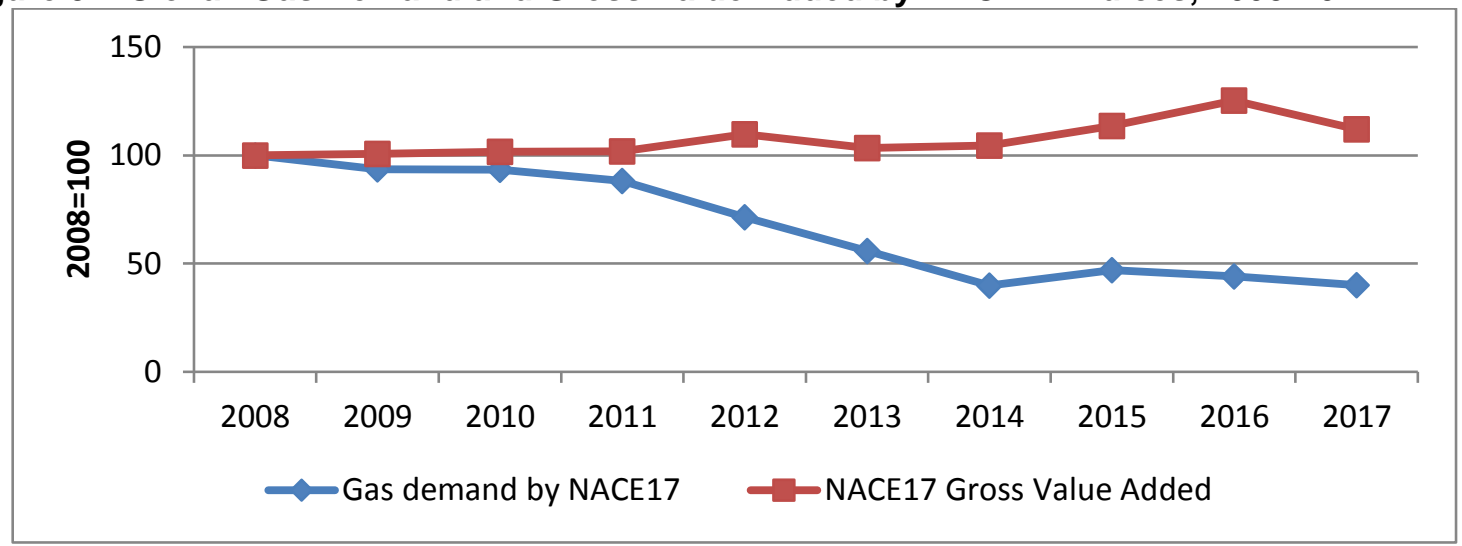

Source: Statistical Office of the Slovak Republic, Energetika

\section{Forecast}

Advantages

The Slovak paper industry has a competitive advantage due to its vicinity to cheap local raw materials, cheap labour and proximity to export markets. The optimistic outlook for the paper sector is enforced by the fact that it is a sector based on renewable sources abundant in Slovakia which can be easily recycled and are generally seen as environmentally friendly.

Lately, the sector has attracted an inflow of investment which will help to modernise and reorganise the industry and make it more energy-efficient. It is expected that current production capacity will be increased substantially in order to cover most of the increase in domestic demand. There will be increasing imports for some special products but the bulk of production is likely to be domestically sourced.

Despite the recent growth in paper and cardboard consumption, Slovakia lags behind the levels of advanced EU countries. Current Slovak consumption of paper was around $87 \mathrm{~kg}$ per capita while the EU average was $158 \mathrm{~kg}$ per capita in 2016. ${ }^{192}$ As living standards are now quickly catching up with the EU average, it can be expected that Slovak consumption will reach some $150 \mathrm{~kg}$ by 2035 . The biggest difference is in consumption of hygienic and packaging paper. The prospect is that increasingly the growing demand for paper products will be covered by domestic production rather than imports.

\section{Challenges to Growth}

On the other hand it can be argued that the flow of international investments into the Slovak paper industry was much slower and later than in the neighbouring countries, which suggests that the Czech and Polish environment for paper production is more competitive than in Slovakia.

The sector is dominated by large enterprises and is partly in foreign ownership, so that there is a danger that the foreign companies may try to extract maximum profit rather than invest in their plants in Slovakia.

The main limitation on natural gas demand is that modern companies are increasingly using renewables rather than more expensive natural gas. For instance, Mondi SCP installed a new recovery boiler in 2013 , which makes the paper mill $100 \%$ energy self-sufficient with over $94 \%$ of its energy coming from

\footnotetext{
192 Statistical Office of the Slovak Republic
} 

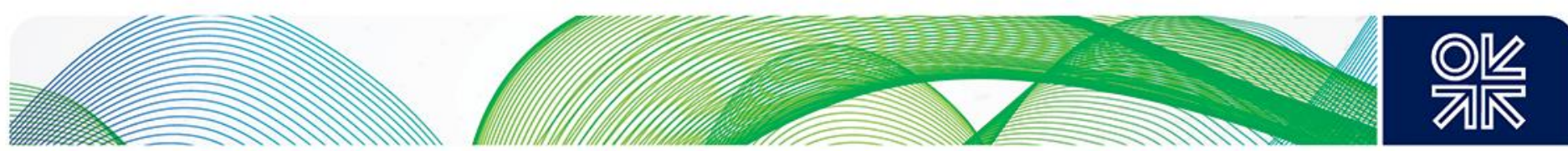

renewable resources. ${ }^{193}$ The current trend is for modern paper mills to install gasification plants which use bark to produce bioenergy and thus are able to cut out fossil fuels altogether, including natural gas. ${ }^{194}$ However, these are very costly investments and the modernisation will only happen gradually.

\section{Reference Scenario}

The Slovak paper and pulp industry, especially in the light of the acceleration in growth since 2014, looks to be set for a healthy growth as further investments flow in. It is also expected that the paper industry will continue to increase its exports to the EU. It is estimated that gas demand by the paper industry will grow as a result at a much slower pace due to further energy savings, by some $2 \% / y$ till 2021 and gradually slowing down to $1 \% / y$ till 2025 and starting to decline again once more paper mills are modernised, switching to renewable energy instead. Natural gas demand by NACE 17 is expected to reach some $0.6 \mathrm{bcm}$ by 2030 , which is just marginally higher than at present.

\section{Optimistic Scenario}

Optimistic scenario is based on the premise that no further major investments into modernisation of local paper mills will flow into the country while demand for paper will grow strongly over the next decade. The paper sector is likely to show rates of growth of $3 \%$ till 2025 and only then it will slow down to $1.5 \%$, largely driven by the local demand for paper. This will require enlargement in capacity of some paper mills and may require switching to natural gas which will drive future gas demand. The more optimistic scenario thus foresees gas demand by the sector to grow from $0.06 \mathrm{bcm}$ in 2017 to $0.08 \mathrm{bcm} / \mathrm{y}$ in 2030. However, the sector is unlikely to play a major role in future country's gas demand as the industry has already largely switched to renewable energy and will not convert back to natural gas.

Figure 98: Slovak Reference Paper Industry Natural Gas Demand Forecast 2015-2030

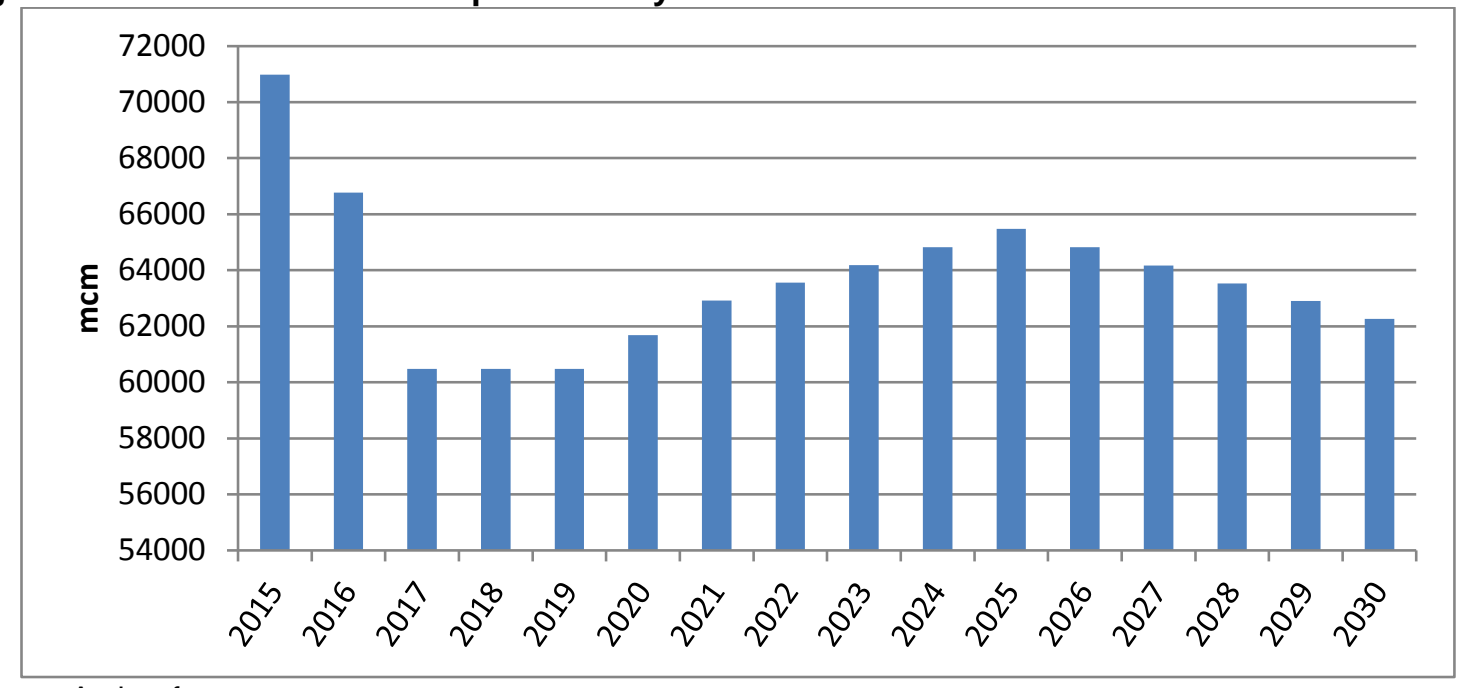

Source: Author forecast

\footnotetext{
${ }^{193}$ https://www.mondigroup.com/en/newsroom/media-centre/press-releases/2012/mondi-scp-invests-128-million-in-greenenergy-projects-at-its-mill-in-ru\%C5\%BEomberok-slovakia/

${ }^{194}$ http://www.cepi.org/system/files/public/documents/publications/othertopics/2014/RESOURCES EFF CEPI.pdf
} 

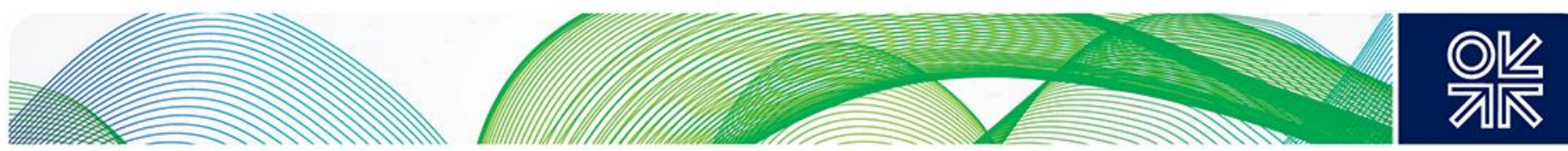

Figure 99: Slovak Optimistic Paper Industry Natural Gas Demand Forecast 2015-2030

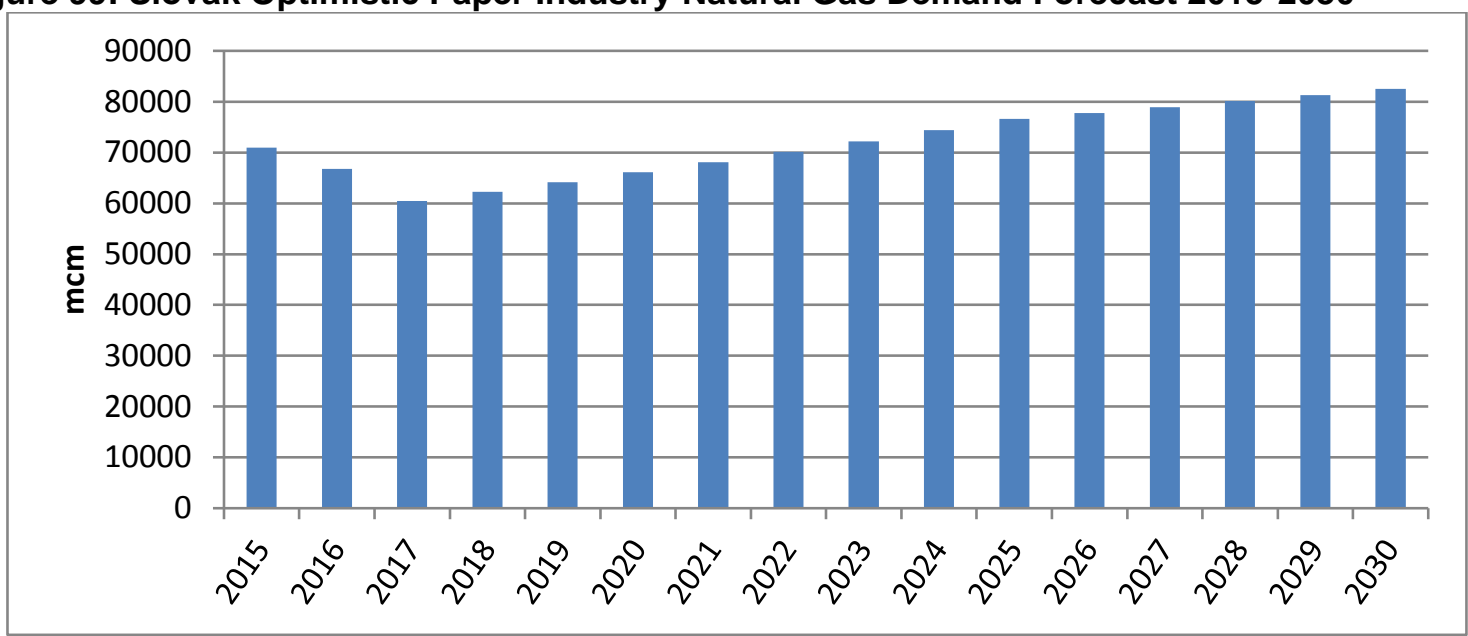

Source: Author forecast

\subsection{The Slovak Glass Industry}

The glass, ceramics and china industry is a subsector of the NACE 23 sector ${ }^{195}$ which represented $2.3 \%$ of total industrial output in 2017. Although the subsector is not important for its GDP contribution, it is an important exporter with exports representing $45 \%$ of total sales and $1.4 \%$ of total Slovak exports in 2017. ${ }^{196}$ The Slovak glass industry is a traditional industry but it has been facing increasing competition from Asian countries lately. Nowadays, Slovak glassmaking depends on glass sand imported from the Czech Republic but benefits from local access to cheap labour and limestone. The glass industry employs just over 3,000 people. The glass companies are largely located in Western Slovakia. 104 producers were active in 2017 and the largest companies have now been partly modernised and reorganised. The Slovak glass and ceramic industry produces mainly container, flat and fibre glass.

The subsector is among the most energy-intensive industries. In 2017, the glass sector was responsible for $8 \%$ of total industrial natural gas demand, and natural gas represents $90 \%$ of the glass industry's energy use for industrial process, as no other fuel can ensure high quality and avoid coloration of final glass products. ${ }^{197}$ There are no separate statistics for the subsector but NACE23, which includes the cement industry, depended on natural gas for $39 \%$ of its fuel, followed by industrial waste $37 \%$, oil products $12 \%$ and coal $12 \%$ in 2017.

\footnotetext{
195 Manufacture of Other Non-metallic Mineral Products

196 Statistical Office of the Slovak Republic

197 Interview with industrial and gas companies
} 

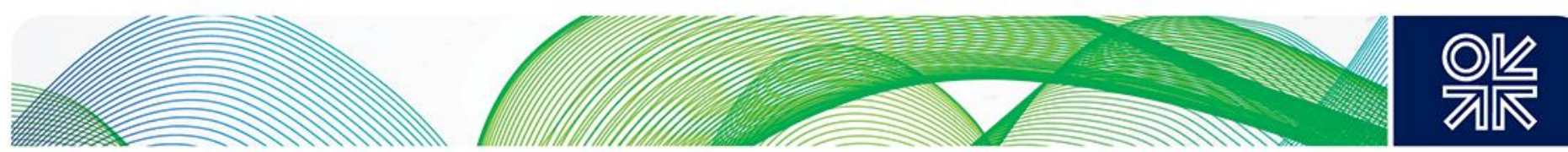

Figure 100: Slovak NACE23 Energy Demand, \% Share by Fuel, 2017

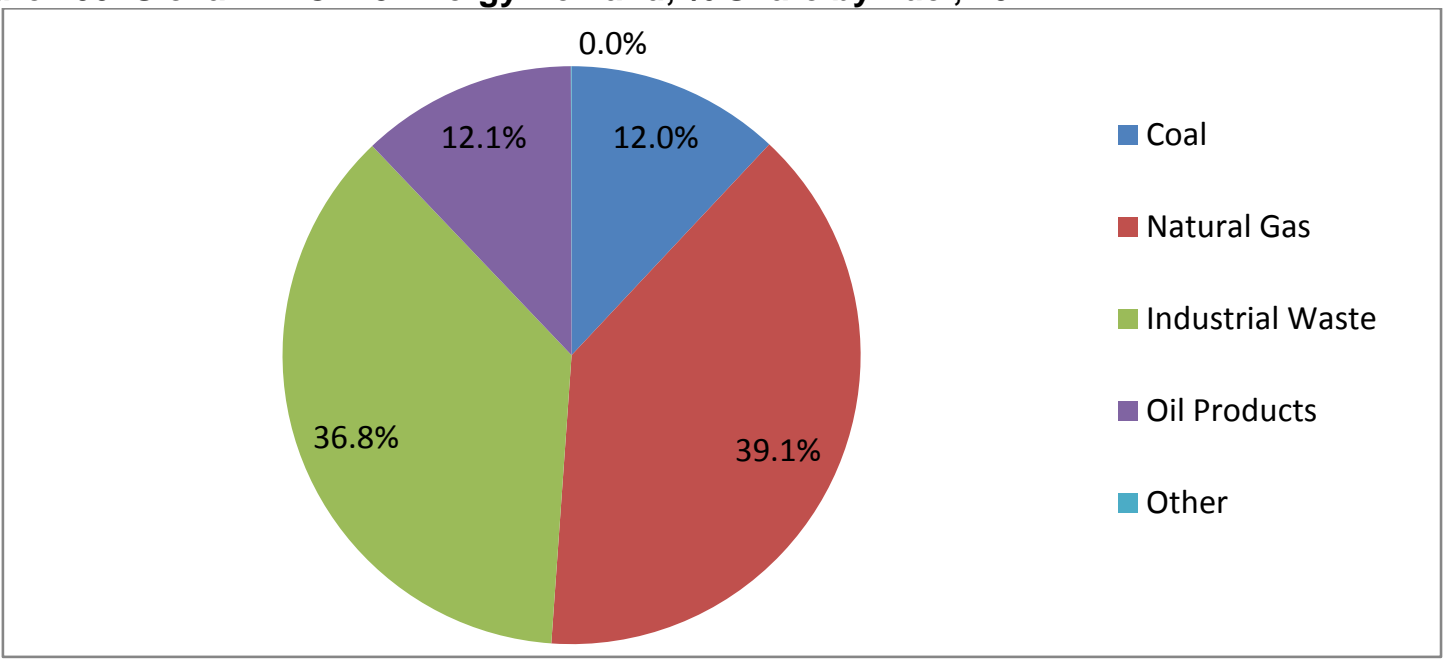

Source: Statistical Office of the Slovak Republic, Energetika

The sector was seriously affected by the recession and has not recovered yet to the pre-recession position. (The national statistical office only shows value added figures for the whole NACE 23 sector, including the cement industry.) The sector showed very strong growth till 2008 but value added slumped in 2009 and has not recovered yet to pre-recession levels although a recovery has been evident since 2014. The hike in energy prices from 2011 led to investment in energy saving technology.

No separate data is available for glass and cement industry natural gas demand, however, the glass industry is responsible for the bulk of natural gas consumption by NACE23 since the cement industry has practically squeezed out natural gas from its fuel portfolio. Gas demand shows a significant drop in consumption in 2009 as the industry was affected by the recession, but recovered in the following two years, driven by growing production. However, gas demand fell again in 2012 and 2013 due to energy saving measures as international gas prices affected profitability of this energy intensive industrial sector. In 2014, gas demand was up again only to fall in 2015. The growth in gas consumption returned in 2016 and 2017 as the rate of production accelerated.

In 2017, natural gas consumption by NACE23 was still $2 \%$ below the pre-recession level of 2008 . Value added by NACE23 is still 19\% below the 2008 level as stiff competition keeps prices down despite increasing production costs. The figures include the results for the cement industry which is very disposed to recession trends. In the period between 2013 and 2016, the rate of growth in gas consumption is much slower than the growth in production as energy savings make an impact. 

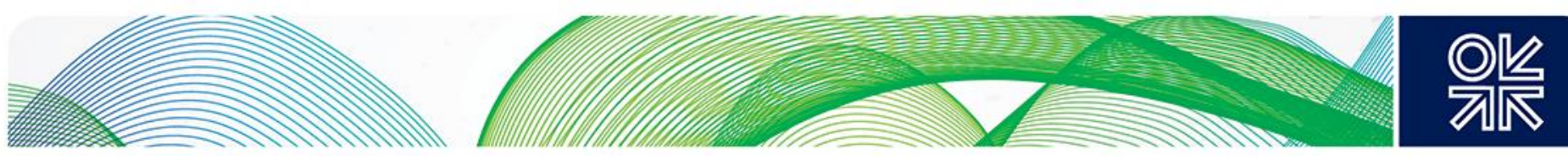

Figure 101: Slovak Natural Gas Demand by NACE23, 2008-2017

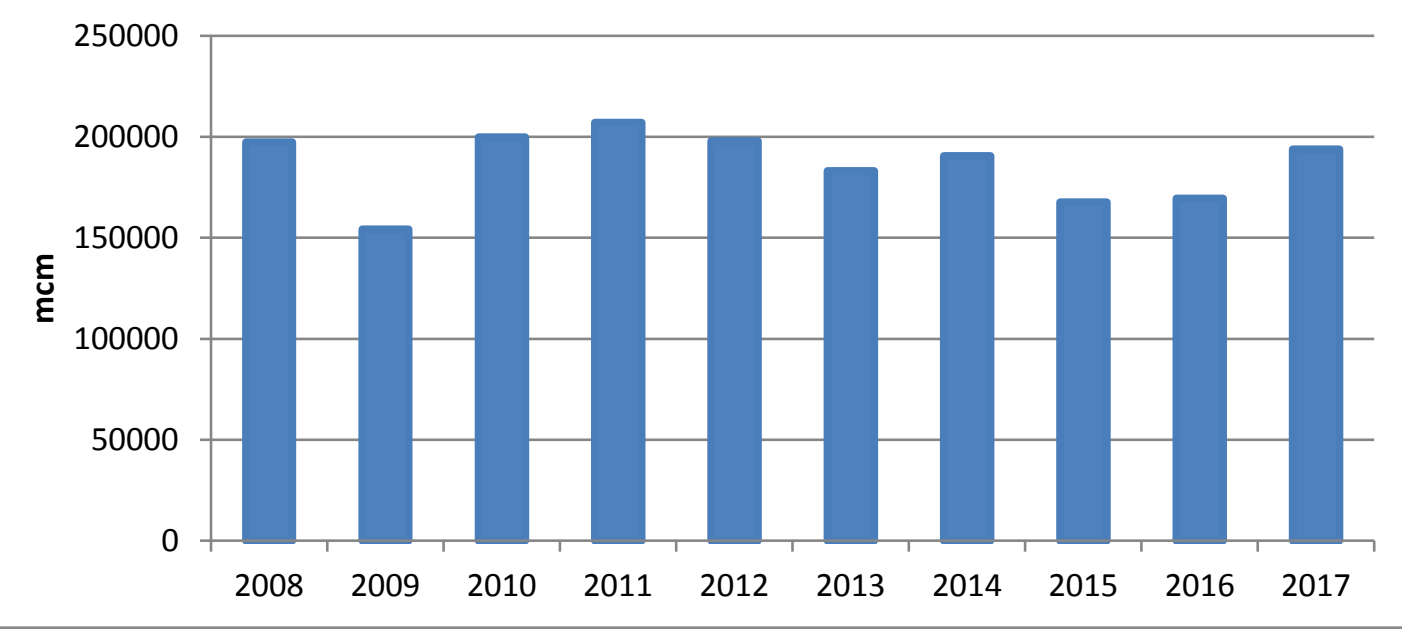

Source: Statistical Office of the Slovak Republic, Energetika

In 2017, natural gas consumption by NACE23 was still $2 \%$ below the pre-recession level of 2008 . Value added by NACE23 is still 19\% below the 2008 level as stiff competition keeps prices down despite increasing production costs. The figures include the results for the cement industry which is very disposed to recession trends. In the period between 2013 and 2016, the rate of growth in gas consumption is much slower than the growth in production as energy savings make an impact.

\section{Figure 102: Slovak Indices of Natural Gas Use and Value Added by NACE 23, 2008-2017}

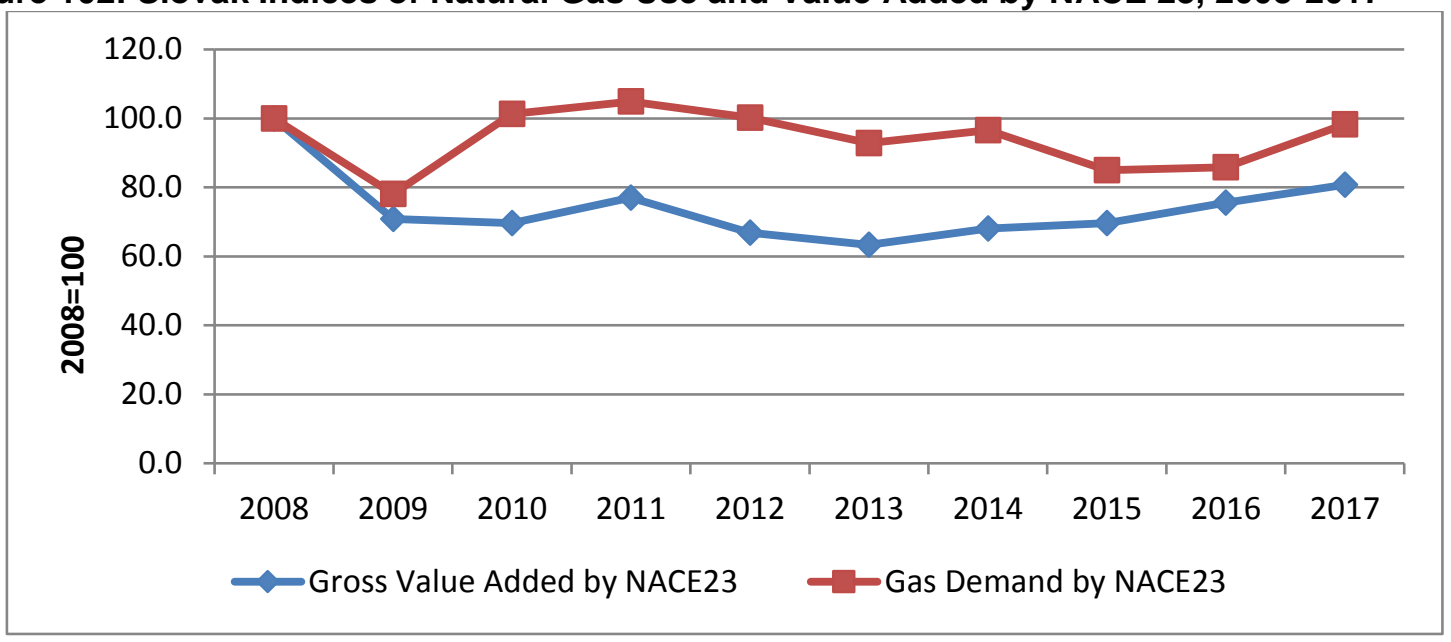

Source: Statistical Office of the Slovak Republic, Energetika

\section{Forecast}

Advantages

The future of the Slovak glass and ceramic industry looks encouraging although it will depend on future investment commitments by the three dominant producers. For instance the leading manufacturer Vetropack Nemšová plans to expand and further improve energy efficiency in its glass production as its current capacity is already fully utilised. The new technology was planned to be installed by end of 2018. ${ }^{198}$

\footnotetext{
${ }^{198} \mathrm{https}: / /$ www.vetropack.com/fileadmin/doc/01 publications/01 Annual Reports/Annual Report 2017.pdf
} 

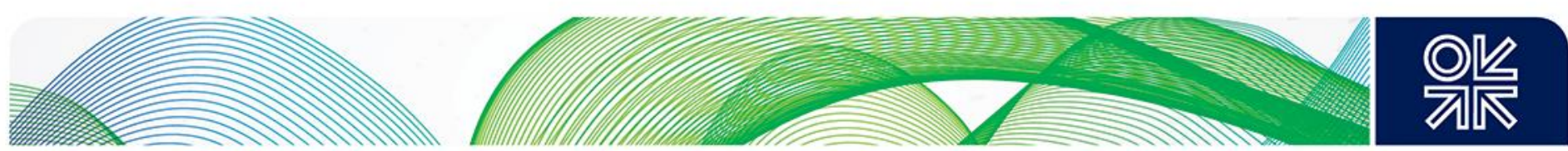

The glass industry has been successful in exporting almost a half of its production, largely to the EU. Since 2013, the sector has shown improvement in value added which suggests a potential for a further growth in future. ${ }^{199}$

\section{Challenges to Growth}

The sector is dependent on imported raw materials and is exposed to international gas prices which limits its otherwise overwhelming competitive advantage. Moreover, the sector has been struggling to recruit qualified workers, which could curtail potential growth. 200

The modernisation of the sector has not been completed and therefore success will depend on the ability to adjust to ever changing demand in technology and upon design in the construction and automotive industries. Future development of the sector will thus copy the trend of both construction and automotive industries. The sector's dependency on these two sectors makes the glass sector vulnerable to recessional trends.

Increasing competition is likely to result in further concentration among manufacturers in order to be able to invest in innovation, according to current market needs.

\section{Reference Scenario}

Bearing in mind that the Slovak glass and ceramic industry has not recovered to pre-recession levels and further investments in the industry are only at the planning stage, it can be assumed that the sector is likely to grow only moderately till 2030. Gas demand is likely to grow till 2020 , driven by increasing output, but new investments, which are planned for post-2020, will reduce the energy intensity of glass production. Even the growth in production will not be able to offset the decline in gas demand by the end of the forecasting period.

The industry will continue to be dependent on natural gas because other fuels cannot guarantee the high quality of glass products. Natural gas consumption is likely to plateau till 2024 and then start to decline from 2025 onwards due to further energy savings as new investments start to take effect. Natural gas demand by NACE 23 is expected to reach some $0.19 \mathrm{bcm} / \mathrm{y}$ by 2030 , when it will be just below the current level.

The graph below incorporates cement industry gas demand, which is marginal as explained in the following chapter and will not make any impact on future NACE 23 gas demand.

\section{Figure 103: Slovak Reference NACE 23 Natural Gas Demand Forecast, 2015-2030}

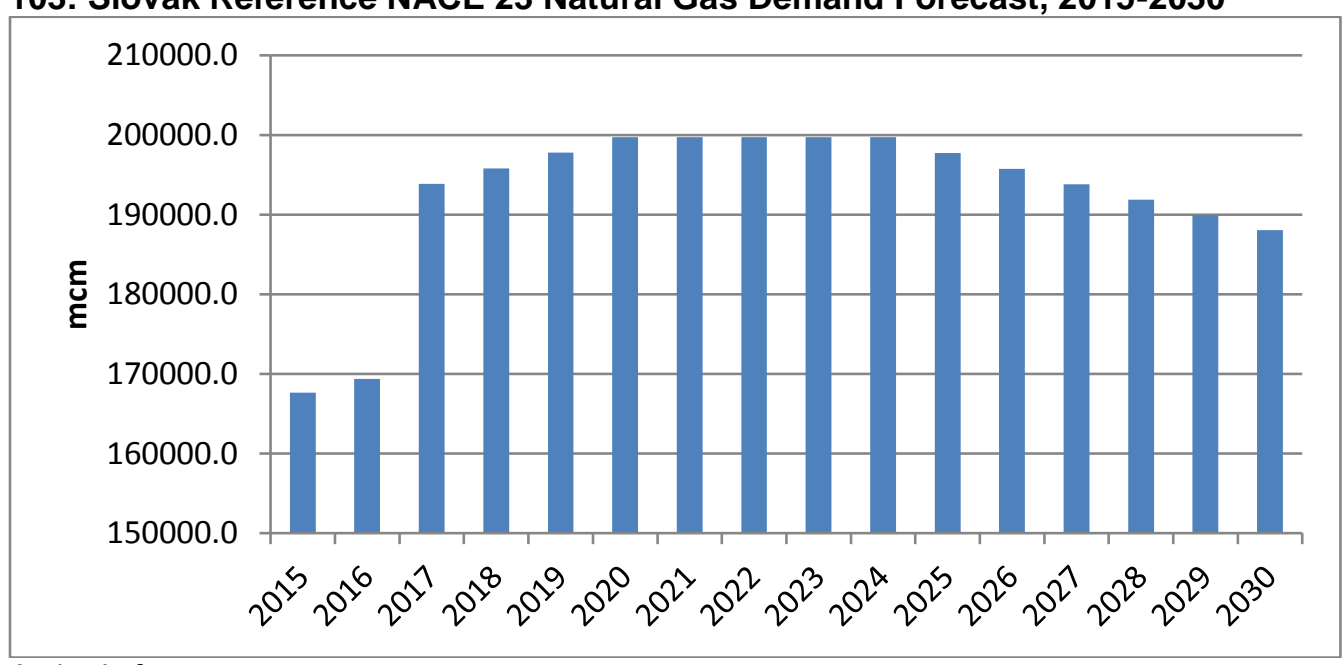

Source: Author's forecast

\footnotetext{
${ }^{199}$ Statistical Office of the Slovak Republic

200 https://www.amrop.sk/pdf/others/2018/cg_2018.pdf
} 

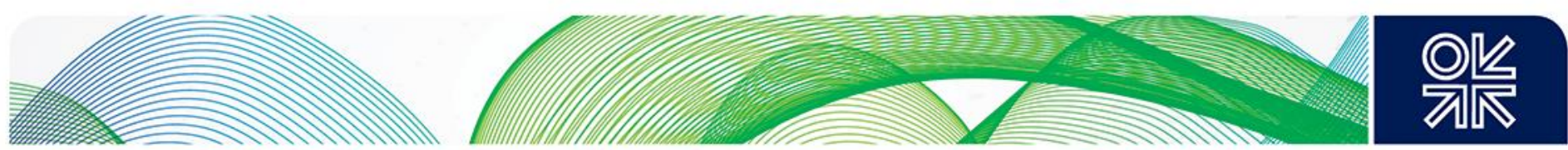

\section{Optimistic Scenario}

The more optimistic scenario for the industry could see much higher rates of growth till 2020 due to higher production driven by exports and increased investment by the dominant glass producers. In such a case, natural gas consumption is likely to only slow down from 2020 to 2025 and from then plateau onwards due to further energy savings as new investments start to take effect. Natural gas demand by NACE 23 is expected to reach some $0.22 \mathrm{bcm} / \mathrm{y}$ by 2030 . This represents an increase in gas demand by $0.02 \mathrm{bcm} / \mathrm{y}$ compared to 2017 .

Figure 104: Slovak Optimistic Natural Gas Demand by NACE 23, 2015-2030

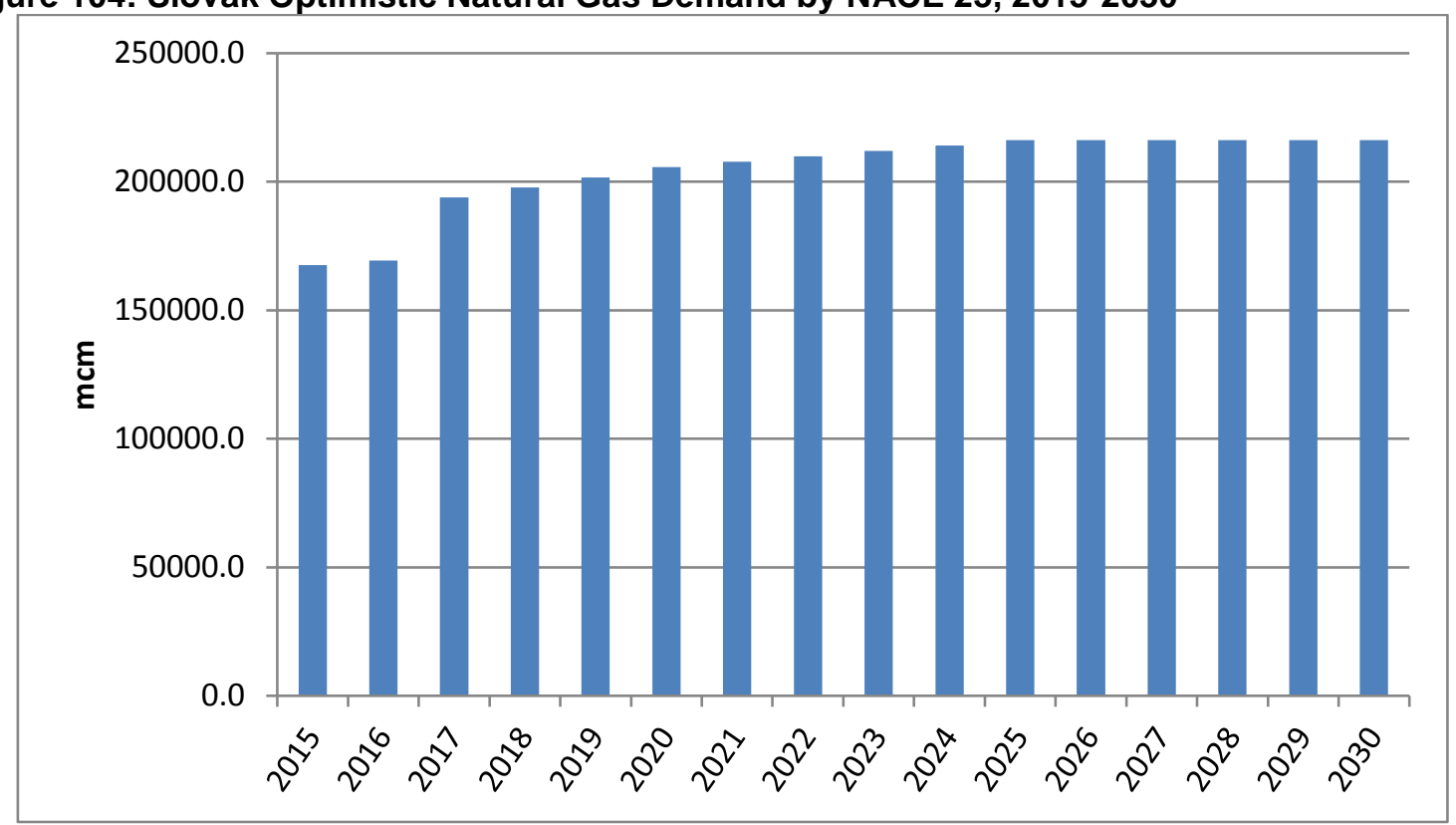

Source: Author forecast

\subsection{The Slovak Cement Industry}

The cement industry belongs to the NACE 23 sector. ${ }^{201}$ Although the cement industry is a small contributor to the national GDP, it is important for the local construction industry. Over the last decade the cement industry experienced ups and downs due to recessional trends and an unresolved legal system. The cement industry is one of the most energy- and capital-intensive industries but breakthrough technologies leading to higher energy efficiency are not in sight according to the findings of $\mathrm{CSI}^{202}$ It is unlikely that the sector will return to natural gas over the next decade. Over the last years the cement industry controlled its costs by switching fuels as energy prices started to increase in the 1990s. Natural gas has now been squeezed out of the fuel portfolio, representing less than $5 \%$ of total fuels used. Natural gas was largely replaced by the cheaper coal, heavy fuel oil and lately biomass.

Slovak production of cement is concentrated in a handful of large international companies, which are better suited to compete on the European market, and will be able to increase production. However, natural gas use will be marginal and the sector will not have any impact on future industrial gas demand. In the most optimistic outlook the cement industry could use up to $0.001 \mathrm{bcm}$ by 2030 .

\footnotetext{
201 NACE 23.5 Manufacture of cement, lime and plaster and NACE 23.6 Manufacture of articles of concrete, cement and plaster 202 https://gccassociation.org/
} 

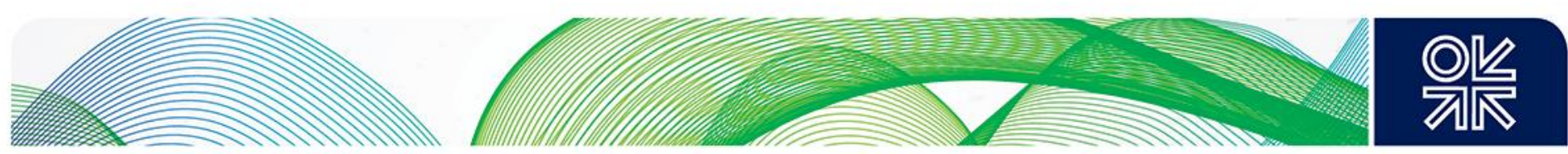

\section{APPENDIX 1- EU Industrial Future Challenges and Policy}

\section{Steel industry \\ Challenges}

The Steel industry continues to be an important sector of the EU economy. The EU is the second largest producer of steel (10\% of global output) in the world after China with its output over 169 million tonnes of crude steel in $2017 .{ }^{203}$ However, a decade ago the EU crude production represented almost $17 \%$ of the world's output. There are currently more than 500 steel production sites across 24 EU Member States. It has a turnover of around $€ 170$ billion and directly employs 320,000 highly-skilled people. The industry is closely associated with downstream industries such as automotive industry, construction, electronics, and mechanical and electrical engineering.

The industry is facing simultaneous effects of low demand and overcapacity in a globalised steel market whilst at the same time being confronted with higher energy prices. This is exacerbated by significant demands to invest in environmental technology and in development of innovative products. The OECD estimates that there was nearly 740 million tonnes of excess capacity worldwide in 2016 , almost half of global demand for steel in 2017, 1.59 billion tonnes, according to the World Steel Association.

The EU Commission considers it essential that Europe remains an important steel producing region for economic, social and environmental reasons as well as for security of supply. One of its tasks set by the EU is to increase industry's share of GDP to $20 \%$ by 2020 . Overall, EU apparent steel consumption are forecast to increase and continue the gradual recovery in steel demand that began in 2014 .

\section{Policy and Legislation}

The steel industry was severely impacted during the recession years. The Commission's response to the crisis in the steel sector was to set out targeted actions to ensure that the industry is able to compete globally, in its Action Plan for a competitive and sustainable steel industry in Europe published in 2013. ${ }^{204}$ Apart from the Action plan the Commission has created various EU funds and policy instruments such as Horizon 2020, Structural Funds, and the Research Fund for Coal and Steel. Implementing Regulation (EU) 2016/670 of 28 April $2016^{205}$ has introduced surveillance of imports of certain iron and steel products originating in some non-EU countries, in order to curtail imports of steel at dumping prices. With the final approval of the new Non-standard Anti-Dumping Methodology (NADM) the EU will have created an overall trade defence regime. ${ }^{206}$

The most important legislation, which affects the EU steel industry, is the Directive 2010/75/of 24 November 2010 on industrial emissions (integrated pollution prevention and control ${ }^{207}$ ). The EU Industrial Emissions Directive (IED) places more stringent emissions requirements on industry from January 2016. However, member states are able to designate specific plants to be granted an additional four and a half years to meet these more stringent emissions levels by incorporating them in the Transitional National Plan. Moreover, the steel industry is also affected by the 2012 Energy Efficiency Directive 2012/27/EU, ${ }^{208}$ which establishes a set of binding measures to help the EU reach its $20 \%$ energy efficiency target by 2020. Under the Directive, all EU countries are required to use energy more efficiently at all stages of the energy chain, from production to final consumption. Moreover, the Commission has put in place strict safeguards against state aid to rescue and restructure steel companies in difficulty in order to avoid subsidy races between EU countries because uncontrolled state aid in one EU country can unfairly put at risk thousands of jobs across the EU.

\footnotetext{
203 http://www.eurofer.org/News\&Events/PublicationsLinksList/201806-AnnualReport.pdf

204 Action Plan for a competitive and sustainable steel industry in Europe

205 http://trade.ec.europa.eu/doclib/docs/2016/april/tradoc 154479.imports-surveillance.en.L115-2016.pdf

${ }^{206} \mathrm{http} / / /$ www.eurofer.org/News\%26Events/News/New\%20AD\%20Methodology\%20agreed\%20in\%20the\%20EP.fhtml

207 http://eur-lex.europa.eu/legal-content/EN/TXT/PDF/?uri=CELEX:32010L0075\&from=EN

208 http://eur-lex.europa.eu/legal-content/EN/TXT/?qid=1399375464230\&uri=CELEX:32012L0027
} 

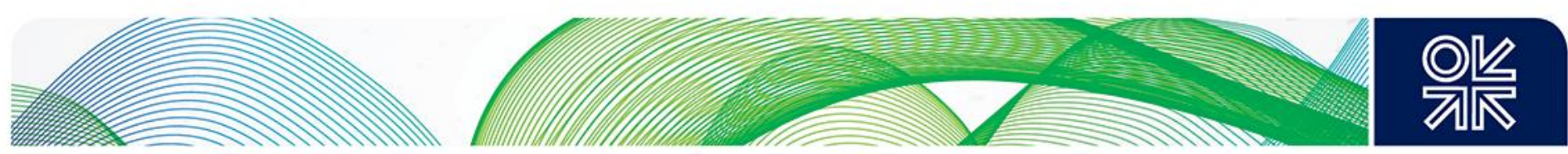

\section{Fertilisers industry \\ Challenges}

The Fertilisers industry is a part of the EU chemical industry which represents some $7 \%$ of total EU industrial production. Over $5 \%$ of the total chemical industry is fertilisers. Over the last decade the industry has been declining although the trend is different in Western, Central and Eastern Europe. According to the latest forecast released by Fertilizers Europe over the 2015/2016 growing season, 11.1 million tonnes of nitrogen fertilizers were applied to 133.7 million hectares while nitrogen fertilizer consumption is forecast to drop to 10.6 million tonnes by the $2025 / 2026$ season, applied to 132.6 million hectares of farmland. That represents a $1 \%$ decline in use of nitrogen fertilizers over the next decade. However, increased consumption is foreseen in most of central and eastern Europe (EU-12), while significant decreases are foreseen in the western European countries. Annual fertilizer consumption over the next 10 years will continue to remain below the more normal levels recorded immediately prior to the $2008 / 2009$ economic downturn.

\section{Policy and Legislation}

The EC fertilisers industry is regulated by the existing EC Fertilisers Regulation No 2003/2003. ${ }^{209}$ The amendment to the Regulation EC adopted Regulation (EU) No. 463/2013210 as the 7th ATP (Adaption to Technical Progress) which came into force on 7 June 2014. In 2012, the European Commission commissioned a review to examine the future direction and setting for EU Fertiliser Regulation, including the need to prevent wasteful use of resources and to widen the regulatory scope for making use of recycled or organic materials for fertilising purposes. Harmonised standards for making fertilisers from recycled or organic materials products on the internal market should be established to incentivise their use. All indications are that the new regulation will continue the current trend and facilitate partial harmonisation. Current expectations are for implementation by Members States in 2019/20. The European Commission's proposed regulation for fertilizing products on the EU market and its Circular Economy Package will increase choices for farmers and so become a significant driver of fertilizer consumption in the EU over the next ten years.

\section{Petrochemical industry Challenges}

The chemicals industry is one of Europe's largest manufacturing sectors, representing around $7 \%$ of EU industrial production. Over $26 \%$ of the total chemical industry is petrochemicals. It is not only an important industry sector, but also the starting point of almost all chemical value chains. In fact, $95 \%$ of all manufactured goods are based on petrochemicals. In addition, the petrochemicals industry provides 300,000 direct and 1.2 million indirect jobs in Europe and contributes to $€ 155$ billion to the overall European GDP. The sector has been undergoing rapid structural change as it has been facing major challenges, including increased competition from other countries and rising costs. However, the industry has recovered quickly from the economic crisis and has remained relatively stable in terms of total sales. Around $80 \%$ of production costs of petrochemicals are related to feedstock and energy.

\section{Policy and Legislation}

Petrochemical industry is regulated by EC Regulation No 1272/2008 of the European Parliament and of the Council of 16 December 2008 on classification, labelling and packaging of substances and mixtures, amending and repealing Directives 67/548/EEC and 1999/45/EC, and amending Regulation (EC) No 1907/2006. ${ }^{211}$ EC also adopted REACH regulation ${ }^{212}$ (EC 1907/2006) which aims to improve the protection of human health and the environment through the four processes of REACH, namely the registration, evaluation, authorisation and restriction of chemicals.

\footnotetext{
209 http://eur-lex.europa.eu/LexUriServ/LexUriServ.do?uri=OJ:L:2003:304:0001:0194:en:PDF

210 http://eur-lex.europa.eu/LexUriServ/LexUriServ.do?uri=OJ:L:2013:134:0001:0014:EN:PDF

1 http://eur-lex.europa.eu/legal-content/EN/TXT/?uri=CELEX:32008R1272

${ }^{212}$ http://eur-lex.europa.eu/legal-content/EN/TXT/?uri=CELEX:32006R1907
} 

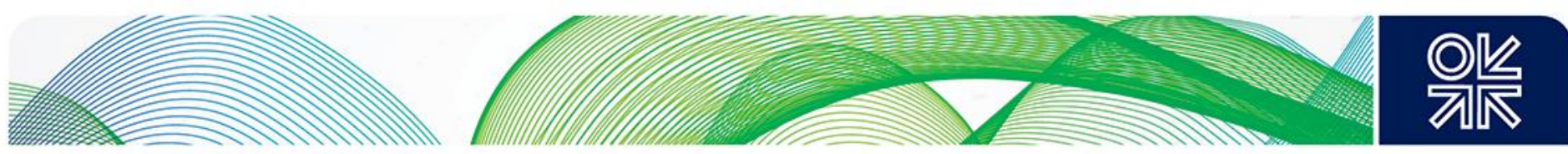

In 2015, the EC commissioned a study on a Cumulative Cost Assessment (CCA) for the European chemical industry. ${ }^{213}$ The aim was to analyse cumulative costs of most relevant EU legislation for the chemical industry in 28 member states during the period $2004-2014$. More than 200 legislative texts were screened and 70 identified as important. The results of the study were published in July 2016. The analysis showed that the legislative packages the EU has enacted in this timeframe have led to additional regulatory costs for petrochemicals of approximately $€ 3$ billion per year from 2004 to 2014 . In fact, the costs of regulation have almost doubled within a decade. The most important regulatory costs of the different legislative packages for petrochemicals are due to emissions and industrial processes regulation (48\%), workers safety legislation $(30 \%)$, chemical packages (REACH) $(10 \%)$, additional energy costs (8\%) and other transport, product specific, custom and trade regulation $(4 \%)$.

A High Level Group on the Competitiveness of the EU Chemicals Industry was set up and steps were taken based on its findings. These include making improvements to the regulatory framework (e.g. undertaking cumulative cost assessments and fitness checks on relevant regulation, and providing guidance and support on regulation to small and medium-sized enterprises).

\section{Pulp and paper industry Challenges}

Pulp and paper producers are part of the much larger forest-based industry sector, which overall represents about $7 \%$ of EU manufacturing GDP. The European forest fibre and paper industry is supplying $23 \%$ of the global market. The sector employs 181,000 people in 920 mills and 505 companies, and adds $€ 16$ billion per year to the European economy, generating an annual turnover of $€ 75$ billion. Over $20 \%$ of European pulp and paper production is exported. The sector mainly uses local raw materials; $83 \%$ of fibres used are sourced in Europe. ${ }^{214}$ The industry was impacted by the recession over the last decade and its output has not yet recovered to pre-crisis levels. Digitalisation of information has also impacted on the industry.

In 2017, European consumption of paper and board rose for the fourth consecutive year, driven by stronger demand for certain categories of paper products, particularly sustainable packaging, hygiene and speciality papers. The pulp and paper manufacturing sector is energy and raw materials intensive, with high capital costs and long investment cycles.

\section{Policy and Legislation}

The Renewable Energy Directive (Directive 2009/28/EC), ${ }^{215}$ the Integrated Pollution Prevention and Control (IPPC) adopted in 2008, the Industrial Emissions Directive of 2013, the Waste Framework Directive are the major regulations affecting the pulp and paper industry which contribute to costs.

In 2011, the Confederation of European Paper Industries (CEPI) launched the "2050 Roadmap to a low-carbon bio-economy". In February 2017, CEPI published the revised Roadmap, ${ }^{216}$ which envisages industry to reduce greenhouse gas emissions by $80 \%$ while creating $50 \%$ more added. Significant progress has been made over the past five years on research and innovation as well as on investments. The industry has already reduced its total (direct and indirect) greenhouse gas emissions by $44 \%$ per tonne of product since 1990.

\section{Glass industry \\ Challenges}

The EU is the world's biggest producer of glass with a market share of around one third of total world production. The industry is known for the quality of its products, its capacity for technological innovation, and its skilled labour force. The glass industry comprises five main sectors covering different glass

\footnotetext{
${ }^{213} \mathrm{https}$ ://www.petrochemistry.eu/mediaroom/regulation-does-shape-profitability/

4 http://www.cepi.org

15 http://eur-lex.europa.eu/legal-content/EN/ALL/?uri=celex\%3A32009L0028

${ }^{216} \mathrm{http} / / /$ www.cepi.org/system/files/public/documents/publications/innovation/2017/roadmap 2050 v07 printable version.pdf
} 

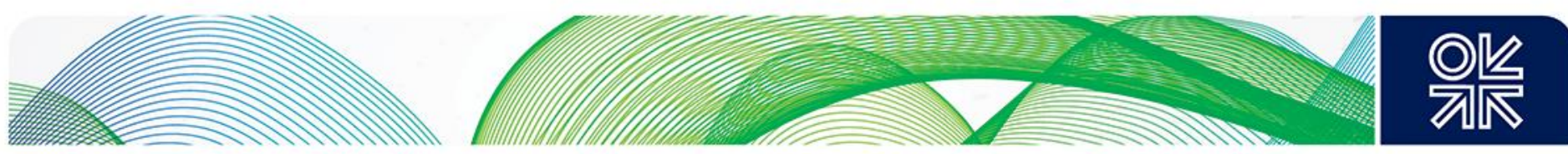

products, applications and markets. These sectors are very different, whether in terms of manufacturing process, products, markets, the economics of the sectors or manufacturers, but they all transform raw materials into glass by a process of melting. Currently, the EU-28 glass industry employs about 185,000 people. The glass industry is interlinked with other sectors such as construction, automotive industry, household and leisure. EU glass production was severely impacted by the economic crisis. In 2017, the EU-28 glass production reached a volume of nearly 36 million tonnes, confirming an improved trend since the crisis in 2008. The EU glass manufacturing industry is highly concentrated and is represented by large EU-based companies. It comprises around 1,000 companies, with over $80 \%$ of glass produced by less than a dozen multinationals each employing more than 1,000 people.

The production process is energy intensive and the manufacturers have to face high start-up costs and tied distribution channels. In Europe energy costs represent around $22 \%$ of production costs while labour costs are around $16 \%$. Glass manufacturing is also a significant emitter of greenhouse gases, particularly carbon dioxide $\left(\mathrm{CO}_{2}\right)$. Production facilities are also capital intensive and require long investment cycles. About $80 \%$ of the glass produced is traded within the EU. Innovation process and development has resulted in improvements of energy savings and environmental protection, a switch from fossil to non-fossil energy, and glass fibre substituting metals and wood through composites. For instance, over the last decades, the energy intensity of glass manufacturing was reduced by $77 \%$ (in 1960 , the energy intensity was $35 \mathrm{GJ} /$ tonne of glass against $8 \mathrm{GJ} /$ tonne today) and $\mathrm{CO}_{2}$. Emissions by $50 \%$ even as production rose.

As recognized by the European Economic and Social Committee, ${ }^{217}$ the glass industries have reached existing physical limits in the state of current knowledge and best available technologies are widespread. Extensive research programmes are currently being financed by glass manufacturers to get to a new break-through and overcome current technological barriers to reducing energy consumption.

\section{Policy and Legislation}

Like all energy intensive industrial sectors, the Integrated Pollution Prevention and Control (IPPC) adopted in 2008, the Industrial Emissions Directive of 2013, the Waste Framework Directive and the Renewable Energy Directive (Directive 2009/28/EC ${ }^{218}$ ) are the main regulations affecting the glass industry which contribute to costs.

The industry falls under the Directives on emissions trading, IED, REACH, packaging and packaging waste, end-of-life vehicles, and restrictions on hazardous substances. The REACH Regulation, Regulation EC No 1907/2006 ${ }^{219}$ on the Registration, Evaluation, Authorization and Restriction of Chemicals, is the European Union's regulatory framework on chemicals and their safe use. It entered into force on 1st June 2007. Currently, all glass manufacturers meet the EU's strict regulatory REACH regulation.

\section{Cement industry \\ Challenges}

The EU cement industry is the third largest producer of cement in the world after China and India. EU28 produces around 167 million tonnes/year of cement, which represents around 5.3\% of the world's production. The cost of a new cement plant is equivalent to around 3 years of turnover, which ranks the cement industry among the most capital-intensive industries. Only huge retrofits like changing from wet to dry processing allow a significant step towards increasing energy efficiency. For these kinds of retrofits a similar investment as for new kilns is required. Therefore, they will only be carried out if the

\footnotetext{
${ }^{217}$ European Economic and Social Committee - Opinion on 'The competitiveness of the European glass and ceramics industry, with particular reference to the EU climate and energy package' - Official Journal of the EU C317/7 - 23

$218 \mathrm{http}: / /$ eur-lex.europa.eu/legal-content/EN/ALL/?uri=celex\%3A32009L0028

${ }^{219}$ http://eur-lex.europa.eu/legal-content/EN/TXT/?uri=CELEX\%3A02006R1907-20140410
} 

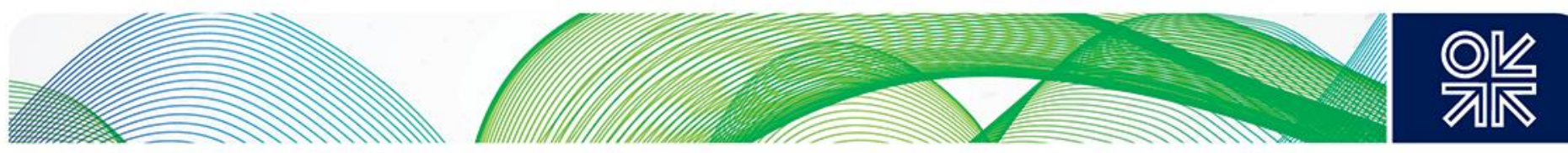

market is booming or equipment is already too obsolete. Traditionally cement could not be economically transported beyond 200 or at most $300 \mathrm{~km}$. However, bulk shipping has changed that and it is now cheaper to cross the Atlantic Ocean with 35,000 tonnes of cargo than to truck it $300 \mathrm{~km}$. The cement industry is highly energy-intensive. A tonne of cement produced requires between 0.6 and 0.13 toe, depending on the cement type and the process used, and about $110 \mathrm{KWh}$ of electricity. Production of cement in EU28 declined rapidly after 2007 and only plateaued since 2013.

\section{Policy and Legislation}

In 2017 the Cement Sustainability Initiative (CSI) decided to initiate a project together with the European Cement Research Academy (ECRA) to update the perspective of available technologies for $\mathrm{CO}_{2}$ abatement and energy efficiency in the cement sector. ${ }^{220}$ According to the findings of CSI, breakthrough technologies which could lead to significantly higher energy efficiency are not in sight. Based on these assumptions the specific fuel energy demand of clinker burning (as a global weighted yearly average) may decrease from 3,510 MJ/t clinker in 2014 to a level of 3,300 to 3,400 MJ/t clinker in 2030 and to 3,150 to $3,250 \mathrm{MJ} / \mathrm{t}$ clinker in 2050 . That means a mere $6 \%$ savings in energy consumption in the cement industry between 2014 and 2030. 

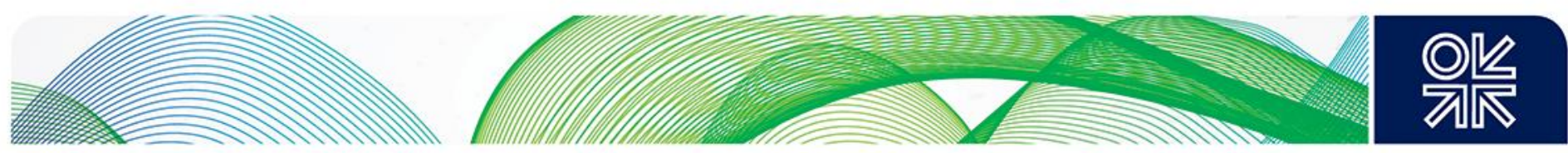

\section{APPENDIX 2 - The Czech Governmental Energy Strategy}

The SEP is founded on the premise of retaining existing coal-fired power plants but retrofitting with costeffective emissions controls or replacing ageing plants with high-efficiency technology as it recognises that coal combustion remains the largest source of greenhouse gas emissions and local air pollution in the Czech Republic. Coal-fired power accounts for $50 \%$ of installed electricity generating capacity and $65 \%$ of GHG emissions. The policy argues that coal use in household heating is a major source of local air pollution and these emissions are difficult, if not impossible, to regulate. In the medium term, retrofitting existing coal-fired power plants with cost-effective flue-gas treatments or replacing ageing plants with high-efficiency plants is endorsed by the SEP. The policy anticipates transition from coalfired power towards nuclear energy and other low-carbon technologies only in the long-term. Nevertheless, the need to increase energy efficiency, especially in the buildings and transportations sectors, is highlighted in the SEP.

As regards the role of gas, the SEP anticipates the share of natural gas in the consumption of primary energy sources to remain stable and slowly growing. Currently, the share of gas in TPES is around $16 \%$. SEP anticipates the share of gas in the energy mix to move between $18 \%$ and $25 \%$ towards 2040 . The growth rate in gas demand in different scenarios will vary according to the rate of switching to gas in power generation, construction of new CHPs and micro-CHPs, also switching from brown coal to gas in electricity generation and growth in use of CNG in transportation. The updated scenarios from 2017 221 anticipate a significant increase in gas demand up to 2050, between $57 \%$ in the Centralized scenario and $77 \%$ in Distributed scenario compared to 2015 . The significant growth in the Distributed variant is driven by strong increase in construction of small-scale and micro-CHP plants in addition to a quick switch to gas-fired electricity plants in case there is a delay in replacing the decommissioned nuclear power plants. The Low-carbon scenario from 2015 anticipates an increase in total gas consumption of approximately $15 \%$ by 2050 due to a rapid growth in renewable energy, which will replace carbon energy, rather than natural gas. These three scenarios are consistently linked to the three electricity forecast scenarios developed by the Ministry of Industry and Trade. They mainly differ in the following assumptions:

- Development of gas storage facilities which will invariably depend on gas price, rate of growth in gas demand and government policy regarding security of supplies; and

- Expansion of gas industry infrastructure which will be driven by future gas demand.

All three scenarios assume:

- The same economic and demographic growth which is based on the assumption that the Czech economy will reach the EU average;

- There is sufficient gas storage capacity;

- The preservation of the EU Emission Trading Scheme (ETS) mechanism on $\mathrm{CO}_{2}$ emissions, although the prices of allowances differ in each individual scenario; and

- The enlargement of pipeline infrastructure to fully accommodate increasing demand.

The government, however, has not set out transparent implementation plans to support these policies. It is also doubtful that the government is fully committed to achieving the EU targets. For instance in October 2015, it made a decision to revoke a government resolution that limited coal mining in some regions. While the decision was made to strengthen the country's energy security, local employment and social concerns were also a factor. However, lifting limits on mining is in contrast with the energy

${ }^{21}$ https://www.mpo.cz/assets/cz/energetika/strategicke-a-koncepcni-dokumenty/2017/8/Zprava-o-ocekavane-dlouhodoberovnovaze-mezi-nabidkou-elektriny-a-plynu- 2016 .pdf 

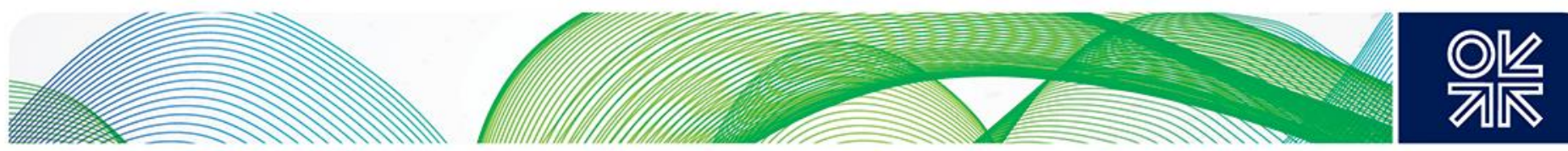

policy. One of the main weaknesses of the SEP is that there is no attention given to industrial customers, although the large industrial customers currently account for almost half of the gas demand. No analysis of industrial gas demand has been undertaken by the government as all the focus is on analysing the development of gas-fired electricity and CHP plants.

Nonetheless, the IEA sees the SEP as a positive development since there will be five-yearly reviews of progress against targets which will form the basis of any future updates. The SEP has also established key targets for energy security, emissions, energy savings, electricity generation and affordability and set out the strategic goals for the proportions of primary energy sources and electricity production, although they are set out in relatively broad ranges. 

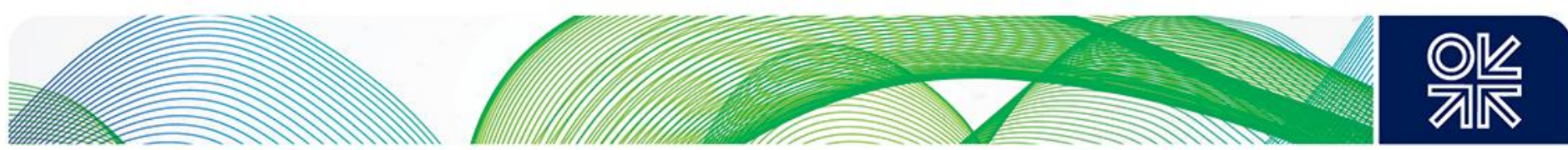

\section{APPENDIX 3 - The Czech Energy Efficiency Progress}

The Ministry of Industry and Trade (MIT), through the Department of Energy Efficiency and Savings, is responsible for planning, developing and implementing energy efficiency policy. Policies are determined by the SEP and the National Energy Efficiency Action Plan (NEEAP222). The Ministry of Environment (MOE), through the Department of Energy and Climate Protection, plays a key role in funding and implementing a wide range of energy efficiency programmes in line with national climate-related policies and priorities.

The government has published the Operational Programme of Initiative and Innovation for Competitiveness (OPPIK). There are 63 measures emphasised by OPPIK that are aiming at reducing the energy intensity of buildings and industrial technology processes. According to the original estimates OPPIK aimed to save 20PJ of energy in the period 2014-2020. The government allocated CZ20 billion. However, it is now clear that the programme has not delivered expected savings which are unlikely to reach even half the planned level (current estimates suggest savings of 9.62 PJ in 2014-2020). According to the EU plan, each Member State is required to achieve annual savings of $1.5 \%$ by the volume of annual sales of energy to final customers.

- The OPPIC programme focused on:

- Installation and modernization of energy meters;

- Modernization, reconstruction and reduction of losses in the electricity and heat distribution in buildings and manufacturing plants;

- Energy insulation of buildings in the business sector;

- Utilisation of energy released in manufacturing processes;

- Improving energy efficiency of production and technological processes;

- Installation of renewable energy for own consumption;

- Installation of cogeneration units with maximum use of electric and heat energy for own consumption; and

- Construction or reconstruction of commercial buildings with zero and passive energy standard.

Apart from OPPIC programme firms have been able to access the ENERG Programme for energy intensity improvements, available since 2017 , focused on smaller companies, especially in the region of Prague. The Ministry of Industry and Trade is also planning to develop so called 'voluntary agreements' with industry and associations on energy efficiency which would simplify the process and need to adopt additional legislative or regulatory measures. The Ministry of Industry and Trade also published additional alternative measures for increasing energy efficiency in Czech industry and Strategic Framework for Sustainable Development. 

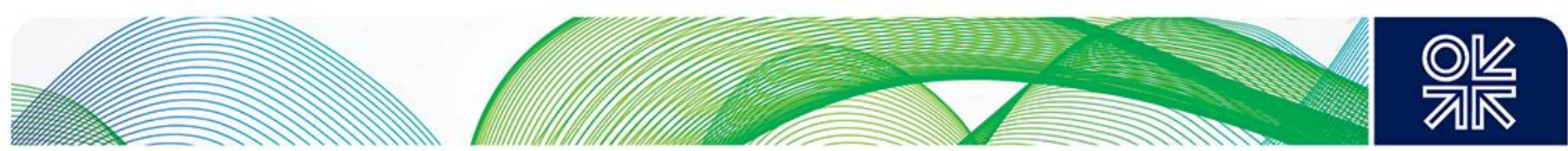

\section{APPENDIX 4 - The Polish Governmental Energy Strategy}

The Polish natural gas policy is incorporated in the draft Energy Policy of Poland till 2040 (PEP2040), published by the government on 23 November $2018 .{ }^{223}$ The policy focuses on diversification of energy sources, improving energy efficiency and increasing use of renewables. The PEP2040 is based on the premise of building nuclear energy capacity in order to strengthen energy independence and security of supply and reduction of emissions. It foresees replacement of lignite with nuclear energy after 2030. However, the nuclear power construction plan has been in existence for 10 years, but the financing model, plan of action and location has yet to be put in place. Ministerstwo Energii (Ministry of Energy) is responsible for energy policy and the management of mineral reserves. The ministry was created in late 2015 when it was split from the Ministry of Infrastructure and Development, by the current government.

The energy policy envisages reduction of electricity produced from coal to $60 \%$ by 2030 , but this is mainly due to the projected increase of energy demand, while the overall amount of coal in megawatts would decrease only marginally before 2030 , with new coal plants still to be built. The new policy is symptomatic of the Polish government being reluctant to address the restructuring of the domestic coal industry, arguing that coal is the main energy reserve Poland is endowed with and therefore it is important for the country's security of energy supplies.

- The main objectives of the policy are:

- Reduction of coal share in electricity production to $60 \%$ by 2030 ;

- Increasing renewables share to $21 \%$ in final energy consumption by 2030 ;

- Construction of nuclear electricity plant in 2033;

- Improvement of energy efficiency by $23 \%$ by 2030 , compared to 2007 ; and

- Reduction of $\mathrm{CO}_{2}$ emissions by $30 \%$ by 2030, compared to 1990 .

The European Parliament earlier this month adopted a new set of energy efficiency regulations. According to the legislation, $32 \%$ of the EU's gross final energy consumption is to come from renewable sources by 2030 , and energy efficiency is to be improved by $32.5 \%$ at the same time.

As regards the role of gas, the PEP2040 anticipates the share of natural gas in the consumption of primary energy sources to remain stable and slowly growing. Currently, the share of gas in TPES is $14.7 \%$ while its share in electricity generation is only $4.7 \%$. PEP2040 anticipates the share of electricity produced by natural gas to grow from $5.8 \%$ in 2020 to $9.5 \%$ in 2030 and $16.4 \%$ by 2040 . The gas consumption by the electricity sector is planned to increase to $2.4 \mathrm{bcm}$ in 2020 , to $4.2 \mathrm{bcm}$ in 2030 and $7.8 \mathrm{bcm}$ in 2040. An important prerequisite condition is liberalisation of the gas market and an increased gasification of the country. The current gasification is around $58 \%$, which is envisaged to grow to $61 \%$ by 2022 . There is only a small increase in cogeneration as gas-fired generation is seen only as a backup policy.

One of the main weaknesses of the PEP2040 is that there is no attention given to industrial customers, although the large industrial customers currently account for half of the gas demand. No analysis of industrial gas demand has been undertaken by the government as all the focus is on analysis of the development of gas-fired electricity and CHP plants.

Nevertheless, PEP2040 is a positive development since the government had not been able to formulate its strategy since 2015. The country lacked any long-term plan for a number of years since the last 

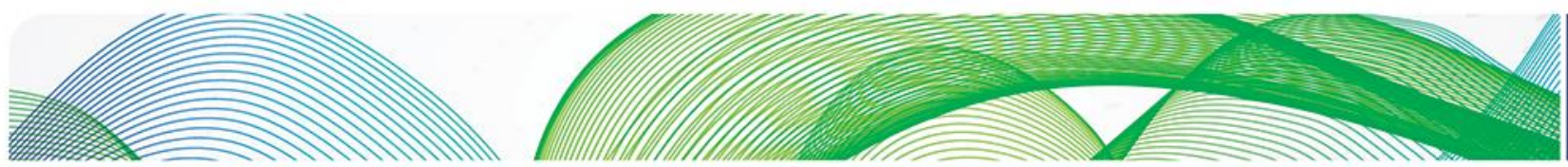

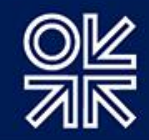

energy strategy was formulated in 2009 by the previous administration, which pursued a very different policy to the current government. For the last three years there was a total vacuum as regards the energy strategy. Although the current goals are not meeting the EU targets, the PEP2040 has established key targets for energy security, emissions, energy savings, electricity generation and affordability and sets out the strategic goals for the proportions of primary energy sources and electricity production. This is, however, only a draft document for public consultation, which means that it can be greatly amended. 

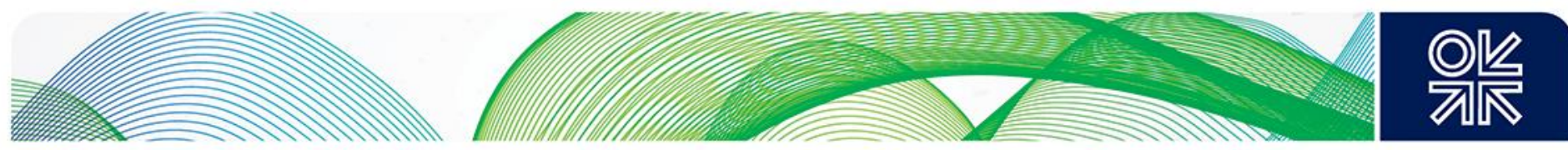

\section{APPENDIX 5 - The Polish Energy Efficiency Progress}

The Ministry of Energy is responsible for planning, developing and implementing energy efficiency policy. National Energy Efficiency Action Plans (the plans no. 1, 2, 3, 4, were drawn up in 2007, 2012, 2014, and 2017 respectively) are approved by the Council of Ministers. The last adopted Fourth Action Plan on energy efficiency was prepared in 2017 and adopted on 23 January 2018. ${ }^{224}$ The plan summarizes the achieved goals of energy efficiency improvement, presents the objectives for 2020 and updates the measures and means planned for their achievement.

With regard to regulation, the Act on Energy Efficiency from 20 May 2016 (Law Gazette, pos. 8310) aims at improvements in energy efficiency and achievement of national energy efficiency targets. The Act introduces a regulation for individual public sectors but preserves the energy efficiency certification system (white certificate scheme) functioning since 2013. One of the provisions from the 2016 Act obliges all large companies to carry out energy audits. The revised white certificate system makes it possible to apply for funds only for planned investments. Other programmes aiming for increased energy efficiency in industry are such as Operational Programme Infrastructure and Environment 20142020 (Measure 1.2-Promotion of energy efficiency and use of renewable energy sources in enterprises); support for projects in the field of low-emission and resource-efficient economy, Lot 4-Energy efficiency in enterprises); and regional operational programmes for the years 2014-2020.

Final energy industry consumption reached the highest value in 2007 when it amounted to 15 Mtoe, and the lowest, at 13 Mtoe two years later due to the effects of international recession. In 2016, after a growth of 0.5 Mtoe, consumption amounted to 14.8 Mtoe. The largest decrease in consumption occurred in liquid fuels (decrease by 53\%). The consumption of heat (-38\%) and coal (-21\%) also decreased. On the other hand, increases were registered in gas consumption $(2 \%)$, electricity $(21 \%)$ and other energy which grew by $115 \%$. Industrial energy consumption therefore declined by a mere $1.4 \%$ between 2007 and 2016 . However, once the growth of industry and structural changes are taken into account, the rate of decline in energy intensity averaged 2\%/year in 2010-2016.

Consumption in the housing and services sectors was relatively stable. In contrast, energy intensity in transport varied considerably; it actually increased year-on-year in 2014-2016. This was due to an increase in industrial production over the period, the consequent increase in exports of manufactured goods and the resulting increase in freight and rail transport demand. Apart from the impact of growing industrial output the transport sector has been expanding strongly which also contributed to growing energy consumption. 

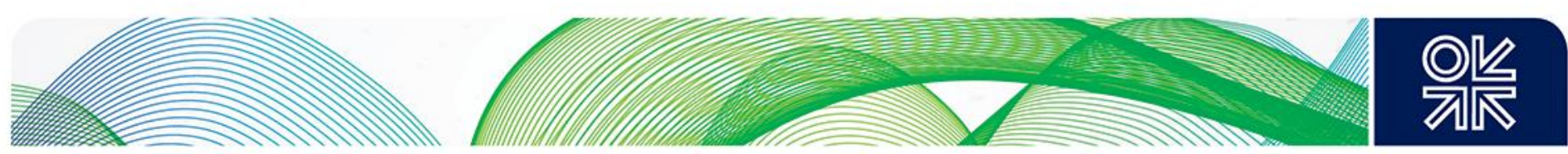

\section{APPENDIX 6 - The Slovak Governmental Energy Strategy}

The Slovak Ministry of Economy published its new version of the Energy Policy in October 2014. It is a strategic document defining the energy sector's primary objectives and priorities to 2035 with a view to 2050. ${ }^{225}$ The Ministry is responsible for the Energy Policy which is updated every five years. The Energy Policy is intended to ensure the sustainability of the Slovak energy sector and the sustainable growth of the national economy and its competitiveness. The priority of the policy is to ensure security and stability of energy supplies, efficient energy utilisation at optimum costs and ensuring environmental protection.

Slovakia is nearly $90 \%$ dependent upon imported primary energy sources: nuclear fuel (100\%), natural gas $(98 \%)$, oil $(99 \%)$ and coal $(68 \%)$. This high dependency on energy imports makes Slovakia especially vulnerable and the security of energy supplies is thus the most important aspect of the Energy Policy. The interruption in natural gas supply in 2009 with its significant negative impact on the Slovak economy confirmed the need for greater energy security and increased focus on the diversification of primary energy sources and transport routes as well as domestic energy sources and RES in particular. The risk of an interruption of supply is currently higher for natural gas and crude oil than it is for black coal and nuclear fuel. Over the last decade there were a number of events which influenced the governmental energy plans: the shutdown of two units at the V1 Jaslovské Bohunice Nuclear Power Plant (NPP V1) $(2 \times 440$ MW) at the end of 2006 and 2008, as a result of which Slovakia in 2007 lost its self-sufficiency in electricity generation; the establishment of the National Nuclear Fund for decommissioning of nuclear facilities; the establishment of Jadrová energetická spoločnost' Slovenska, a.s. (JESS, a.s.) to secure the preparation, construction and operations of a new nuclear power plant at Jaslovské Bohunice and the creation of the short-term electricity market operator as a $100 \%$ subsidiary of the transmission system operator Slovenská elektrizačná prenosová sústava, a.s. (SEPS, a.s.)

The Energy Policy is also predisposed by the EU targets of a $20 \%$ reduction of greenhouse gas emissions, a $20 \%$ increase in energy efficiency and a $20 \%$ utilisation rate of RES by 2020 .

It also takes into account Regulation (EU) No 994/2010226 of the European Parliament and of the Council concerning measures to safeguard security of gas supply, which should ensure an infrastructure standard that safeguards the ability of member states to supply gas in the event of an interruption using their single largest gas infrastructure.

The Ministry of Economy has developed three scenarios: high; reference; and energy-saving. The high scenario projects significant GDP growth which will drive growth in primary energy consumption up to 868 PJ. This scenario is the least probable. The reference scenario anticipates growth to a level of around 800 PJ by 2030, after which it should stagnate. A decrease in coal consumption is expected, balanced out with an increase in the consumption of nuclear electricity, natural gas and RES. The energy-saving scenario envisages a decline in consumption of primary energy sources in line with the current trend of significant reduction in energy intensity while GDP growth will continue up to $3 \% / y e a r$. This development in the consumption of primary energy sources involves implementation of full-scale energy efficiency and rationalisation measures in every sector of the economy, in particular in housing and transport.

\footnotetext{
${ }^{225}$ http://www.economy.gov.sk/uploads/files/47NgRIPQ.pdf

${ }^{226}$ http://eur-lex.europa.eu/LexUriServ/LexUriServ.do?uri=OJ:L:2010:295:0001:0022:EN:PDF
} 

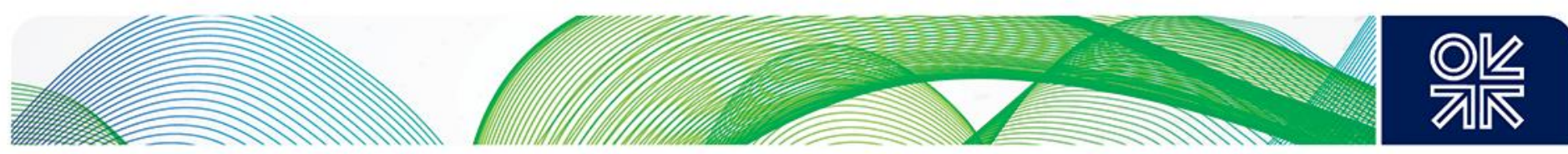

Gross inland energy consumption development scenarios, (PJ)

\begin{tabular}{|l|l|l|l|l|l|l|l|l|}
\hline & $\mathbf{2 0 0 0}$ & $\mathbf{2 0 1 0}$ & $\mathbf{2 0 1 5}$ & & $\mathbf{2 0 2 0}$ & $\mathbf{2 0 2 5}$ & $\mathbf{2 0 3 0}$ & $\mathbf{2 0 3 5}$ \\
\hline High scenario & \multirow{3}{*}{778} & \multirow{3}{*}{743} & 712 & & 797 & 835 & 860 & 868 \\
\cline { 1 - 7 } & & & 694 & & 769 & 792 & 800 & 790 \\
\cline { 1 - 6 } $\begin{array}{l}\text { Reference scenario } \\
\text { scenario }\end{array}$ & & 686 & & 735 & 721 & 714 & 708 \\
\hline
\end{tabular}

Source: Statistical Office of the Slovak Republic, Ministry of Economy

The reference scenario is the medium scenario, which envisages a significant increase in gross inland energy consumption supported by increased nuclear electricity consumption with the start-up of Mochovce 3 and 4 nuclear power plant and the planned new nuclear power plant at Jaslovské Bohunice. A decline in coal consumption is expected, balanced out with an increase in consumption of nuclear electricity, natural gas and RES. In 2020, nuclear power should represent almost $31 \%$, natural gas $23 \%$, coal $16.5 \%$, oil $18.6 \%$ and RES $11 \%$. In 2030 , nuclear power should represent almost $31 \%$, natural gas $23 \%$, coal $12.5 \%$, oil $17.8 \%$ and RES $15.8 \%$. The slight growth in use of natural gas is seen as an option to reduce $\mathrm{CO} 2$ emissions.

Reference Scenario: Development in gross inland energy consumption, (PJ)

\begin{tabular}{|l|l|l|l|l|l|l|l|}
\hline & $\mathbf{2 0 0 0}$ & $\mathbf{2 0 1 0}$ & $\mathbf{2 0 1 5}$ & $\mathbf{2 0 2 0}$ & $\mathbf{2 0 2 5}$ & $\mathbf{2 0 3 0}$ & $\mathbf{2 0 3 5}$ \\
\hline Coal & 170 & 162 & 140 & 127 & 115 & 100 & 80 \\
\hline Natural gas & 245 & 210 & 170 & 175 & 189 & 185 & 185 \\
\hline Oil & 121 & 152 & 143 & 145 & 147 & 142 & 137 \\
\hline Nuclear fuel & 212 & 154 & 170 & 237 & 237 & 247 & 247 \\
\hline RES & 30 & 65 & 71 & 85 & 104 & 126 & 141 \\
\hline Total & $\mathbf{7 7 8}$ & $\mathbf{7 4 3}$ & $\mathbf{6 9 4}$ & $\mathbf{7 6 9}$ & $\mathbf{7 9 2}$ & $\mathbf{8 0 0}$ & $\mathbf{7 9 0}$ \\
\hline
\end{tabular}

Source: Statistical Office of the Slovak Republic, Ministry of Economy

A section of the Energy Policy is dedicated to industry energy savings. Some of the measures envisaged would be mandatory energy audits in the energy industry; a financial mechanism for voluntary energy audits for small and medium enterprises.

As regards future developments in the gas industry the Energy Policy foresees the construction of the north-south gas pipeline which will connect Slovakia with LNG terminals in Poland and Croatia. The Energy Policy also points out the importance of preserving the transit of Russian gas across the country. The volume of transmitted gas decreased in connection with the Nord Stream pipeline start-up and the redirection of a portion of transit gas, in particular to Germany and the Czech Republic. This is one of the main reasons why utilising the reverse flows have not been fully utilised as the long-term interest of Slovakia is to use traditional east-west flow for Russian natural gas.

Although gas demand will be declining due to switches to more energy efficient technologies, improved insulation of existing buildings, measures focused on gas savings and increased use of biomass, solar collectors and geothermal energy to generate heat and hot water, the savings will be more than compensated by increased demand for natural gas due to replacement of coal, in particular in the heat industry. The higher use of CNG in transport is also foreseen. It is also considered that natural gas will be used in future technologies to store $\mathrm{CO}_{2}$. Based on these trends there is an expectation that natural gas consumption will fluctuate around its current levels over the mid-term and may rise slightly depending on the extent to which natural gas is used as a replacement for coal in combined cycle power plants. Two scenarios for natural gas consumption are considered. The reference scenario does not consider restarting the currently mothballed gas power plant. The growth scenario includes the restarting of the large power plants as economic conditions for electricity generation improve. 

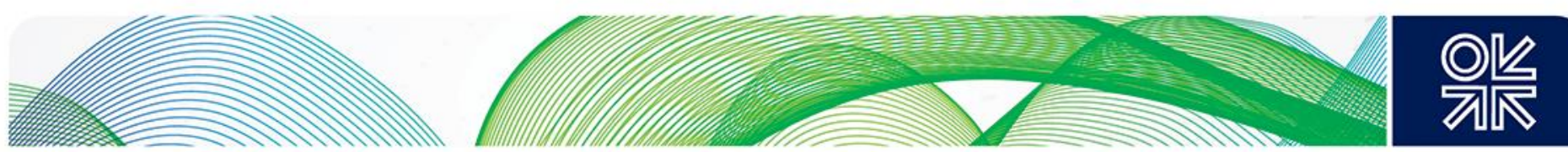

\section{The Energy Policy sets the following objectives for the gas industry:}

- To connect Slovak gas infrastructure with neighbouring states;

- To construct sufficient natural gas storage capacity;

- To improve the infrastructure for the use of CNG;

- To achieve technical harmonisation with the standards introduced in neighbouring countries;

- To safeguard secure, reliable and effective transport and distribution of natural gas; and

- To maximise the utilisation of the pipeline network through Slovakia.

Increasing the share of RES in energy consumption is one of the priorities of the Energy Policy. Biomass has the largest energy potential among RES in Slovakia with theoretical potential of 120 PJ. Biomass represents also an important potential for the development of regional and local economies. Slovakia is obliged to increase the use of RES compared to gross final energy consumption from $6.7 \%$ in 2005 to $14 \%$ in 2020. Expected total RES consumption should reach around $80 \mathrm{PJ}$ in 2020. RES consumption represented $12 \%$ of gross final energy consumption in 2016. The basic document related to achievement of the 14\% target is the National Action Plan for Renewable Energy Sources approved by the Slovak government on 6 October 2010 in Resolution No. 677/2010.

Electricity generation from domestic lignite has been supported to reduce dependency on energy imports and for social reasons. In 2015, government support to domestic coal mining accounted for almost $€ 120$ million. The government continues to support directly the local mines through higher electricity prices. A special fee to support domestic coal mining is included in all electricity bills. Coal mines are also supported indirectly through exemptions from the excise duty tax for electricity production from coal. According to estimates by the Ministry of Finance, these exemptions amounted to $€ 15$ million in 2015. Moreover, the Ministry of Economy provides direct subsidies to failing mines. Coal mines only operate thanks to this generous support scheme; they are not competitive, nor economically viable. ${ }^{227}$ 

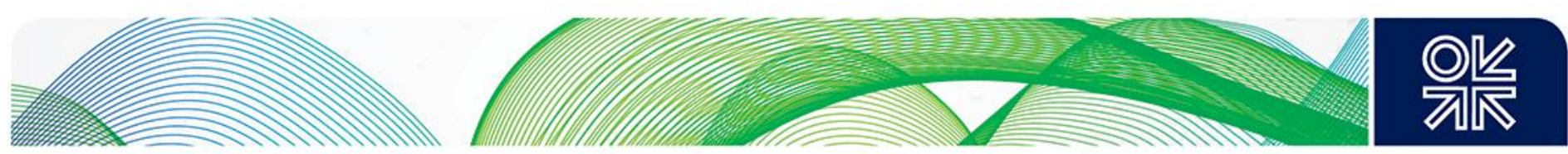

\section{APPENDIX 7 - The Slovak Energy Efficiency Progress}

The Ministry of Economy of the Slovak Republic, through the Department of Energy, is responsible for planning, developing and implementing the energy efficiency policy in the country. These policies are determined by the National Energy Efficiency Action Plan (NEEAP ${ }^{228}$ ). In October 2014, the government published the Operational Programme Research and Innovation and the Operational Programme Environmental Quality. The strategic objective to achieve a competitive low-carbon energy industry is encompassed in the Energy Policy of the Slovak Republic (No 548/2014). There are numerous measures emphasised by the programme that are aiming at reducing the energy intensity of buildings and industrial technology processes.

Two types of national energy efficiency targets have been set:

a) Targets set out by Directive 2006/32/EU on energy services

Energy efficiency targets were set out in the Energy Efficiency Policy approved under Government Resolution No 576/2007 for 2007-2016. The annual energy saving target for the period was set at $1 \%$ of the average final energy consumption in 2001-2005 (3,122 TJ/y or $28,098 \mathrm{TJ}$ in total for the period until 2016 . The planned target was only met by $93.17 \%$ as Slovakia managed to save 26,178 TJ.

b) Targets set out by Directive 2012/27/EU on energy efficiency

Energy efficiency targets were set out at $1.5 \%$ of annual energy sales to final customers for each energy supplier ( $948.75 \mathrm{GWh} / \mathrm{y})$ a total of $26,565 \mathrm{GWh}$ by 2020 . However, Slovakia has been failing to achieve the target. By 2016 , Slovakia had achieved only $68.1 \%$ of the updated annual target. Consequently, the annual targets for 2017-2020 were revisited and recalculated to $1,019.5 \mathrm{GWh} / \mathrm{y}$. It seems that the public sector and energy transformation, transmission and distribution are the most failing sectors while energy savings in industry have been achieved ahead of the targets. Energy efficiency measures in the industry sector have focused especially on supporting innovation, technology transfers and energy saving processes in industrial processes on a company level, and implementation of measures recommended by compulsory energy audits.

Financing from the European Structural and Investment Fund ESIF (2014-2020), in particular via the Operational Programme Research and Innovation and the Operational Programme Environmental Quality, has been drawn on in order to meet the targets. The Programme is geared towards the support of preparations for energy audits at small and medium enterprises and the implementation of measures recommended by those energy audits.

Slovakia is generally on track to meet its 2020 targets on energy efficiency. Its primary energy consumption (16.15 Mtoe in 2017) was already under the 2020 target of 16.4 Mtoe. However, the final energy consumption (11.13 Mtoe in 2017) still shows a remaining gap to the 2020 target of 9 Mtoe. 229 Both numbers marked a slight increase in 2016 compared to the previous year (with $0.7 \%$ and $3 \%$ respectively) and the trend continued in 2017.

However, it seems that the country is now falling behind already uninspiring targets. The Slovak government seems to underestimate the role of research and innovation in the energy sector. There is no grand strategy being prepared for energy innovation in Slovakia and if there are research and development projects being implemented, it is more likely by private firms than by state institutions. In

energy production, it is focused on the centralised utilisation of big nuclear power plants while renewable energy sources are underestimated and research in the area is lacking. ${ }^{230}$

\footnotetext{
${ }^{228}$ http://www.rokovania.sk/Rokovanie.aspx/BodRokovaniaDetail?idMaterial=26443

${ }^{229}$ Commission Staff Working Document; Energy Union Factsheet Slovak Republic, Third Report on the State of the Energy Union, Brussels, 23.11.2017

${ }^{230}$ https://www.ceep.be/www/wp-content/uploads/2018/01/Innovation-of-Energy-Sector-in-Slovakia CEDE2017.pdf
} 